\begin{abstract}
UNIVERSIDADE DE SÃO PAULO
FACULDADE DE FILOSOFIA, LETRAS E CIÊNCIAS HUMANAS

DEPARTAMENTO DE LETRAS MODERNAS

PROGRAMA DE ESTUDOS LINGÜÍSTICOS E LITERÁRIOS EM INGLÊS
\end{abstract}

A terminologia do Ecoturismo como espelho de diferentes visões: agências de turismo, ambientalistas e governo

Josimeire Cristina Martins

São Paulo

2007 


\begin{abstract}
UNIVERSIDADE DE SÃO PAULO
FACULDADE DE FILOSOFIA, LETRAS E CIÊNCIAS HUMANAS

DEPARTAMENTO DE LETRAS MODERNAS

PROGRAMA DE ESTUDOS LINGÜÍSTICOS E LITERÁRIOS EM INGLÊS
\end{abstract}

\title{
A terminologia do Ecoturismo como espelho de diferentes visões: agências de turismo, ambientalistas e governo
}

Josimeire Cristina Martins

Dissertação apresentada ao Programa de PósGraduação em Estudos Lingüísticos e Literários em Inglês, do Departamento de Letras Modernas da Faculdade de Filosofia, Letras e Ciências Humanas da Universidade de São Paulo, para obtenção do título de Mestre em Letras.

Orientadora: Profa. Dra. Stella Esther Ortweiler Tagnin

São Paulo

2007 
Ao meu marido, Silvio, e meus filhos, João, Renato e Luiza, por darem tantas cores à minha vida. 


\section{AGRADECIMENTOS}

Em primeiro lugar, gostaria de agradecer aos meus pais, Lafaiete e Ivone, sempre presentes e orgulhosos das minhas conquistas, por entenderem o meu distanciamento.

Ao meu marido, Silvio, pela paciência, motivação e amor demonstrados durante toda a minha jornada.

Aos meus filhos, João, Renato e Luiza, pela compreensão das horas passadas trabalhando longe deles.

Em especial ao meu filho João, grande incentivador, sempre cobrando a minha produção e levantando o meu ânimo.

Aos meus amigos, pelo interesse, questionamento e sugestões. Em especial à Helmara e Luciana Ginezi, grandes amigas, sempre interessadas e prontas a ajudar, e à Idalina e ao João Carlos, driblando o tempo para me socorrer.

Um agradecimento ao pessoal da SOS Mata Atlântica, em especial à Márcia Hirota e ao Mário Mantovani, pelo pontapé inicial nessa busca e colocações importantes que nortearam o meu caminho.

Aos meus professores, pelo carinho dispensado e sugestões sempre pontuais, em especial à Prof. Dra. Maria Aparecida Barbosa.

Agradeço, especialmente, a minha orientadora, Profa. Dra. Stella Tagnin, simplesmente maravilhosa, pela presença, disposição, sugestões e críticas, pela oportunidade de crescimento que me ofereceu e, principalmente, pela grande paciência e carinho sempre demonstrados.

E a tantas outras pessoas que, apesar de não serem nomeadas, sempre colaboraram e me ajudaram nessa jornada.

Acima de tudo, gostaria de agradecer a Deus, sem o qual nada seria possível. 


\section{SUMÁRIO}

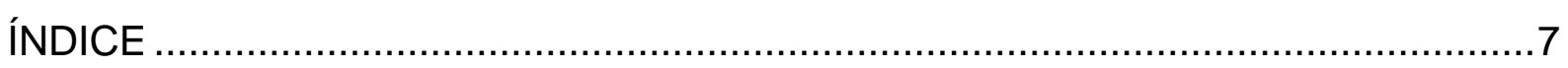

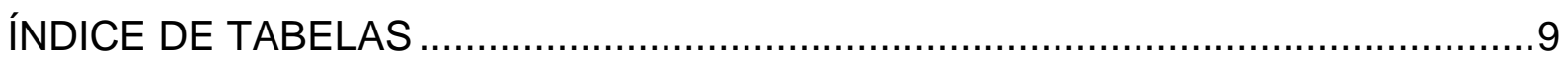

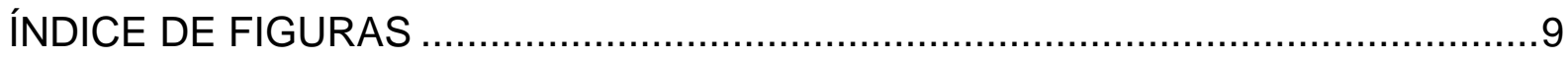

RESUMO

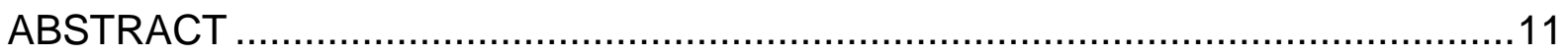

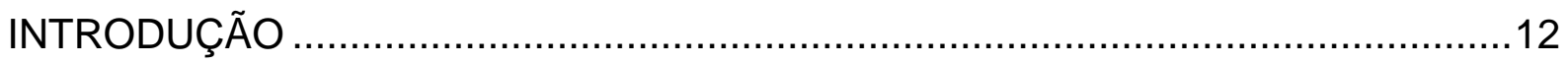

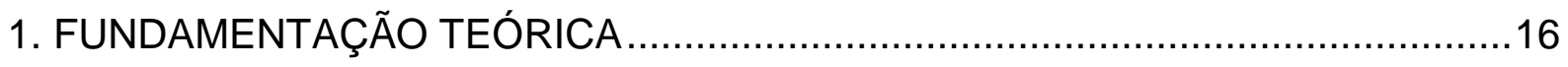

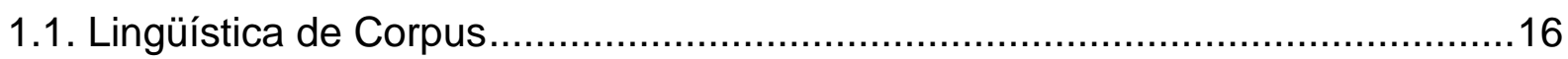

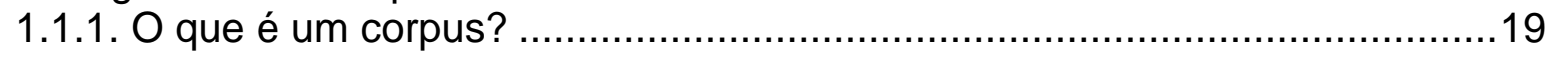

1.1.2. O que são linhas de concordância? ........................................................21

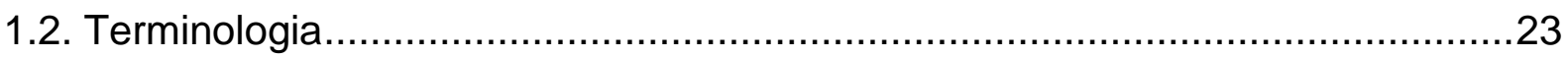

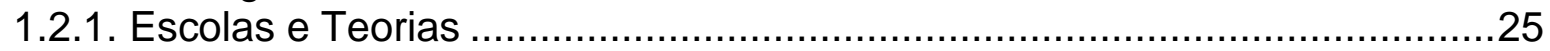

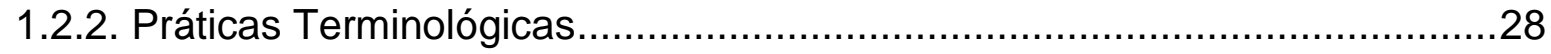

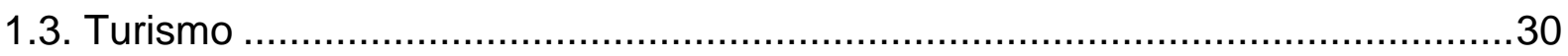

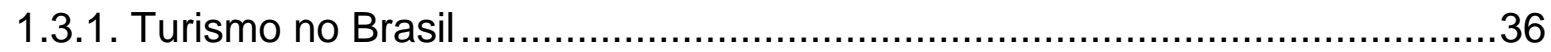

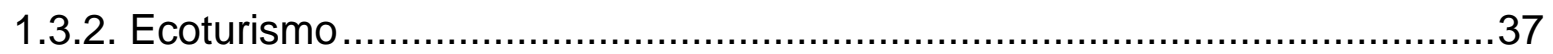

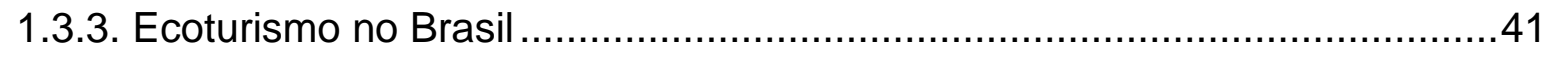

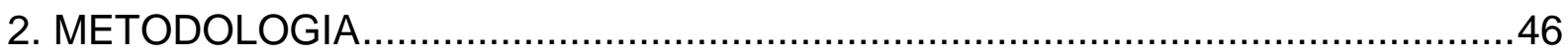

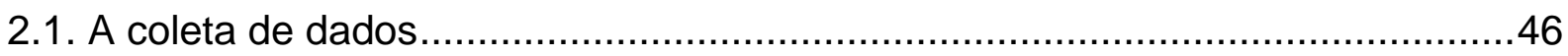

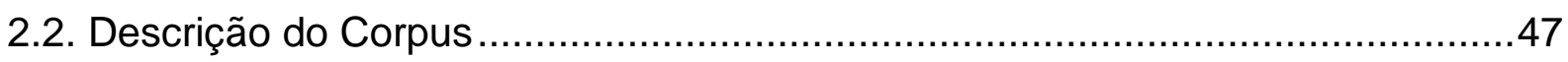

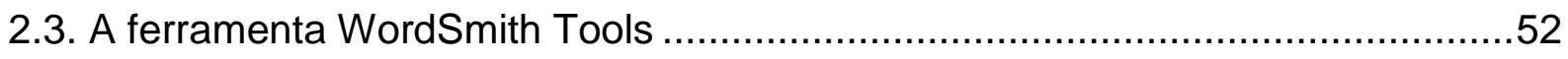

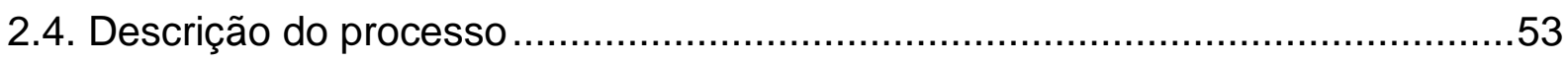

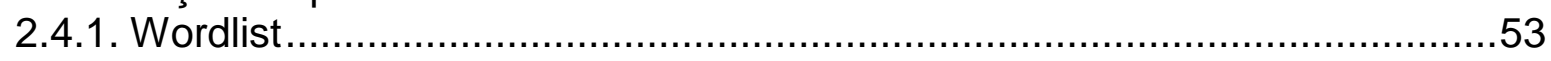

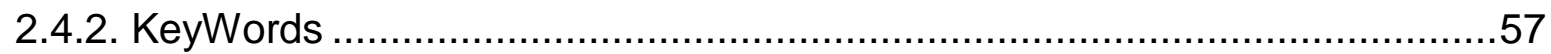

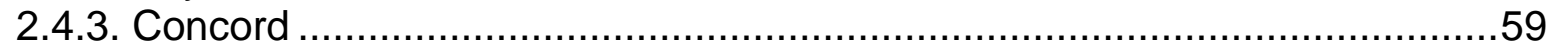

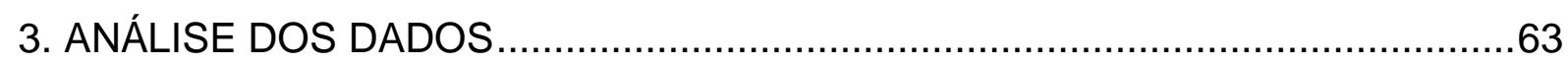


3.1 Wordlists. .63

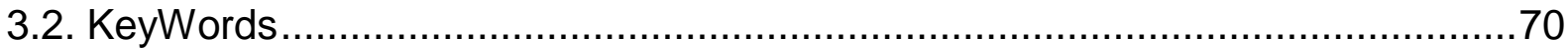

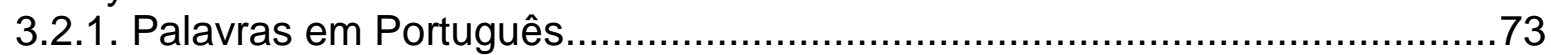

3.2.2. Palavras em inglês............................................................ 91

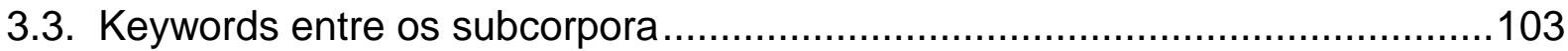

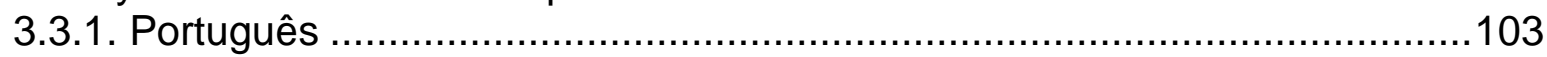

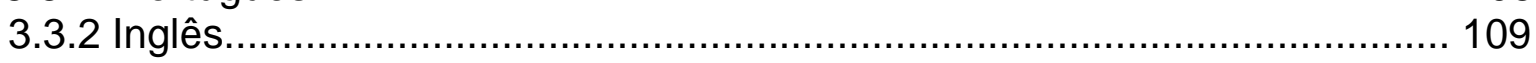

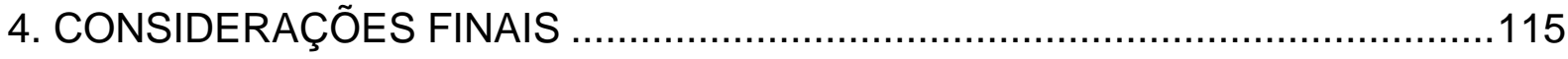

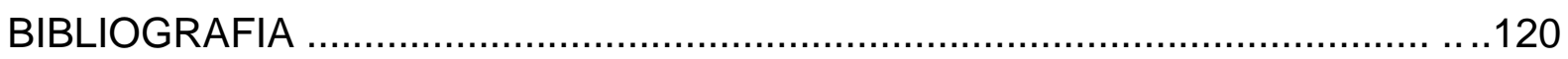

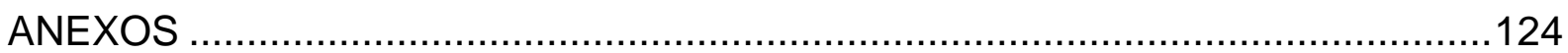

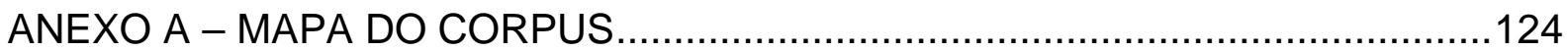

ANEXO B - KEYWORDS: RESULTADO DO CRUZAMENTO DAS LISTAS DOS SUBCORPORA DE ESTUDO EM PORTUGUÊS COM O RESPECTIVO CORPUS

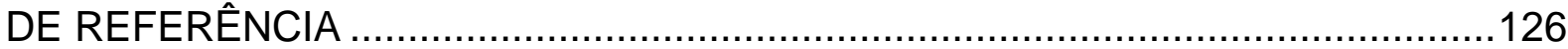

ANEXO C - KEYWORDS: RESULTADO DO CRUZAMENTO DAS LISTAS DOS SUBCORPORA DE ESTUDO EM INGLÊS COM O RESPECTIVO CORPUS DE REFERÊNCIA

ANEXO D - RELAÇÃO DAS KEYWORDS EM PORTUGUÊS JÁ LIMPAS ............148

ANEXO E - RELAÇÃO DAS KEYWORDS EM INGLÊS JÁ LIMPAS ...................151

ANEXO F - LISTA DE PALAVRAS QUE OCORREM NOS CORPORA EM PORTUGUÊS E EM INGLÊS

ANEXO G - PALAVRAS-CHAVE: CRUZAMENTO ENTRE AS LISTAS DE PALAVRAS-CHAVE EM PORTUGUÊS

ANEXO H - PALAVRAS-CHAVE: CRUZAMENTO ENTRE AS LISTAS DE PALAVRAS-CHAVE EM INGLÊS 


\section{ÍNDICE}

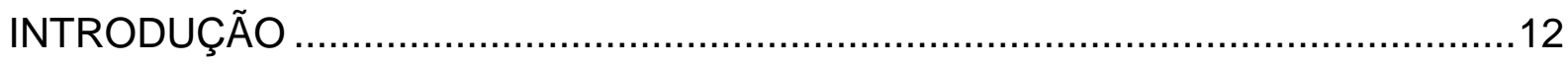

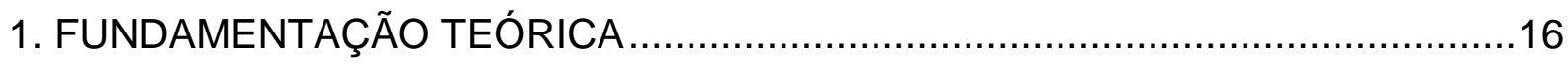

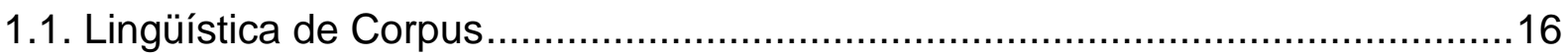

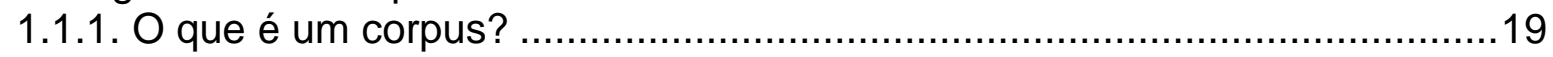

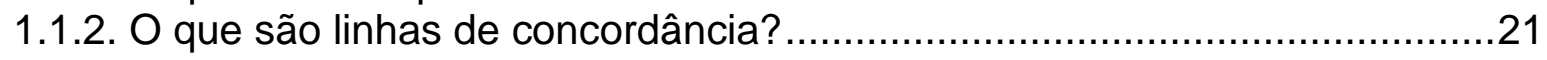

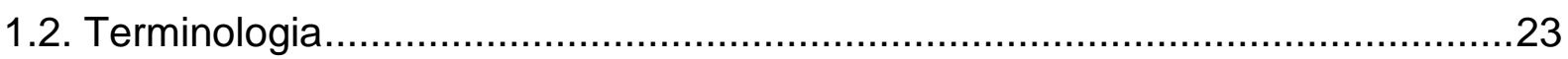

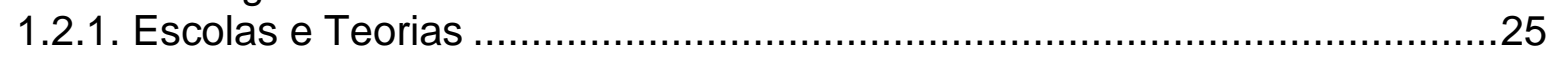

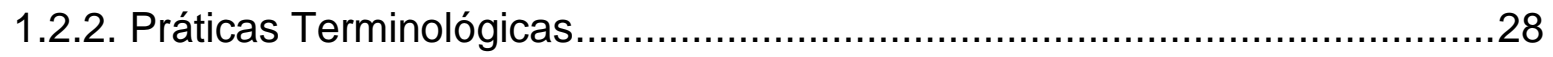

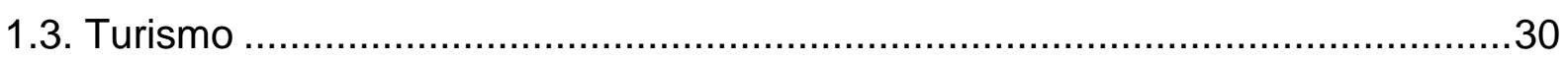

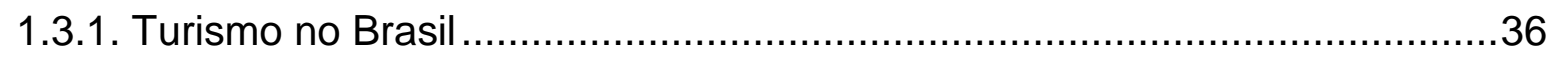

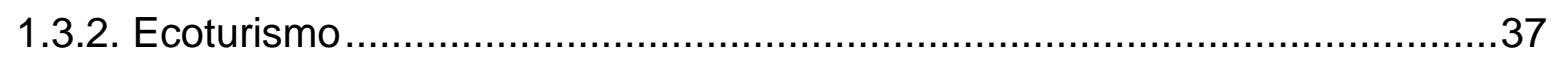

1.3.3. Ecoturismo no Brasil ..................................................................... 41

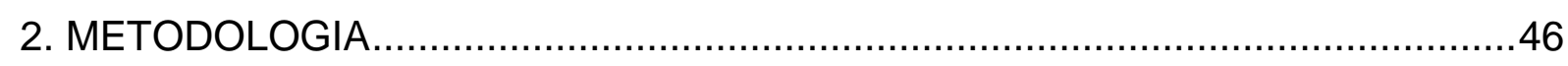

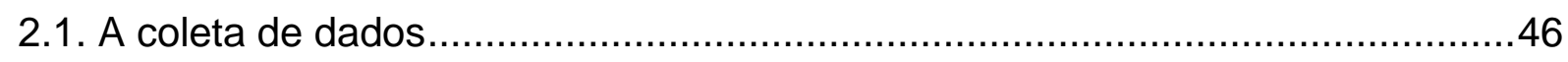

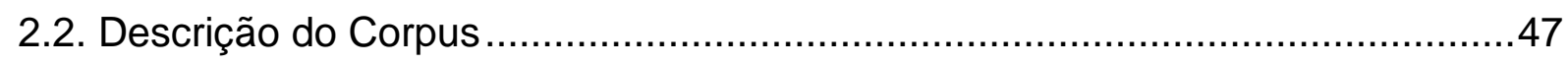

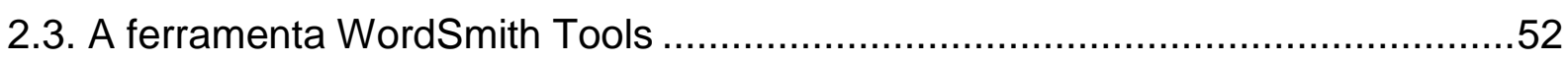

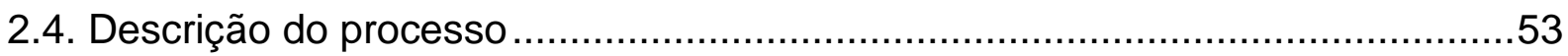

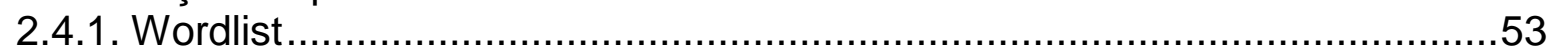

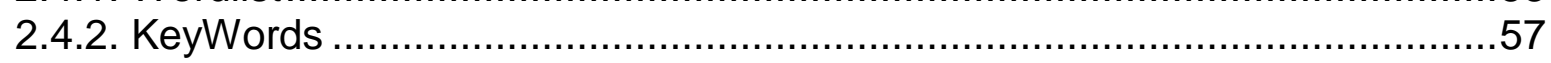

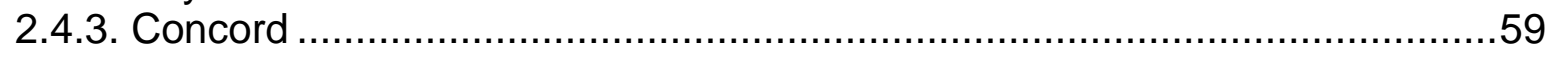

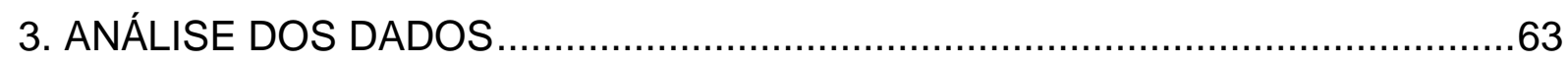

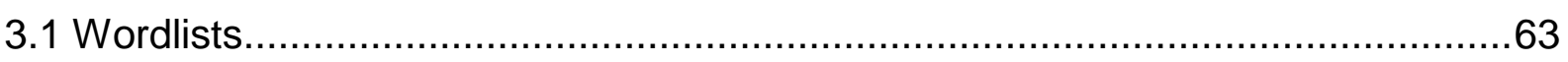

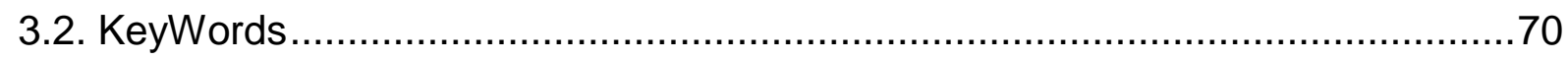

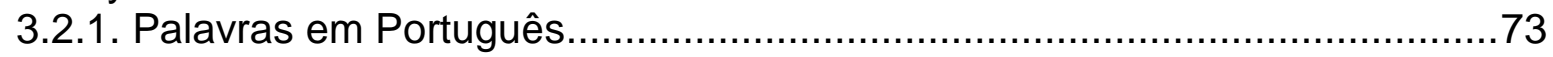

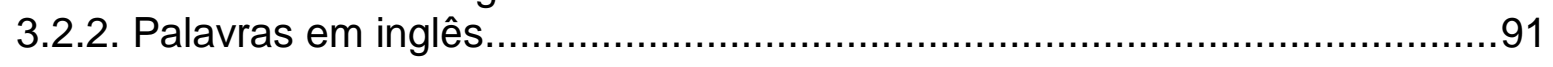

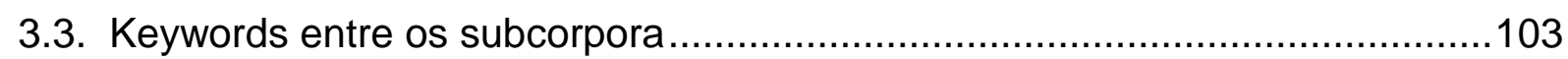

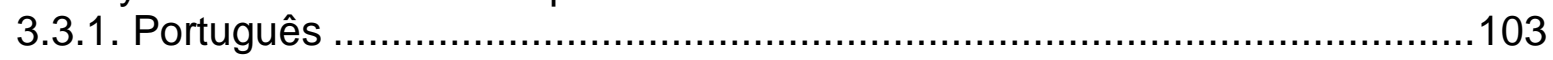

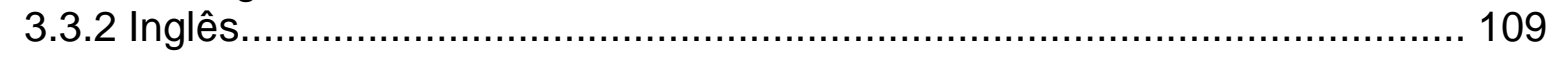

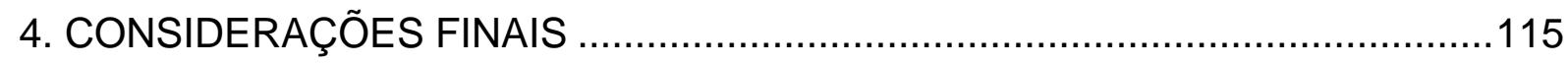


BIBLIOGRAFIA

ANEXOS

ANEXO A - MAPA DO CORPUS

ANEXO B - KEYWORDS: RESULTADO DO CRUZAMENTO DAS LISTAS DOS SUBCORPORA DE ESTUDO EM PORTUGUÊS COM O RESPECTIVO CORPUS DE REFERÊNCIA 126

ANEXO C - KEYWORDS: RESULTADO DO CRUZAMENTO DAS LISTAS DOS SUBCORPORA DE ESTUDO EM INGLEES COM O RESPECTIVO CORPUS DE REFERÊNCIA

ANEXO D - RELAÇÃO DAS KEYWORDS EM PORTUGUÊS JÁ LIMPAS. 148

ANEXO E - RELAÇÃO DAS KEYWORDS EM INGLÊS JÁ LIMPAS 151

ANEXO F - LISTA DE PALAVRAS QUE OCORREM NOS CORPORA EM PORTUGUÊS E EM INGLÊS

ANEXO G - PALAVRAS-CHAVE: CRUZAMENTO ENTRE AS LISTAS DE PALAVRAS-CHAVE EM PORTUGUÊS

ANEXO H - PALAVRAS-CHAVE: CRUZAMENTO ENTRE AS LISTAS DE PALAVRAS-CHAVE EM INGLÊS 


\section{ÍNDICE DE TABELAS}

TABELA 1. COMPOSIÇÃO DO CORPUS.

\section{ÍNDICE DE FIGURAS}

FIGURA 1. TURISMO ALTERNATIVO. .34

FIGURA 2. ESTRUTURA DO CORPUS. .50

FIGURA 3. LISTA POR ORDEM ALFABÉTICA. .55

FIGURA 4. LISTA POR ORDEM DE FREQÜÊNCIA. .56

FIGURA 5. LISTA DE PALAVRAS - DADOS ESTATÍSTICOS. .56

FIGURA 6. PALAVRAS-CHAVE (SUBCORPORA EM PORTUGUÊS DE ENTIDADES AMBIENTALISTAS E AGÊNCIAS DE TURISMO). .58

FIGURA 7. LINHAS DE CONCORDÂNCIA PARA A PALAVRA TOURISM. .59

FIGURA 8. CONTEXTO AMPLIADO DA PALAVRA DE BUSCA TOURISM. 60

FIGURA 9. COLOCAÇÕES COM A PALAVRA "TURISMO". .61

FIGURA 10. CLUSTERS COM TRÊS PALAVRAS PARA "TURISMO" .61 


\section{RESUMO}

O objetivo desta pesquisa é estabelecer uma comparação entre o modo como três setores distintos relacionados à área de ecoturismo - agências de turismo, entidades ambientalistas e órgãos governamentais - buscam propagar suas idéias, e como isso pode se refletir na forma como denominam suas atividades e nos conceitos com relação a essa área.

Para que esse objetivo fosse atingido, foi compilado um corpus comparável em português e inglês com textos autênticos dos três setores mencionados a partir de sites brasileiros e neozelandeses. Os dados foram levantados com o uso de uma ferramenta computacional para análise lingüística, o WordSmith Tools.

Este trabalho está embasado em três áreas - Lingüística de Corpus, Terminologia e Turismo - e possibilitou uma reflexão a respeito do processo de extração de termos utilizando-se a Lingüística de Corpus, demonstrando como esse procedimento pode auxiliar a tornar a pesquisa lingüística e a extração de termos mais precisa e confiável, oferecendo contribuições relevantes para o processo tradutório, o ensino de línguas para fins específicos e a produção de glossários e dicionários terminológicos.

Palavras-chave: Lingüística de Corpus, Terminologia, Tradução, Ecoturismo, Ensino de Línguas, Agências de turismo, Entidades Ambientalistas, Órgãos do Governo. 


\section{ABSTRACT}

The aim of this study is to establish a comparison between the way three distinct areas related to Ecotourism - travel agencies, environmental organizations and the government - try to spread their ideas, which is reflected in the way they name their activities and the concepts they adopt concerning ecotourism.

In order to achieve our goals, a comparable Portuguese and English corpus was compiled with authentic texts from Brazilian and Newzeland sites in the three areas mentioned. The data was obtained with the use of a computational tool for linguistics analysis, the WordSmith Tools.

This study is grounded in three areas: Corpus Linguistics, Terminology and Tourism and enabled a reflection about the process of term extraction with the help of Corpus Linguistics, showing how this procedure can help making linguistic research and term extraction more precise and reliable, and how, in turn, this can offer useful contributions to the translation process, the teaching of language for specific purposes and the production of glossaries and terminological dictionaries.

Keywords: Corpus Linguistics, Terminology, Translation, Ecotourism, Language Teaching, Travel agencies, Environmental organizations, Government. 


\section{INTRODUÇÃO}

"A humanidade estava apenas iniciando seu despertar para o desenvolvimento com respeito aos direitos das futuras gerações, ainda na década de 80 , mas as primeiras respostas para garantir o cuidado e a proteção ao meio ambiente já começavam a ser dadas. É nesta década que o mundo assiste aos protestos de manifestantes contra petroleiros e usinas atômicas, enquanto acompanha a incipiente construção do conceito de desenvolvimento sustentável" " (SOS Mata Atlântica: 2007).

Nessa época, a sociedade, principalmente os jovens, se mobiliza em torno da criação de "Organizações Não-Governamentais", as ONGs, e passa a participar de forma mais efetiva das decisões sobre o futuro, abraçando muitas causas relacionadas ao meio ambiente. Também nessa época surge a denominação "ecoturismo", referindo-se a uma atividade de lazer baseada na conservação do ambiente natural.

O desenvolvimento da indústria turística, considerada uma das maiores do mundo, leva também ao crescimento do ecoturismo, que se destaca, atualmente, como uma das formas de turismo que mais se expandem.

Tudo isso despertou o interesse das agências de turismo, que passaram a investir na divulgação de roteiros em áreas de extrema beleza natural. O conceito de turismo, que antes servia para designar qualquer tipo de viagem de lazer, é ampliado, oferecendo novas opções de entretenimento. Hoje, temos conceitos diferentes como turismo de massa, rural, histórico, cultural, esotérico, e ecoturismo, entre outros, cada um com suas especificidades.

No entanto, em 1998, um estudo comparativo sobre a política de ecoturismo nas Américas levantou a problemática da grande variedade de denominações para o ecoturismo. De acordo com o relatório, essas denominações variavam de região para região, sendo muitas vezes criadas com o objetivo de atingir um número maior de pessoas interessadas em atividades relacionadas ao assunto.

\footnotetext{
${ }^{1}$ Disponível em: <http://www.sosmatatlantica.org.br/index.php?section=who\&action=history $>$.
} 


\begin{abstract}
De acordo com o documento "Diretrizes para uma Política Nacional de Ecoturismo", o ecoturismo é
\end{abstract}

\begin{abstract}
"um segmento da atividade turística que utiliza, de forma sustentável, o patrimônio natural e cultural, incentiva sua conservação e busca a formação de uma consciência ambientalista através da interpretação do ambiente, promovendo o bem-estar das populações envolvidas".
\end{abstract}

Ou seja, há um interesse cada vez maior no aumento da receita gerada nas áreas conservadas, ordenação das visitas e preservação dos recursos naturais, o que leva a uma maior divulgação das possibilidades de exploração do ecoturismo, não apenas no Brasil, mas no mundo. Esse interesse acaba por despertar a atenção de todos os envolvidos com o assunto turismo e meio ambiente, especialmente de três áreas: agências de turismo, entidades ambientalistas e o próprio governo.

Mas como podemos definir cada uma dessas áreas?

De modo geral, uma agência de turismo se preocupa com a revenda de pacotes turísticos elaborados pelas operadoras, ganhando uma comissão para cada uma das vendas realizadas ${ }^{3}$.

As entidades ambientalistas dedicam-se a atividades que visam à preservação ou recuperação do meio ambiente. Entre as inúmeras entidades existentes, podemos citar a SOS Mata Atlântica, a WWF (World Wildlife Fund), o Greenpeace e o Projeto Tamar.

O governo, por sua vez, tem órgãos, no nível federal, estadual e municipal, responsáveis tanto pelo desenvolvimento de atividades de preservação e conservação do patrimônio natural quanto pela fiscalização do uso dos recursos naturais. Entre eles, podemos citar o IBAMA (Instituto Brasileiro do Meio Ambiente e dos Recursos Naturais Renováveis), responsável pela execução da Política Nacional do Meio Ambiente.

Dessa forma temos, de um lado, o governo, que, interessado em desenvolver o potencial ecoturístico do país, busca a divulgação dos atrativos que as regiões do

\footnotetext{
${ }^{2}$ Disponível em: <http://www.ibama.gov.br/ambtec/secao.php?cdt=2\&cds=388>.

${ }^{3}$ Disponível em: <http://www.procon.sp.gov.br/texto.asp?id=732>.
} 
país oferecem. Do outro, temos as agências de turismo, que, tendo em mãos um patrimônio tão rico, lançam mão das mais diversas estratégias para atingir um público interessado em novas formas de lazer. Essas estratégias envolvem a criação de novos roteiros e, principalmente, de novas terminologias para vender um produto aparentemente distinto e inovador que possa atrair o consumidor, levando-os a conhecer o que as agências chamam de diferentes atividades turísticas.

Em meio a isso tudo, temos as entidades ambientalistas, preocupadas com os danos que o turismo pode trazer a áreas extremamente delicadas, danos esses que podem destruir todo o potencial de uma região. Ao mesmo tempo em que se preocupam com esse interesse que as agências têm por determinadas regiões, essas entidades reconhecem a importância do turismo para promover a sustentabilidade dessas regiões, o que as leva a buscar soluções mais viáveis para integrar o morador local ao desenvolvimento turístico, de modo sustentável e consciente da necessidade de preservação local.

Isso nos levou a pensar nos problemas que essa variedade de termos poderia causar ao público em geral, aos tradutores e estudiosos dessas áreas. Ainda mais com o desenvolvimento tecnológico e facilidade de obtermos informações sobre as mais diversas áreas, o que tornou cada vez mais necessária a produção de glossários e dicionários terminológicos que possam facilitar 0 acesso a essa terminologia. Essa questão nos fez refletir sobre os procedimentos a serem seguidos na compilação de material que pudesse ser útil tanto para o leitor comum quanto, em especial, para o profissional de tradução.

Assim sendo, podemos definir os objetivos deste trabalho:

1. A partir de um corpus comparável em português e inglês de textos autênticos extraídos de sites brasileiros e neozelandeses, identificar o vocabulário específico de ecoturismo.

2. Analisar as semelhanças e diferenças com relação à linguagem utilizada por essas três áreas na divulgação de seus trabalhos relacionados ao ecoturismo.

3. refletir sobre a utilização da Lingüística de Corpus na extração de termos e levantamento de vocabulário específico. 
Deste modo, no capítulo 1, "Fundamentação teórica", apresentaremos as bases teóricas do nosso estudo, por meio de uma panorama geral da Lingüística de Corpus e dos modelos teóricos da Terminologia e do Turismo.

Em seguida, no capítulo 2, "Metodologia", descreveremos o processo de construção de nosso corpus, desde sua primeira compilação, até a compilação final, passando pelas mudanças que nosso projeto sofreu, seguindo-se a descrição das etapas de nossa pesquisa e da ferramenta para análise lingüística utilizada, o WordSmith Tools.

No capítulo 3, "Análise dos Dados", discutiremos os dados obtidos e as análises extraídas a partir desses dados.

As conclusões deste estudo serão apresentadas no capítulo 4, "Considerações finais", em que avaliaremos se conseguimos responder às nossas perguntas e apontaremos desdobramentos possíveis desta pesquisa. 


\section{FUNDAMENTAÇÃO TEÓRICA}

Neste capítulo, apresentaremos um panorama da fundamentação teórica do nosso trabalho, que compreende a Lingüística de Corpus, a Terminologia e o Turismo. Ao longo da dissertação, esses aspectos serão discutidos e as relações entre eles serão estabelecidas.

\subsection{Lingüística de Corpus}

O corpus na pesquisa lingüística já é utilizado há muito tempo, porém o desenvolvimento tecnológico tornou possível a pesquisa em corpora cada vez maiores, tanto pela facilidade de compilação quanto pelo desenvolvimento de ferramentas computacionais que tornaram possível a análise de imensos corpora. Esse desenvolvimento promoveu mudanças na metodologia da pesquisa, criando a possibilidade de trabalhar com um volume maior de textos de modo confiável. A Lingüística de Corpus trabalha com a coleta e a exploração de corpora para pesquisas de uma língua ou variedade lingüística.

Ainda hoje não há um consenso para a classificação da Lingüística de Corpus, que alguns definem como teoria, outros como metodologia (McEnery e Wilson: 1996) e outros ainda como abordagem (Tognini-Bonelli: 2001; Hoey: 1997). A Lingüística de Corpus não tem um objeto de pesquisa delimitado e nem se dedica a um assunto específico, não podendo ser, portanto, considerada uma teoria. No entanto, pode ser considerada uma metodologia, pois representa uma forma de conduzir uma pesquisa ou as etapas a serem seguidas num dado processo, além de ter como produto um conhecimento novo, contestando, muitas vezes, práticas correntes. 
Além disso, a Lingüística de Corpus ocupa-se em mostrar uma nova forma de estudar a língua, podendo também ser considerada uma abordagem. De acordo com Leech (1992: 106)

"[A Lingüística de Corpus define] não somente uma nova metodologia emergente para o estudo da linguagem, mas uma nova empreitada de pesquisa e, na verdade, uma nova abordagem filosófica." ${ }^{5}$

Biber (1998) também defende esse termo, referindo-se à Lingüística de Corpus como uma abordagem baseada em corpus (corpus-based approach), o que nos leva a crer que haja uma sobreposição desses conceitos, fazendo com que a Lingüística de Corpus seja vista ora como metodologia, ora como abordagem.

Segundo Berber Sardinha (2004: 3), a Lingüística de Corpus

"ocupa-se da coleta e da exploração de corpora, ou conjuntos de dados lingüísticos textuais coletados criteriosamente, com 0 propósito de servirem para a pesquisa de uma língua ou variedade lingüística. Como tal, dedica-se à exploração da linguagem por meio de evidências empíricas, extraídas por computador".

A Lingüística de Corpus trabalha com uma abordagem empiricista, a partir da observação dos dados obtidos da análise de um corpus. Para Halliday (TogniniBonelli, 2001: 48), os corpora permitem que teoria e dados caminhem juntos. Essa posição opõe-se à visão racionalista, introduzida por Noam Chomsky com o lançamento do livro Syntatic Structures, em 1957. Para esse autor, os dados já estavam presentes dentro da mente do lingüista, que se valia da introspecção para acessá-los.

De acordo com Chomsky, caberia ao lingüista determinar os enunciados possíveis e não possíveis. Porém isso representa um problema, pois um lingüista

\footnotetext{
4 “(...) defines not just a newly emerging methodology for studying language, but a new research enterprise, and in fact a new philosophical approach to the subject."

5 Tradução minha.
} 
pode "criar" exemplos que venham ao encontro de sua teoria e sua intuição nem sempre é comprovada.

Esse modelo racionalista levou a um enfraquecimento dos estudos baseados em corpora. Esse enfraquecimento, no entanto, não significou o fim das pesquisas empíricas, mas o argumento de que as análises baseadas em corpus não eram confiáveis, por serem processadas manualmente, ganhou força.

Portanto, de um lado temos Chomsky e sua visão racionalista, entendendo a linguagem como possibilidade, e, de outro, Halliday, com sua visão empiricista, na qual a linguagem é abordada como probabilidade, ou seja, a língua apresenta traços lingüísticos teoricamente possíveis, mas que nem sempre ocorrem freqüentemente (Berber Sardinha, 2004: 30-31).

Os avanços tecnológicos possibilitaram o trabalho com corpora eletrônicos, 0 que tornou a análise mais confiável e deu um novo impulso à pesquisa empiricista, que passou a contar com programas e ferramentas computacionais que realizam o processo de forma rápida e confiável, deixando para o lingüista a parte de análise dos resultados obtidos dessa forma.

As diferenças entre a Lingüística de Corpus e a lingüística Chomskyana foram assim resumidas por Leech (1992 apud Berber Sardinha, 2004: 33):

- Desempenho lingüístico, em vez de competência.

- Descrição lingüística, em vez de universais lingüísticos.

- Visão mais empiricista do que racionalista da pesquisa.

Em seu livro Corpus Linguistics, McEnery \& Wilson (1996: 01) descrevem a Lingüística de Corpus como o "estudo de uma língua baseado em exemplos extraídos da língua em uso"6. Esse é um fator importante no que se refere ao estudo de uma língua, pois podemos trabalhar com exemplos autênticos, e não construídos, analisando a língua natural.

É importante lembrar que "a Lingüística de Corpus não é um fim em si mesmo, mas uma das fontes de evidências para melhorar as descrições da estrutura

\footnotetext{
6 “(...) the study of language based on examples of 'real life' language use."
} 
e do uso das línguas" (Kennedy, 1998: 1) ${ }^{7}$. Trata-se, enfim, de uma abordagem que nos permite investigar a língua em suas mais diferentes situações, o que pode ser útil tanto para aprofundarmos o conhecimento da língua, quanto para desenvolvermos estratégias mais eficazes para o ensino ou encontrarmos a forma mais adequada de utilizar a Lingüística de Corpus para auxiliar em uma tradução.

Essa abordagem também pode ser muito útil nos estudos terminológicos, uma vez que permite a construção de um corpus dentro de uma área bastante específica, possibilitando, com o uso de ferramentas computacionais, sua análise, tornando a pesquisa mais acurada.

Uma vez que o corpus é compilado de acordo com os objetivos da pesquisa, uma alteração no rumo desta ou a descoberta de um dado novo pode levar a uma alteração ou ampliação do corpus, de acordo com os dados que queremos obter. Foi o que ocorreu em nossa pesquisa, conforme relatado no item 2.2, Descrição do corpus.

\subsubsection{O que é um corpus?}

De acordo com Tagnin (2005: 21), um corpus é:

"uma coletânea de textos, necessariamente em formato eletrônico, compilados e organizados segundos critérios ditados pelo objetivo de pesquisa a que se destina. $O$ formato eletrônico permite que esses textos sejam investigados e analisados automaticamente, com o uso de ferramentas computacionais específicas."

O fato de os textos serem compilados eletronicamente e a existência de ferramentas de análise específicas possibilitam a compilação de um grande número de textos escritos originalmente em uma determinada língua, ou também de traduções, o que nos permite verificar a ocorrência de determinados dados em seu contexto original.

\footnotetext{
7 "Corpus linguistics is not an end in itself but is one source of evidence for improving descriptions of the structure and use of languages (...)"
} 
Entre as várias definições de corpus, Berber Sardinha (2004: 18) apresenta a de Sanchez (1995: 8-9 apud Berber Sardinha 2004: 18)

"[Corpus é] um conjunto de dados lingüísticos (pertencentes ao uso oral ou escrito da língua, ou a ambos), sistematizados segundo determinados critérios, suficientemente extensos em amplitude e profundidade, de maneira que sejam representativos da totalidade do uso lingüístico ou de algum de seus âmbitos, dispostos de tal modo que possam ser processados por computador, com a finalidade de propiciar resultados vários e úteis para a descrição e análise."

Berber Sardinha a considera a definição mais completa por especificar todas estas características:

- a origem dos textos;

- o propósito do corpus;

- sua composição;

- sua formatação;

- sua representatividade;

- sua extensão.

Ao desenvolvermos uma pesquisa, podemos optar por trabalhar com um corpus já existente ou fazer nossa própria compilação de textos. Neste último caso, conforme as definições acima, a coleta deve ser feita seguindo critérios bem definidos que garantam a representatividade de certa área ou da língua que o corpus representa. No nosso caso, o corpus é escrito, bilíngüe e comparável, composto por textos originais em português e em inglês coletados da internet, entre 2005 e 2006, sobre o tema "ecoturismo".

Esse tipo de corpus é muito importante, entre outros aspectos, para a tradução, pois permite a análise de textos reais e investigação das correspondências em cada uma das línguas. 
Podemos trabalhar ainda com um corpus de língua geral, contendo exemplos dos mais variados gêneros textuais e assuntos, servindo de referência para estudos lexicais e podendo ser utilizado como um contraste com o corpus de estudo.

\subsubsection{O que são linhas de concordância?}

Quando vamos fazer a análise dos dados obtidos, é necessário que eles estejam organizados de maneira a tornar nosso trabalho mais fácil. Uma das formas de apresentação desses dados é em linhas de concordância, ou seja, uma apresentação na qual cada resultado obtido é apresentado em uma linha. Essas linhas apresentam a palavra ou expressão de busca, em geral centralizada, inserida em seu contexto, facilitando a análise, seja em uma leitura horizontal, isto é, dentro do seu contexto, seja em uma leitura vertical, observando todas as ocorrências encontradas em busca de um determinado padrão.

Entre outros aspectos, essa análise nos permite verificar, tanto no eixo horizontal quanto no vertical (Tognini-Bonelli, 2001):

- repetição de palavras que co-ocorrem (colocados) com a palavra de busca;

- repetição de padrões gramaticais;

- repetição em nível semântico (campo semântico e prosódia semântica).

Apresentamos abaixo um exemplo de linhas de concordância para o termo "turismo de aventura" obtidas a partir do site do WebCorp"

\begin{tabular}{|lr|}
\hline 1. & no sudoeste do Estado, oferece turismo de aventura, ecoturismo (incluindo o Parque \\
2. & empresa americana especializada em turismo de aventura na costa oeste dos EUA \\
3. & qualidade operacional voltados para o $\underline{\text { turismo de aventura, }}$, de mergulho, pesca esportiva, \\
4. & a Nova Zelândia, excelência em turismo de aventura; a Argentina, excelência em \\
5. & mapeamento dos principais pontos do turismo de aventura nacionais, como forma de \\
6. & para pessoas acostumadas com turismo de aventura. Para chegar ao topo não \\
7. & potencialidades do ecoturismo e do turismo de aventura no Brasil O ecoturismo será \\
8. & natureza, além do setor de turismo de aventura ou lazer. Tipo:esportivo Local
\end{tabular}

\footnotetext{
${ }^{8}$ www.webcorp.org.uk
} 
9. verticais, esportes de aventura, turismo de aventura e ecoturismo. Venda de 10. cidade Cachoeiras na rota do turismo de aventura Museu Histórico de Araxá -

As linhas de concordâncias são, portanto, a fonte na qual o investigador vai buscar respostas a questionamentos sobre a língua e seu funcionamento, fixando-se não apenas nas palavras, mas também nos textos nos quais essas palavras ocorrem.

De acordo com Hoey (1997: 3), o pesquisador precisa preocupar-se não apenas com as palavras e os padrões lingüísticos, mas também com os textos nos quais esses padrões se inserem. $O$ autor resume esses aspectos em cinco perguntas:

"1. De quais padrões lexicais a palavra faz parte?

2. A palavra associa-se regularmente a outros significados específicos?

3. Em quais estruturas ela ocorre?

4. Há qualquer correlação entre os usos/significados das palavras e as estruturas em que ocorre?

5. A palavra é associada a (alguma posição em qualquer) organização textual?"'

Essas perguntas se relacionam à padronização nos diversos níveis: lexical, sintático e textual, como sendo algo regular na língua. Em nosso estudo, iremos trabalhar com duas perguntas de Hoey: a primeira trata da associação entre itens lexicais (colocação), que faz com que certas palavras apareçam juntas com uma determinada freqüência, o que levou Firth (1957, apud Berber Sardinha, 2004: 41) a afirmar que uma palavra pode ser julgada de acordo com sua companhia, e a segunda busca outros significados para determinadas palavras em cada uma das entidades estudadas, agências de turismo, entidades ambientalistas e governo.

A importância da pesquisa com corpus fica clara quando Fillmore diz que "não há nenhum corpus que contenha toda a informação que eu quero explorar", mas que

\footnotetext{
9 "1. What lexical patterns is the word part of? 2. Does the word regularly associate with particular other meanings? 3. What structure(s) does it appear in? 4. Is there any correlation between the word's uses/meanings and the structures in which it participates? 5 . Is the word associated with (any position in any) textual organization?"
} 
"todo corpus me ensinou coisas sobre a linguagem que eu não teria descoberto de nenhum outro modo" (Fillmore, 1992 apud Berber Sardinha 2004: 43).

Uma das áreas em que se utiliza muito a Lingüística de Corpus é a Terminologia.

\subsection{Terminologia}

O homem sempre procurou palavras para dar nomes às coisas. A necessidade de uma comunicação mais eficaz fez com que houvesse uma padronização dessa nomeação, principalmente quando nos referimos a termos técnico-científicos, buscando a univocidade. No entanto, apenas na segunda metade do século XX surge uma área que se dedica a isso.

A Terminologia clássica tem origem na Teoria Geral da Terminologia (TGT) de Wüster, que tinha como objetivo alcançar a precisão e possibilitar uma comunicação profissional por meio da normalização. Sua preocupação se restringia à função denominativa da língua, não vendo na linguagem a função de comunicação. Essa teoria denominativa é mais onomasiológica, ou seja, preocupase em investigar os vários nomes atribuídos a um conceito, e é útil quando se tem uma coerência e correspondência entre as noções e os termos técnicos. Wüster partia do princípio de que cada termo deve designar um único conceito e vice-versa, o que não condiz com a realidade lingüística dos domínios de especialidade.

Ele passou a estudar os problemas terminológicos para superar os obstáculos encontrados na comunicação profissional causados pela falta de precisão e pela diversificação da linguagem natural. Sua preocupação era com a metodologia, e não com o funcionamento dos léxicos terminológicos. Por seu trabalho, Wüster é considerado o fundador da Terminologia moderna, concebida como uma disciplina autônoma e multidisciplinar, que demanda conhecimentos lingüísticos, cognitivos, lógicos, ontológicos e das ciências de informação (Krieger \& Finatto, 2004).

Essa área foi, originalmente, concebida como parte da Lingüística Aplicada:

"Pertencer à lingüística aplicada é precisamente o que caracteriza, em larga medida, o estudo científico geral da Terminologia. Isso 
torna implícito o fato de que ela é um ramo da Lingüística Aplicada. Eis aqui, com efeito, a descrição que se deu desta última e que é tomada a Gunther Kandler. Ela vai além da Lingüística por reunir conhecimentos lingüísticos em todos os domínios da vida e de tornálos úteis a todos os domínios da vida" (Wüster, 1974 apud Krieger \& Finatto, 2004: 21).

Apesar dessa concepção, Wüster deixou claro que a Lingüística tinha como objetivo a língua geral e a Terminologia, o léxico especializado.

Atualmente, no entanto, há controvérsias sobre a Terminologia como ramo da Lingüística Aplicada. Uma das questões relaciona-se ao fato de que um termo pode ser, ao mesmo tempo, objeto teórico, descritivo ou aplicado. Apesar disso, os estudos terminológicos têm crescido cada vez mais, abrindo caminho para diversas pesquisas sobre textos especializados.

A globalização e o avanço da ciência e da tecnologia são responsáveis pelo crescimento das unidades terminológicas e, como conseqüência, há a necessidade de analisar as denominações já existentes e redefini-las para que possam abarcar todos esses novos campos de conhecimento.

Um outro fator importante é que o interesse pela terminologia deixou de restringir-se aos especialistas. Atualmente, ela é de interesse de alunos, tradutores, intérpretes, redatores técnicos, lexicógrafos e terminógrafos, além do cidadão comum, que, por ter mais acesso à informação, acaba por ter contato com o léxico especializado e toma consciência de sua importância no processo comunicativo.

Segundo Auger (1988 apud Krieger \& Finatto, 2004: 28), há três grandes orientações que direcionam o desenvolvimento dos termos técnico-científicos:

- uma orientação lingüístico-terminológica, relacionada aos estudos teóricos do léxico especializado;

- uma orientação voltada para a tradução;

- uma orientação voltada para os propósitos de planificação lingüística, que torne a comunicação técnico-científica cada vez mais padronizada. 
O avanço tecnológico, além de criar a necessidade de novas denominações, contribuiu muito para o desenvolvimento da pesquisa terminológica.

A Tecnologia da Informação, por exemplo, propiciou a criação de grandes bancos de dados terminológicos como o Eurodicautom, da União Européia, e o Termium, do Canadá. Além disso, viabilizou a compilação de grandes corpora, que, com o uso de ferramentas computacionais, possibilitam a extração de termos a partir de textos autênticos.

Todos esses aspectos fazem com que as atividades da Terminologia sejam cada vez mais consolidadas.

\subsubsection{Escolas e Teorias}

A preocupação com a terminologia levou ao desenvolvimento de estudos que deram origem às Escolas de Terminologia. As três primeiras Escolas, a de Viena, a de Praga e a Russa, são consideradas clássicas e foram responsáveis por estabelecer as bases da disciplina, como é o caso de Wüster, fundador da Escola de Viena. Essas escolas têm em comum o enfoque cognitivo e baseiam-se no princípio de que os termos são denominações de conceitos (Krieger \& Finatto, 2004), objetivando a padronização do léxico, o que pode garantir uma comunicação mais eficiente.

No entanto, as escolas clássicas não desenvolveram o potencial explicativo da teoria da Terminologia, mas, assim mesmo, a TGT, legado da Escola de Viena, tornou-se referência internacional.

De acordo com Cabré (1998: 43), a TGT tem como propostas:

- o estudo dos termos técnico-científicos;

- a visão dos termos como unidades compostas de conceito e denominação;

- a visão do conhecimento padronizado - objetivando a comunicação internacional de um registro profissional formal;

- a garantia da precisão e univocidade da comunicação profissional;

- a análise dos termos a partir do conceito que representam. 
O histórico da terminologia mostra uma área que era relacionada apenas à produção de glossários e dicionários especializados, envolvendo muito método e pouca ciência. Os terminólogos não eram lingüistas e sim pessoas de áreas diversas que zelavam pela "língua dos sábios". Mesmo assim, eram pouco prestigiados, uma vez que abandonavam a pesquisa em sua área para cuidar da terminologia.

Com o tempo, houve a necessidade de reavaliar esses princípios devido a três fatores (Cabré, 1999: 2):
"a. a diversificação das necessidades terminológicas atuais
b. a tendência a adequar os conceitos de trabalho e suas aplicações às características de cada trabalho, contexto e situação
c. a introdução de novas tecnologias de informação e a comunicação no processo de trabalho." ${ }^{\text {"10 }}$

Sente-se a necessidade de um novo viés, que possa abarcar seu caráter interdisciplinar: os aspectos cognitivos, lingüísticos e sociais. Essas críticas não invalidam a TGT, mas apontam suas limitações para explicar as unidades terminológicas e suas funções na comunicação especializada.

Nas décadas de 80 e 90, houve um aumento no interesse dos estudos das línguas de especialidade. Surgiu então a socioterminologia, na qual os termos especializados não estão fechados em um determinado cenário comunicativo, ou seja, nos contextos de ocorrência do termo. De acordo com Gambier (1993), a terminologia enfrentava crises de crescimento, identidade e autoridade, além da ausência de uma dimensão social.

Há também uma crítica em relação aos glossários e dicionários técnicos, que não expressam a realidade dos usos terminológicos. A partir disso, a variação terminológica nas comunicações especializadas passa a ser reconhecida.

\footnotetext{
10 "a. la diversificación de las necesidades terminológicas actuales

b. la tendencia a adecuar los planteamientos de trabajo y sus aplicaciones a las características de cada trabajo, contexto y situación

c. la introducción de las nuevas tecnologías de la información y la comunicación en el proceso de trabajo."
} 
A denominação "socioterminologia" apareceu pela primeira vez em um artigo de Boulanger (1981 apud Faulstich, 1995: 2), levando diversos lingüistas a defender o estudo do registro social do texto, reconhecendo, portanto, que as terminologias são suscetíveis à variação.

Os estudos da variação lexical podem ser feitos na língua geral (sociolingüística) ou na de especialidade (socioterminologia). Passa-se, com essa nova abordagem, a investigar não somente as formas escritas do texto, mas também as faladas.

O termo, por sua vez, perde sua característica unívoca e passa a ser variacionista, considerando as diversidades da comunicação. Assim, as variantes são resultantes dos diferentes usos que a comunidade, em sua diversidade social, lingüística e geográfica, faz do termo, ou seja, a diversidade cultural se reflete na terminologia cotidiana. Isso leva à necessidade de conhecer as características da empresa ou instituição na qual a terminologia é gerada, além de outros dados, como o tipo de atividade, as características do pessoal e os postos que ocupam, a competência e os usos lingüísticos, entre outros aspectos.

No Canadá, a necessidade de uma extensa produção bilíngüe, devido à existência de duas línguas oficiais, levou a uma reorganização terminológica e reflexões socioterminológicas.

Tudo isso trouxe uma mudança de cenário, em que, cada vez mais, lingüistas, profissionais do texto e tradutores desempenham o trabalho terminológico, fazendo o levantamento terminológico ou mesmo criando termos. Esses profissionais não são experts na área de conhecimento em foco, mas são conhecedores da terminologia e dos estudos da linguagem.

Toda essa mudança nas pesquisas terminológicas fez surgir uma nova teoria, a Teoria Comunicativa da Terminologia, TCT, proposta por Maria Teresa Cabré e pelo grupo de pesquisadores do Instituto de Lingüística Aplicada da Universidade Pompeu Fabra, em Barcelona. Segundo essa teoria, os termos não são considerados unidades isoladas, mas sim pertencentes à língua natural, dependentes de cada situação de uso. 
Parte-se, então, de uma perspectiva onomasiológica, que vai do significado para o termo, ou semasiológica, que vai da palavra para a distinção de seus diversos significados ou acepções.

A TCT levou a um conhecimento mais profundo do principal objeto da Terminologia, o termo, e não o conceito.

"A Terminologia trata de conceitos e, portanto, de estruturas de conhecimento apenas na medida em que estão representados no léxico da língua. Os conceitos são elementos da estrutura do conhecimento e, como tais, ocupam um lugar importante dentro da filosofia das ciências e das teorias cognitivas. A Terminologia não tem esses propósitos" (Sager, 1993 apud Krieger \& Finatto, 2004: $36)$.

Mais tarde surge a Teoria Sociocognitiva da Terminologia (TST), proposta por Rita Temmerman (2000), na qual os termos são vistos como unidades de compreensão e de representação, colocando em destaque os modelos cognitivos, que mostram a relação entre os processos de categorização e a linguagem. Para a TST, as unidades terminológicas estão em constante evolução.

Apesar das inovações, todas essas teorias têm pontos em comum, revelando a evolução dos estudos lingüísticos.

\subsubsection{Práticas Terminológicas}

Em seu artigo, A renovação lexical nos domínios de especialidade, Alves (2006), aborda a relação entre evolução científica, técnica, social e terminológica. A autora afirma que "o desenvolvimento das ciências e das técnicas, que se processa de maneira crescente, gera, conseqüentemente, um número igualmente crescente de novos termos, necessários para denominar os novos inventos, as novas tecnologias", ou seja, o desenvolvimento científico e a produção terminológica caminham juntos em uma sociedade. 
Os estudos terminológicos passam a ser aplicados nas mais diversas áreas, como a tradução especializada, a documentação, o jornalismo científico, as ciências sociais, o ensino de línguas, o ensino de disciplinas técnicas e científicas (Barros, 2006).

A tradução, por exemplo, depende da utilização correta das unidades terminológicas para que seja considerada de qualidade. A falta de normalização quanto ao uso terminológico pode trazer problemas à tradução, como a inadequação, além de evidenciar a falta de naturalidade do texto.

Segundo Cabré (1999: 7), ainda há casos em que as obras terminológicas não são capazes de resolver os problemas encontrados pelos tradutores, seja pela falta de terminologia disponível na língua de chegada, pela falta de uma terminologia normalizada ou ainda por problemas como a falta de adequação dos glossários terminológicos às necessidades do tradutor.

Além de todos os problemas relacionados à dificuldade de um tratamento terminológico que considere as variações sociolingüísticas contextuais, temos ainda os problemas relacionados à própria Terminologia. De acordo com Cabré (2001: 9), embora a Terminologia não seja uma disciplina nova, ainda é um campo bastante desconhecido mesmo dentro dos círculos acadêmicos. Essa falta de conhecimento se reflete nos dicionários de especialidade, ou glossários, encontrados no mercado, que deixam clara a falta do trabalho conjunto entre o especialista e o terminólogo, dificultando a padronização da sua produção.

Atualmente, a prática terminográfica tem contado com duas novas áreas de grande importância: a Lingüística Computacional e a Lingüística de Corpus, que permitem o trabalho em grandes corpora. Almeida et al. (2006) nos mostram que a utilização da informática permite procedimentos automatizados ou semiautomatizados como:

- criação de corpora descartáveis;

- extração automática de candidatos a termos;

- inserção dos termos numa ontologia;

- elaboração e edição de fichas terminológicas;

- elaboração e constante atualização da base definicional; 
- elaboração de definições;

- edição de verbetes;

- difusão dos dados.

Podemos vislumbrar, portanto, relações de cooperação entre diferentes áreas científicas e técnicas com lexicógrafos e terminógrafos, por exemplo.

Nossa preocupação, neste trabalho, é, utilizando-se da Lingüística de Corpus e da perspectiva comunicativa da Terminologia, a identificação dos termos que possam ser caracterizados como técnicos na área de Ecoturismo e como esses termos se comportam em cada um dos tipos de textos analisados: agências de turismo, entidades ambientalistas e órgãos do governo.

\subsection{Turismo}

O termo turismo surgiu no século $\mathrm{XIX}$, época em que os jovens aristocratas partiam em grandes viagens, conhecidas como Grand Tours, com o objetivo de completar seus estudos e ganhar experiência pessoal. Sua origem vem da palavra francesa tour, que significa "volta, viagem".

Em 1841, o inglês Thomas Cook fundou o que poderíamos considerar a primeira agência de viagens, quando arrendou um trem para levar passageiros para participarem de um encontro contra o alcoolismo. Notando que esse poderia ser um bom negócio, passou a trabalhar com viagens em tempo integral. Com a expansão de seu empreendimento, Cook passou a organizar viagens a diversos países da Europa e, em 1866, aos Estados Unidos. Em 1872, organizou sua primeira volta ao mundo, numa viagem que durou 222 dias. Seu pioneirismo fez com que fosse considerado o pai do turismo moderno.

Muitos aproveitaram as oportunidades abertas por Cook. O setor hoteleiro se expandiu e a segunda metade do século XIX viu um crescimento muito rápido da atividade turística. Além disso, as novas condições econômicas, sociais e culturais resultantes da Revolução Industrial possibilitaram a introdução de novas atividades na civilização urbana da época, entre elas a viagem para o lazer e para a saúde. 
Esse período de grande crescimento foi interrompido na época das duas grandes guerras, porém, entre 1950 e 1973, o mundo viu o surgimento de um "boom" turístico, quando a atividade cresceu num ritmo muito superior ao de toda a sua história. Isso se deveu à estabilidade social, ao desenvolvimento da cultura do ócio no mundo ocidental, ao surgimento de um interesse por viagens e ao desejo de escapar da rotina das cidades. Surgem, então, os pacotes turísticos, levando a uma padronização na forma de viajar no mundo inteiro. Esse crescimento fica mais claro ao contrastarmos os dados dessa época: em 1950 havia cerca de 25 milhões de turistas, enquanto em 1973 esse número havia subido para 190 milhões.

A definição mais antiga para o termo turismo é de 1910, de Herman von Schullard (Wahab, 1991: 24):

\footnotetext{
"a soma das operações, especialmente as de natureza econômica, diretamente relacionadas com a entrada, a permanência e 0 deslocamento de estrangeiros para dentro e para fora de um país, cidade ou região."
}

Em sua definição, Schullard utiliza a palavra estrangeiros para se referir a qualquer pessoa que não pertença ao local visitado. Muitas definições se seguiram à de Schullard, sem que se conseguisse, no entanto, englobar todas as características do fenômeno. Andrade (2002: 38) nos dá uma definição mais geral ao se referir ao turismo como

\footnotetext{
"um conjunto de serviços que tem por objetivo o planejamento, a promoção e a execução de viagens, e os serviços de recepção, hospedagem e atendimento aos indivíduos e aos grupos, fora de suas residências habituais."
}

Poderíamos apresentar aqui uma grande variedade de definições de turismo, o que nos mostra sua complexidade. Optamos, porém, por utilizar a definição da Organização Mundial de Turismo (OMT), adotada pela EMBRATUR, que define os turistas, e não a atividade, como 
"pessoas que viajam a lugares distintos de seu entorno habitual, aí permanecendo pelo menos 24 horas ou um pernoite e no máximo um ano no local visitado, com fins de lazer, negócios e outros."

Embora a definição da OMT abarque uma grande variedade de formas de viagens, ela não considera um passeio de um dia a um determinado destino, como um dia na praia ou uma visita a uma cachoeira, como sendo uma atividade turística, o que, hoje em dia, devido à facilidade de locomoção, tornou-se possível e bastante comum. A definição da OMT ainda pode vir a sofrer alterações para atualizar-se e englobar as atividades consideradas turísticas de maneira ainda mais ampla.

Além disso, a princípio a atividade turística não englobava viagens com fins de negócios ou para tratamentos médicos, pois elas fugiam da definição do compromisso com o lazer. Atualmente, porém, as mais variadas formas de viagens são consideradas atividades turísticas, por envolverem uma viagem a um determinado lugar.

Cruz (2001) nos sugere que a definição da OMT permitiu o surgimento de uma segmentação na área de turismo, ao considerar toda viagem como atividade turística, independentemente da motivação do deslocamento, fazendo com que todo viajante seja um turista potencial.

Assim, apesar de ser considerada uma prática social (Cruz, 2001), a atividade turística também passou a ser um campo de atividade profissional, o que levou a uma integração com áreas diferentes que, de seus pontos de vista, buscam conceituá-la adequadamente.

O interesse pelo turismo fez com que em 1929 surgisse o Centro de Pesquisas Turísticas, na Faculdade de Economia da Universidade de Berlim. No entanto, a preocupação do centro não era analisar o fenômeno turístico, mas sim o conjunto de viagens, consumo e serviços que poderiam possibilitar a distinção entre turismo, migração e viagens de negócios.

Com isso, o turismo passou a ser muito mais que viagem: tornou-se também um campo de atividade profissional, conformando, como o conhecemos hoje, um fenômeno relativamente recente. Além disso, o grande potencial econômico que a 
área envolve, a criação de cursos de turismo, o aumento no número de escolas e universidades que oferecem esse curso e até mesmo o desenvolvimento da Tecnologia da Informação, que nos possibilita um acesso maior à informação, atraíram a atenção de profissionais de áreas diversas, que passaram a se interessar por pesquisas sobre turismo.

Basicamente, a atividade turística pode ser classificada como turismo convencional ou de massa e turismo alternativo. De acordo com Cruz (2001: 6), turismo de massa é a

"forma de organização do turismo que envolve o agenciamento da atividade bem como a interligação entre agenciamento, transporte, hospedagem, de modo a proporcionar o barateamento dos custos de viagem e permitir, conseqüentemente, que um grande número de pessoas viajem. Faz-se necessário lembrar, entretanto, que essa quantidade de pessoas que viaja está muito longe de corresponder ao total da população mundial e muito longe, portanto, de corresponder à massa da população do planeta."

Já o turismo alternativo engloba as formas que se contrapõem ao turismo de massa e que requerem uma gama restrita de infra-estrutura. Para Wearing \& Neil (2001: 04), o turismo alternativo pode ser definido como

\footnotetext{
"formas de turismo que demonstram ser coerentes com os valores natural, social e comunitário e que permitem que tanto hospedeiros quanto hóspedes desfrutem uma interação positiva e conveniente, e compartilhem experiências."
}

Ou seja, é uma atividade que tem um foco maior no espaço natural e na interação com esse espaço e com as pessoas que desfrutam dele.

A figura de Mieczkowsi nos mostra algumas das formas de turismo alternativo em oposição ao turismo de massa. No entanto, o autor não classifica ecoturismo como uma das formas de turismo alternativo. Para Mieczkowsi, o ecoturismo está presente em cada uma das suas formas de turismo alternativo. No entanto, o autor 
não classifica ecoturismo como uma forma distinta de turismo alternativo, mas sim como integrando cada uma das formas apresentadas por ele.

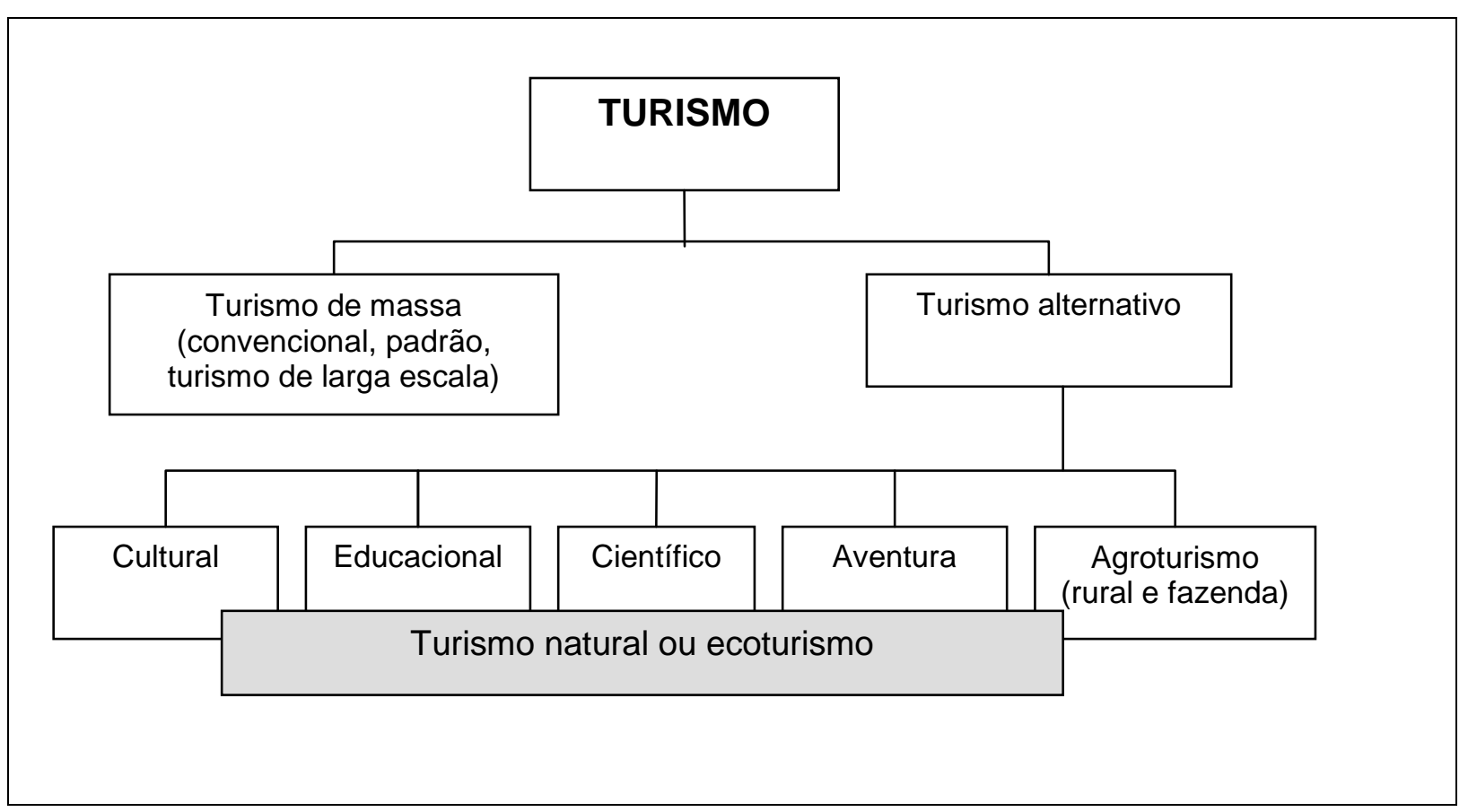

Figura 1. Turismo alternativo.

(Mieczkowsi, 1995 apud Wearing \& Neil, 2001: 5)

A atividade turística ainda pode ser classificada de diversas maneiras, como (Andrade, 2002):

- Local visitado - turismo interno ou doméstico, externo (internacional), receptivo (do ponto de vista do país que acolhe o turista), intermediário (hospedagem provisória antes de se chegar ao destino final).

- Atividades - turismo de férias, cultural, negócios, desportivo, de saúde, religioso.

- Modo como as pessoas se organizam - turismo individual ou organizado (pacotes turísticos).

- Motivação - desejo de evasão, espírito de aventura, necessidade de tranqüilidade, cultura, compras etc. 
A Organização Mundial de Turismo previu que até 2005 o turismo absorveria mais 144 milhões de pessoas. Em 2006, o crescimento foi de 4,5\%, batendo um novo recorde, e os dados indicam que em 2007 o crescimento deve se manter em torno dos $4 \%$, o que faz com que este seja o setor que mais cresce no mundo. As despesas com tarifas de viagens, compras, hospedagem e lazer são comuns a todas as formas de turismo, tornando essa atividade altamente rentável e competitiva.

A crescente demanda por atividades turísticas levou à criação de diferentes formas de turismo, ou de diferentes nomenclaturas, que pudessem atrair um público com um determinado perfil. Podemos resumi-las em:

- Aventura - atividades como rafting, rapel, mergulho, trekking.

- Bem-estar - atividades para equilibrar as condições físicas ou espirituais, como spas e clínicas para desintoxicação.

- Compras - busca de produtos ainda não encontrados na região de origem do turista, e relacionados ao preço e exclusividade, como objetos de arte e artesanato.

- Científico - viagens com o objetivo de realizar estudos ou pesquisas científicas.

- Cultural - programas destinados a pessoas que se interessam em conhecer os costumes de um povo ou de uma determinada região.

- Estudos - visita a um local para aprendizado ou treinamento com profissionais do local.

- Eventos - participação em feiras, festivais, convenções, congressos.

- Esportivo

- Rural

- Terceira idade

- Single - para solteiros.

- Pessoas com necessidades especiais

- Gay 
O crescimento inesperado e desordenado do setor teve conseqüências tanto positivas quanto negativas. De um lado, as empresas hoteleiras tiveram a oportunidade de oferecer novas formas para o turista aproveitar o tempo livre, com a criação de parques temáticos, resorts etc. e um desenvolvimento do marketing turístico, possibilitando ao turista ter maior acesso a informações e novas experiências. Por outro lado, a falta de planejamento, sem a devida previsão de demanda por pacotes turísticos, ou dos impactos sócio-ambientais causados pelos turistas, foi extremamente danosa ao meio ambiente. Essas conseqüências levaram à necessidade de se criar uma legislação que pudesse nortear as atividades do setor.

\subsubsection{Turismo no Brasil}

A internacionalização do país teve início com a vinda da família real para o Brasil e a Carta Régia de 28/01/1808 abrindo os portos às nações amigas. Com isso, o Brasil ficou aberto à curiosidade mundial, uma vez que era visto como um reino exótico, noção que perdura até hoje.

Em 1966, dois anos após o golpe militar, foi criada a EMBRATUR (Empresa Brasileira de Turismo), a primeira empresa pública do Brasil ${ }^{11}$ com o objetivo de divulgar uma imagem positiva do Brasil.

Como porta-voz do governo, a EMBRATUR mostra um país multirracial e democrático, explora a grande diversidade cultural do Brasil assim como o erotismo e a beleza da mulher brasileira, sendo o grande responsável pela visão que o mundo tem do Brasil, o país do carnaval e do futebol.

Isso fica mais evidente nos dados levantados por Alfonso em sua dissertação de mestrado, "Embratur: Formadora de imagens da nação brasileira"12. A autora mostra que já na década de 80 a Embratur exibia uma brasileira com roupas de banho na frente de fotos do Brasil em um estande da entidade em Nova York. Para sua pesquisa, a autora teve acesso ao acervo da Embratur, que mostra toda a trajetória da instituição e que seria descartado por ser considerado ultrapassado.

\footnotetext{
${ }^{11}$ Fonte: Ministério do Turismo

${ }^{12}$ Unicamp, IFCH, fevereiro de 2006
} 
Em 2003, com a criação do Ministério do Turismo, a EMBRATUR passou a cuidar exclusivamente da promoção do Brasil no exterior, sendo conhecida atualmente como Instituto Brasileiro de Turismo.

O desenvolvimento da indústria turística no Brasil levou o Governo Federal a lançar, em 2003, o Plano Nacional de Turismo, uma nova estratégia de apresentação do Brasil, estabelecendo onze produtos turísticos para atrair turistas estrangeiros, que são: Sol \& Mar, Negócios \& Eventos, Festas \& Eventos Populares, Ecoturismo, Aventura, Pesca Esportiva, Mergulho, Golfe, Resorts, Cidades Patrimônio e Turismo de Incentivo (viagens-prêmio pagas por empresas aos seus profissionais).

Mais tarde, o Ministério do Turismo fez uma reformulação e passou a apresentar sete produtos: Sol \& Praia, Cultura, Ecoturismo, Esportes, Negócios \& Eventos, Aventura e Rural.

Após a criação do Ministério do Turismo e a implantação do Plano Nacional de Turismo, o setor cresceu cerca de 17\% entre os anos de 2004 e 2005. Assim, o turismo passou a representar uma das maiores fontes de entrada de dólares no país, o que evidencia a importância da atividade para o Brasil.

Dados do Ministério do Turismo mostram que 2006 foi o melhor ano da história do turismo, com um aumento de $11,77 \%$ em relação a 2005 . O mês de fevereiro de 2007 também registrou um recorde. O crescimento em relação a fevereiro de 2006 foi de 15,10\%. Apesar disso, as visitas ainda estão muito abaixo do esperado, principalmente devido à falta de infra-estrutura e à violência nos grandes centros (Camargo, 2002).

Uma das principais atrações turísticas do Brasil é sua riqueza natural, o que torna o ecoturismo um dos produtos mais importantes e com maior potencial de desenvolvimento no país, uma das razões que despertaram nosso interesse pela área.

\subsubsection{Ecoturismo}

Não se conhece muito bem a origem do termo ecoturismo, mas alguns acreditam que foi W. Hetzer que o utilizou pela primeira vez em 1965, identificando o 
que ele definiu como princípios básicos do turismo responsável: o respeito pelas culturas locais, a minimização dos impactos ambientais, a maximização da satisfação do visitante e a maximização dos benefícios para as comunidades locais.

O termo teria surgido a partir do termo turismo ecológico, ou ecological tourism em inglês, mais tarde transformando-se em ecoturismo.

Outros autores, como Pires (2002), atribuem a criação do termo ao arquiteto mexicano Hector Ceballos-Lascurain, para quem o ecoturismo é "uma forma de viagem na qual o ambiente natural é o foco principal". O termo foi empregado pela primeira vez na revista American birds, na edição de março/abril de 1984, como propaganda para uma atividade turística dirigida por Lascurain.

Embora o termo ecoturismo seja relativamente novo, a atividade ecoturística, ou seja, a prática de observar e integrar-se ao ambiente natural, sempre existiu.

Nos anos 80, vários países já utilizavam o termo ao se referirem a uma atividade que tinha como base a conservação e o respeito pelo meio ambiente, fazendo com se tornasse um segmento com grandes oportunidades de crescimento. Além disso, a maior conscientização com relação ao meio ambiente, associada à necessidade de criação de novas formas para satisfazer o visitante que buscava alternativas ao já "batido" turismo de massa, contribuiu para o desenvolvimento da atividade, fazendo com que o termo fosse cada vez mais utilizado.

Contudo, há muitas definições diferentes para o termo, não existindo ainda uma que seja universal. A primeira foi dada em 1987 por Ceballos-Lascurain (1998: $7)^{13}$

\begin{abstract}
"Modalidade turística ambientalmente responsável que consiste em viajar ou visitar áreas naturais relativamente intocadas com o fim de desfrutar, apreciar e estudar os atrativos naturais (paisagem, flora e fauna silvestres) dessas áreas, assim como qualquer manifestação cultural (do presente e do passado) que aí se possam encontrar,
\end{abstract}

\footnotetext{
13 "Aquella modalidad turística ambientalmente responsable consistente en viajar o visitar áreas naturales relativamente sin disturbar con el fin de disfrutar, apreciar y estudiar los atractivos naturales (paisaje, flora y fauna silvestres) de dichas áreas, así como cualquier manifestación cultural (del presente y del pasado) que puedan encontrarse ahí, a través de un proceso que promueve la conservación, tiene bajo impacto ambiental y cultural y propicia un involucramiento activo y socioeconómicante benéfico de las poblaciones locales (Ceballos-Lascurain)."
} 
através de um processo que promova a conservação, tendo baixo impacto ambiental e cultural e propicie um envolvimento ativo e sócio-economicamente benéfico para as populações locais."14

O autor ainda sugere que a promoção dessa atividade pode estimular as comunidades locais a conservarem seus recursos, por iniciativa própria, sem pressões externas ou legais.

Outros autores, como Western (1999: 17), descrevem o ecoturismo como uma "viagem responsável a áreas naturais, visando preservar o meio ambiente e promover o bem-estar da população".

Como em outras definições, há sempre a idéia de um compromisso com a responsabilidade social e a natureza, tanto que Sachs (1993) afirma que a comunidade local é fundamental no processo de planejamento, implementação e desenvolvimento do ecoturismo, pois a ausência de estratégias eficazes resulta em impactos negativos ao ambiente natural e social.

A necessidade de atrair a atenção dos turistas fez com que fossem criadas formas distintas para nomear a atividade, como turismo natural, inóspito, de baixo impacto, verde, orientado pela natureza, brando e defensivo, entre outras (Wearing \& Neil, 2001; Swarbrooke, 2000).

Há, inclusive, aspectos diferentes nessa forma de turismo, conforme a atividade desenvolvida pelo turista e a sua relação com o meio ambiente. A observação de pássaros, por exemplo, depende da natureza, enquanto o camping é realçado por ela. No entanto, quando o interesse é por algo diferente, por exemplo uma atividade de aventura como tirolesa, rafting, cascading, rapel, bóia-cross, não há preocupação com o ambiente natural e nesse caso pode haver maior degradação.

$\mathrm{Na}$ verdade, podemos dizer que o ecoturismo abarca quatro elementos fundamentais: viagem, natureza, conservação e papel educativo. Esses elementos têm a função de minimizar os impactos ao meio ambiente e desenvolver a conscientização ambiental. (Wearing \& Neil, 2001)

\footnotetext{
${ }^{14}$ Tradução minha
} 
Essa preocupação com a preservação do ambiente natural e da comunidade local para a manutenção da atividade turística levou à idéia de sustentabilidade, conceito segundo o qual a ecologia sustenta a economia e a sustentabilidade ambiental passa a ser fundamental para o crescimento econômico, permitindo a inclusão e o exercício da justiça social.

A idéia de sustentabilidade pode ser vista como a garantia da perpetuação da vida, em qualquer uma de suas formas, donde surgiu um novo termo, o "turismo sustentável". O acordo de Mohonk ${ }^{15}$ definiu turismo sustentável como

"aquele que visa minimizar impactos ecológicos e sócio-culturais, enquanto promove benefícios econômicos para as comunidades locais e países receptores".

Essa forma de turismo é considerada ideal para as comunidades locais, pois, além de propiciar maior reversão de renda para elas, permite a sua participação no setor turístico. No entanto, é importante ressaltar que, apesar de toda essa preocupação, o turismo na natureza não é, a princípio, ecologicamente correto, pois a presença do turista sempre acaba por trazer uma perturbação ao ambiente natural, seja pelo barulho, pela depredação ou pela deposição de resíduos.

Um exemplo é o aumento do número de pessoas que viajam para observar baleias na Nova Zelândia. Embora isso possa ser importante para o conhecimento sobre espécies em extinção, o número desordenado de visitantes pode causar danos por perturbarem as baleias, gerando estresse, que acaba por causar desequilíbrios no ecossistema.

O interesse pela área do turismo pode ser demonstrado pela determinação da Organização das Nações Unidas (ONU) de declarar o ano de 2002 como o ano Internacional do Ecoturismo (International Year of Ecotourism - IYE)

\footnotetext{
${ }^{15}$ Evento internacional realizado em 2000 em New Paltz, Estados Unidos, na Mohonk Mountain House, com a participação de 20 países para discutir os princípios e componentes que devem fazer parte do programa de certificação de turismo sustentável (Fonte: http://www.ecobrasil.org.br/pagina.asp?lng=p\&pagina_id=47).
} 


\title{
1.3.3. Ecoturismo no Brasil
}

No Brasil, a definição adotada pelos órgãos oficiais (EMBRATUR) é a de um

\begin{abstract}
"segmento da atividade turística que utiliza, de forma sustentável, o patrimônio natural e cultural, incentiva sua conservação e busca a formação de uma consciência ambientalista através da interpretação do ambiente, promovendo o bem-estar das populações."
\end{abstract}

A EMBRATUR, atualmente conhecida como Instituto de Brasileiro de Turismo, coloca alguns pontos como condições básicas para a existência dessa modalidade:

a) respeito às comunidades locais;

b) envolvimento econômico efetivo das comunidades locais;

c) respeito às condições naturais - conservação do meio ambiente;

d) interação educacional - a garantia de que o turista incorpore em vida o que aprende em sua visita, gerando consciência para a preservação da natureza e do patrimônio histórico/cultural/étnico.

Esses pontos sintetizam os princípios da atividade turística defendidos por Honey (1999), sendo que a ausência de qualquer um deles descaracteriza a prática ecoturística.

De acordo com a OMT, $10 \%$ das pessoas que viajam pelo mundo são ecoturistas. Embora não haja dados específicos de quantas pessoas, desses $10 \%$, visitam o Brasil, é provável que o país figure entre os principais destinos ecoturísticos no mundo. Isso se deve ao grande potencial do Brasil, que tem cavernas, desertos, rios, lagoas, corredeiras, cascatas, florestas, montanhas, cânions, pântanos, praias, ilhas, planaltos e planícies.

O Brasil ainda tem atrações folclóricas, étnicas, musicais e culturais variadas, além de possuir a maior biodiversidade do planeta, segundo o IBAMA (2002), destacando-se as regiões amazônica e pantaneira como os maiores pólos ecoturísticos. 
Os dados do Instituto de Ecoturismo do Brasil indicam que essa atividade foi responsável pela movimentação de $R$ \$ 2,2 bilhões em 1994 e de $R$ \$ 3 bilhões em 1995, com um crescimento de $36 \%$ em relação ao ano anterior.

Em 1994 o Ministério do Meio Ambiente e da Amazônia Legal e o Ministério da Indústria, do Comércio e do Turismo, por intermédio da Embratur, elaboraram um documento intitulado "Diretrizes para uma política nacional de Ecoturismo", política que ainda hoje não foi implantada.

É importante ressaltar que no Brasil as atividades ecoturísticas ainda são elitistas e degradantes, apesar dos esforços realizados por Organizações NãoGovernamentais (ONGs) e institutos governamentais ligados ao meio ambiente. $\mathrm{O}$ termo ecoturismo utilizado nas Unidades de Conservação ${ }^{16}$, que implica a valorização do patrimônio natural e cultural, ainda é pouco praticado e parece não haver um consenso entre os interesses da Embratur, por um lado, e os do IBAMA e demais órgãos de controle ambiental, por outro. De um lado, temos uma instituição voltada para a ampliação das diversas atividades ecoturísticas no país, e, de outro, órgãos de proteção ambiental que tentam cuidar da preservação do meio ambiente.

A observação da natureza e a preferência por atividades físicas desafiadoras em um ambiente natural possibilitam que se proponha uma categoria de turismo chamada turismo de aventura. De acordo com Fennel (2002), o interesse em atividades que exijam habilidade e concentração resultam em produção de adrenalina e demandam esforço maior na sua realização que na apreciação do ambiente natural o que faz com que a experiência pela qual o indivíduo está passando não possa ser considerada ecoturística. O turismo de aventura foi, e ainda é, uma das muitas nomenclaturas aplicadas ao ecoturismo, sendo considerado por muitos um subproduto do mesmo, o que, no entanto, não pode ser aceito porque as atividades praticadas acabam por causar danos ao ambiente natural, fugindo aos princípios básicos do ecoturismo, definidos pela Conferência Global, em 1990, em Vancouver, Canadá, conforme apresentados por Wearing \& Neil (2001: 13):

\footnotetext{
${ }^{16}$ Unidades de Conservação são porções do território nacional com características naturais de relevante valor sob regimes especiais de administração e às quais se aplicam garantias de proteção.
} 
- O ecoturismo estimula a compreensão dos impactos do turismo sobre o meio natural, cultural e humano.

- O ecoturismo assegura uma distribuição justa dos benefícios e custos.

- O ecoturismo gera emprego local, tanto diretamente no setor de turismo, como em diversos setores da administração de apoio e de recursos.

- O ecoturismo estimula as indústrias locais rentáveis - hotéis e outras instalações de alojamento, restaurantes e outros serviços de alimentação, sistemas de transporte, produção de artesanato e serviços de guia.

- O ecoturismo gera divisas estrangeiras para o país e injeta capital e dinheiro novo na economia local.

- O ecoturismo diversifica a economia local, particularmente nas áreas rurais, onde o emprego agrícola pode ser esporádico ou insuficiente.

- O ecoturismo busca a tomada de decisões em todos os segmentos da sociedade, inclusive nas populações locais, de modo que o turismo e outros usuários dos recursos possam coexistir. $O$ ecoturismo incorpora o planejamento e o zoneamento, assegurando o desenvolvimento turístico apropriado para a capacidade de sustentação do ecossistema.

- O ecoturismo estimula a melhoria do transporte, da comunicação e de outros elementos da infra-estrutura comunitária local.

- O ecoturismo cria instalações recreativas que podem ser usadas pelas comunidades locais, pelos visitantes domésticos e internacionais. Também estimula, auxiliando seu custeio, a preservação dos sítios arqueológicos e de edifícios e bairros históricos.

- O turismo natural estimula o uso produtivo das terras marginais para a agricultura, permitindo que grandes áreas conservem sua cobertura de vegetação natural.

- O turismo cultural aumenta a auto-estima da comunidade local e proporciona a oportunidade de maior entendimento e comunicação entre pessoas de diversas origens.

- O turismo ambientalmente sustentável demonstra a importância dos recursos naturais e culturais para o bem-estar econômico e social da comunidade, podendo ajudar a preservá-los.

- O ecoturismo monitora, avalia e administra os impactos do turismo, desenvolve métodos confiáveis de contabilidade ambiental e calcula qualquer efeito negativo.

Entretanto, Swarbrooke (2000) chama a atenção para a utilização do termo turismo sustentável como sendo sinônimo de ecoturismo. A questão da 
sustentabilidade é importante para que sejamos mais cuidadosos com o meio ambiente, porém vale lembrar que esse trabalho de conservação não pode ser feito de modo a impor cargas indesejáveis às gerações futuras, ou seja, devem-se prever os impactos que o trabalho vai gerar a longo prazo.

Esse autor ressalta também que, para muitos, o ecoturismo é uma forma de turismo feita por turistas esclarecidos e bem educados. Isso não é bem verdade, porque, conforme observamos, se assim fosse, essas áreas não estariam sofrendo a ação de degradação que vemos.

Podemos resumir o que o autor apresenta como aspectos positivos e negativos com relação à sustentabilidade:

\section{Positivos}

- traz benefícios econômicos para a população local e pode ser fonte de renda para projetos de conservação;

- tende a ocorrer numa escala pequena;

- envolve turistas conscientes ou que pelo menos se comportam melhor que outros turistas;

- aumenta a conscientização dos problemas do turismo.

\section{Negativos}

- o ecoturismo pode se tornar sinônimo de egoturismo, ou seja, a preocupação maior do turista é com ele mesmo, com o que ele deseja fazer, ou ver;

- o ecoturismo de hoje pode se transformar no turismo de massa de amanhã. Isso se deve ao aumento no consumo do produto.

O autor ainda cita como exemplo o trekking no Nepal, que começou como uma forma de busca espiritual e se transformou em turismo de massa, gerando desmatamento, descarte de material não biodegradável, contaminação de riachos por esgotos, etc. 
Em 1999, Hartmann listou os obstáculos para o desenvolvimento ordenado e articulado do Ecoturismo no Brasil:

1. ação deficiente dos empresários;

2. ação político-governamental insuficiente;

3. comportamento inadequado do ecoturista;

4. pouca ou nenhuma atividade comunitária;

5. fraca interação empresarial e interinstitucional;

6. infra-estrutura deficiente ou inadequada para o ecoturismo;

7. necessidade de profissionais capacitados;

8. desconhecimento de critérios operacionais de sustentabilidade.

Esses problemas ainda não foram resolvidos, principalmente devido aos conflitos enfrentados pelas partes interessadas nesse desenvolvimento: o governo, as agências de viagens e as entidades ambientalistas.

De acordo com Ruschmann (2000), a degradação ambiental de diversos recursos turísticos em todo mundo exigiu que se tomassem iniciativas que pudessem proteger o meio ambiente, pois a exploração intensiva de regiões extremamente frágeis altera o patrimônio ambiental de forma irreversível. Mesmo assim, não se pode desconsiderar o fato de que o turismo é uma fonte importante para o desenvolvimento socioeconômico de determinadas regiões.

O ecoturismo só pode ocorrer se houver uma política eficaz de preservação. Isso envolve custos e o ecoturista muitas vezes não quer pagar grandes quantias para visitar um "ambiente natural", preferindo, por isso, outros destinos.

A autora também faz um alerta com relação aos papel das operadoras de viagem, que se envolvem cada vez mais no assunto devido a sua preocupação com lucro e vendas, e do próprio governo, que, preocupado em atrair turistas, gasta grandes quantias em pontos turísticos, mas não se preocupa em investir na saúde e na educação da população local, por exemplo.

Vale lembrar que a viabilidade econômica ligada à proteção do meio ambiente só poderá se concretizar a longo prazo e que muitas vezes as agências e mesmo a comunidade local não têm paciência de esperar para ver os benefícios aparecerem. 


\section{METODOLOGIA}

Neste capítulo, descreveremos o desenvolvimento de nossa pesquisa, da primeira compilação do corpus às mudanças ocorridas durante a sua realização, que nos levaram a uma nova compilação, mais adequada aos nossos objetivos.

A primeira idéia para este projeto surgiu do interesse em compilar textos em português e inglês relacionados ao Meio Ambiente e comparar os dados obtidos nas duas línguas com relação à terminologia empregada pela área.

A área de Meio Ambiente tem sido foco dos mais diversos tipos de estudos, principalmente em decorrência dos prejuízos que a natureza vem sofrendo pela falta de educação e políticas de preservação e conservação. Uma das áreas em que fica patente essa agressão é o turismo, uma das indústrias de maior desenvolvimento no mundo atual. Assim, a partir das diversas possibilidades de pesquisa, decidimos trabalhar com a área que congrega o meio ambiente e o turismo, ou seja, o turismo ecológico ou ecoturismo.

\subsection{A coleta de dados}

O ponto de partida para a compilação foi um documento intitulado Ecotourism Policy in the Americas (1998), no qual uma das questões levantadas foi a diversidade de definições para o termo "ecoturismo". Desse modo, nossa primeira compilação do corpus foi feita a partir de textos originais em português e inglês na área de ecoturismo dos quais pretendíamos extrair o vocabulário específico bem como analisar suas correlações nas duas línguas. Esse corpus continha cerca de 200 mil palavras para cada língua e integra o projeto $\mathrm{COMET}^{17}$ (Corpus Multilingüe para Ensino e Tradução), fazendo parte de um de seus subcorpora, o CorTec. ${ }^{18}$

O projeto COMET visa à compilação de corpora com o objetivo de servir de suporte para pesquisas lingüísticas nas áreas de tradução, terminologia e ensino de línguas. Esse projeto está em desenvolvimento junto ao Departamento de Línguas

\footnotetext{
${ }^{17}$ Projeto Comet, disponível no site <http://www.fflch.usp.br/dlm/comet/>

${ }^{18}$ Construído com recursos do CNPq, processo 40.3120-2003-9.
} 
Modernas da Faculdade de Filosofia, Letras e Ciências Humanas da Universidade de São Paulo. Divide-se em três partes:

CorTec: Corpus Técnico-Científico

CoMAprend: Corpus Multilíngüe de Aprendizes

CorTrad: Corpus de Tradução

Sua primeira versão, lançada em setembro de 2005, foi construída e implementada em parceria com o NILC (Núcleo Interinstitucional de Lingüística Computacional) do ICMC (Instituto de Ciências Matemáticas e de Computação) da USP de São Carlos. O objetivo é que o CorTec seja ampliado sistematicamente, tanto nas áreas que já existem quanto inserindo novas.

\subsection{Descrição do Corpus}

No início, a compilação do nosso corpus foi feita com base nos resultados obtidos para as buscas da palavra "ecoturismo" com a utilização da ferramenta Google, tanto em português quanto em inglês. Pudemos observar que a maior parte dos textos tinha como origem sites de agências de turismo, entidades ambientalistas e órgãos governamentais, e que neles havia variações significativas, como a utilização do termo "turismo sustentável", por parte das entidades ambientalistas, como sinônimo de "ecoturismo".

Uma breve conversa com pessoas ligadas a essas organizações mostrou que esse termo era o preferido por essas entidades por estar mais de acordo com suas propostas, ou seja, proteger as áreas preservadas e gerar renda que pudesse ser revertida à população local, levando-a a envolver-se nos projetos de proteção ambiental, ajudando na preservação de áreas com grande potencial ecoturístico e recebendo benefícios por essa preservação. A utilização desses dois termos levounos à primeira alteração do corpus, quando incorporamos o termo "turismo sustentável" (sustainable tourism) às nossas palavras de busca na nova compilação.

Essa compilação e as informações contidas nos sites dos quais os textos foram extraídos mostraram-nos uma nova questão: a diferença de utilização dos 
termos entre as três áreas já mencionadas, levando-nos a um novo rumo para o nosso projeto: não mais as relações entre o vocabulário específico dos subcorpora em português e inglês, mas sim a análise do vocabulário utilizado por cada uma dessas áreas, verificando, em especial, as diferenças de significação desse vocabulário em cada uma delas, as palavras mais utilizadas e o tratamento dado por cada uma dessas áreas ao tema.

Até então, os textos do subcorpus em inglês haviam sido extraídos de sites de vários países de língua inglesa. Porém, como todos os textos do subcorpus em português haviam sido extraídos de sites brasileiros, percebemos que deveríamos fazer o mesmo com o subcorpus em inglês, selecionando textos originais de apenas um país de língua inglesa, para que pudéssemos analisar o modo como cada uma das três áreas desses dois países lidava com o assunto "ecoturismo".

Um dos aspectos a serem considerados dizia respeito ao potencial ecoturístico do país. A imensa riqueza natural do Brasil faz com que ele seja considerado um dos países mais completos para a prática de atividades ecoturísticas, o que tornava importante que o país escolhido tivesse um perfil semelhante.

Além disso, a escolha deveria recair sobre um país que pudesse ser facilmente identificado nas buscas eletrônicas por meio de seu "domínio", isto é, a extensão que identifica o país. A pesquisa avançada da ferramenta Google permite selecionar o "domínio" desejado. Os sites brasileiros, por exemplo, apresentam a terminação ".br", o que facilita a busca e compilação de material. Já os Estados Unidos não apresentam uma extensão que os identifique, o que dificulta determinar a origem dos sites.

A partir desses critérios, optamos pela Nova Zelândia, um país de língua inglesa com um imenso patrimônio natural, capaz de oferecer uma grande variedade de opções de ecoturismo e que pode ser pesquisado por meio da especificação do domínio de país ".nz".

Assim, fizemos a compilação de um corpus comparável, ou seja, constituído de textos originais divididos em dois subcorpora, um em inglês e outro em português. A pesquisa, feita com a ferramenta Google durante todo o processo, teve 
como principais palavras de busca "ecoturismo lecotourism" e "turismo sustentável/sustainable tourism".

Além disso, fizemos a seleção dos domínios “.br" e ".nz" para o Brasil e Nova Zelândia, respectivamente, e utilizamos filtros para direcionar a busca a sites de órgãos governamentais (.gov e .govt) e de entidades ambientalistas (.org).

Para que pudéssemos verificar a real necessidade desses filtros, realizamos as primeiras buscas com e sem eles e comparamos os resultados. Com isso, notamos que sua utilização melhorou muito o resultado obtido, levando-nos à seleção de sites mais específicos em cada área.

A coleta de dados foi feita em três etapas para cada uma das línguas. A primeira consistiu na busca e seleção de textos de sites de agências de turismo que divulgassem atividades relacionadas ao ecoturismo, em pacotes, roteiros ou outras informações sobre o assunto.

A segunda etapa, a busca e compilação de textos de sites governamentais, incluiu também legislações, diretrizes, planos-diretores ${ }^{19}$, entre outros, e a terceira dedicou-se a sites de entidades ambientalistas que desenvolvem projetos de conscientização, sustentabilidade e desenvolvimento de projetos relacionados ao ecoturismo.

Durante a coleta, buscamos uma uniformização com relação ao número de páginas para cada área, visando um corpus com cerca de 70.000 palavras para cada grupo, em cada língua. O subcorpus de agências de turismo possui um número maior de textos porque os que constam nos pacotes e nas informações gerais são normalmente mais curtos que os outros. Isso foi necessário para que houvesse um número de palavras semelhante em cada subcorpus.

Fizemos ainda a compilação de dois outros corpora. Um com textos que não se enquadravam no perfil dos subcorpora de análise, como artigos acadêmicos e dissertações, que poderiam ser úteis como fonte de informações e comparação terminológica dos subcorpora. O outro, com material coletado de organizações que desempenham um papel importante nos estudos dessa área no mundo, como a OMT (Organização Mundial de Turismo), a Rainforest-Alliance e a WWF (World Wild

\footnotetext{
${ }^{19}$ O Plano Diretor é uma lei municipal que estabelece diretrizes para a ocupação da cidade (Fonte: Governo Estado de São Paulo, http://www.cidades.gov.br/planodiretorparticipativo).
} 
Fund). Essas duas últimas têm representação nos dois países pesquisados e ofereciam tanto material autêntico na língua de cada país, quanto textos que haviam sido traduzidos para o português. O material produzido originalmente na língua do país foi incorporado ao corpus de análise.

$O$ corpus (português-inglês) foi dividido em três subcorpora para cada língua:

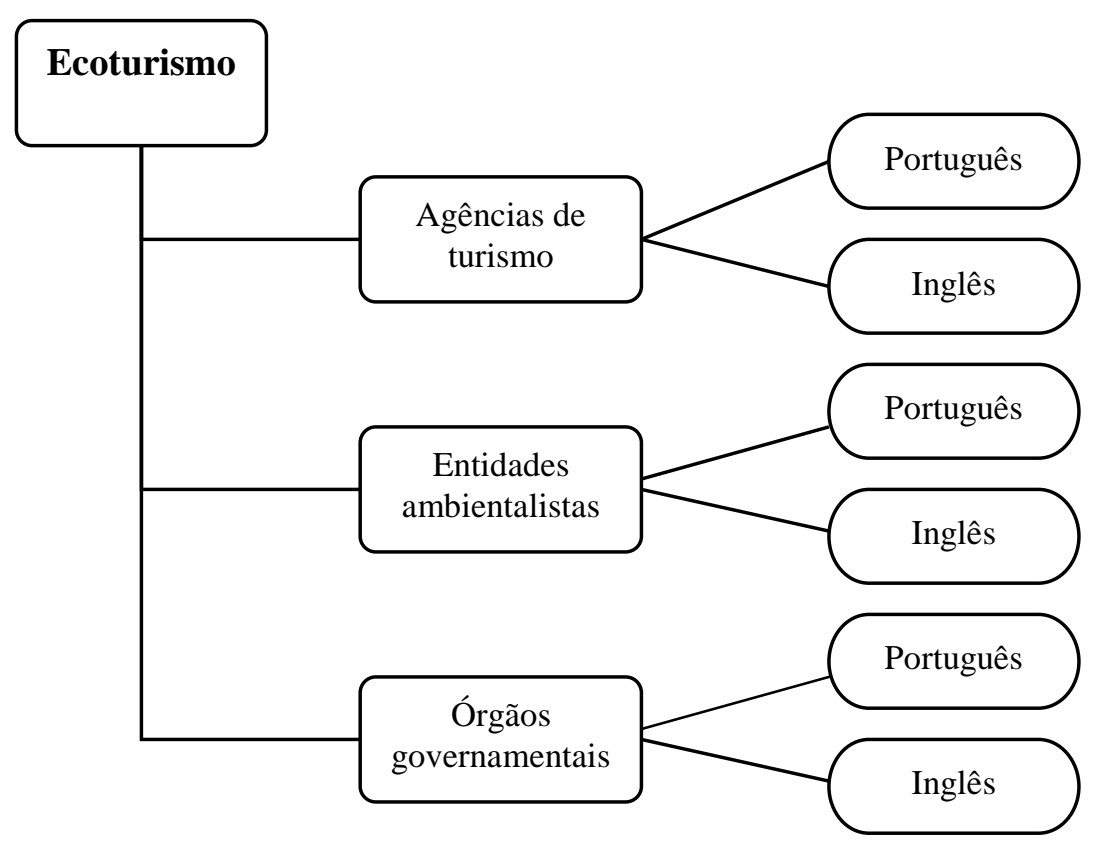

Figura 2. Estrutura do corpus.

O material compilado foi organizado em pastas e subpastas, contendo o original gravado no Word, com os dados do site do qual o material foi extraído e a data da coleta, e uma cópia no formato .txt, que seria analisada com o programa WordSmith Tools.

Para possibilitar a identificação dos arquivos, utilizamos as seguintes abreviaturas:

$\mathrm{Ag}$ - Agências de turismo

Amb - Entidades ambientalistas

Gov - Órgãos governamentais

$\mathrm{P}$ - Português

I- Inglês 
Assim, os arquivos poderiam ser identificados da seguinte forma:

AgP001 - Agência de turismo / Português / n. 001

AgP002 - Agência de turismo / Português / n. 002

Agl001 - Agência de turismo / Inglês / n. 001

Agl002 - Agência de turismo / Inglês / n. 002

AmbP001 - Entidades ambientalistas / Português / n. 001

AmbP002 - Entidades ambientalistas / Português / n. 002

Ambl001 - Entidades ambientalistas / Inglês / n. 001

Ambl002 - Entidades ambientalistas / Inglês / n. 002

GovP001 - Órgãos governamentais / Português / n. 001

GovP002 - Órgãos governamentais / Português / n. 002

Govl001 - Órgãos governamentais / Inglês / n. 001

Govl002 - Órgãos governamentais / Inglês / n. 002

E assim sucessivamente para cada um dos subcorpus.

A composição final do corpus foi:

\begin{tabular}{|c|c|c|c|c|}
\hline Corpora & $\begin{array}{c}\text { Português } \\
\text { n.o de textos }\end{array}$ & Palavras & $\begin{array}{c}\text { Inglês } \\
\text { n.- de textos }\end{array}$ & Palavras \\
\hline $\mathrm{Ag}$ & 109 & 72.465 & 100 & 69.560 \\
\hline $\mathrm{Amb}$ & 51 & 64.841 & 39 & 62.841 \\
\hline Gov & 28 & 70.907 & 30 & 66.359 \\
\hline Total & $\mathbf{1 8 8}$ & $\mathbf{2 0 8 2 1 3}$ & $\mathbf{1 6 9}$ & $\mathbf{1 9 8 7 6 0}$ \\
\hline
\end{tabular}

Tabela 1. Composição do corpus.

Após a compilação do material, iniciamos o trabalho com o programa WordSmith Tools. 


\subsection{A ferramenta WordSmith Tools}

O WordSmith Tools é um programa computacional criado por Mike Scott (1996), que possibilita a análise de textos em formato eletrônico. Para que possamos trabalhar com o corpus é necessário que todos os textos sejam gravados no formato ".txt". O programa é composto por três ferramentas que disponibilizam 17 instrumentos de análise, entre elas as listas de palavras individuais e de multipalavras, as listas de colocados e agrupamentos lexicais e as listas de palavras chave (Berber Sardinha, 1999)

As ferramentas são:

- Wordlist: ferramenta que produz três tipos de listas das palavras do corpus: uma em ordem alfabética $(A)$, uma em ordem de freqüência $(F)$ e uma última lista que apresenta dados como a dimensão do corpus e informações estatísticas (S).

- Keywords: permite a obtenção das palavras-chave em um corpus. Para que isso seja possível, é necessário fazer um cruzamento de dados da lista de palavras do corpus de pesquisa com uma lista de palavras de um corpus de referência.

- Concord: ferramenta utilizada na investigação da recorrência de palavras no corpus compilado, permitindo a investigação de cada uma das ocorrências do item pesquisado. Essas ocorrências são apresentadas na forma de linhas de concordância, o que facilita o processo de investigação.

Essas ferramentas possibilitam diversas aplicações no estudo da linguagem, entre elas caracterizar um texto, identificar o vocabulário específico de uma determinada área, averiguar as inovações vocabulares ou os usos típicos de uma palavra determinada (Berber Sardinha, 1999).

O WordSmith Tools, assim como outros programas para análise lingüística, baseia-se em três princípios básicos (Berber Sardinha, 2004: 90):

a. Ocorrência - os itens precisam estar presentes para que possam ser observados. Embora a ausência de um item possa ser significativa, só podemos trabalhar concretamente com os itens que ocorrem no corpus. 
b. Recorrência - um item precisa ocorrer pelo menos duas vezes. Isso não significa que iremos desconsiderar as palavras que ocorrem uma só vez em um corpus. No entanto, a freqüência com que uma palavra ocorre em um corpus é a chave para nosso interesse em analisá-la.

c. Coocorrência - um item, para ser analisado, precisa estar rodeado de outros itens, ou seja, dentro de um contexto. Isso significa que as palavras que ocorrem próximas do item analisado são importantes para entendermos seu uso.

Esses princípios irão nos fazer "ver" dados que normalmente não chamariam nossa atenção em um texto e são fundamentais para que possamos identificar semelhanças e diferenças nos subcorpora em cada uma das línguas.

Com o auxílio dessas ferramentas, iniciamos nossa pesquisa, cujos passos serão descritos a seguir.

\subsection{Descrição do processo}

\subsubsection{Wordlist}

A primeira ferramenta a ser utilizada foi a Wordlist, que possibilita a obtenção de uma lista de palavras do corpus selecionado. Em nossa pesquisa, selecionamos todo o corpus em português e obtivemos uma lista de palavras.

Em seguida, selecionamos cada um dos subcorpora, separadamente, para a obtenção de listas de palavras de cada um deles: agências de turismo, entidades ambientalistas e governo. O mesmo procedimento foi feito com o subcorpus em inglês.

Além disso, obtivemos uma lista para cada língua a partir de um corpus de referência. Tanto para o português quanto para o inglês, utilizamos a lista de palavras do corpus do Banco de Português $^{20}$ e do Banco de Inglês ${ }^{21}$, respectivamente, do Lael (Lingüística Aplicada e Estudos da Linguagem) da PUCSP.

\footnotetext{
${ }^{20}$ Disponível no site <http://www2.lael.pucsp.br/corpora/bp/index.htm>.

${ }^{21}$ Disponível no site < http://www2.lael.pucsp.br/corpora/bi/index.htm>.
} 
Das três listas oferecidas ( $\mathrm{A}, \mathrm{F}$ e S), a mais utilizada em nossa pesquisa foi a lista por ordem de freqüência das palavras $(F)$.

Todos os arquivos foram nomeados com a extensão ".Ist":

Arquivos:

wlp_g - lista de palavras do corpus de estudo em português

wlp_ag - lista de palavras do subcorpus de agência de turismo em português

wlp_amb - lista de palavras do subcorpus de entidades ambientalistas em português

wlp_gov - lista de palavras do subcorpus de órgãos governamentais em português

wlp_ref - lista de palavras do corpus de referência em português

wli_g - lista de palavras do corpus de estudo em inglês

wli_ag - lista de palavras do subcorpus de agência de turismo em inglês

wli_amb - lista de palavras do subcorpus de entidades ambientalistas em inglês

wli_go - lista de palavras do subcorpus de órgãos governamentais em inglês

wli_ref - lista de palavras do corpus de referência em inglês

Como já foi mencionado, a ferramenta Wordlist apresenta três listas de palavras: uma em ordem alfabética $(A)$, outra por ordem de freqüência das palavras no texto (F) e a última com os dados estatísticos do corpus (S).

A terceira lista nos apresenta, entre outros dados, o número de itens (tokens), ou seja, o total de palavras do texto (considerando as repetições de cada palavra), e o número de formas (types), isto é, o número de palavras diferentes que compõem o corpus.

Esses dados permitem obter a razão forma/item (type/token ratio) do corpus e de cada um dos textos separadamente. Esse valor indica a riqueza lexical do texto. Quanto mais palavras diferentes o corpus contém, maior o valor apresentado. No entanto, o valor obtido não pode ser utilizado para compararmos a riqueza lexical 
entre corpora diferentes, uma vez que esse valor não leva em consideração o tamanho dos corpora. Para solucionar esse problema, o programa apresenta uma forma padronizada, a razão forma/item padronizada (Standardised type-token), que neutraliza as diferenças de tamanho dos textos, o que é útil em nossa pesquisa, uma vez que alguns tipos de texto, como os das agências, são muito curtos, quando comparados aos outros textos.

É importante salientar que as listas de palavras consideram todas as palavras do texto, e que as palavras gramaticais, como artigos, pronomes, conjunções etc., por ocorrerem com alta freqüência, são, em geral, as primeiras palavras da lista de freqüência. Uma vez que nosso estudo está centrado no vocabulário específico da área de Ecoturismo, essas palavras não serão consideradas.

Apresentamos, abaixo, um exemplo das listas de palavras do subcorpus em inglês de agências de turismo obtidas com a ferramenta Wordlist:

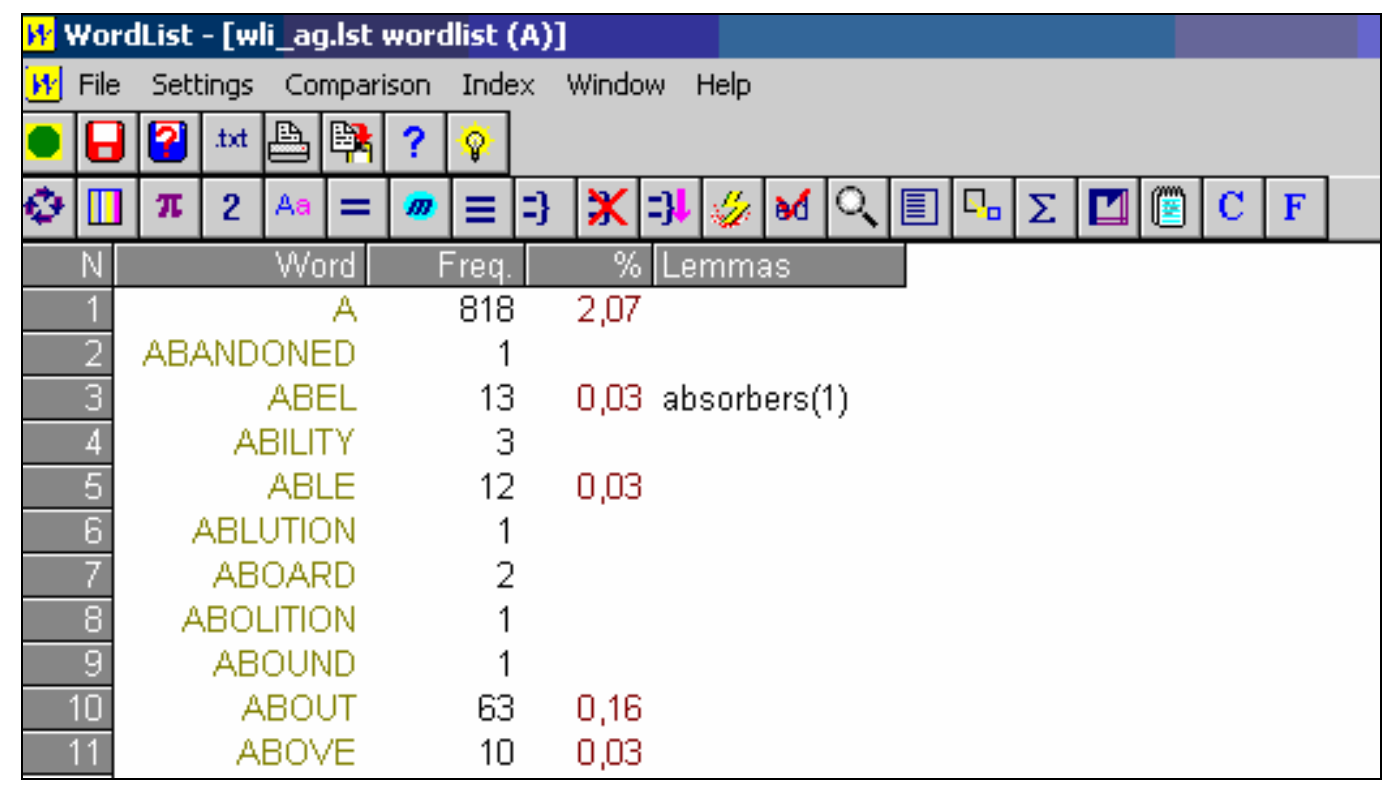

Figura 3. Lista por ordem alfabética. 


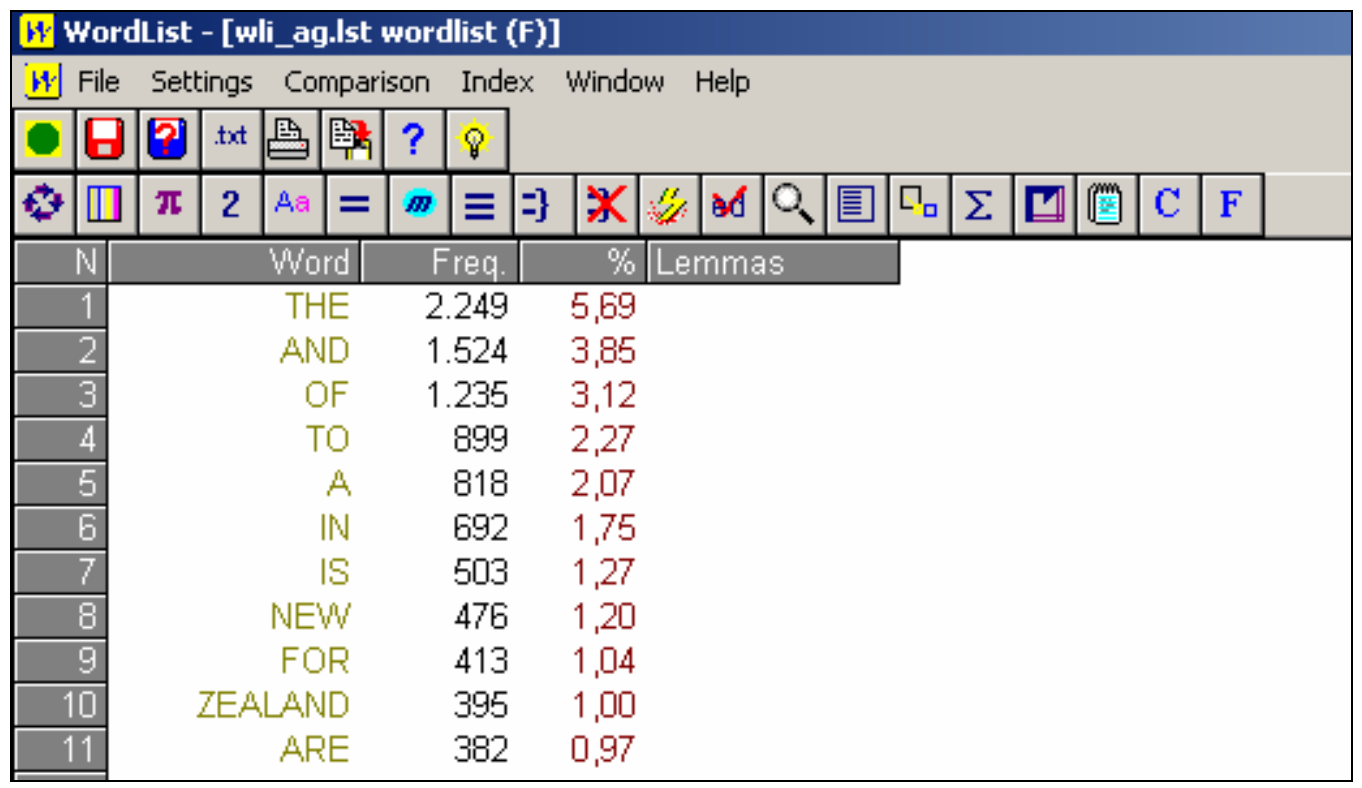

Figura 4. Lista por ordem de freqüência.

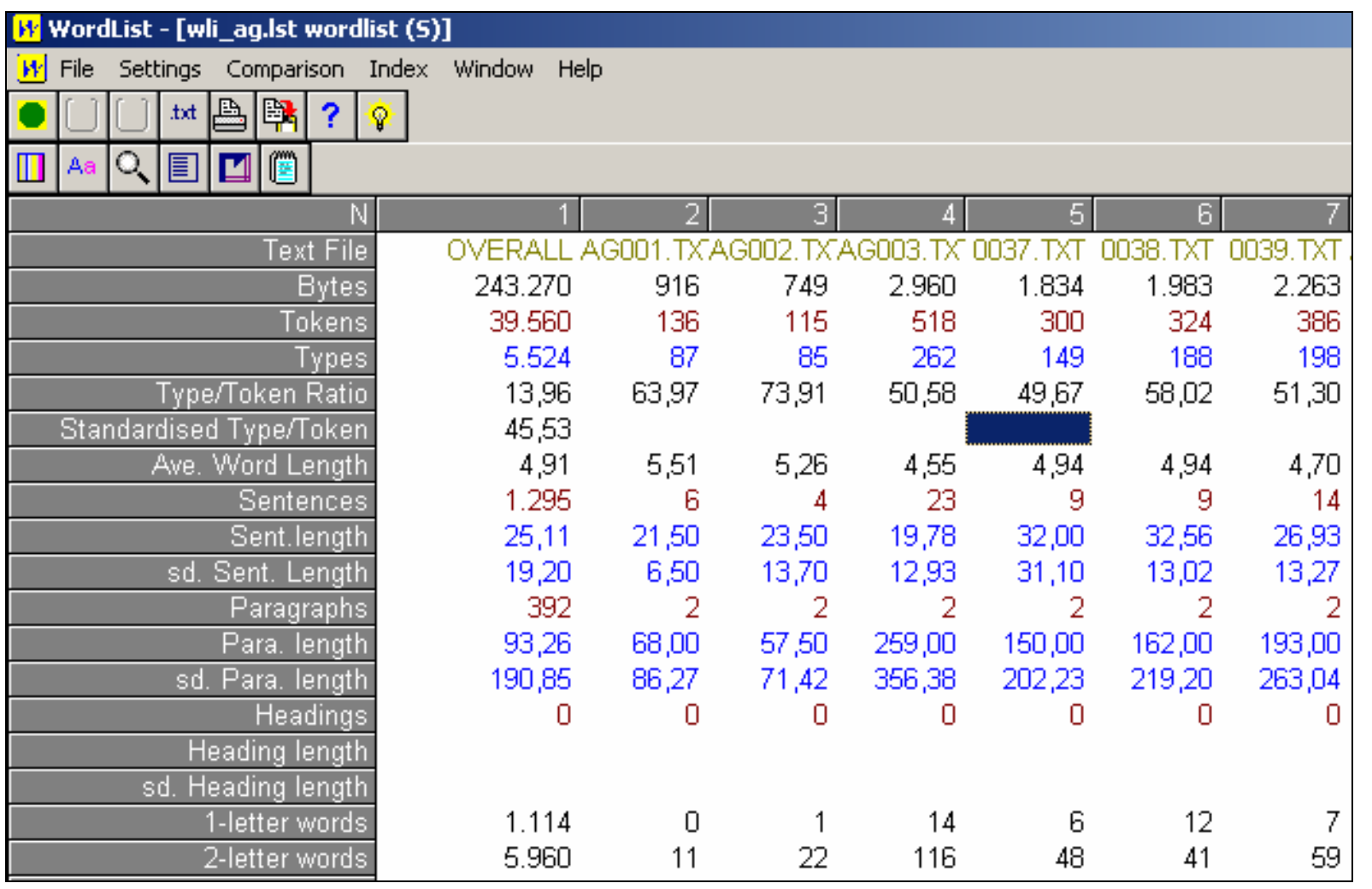

Figura 5. Lista de palavras - dados estatísticos. 


\subsubsection{KeyWords}

O passo seguinte foi a obtenção de várias listas de palavras resultantes do cruzamento das listas obtidas com a primeira ferramenta. O procedimento foi feito, primeiramente, entre o corpus geral de cada língua com o respectivo corpus de referência e, em seguida, entre os diversos subcorpora. Isso possibilitou o aparecimento das palavras mais específicas em cada corpus, nas chamadas listas de "palavras-chave".

Neste procedimento, fizemos os seguintes cruzamentos:

Português:

- wlp_g x wlp_ref (lista de palavras do corpus de estudo total com a lista de palavras do corpus de referência).

- wlp_ag x wlp_amb (lista de palavras do corpus de estudo de agências de turismo com o corpus de estudo de entidades ambientalistas)

- wlp_ag x wlp_gov (lista de palavras do corpus de estudo de agências de turismo com o corpus de estudo de órgãos governamentais)

- wlp_amb x wlp_gov (lista de palavras do corpus de estudo de entidades ambientalistas com o corpus de estudo de órgãos governamentais

Inglês:

- wli_g x wli_ref (lista de palavras do corpus de estudo total com a lista de palavras do corpus de referência)

- wli_ag x wli_amb (lista de palavras do corpus de estudo de agências de turismo com o corpus de estudo de entidades ambientalistas)

- wli_ag x wli_gov (lista de palavras com o corpus de estudo de agências de turismo com o corpus de estudo de órgãos governamentais)

- wli_amb x wli_gov (lista de palavras com o corpus de estudo de entidades ambientalistas com o corpus de estudo de órgãos governamentais)

As listas de palavras resultantes desses cruzamentos foram nomeadas da seguinte forma: 
pag_amb - português / agências de turismo $x$ entidades ambientalistas

pag_gov - português / agências de turismo x órgãos governamentais pamb_gov - português / entidades ambientalistas $x$ órgãos governamentais iag_amb - inglês / agências de turismo $x$ entidades ambientalistas iag_gov - inglês / agências de turismo x órgãos governamentais iamb_gov - inglês / agências de turismo $x$ entidades ambientalistas

Mostramos, a seguir, um exemplo dos resultados desses cruzamentos:

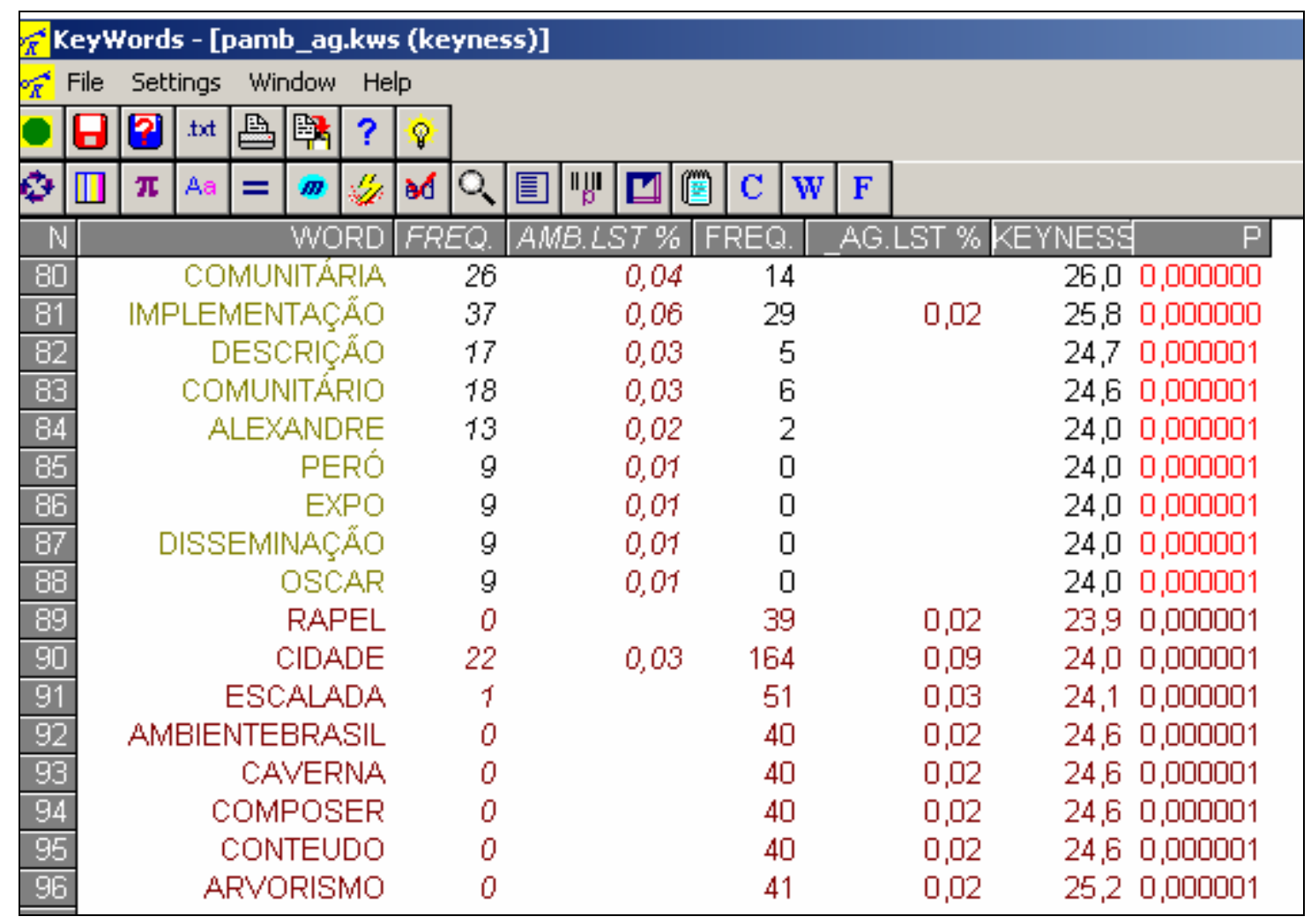

Figura 6. Palavras-chave (subcorpora em português de entidades ambientalistas e agências de turismo).

As palavras-chave são positivas ou negativas. As positivas são as palavras cujas freqüências são superiores no corpus de estudo em relação ao corpus de referência. As negativas indicam palavras que ocorrem menos no corpus de estudo e mais no corpus de referência. Essas palavras aparecem no fim da lista, em vermelho. 
Ao obtermos essas listas de palavras-chave, analisamos os resultados para os "candidatos" a termo, ou seja, palavras que parecem ser específicas da área pesquisada, de ecoturismo. A partir desse ponto, vamos investigar como essas palavras se "comportam" nos textos de cada subcorpus com o uso da terceira ferramenta do WordSmith Tools, o Concord, ou concordanciador.

\subsubsection{Concord}

Essa ferramenta produz linhas de concordâncias a partir de uma determinada palavra de busca. Essas concordâncias são muito importantes na investigação dos corpora, pois nos permitem analisar o contexto no qual as palavras estão inseridas, além das palavras que ocorrem junto com elas.

A partir das listas de palavras-chave, podemos selecionar as palavras que nos interessam e, por meio das linhas de concordância, iniciar o levantamento dos dados.

No exemplo abaixo, temos um exemplo das linhas de concordância para a palavra tourism extraídas do subcorpus de agências de turismo.

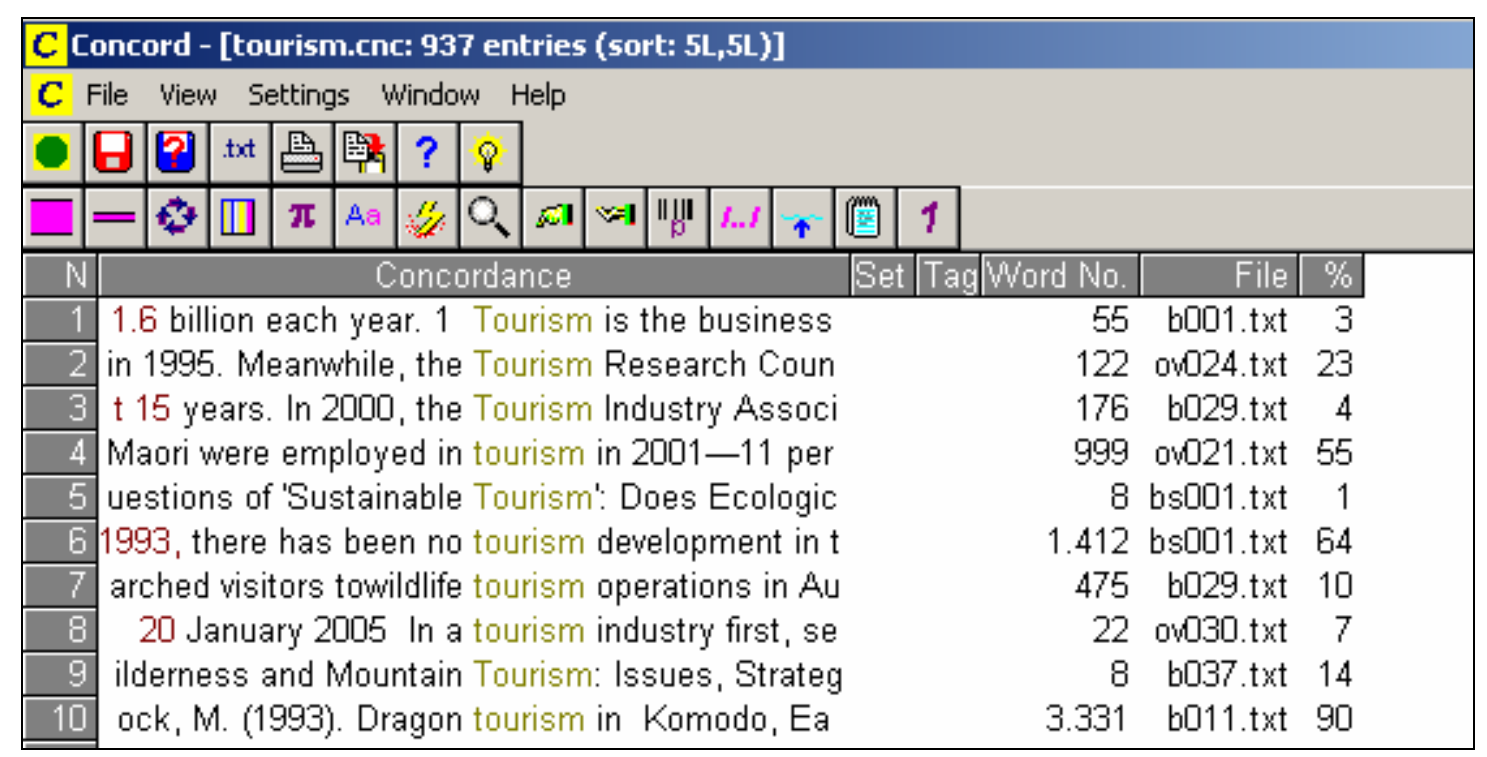

Figura 7. Linhas de concordância para a palavra tourism. 
Quando clicamos na palavra de busca, nas linhas de concordância, podemos visualizar o texto do qual o termo foi extraído. Isso faz com que seja possível ter acesso a um trecho maior do texto, para obtermos mais informações sobre o contexto no qual a palavra de busca está inserida.

No exemplo abaixo, temos um trecho de um texto obtido a partir de uma concordância com a palavra tourism:

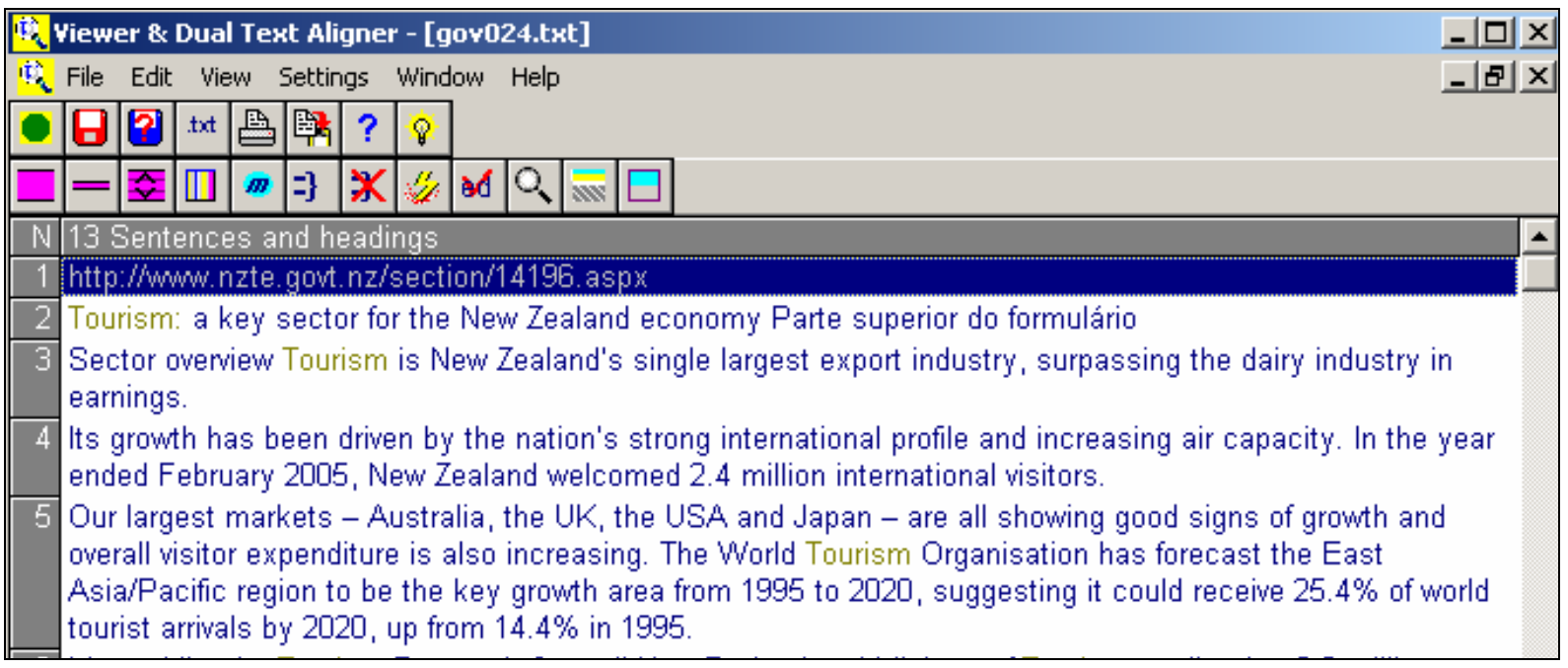

Figura 8. Contexto ampliado da palavra de busca tourism.

Como já foi mencionado anteriormente, a palavra deve ser analisada dentro do seu contexto. Isso torna as palavras ao redor do texto muito importantes, pois nos oferecem o sentido real daquela que estamos analisando. Além disso, é importante observarmos as palavras que mais ocorrem com a palavra de busca.

Essas palavras são conhecidas como "colocados" (collocates). O termo colocação foi introduzido pelo lingüista J. R. Firth para descrever palavras que normalmente "andam juntas" (Tagnin, 2005: 37). A colocação é formada por uma palavra base, ou seja, o ponto de referência, que pode ser, por exemplo, a palavra de busca das linhas de concordância, e o colocado, ou seja, a palavra que a acompanha. Há diferentes graus de fixidez entre as colocações.

Ao buscarmos os colocados para a palavra "turismo", por exemplo, vamos encontrar formas que já são bastante conhecidas e outras que podem atrair a nossa atenção se ocorrerem com certa freqüência. 
Temos, a seguir, alguns exemplos de colocações da palavra turismo:

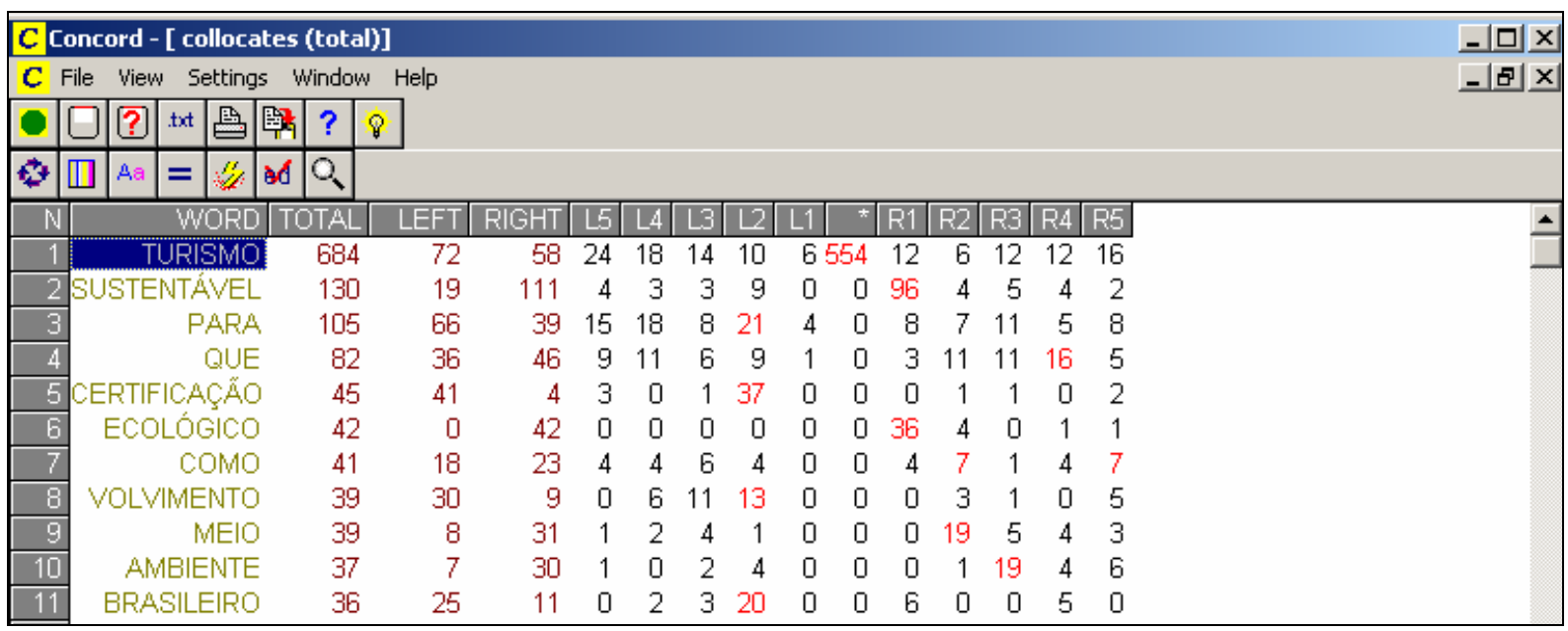

Figura 9. Colocações com a palavra "turismo".

As colocações encontradas foram analisadas ainda de acordo com um outro aplicativo, o cluster, lista de agrupamentos lexicais que permite determinarmos seqüências fixas recorrentes nas concordâncias.

Apresentamos, abaixo, um exemplo de agrupamentos com três palavras:

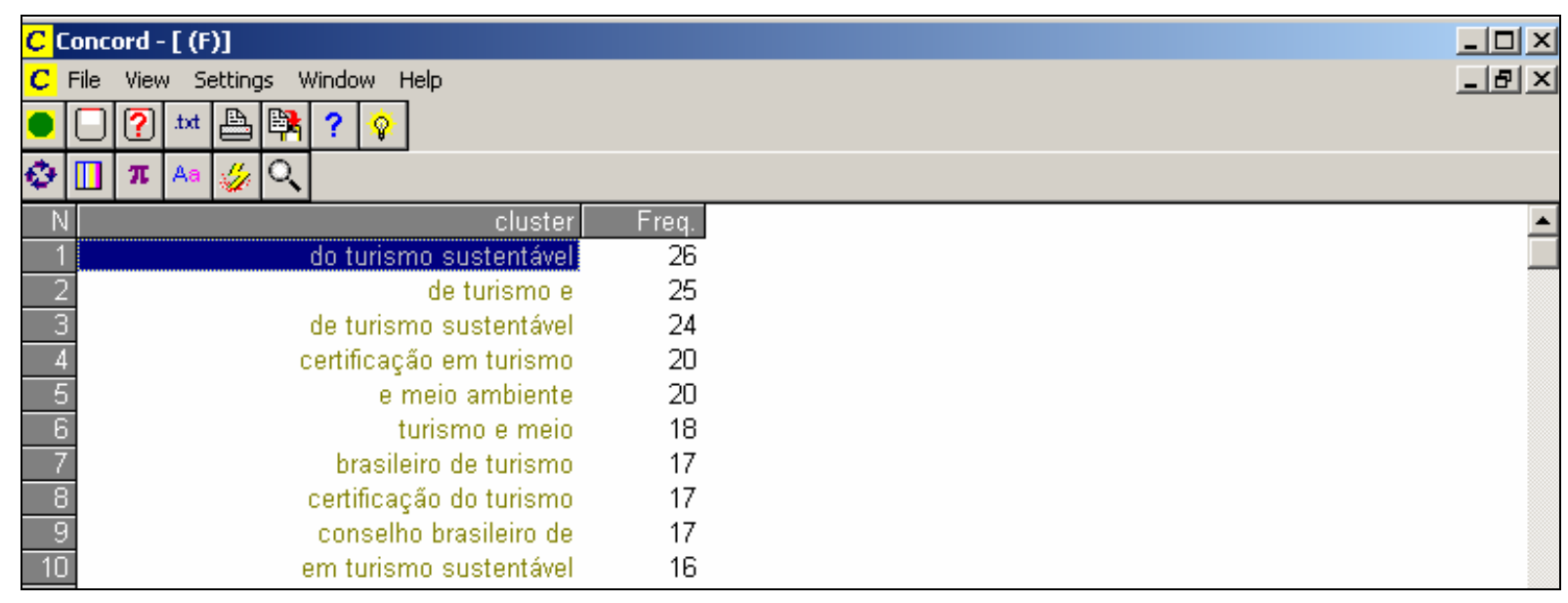

Figura 10. Clusters com três palavras para "turismo"

A utilização da ferramenta WordSmith Tools produziu uma série de dados para serem analisados de acordo com nossas perguntas de pesquisa. 
No próximo capitulo, apresentaremos os resultados obtidos com a investigação desses dados. 


\section{ANÁLISE DOS DADOS}

Neste capítulo, apresentaremos os dados resultantes da análise do corpus comparável português-inglês de textos extraídos de sites brasileiros e neozelandeses sobre ecoturismo. Esses textos foram compilados a partir de três áreas distintas: agências de turismo, entidades ambientalistas e órgãos governamentais.

Cada uma das áreas mencionadas tem objetivos específicos que norteiam a forma como as informações são apresentadas. Tais objetivos exigem uma escolha não apenas da forma como a mensagem é apresentada, mas também do vocabulário utilizado na mensagem. A partir da análise dos dados, buscamos mostrar as diferenças entre as três áreas e como isso se reflete nas escolhas lexicais.

Para que os dados obtidos pela análise possam ser mais facilmente compreendidos, optamos por apresentá-los a partir de uma perspectiva mais ampla até os detalhes mais significativos de cada corpus.

\subsection{Wordlists}

Como já foi descrito na metodologia, iniciamos o processo de análise pela obtenção de listas de palavras de cada um dos subcorpora, tanto em português quanto em inglês. Vale lembrar que o programa WordSmith Tools nos oferece três listas de palavras: em ordem alfabética $(A)$, em ordem de freqüência $(F)$ e dados estatísticos (S), sendo que a lista por ordem de freqüência foi a mais utilizada em nossa pesquisa.

Uma vez que a lista de palavras apresenta todas as palavras que compõem o texto, apresentaremos aqui as primeiras cem palavras de cada subcorpus. As palavras estão organizadas por ordem de freqüência, seguidas pelo número de ocorrências e pela porcentagem que essas ocorrências representam dentro do 
corpus, seguidas de comentários sobre a primeira impressão na verificação da composição do corpus.

\section{Lista de Palavras por ordem de freqüência - corpus em português}

\begin{tabular}{|c|c|c|c|}
\hline \multicolumn{4}{|c|}{ Agências de turismo } \\
\hline $\mathbf{N}$ & Word & Freq. & $\%$ \\
\hline 1 & $D E$ & 4.637 & 5,69 \\
\hline 2 & $\mathrm{E}$ & 3.073 & 3,77 \\
\hline 3 & A & 2.677 & 3,29 \\
\hline 4 & $\mathrm{O}$ & 1.982 & 2,43 \\
\hline 5 & DO & 1.671 & 2,05 \\
\hline 6 & DA & 1.240 & 1,52 \\
\hline 7 & QUE & 1.090 & 1,34 \\
\hline 8 & COM & 1.047 & 1,29 \\
\hline 9 & EM & 1.035 & 1,27 \\
\hline 10 & PARA & 974 & 1,20 \\
\hline 11 & É & 760 & 0,93 \\
\hline 12 & UMA & 628 & 0,77 \\
\hline 13 & UM & 626 & 0,77 \\
\hline 14 & OS & 606 & 0,74 \\
\hline 15 & SE & 606 & 0,74 \\
\hline 16 & NO & 553 & 0,68 \\
\hline 17 & AS & 535 & 0,66 \\
\hline 18 & DOS & 450 & 0,55 \\
\hline 19 & NA & 448 & 0,55 \\
\hline 20 & SÃO & 448 & 0,55 \\
\hline 21 & POR & 438 & 0,54 \\
\hline 22 & MAIS & 417 & 0,51 \\
\hline 23 & COMO & 409 & 0,50 \\
\hline 24 & DAS & 356 & 0,44 \\
\hline 25 & ECOTURISMO & 325 & 0,40 \\
\hline 26 & $\mathrm{AO}$ & 322 & 0,40 \\
\hline 27 & OU & 318 & 0,39 \\
\hline 28 & NÃO & 251 & 0,31 \\
\hline 29 & RIO & 234 & 0,29 \\
\hline 30 & REGIÃO & 223 & 0,27 \\
\hline 31 & SER & 222 & 0,27 \\
\hline 32 & À & 205 & 0,25 \\
\hline 33 & SUA & 203 & 0,25 \\
\hline 34 & TURISMO & 201 & 0,25 \\
\hline 35 & GRANDE & 198 & 0,24 \\
\hline 36 & BR & 169 & 0,21 \\
\hline 37 & PELA & 166 & 0,20 \\
\hline 38 & ENTRE & 165 & 0,20 \\
\hline 39 & BRASIL & 161 & 0,20 \\
\hline 40 & WWW & 155 & 0,19 \\
\hline 41 & ATIVIDADES & 151 & 0,19 \\
\hline
\end{tabular}

\begin{tabular}{|c|c|c|c|}
\hline \multicolumn{4}{|c|}{ Entidades ambientalistas } \\
\hline $\mathbf{N}$ & Word & Freq. & $\%$ \\
\hline 1 & $\mathrm{DE}$ & 4.011 & 6,19 \\
\hline 2 & $\mathrm{E}$ & 2.650 & 4,09 \\
\hline 3 & A & 1.992 & 3,07 \\
\hline 4 & $\mathrm{O}$ & 1.679 & 2,59 \\
\hline 5 & DO & 1.549 & 2,39 \\
\hline 6 & DA & 1.134 & 1,75 \\
\hline 7 & QUE & 944 & 1,46 \\
\hline 8 & PARA & 884 & 1,36 \\
\hline 9 & EM & 844 & 1,30 \\
\hline 10 & COM & 630 & 0,97 \\
\hline 11 & UM & 567 & 0,87 \\
\hline 12 & TURISMO & 558 & 0,86 \\
\hline 13 & NO & 523 & 0,81 \\
\hline 14 & OS & 492 & 0,76 \\
\hline 15 & UMA & 478 & 0,74 \\
\hline 16 & DOS & 440 & 0,68 \\
\hline 17 & ECOTURISMO & 431 & 0,66 \\
\hline 18 & SE & 428 & 0,66 \\
\hline 19 & COMO & 397 & 0,61 \\
\hline 20 & AS & 392 & 0,60 \\
\hline 21 & É & 384 & 0,59 \\
\hline 22 & NA & 372 & 0,57 \\
\hline 23 & DAS & 301 & 0,46 \\
\hline 24 & DESENVOLVIMENTO & 290 & 0,45 \\
\hline 25 & POR & 287 & 0,44 \\
\hline 26 & $\mathrm{AO}$ & 240 & 0,37 \\
\hline 27 & AMBIENTAL & 236 & 0,36 \\
\hline 28 & BRASIL & 236 & 0,36 \\
\hline 29 & NÃO & 231 & 0,36 \\
\hline 30 & SUSTENTÁVEL & 221 & 0,34 \\
\hline 31 & MEIO & 215 & 0,33 \\
\hline 32 & SÃO & 203 & 0,31 \\
\hline 33 & $\grave{A}$ & 194 & 0,30 \\
\hline 34 & OU & 190 & 0,29 \\
\hline 35 & AMBIENTE & 183 & 0,28 \\
\hline 36 & MAIS & 173 & 0,27 \\
\hline 37 & SER & 166 & 0,26 \\
\hline 38 & SOBRE & 161 & 0,25 \\
\hline 39 & CONSERVAÇÃO & 136 & 0,21 \\
\hline 40 & NATUREZA & 129 & 0,20 \\
\hline 41 & WWF & 127 & 0,20 \\
\hline
\end{tabular}

\begin{tabular}{|c|c|c|c|}
\hline \multicolumn{4}{|c|}{ Órgãos governamentais } \\
\hline $\mathbf{N}$ & Word & Freq. & $\%$ \\
\hline 1 & DE & 4.857 & 6,85 \\
\hline 2 & E & 2.632 & 3,71 \\
\hline 3 & A & 2.077 & 2,93 \\
\hline 4 & DO & 1.726 & 2,43 \\
\hline 5 & 0 & 1.455 & 2,05 \\
\hline 6 & DA & 1.041 & 1,47 \\
\hline 7 & PARA & 955 & 1,35 \\
\hline 8 & QUE & 912 & 1,29 \\
\hline 9 & EM & 833 & 1,17 \\
\hline 10 & OS & 671 & 0,95 \\
\hline 11 & NO & 616 & 0,87 \\
\hline 12 & COM & 615 & 0,87 \\
\hline 13 & DOS & 559 & 0,79 \\
\hline 14 & AS & 484 & 0,68 \\
\hline 15 & DAS & 471 & 0,66 \\
\hline 16 & TURISMO & 463 & 0,65 \\
\hline 17 & SÃO & 447 & 0,63 \\
\hline 18 & SE & 439 & 0,62 \\
\hline 19 & COMO & 405 & 0,57 \\
\hline 20 & É & 397 & 0,56 \\
\hline 21 & UMA & 388 & 0,55 \\
\hline 22 & UM & 386 & 0,54 \\
\hline 23 & NA & 354 & 0,50 \\
\hline 24 & ECOTURISMO & 327 & 0,46 \\
\hline 25 & $\mathrm{AO}$ & 317 & 0,45 \\
\hline 26 & POR & 300 & 0,42 \\
\hline 27 & OU & 294 & 0,41 \\
\hline 28 & PARQUES & 255 & 0,36 \\
\hline 29 & ATIVIDADES & 247 & 0,35 \\
\hline 30 & À & 245 & 0,35 \\
\hline 31 & PROJETO & 245 & 0,35 \\
\hline 32 & ESTADO & 232 & 0,33 \\
\hline 33 & DESENVOLVIMENTO & 217 & 0,31 \\
\hline 34 & CONSERVAÇÃO & 208 & 0,29 \\
\hline 35 & NÃO & 201 & 0,28 \\
\hline 36 & ATIVIDADE & 196 & 0,28 \\
\hline 37 & MAIS & 178 & 0,25 \\
\hline 38 & AMBIENTAL & 169 & 0,24 \\
\hline 39 & PAULO & 167 & 0,24 \\
\hline 40 & AVENTURA & 165 & 0,23 \\
\hline 41 & VISITAČÃO & 161 & 0,23 \\
\hline
\end{tabular}




\begin{tabular}{|c|c|c|c|}
\hline 42 & TEM & 146 & 0,18 \\
\hline 43 & NATURAIS & 143 & 0,18 \\
\hline 44 & ONDE & 142 & 0,17 \\
\hline 45 & AVENTURA & 139 & 0,17 \\
\hline 46 & PELO & 133 & 0,16 \\
\hline 47 & TAMBÉM & 130 & 0,16 \\
\hline 48 & NAS & 126 & 0,15 \\
\hline 49 & ÁREA & 124 & 0,15 \\
\hline 50 & ATÉ & 124 & 0,15 \\
\hline 51 & SEU & 123 & 0,15 \\
\hline 52 & LOCAL & 122 & 0,15 \\
\hline 53 & NOS & 122 & 0,15 \\
\hline 54 & MEIO & 120 & 0,15 \\
\hline 55 & AMBIENTAL & 118 & 0,14 \\
\hline 56 & HTTP & 118 & 0,14 \\
\hline 57 & NATUREZA & 115 & 0,14 \\
\hline 58 & RIOS & 115 & 0,14 \\
\hline 59 & ESTÁ & 114 & 0,14 \\
\hline 60 & FOI & 113 & 0,14 \\
\hline 61 & SERRA & 113 & 0,14 \\
\hline 62 & ALÉM & 111 & 0,14 \\
\hline 63 & KM & 110 & 0,14 \\
\hline 64 & ITACARÉ & 108 & 0,13 \\
\hline 65 & MAIOR & 108 & 0,13 \\
\hline 66 & PARQUE & 108 & 0,13 \\
\hline 67 & AMBIENTE & 107 & 0,13 \\
\hline 68 & CONSERVAÇÃO & 107 & 0,13 \\
\hline 69 & SEUS & 104 & 0,13 \\
\hline 70 & PODE & 101 & 0,12 \\
\hline 71 & ÁREAS & 97 & 0,12 \\
\hline 72 & MATA & 96 & 0,12 \\
\hline 73 & DESENVOLVIMENTO & 94 & 0,12 \\
\hline 74 & ÁGUA & 93 & 0,11 \\
\hline 75 & AINDA & 93 & 0,11 \\
\hline 76 & HTML & 92 & 0,11 \\
\hline 77 & ATIVIDADE & 91 & 0,11 \\
\hline 78 & PANTANAL & 91 & 0,11 \\
\hline 79 & AOS & 88 & 0,11 \\
\hline 80 & ESTADO & 88 & 0,11 \\
\hline 81 & FAUNA & 88 & 0,11 \\
\hline 82 & ALAYA & 87 & 0,11 \\
\hline 83 & PRAIA & 87 & 0,11 \\
\hline 84 & ÀS & 86 & 0,11 \\
\hline 85 & CIDADE & 86 & 0,11 \\
\hline 86 & SUL & 85 & 0,10 \\
\hline 87 & CAVERNAS & 84 & 0,10 \\
\hline 88 & HÁ & 82 & 0,10 \\
\hline 89 & MUNICÍPIO & 82 & 0,10 \\
\hline 90 & RECURSOS & 81 & 0,10 \\
\hline 91 & SEM & 80 & 0,10 \\
\hline 92 & ESPÉCIES & 79 & 0,10 \\
\hline 93 & TRILHA & 79 & 0,10 \\
\hline
\end{tabular}

\begin{tabular}{|c|c|c|c|}
\hline 42 & ENTRE & 126 & 0,19 \\
\hline 43 & $\mathrm{FOI}$ & 125 & 0,19 \\
\hline 44 & SUA & 123 & 0,19 \\
\hline 45 & PELA & 122 & 0,19 \\
\hline 46 & PELO & 119 & 0,18 \\
\hline 47 & PROJETO & 119 & 0,18 \\
\hline 48 & SUSTENTABILIDA+ & 111 & 0,17 \\
\hline 49 & TAMBÉM & 111 & 0,17 \\
\hline 50 & CERTIFICAÇÃO & 109 & 0,17 \\
\hline 51 & LOCAIS & 108 & 0,17 \\
\hline 52 & NACIONAL & 108 & 0,17 \\
\hline 53 & REGIÃO & 108 & 0,17 \\
\hline 54 & ÁREAS & 106 & 0,16 \\
\hline 55 & NOS & 106 & 0,16 \\
\hline 56 & CULTURAL & 104 & 0,16 \\
\hline 57 & PROGRAMA & 104 & 0,16 \\
\hline 58 & COMUNIDADES & 100 & 0,15 \\
\hline 59 & EDUCAÇÃO & 99 & 0,15 \\
\hline 60 & RECURSOS & 99 & 0,15 \\
\hline 61 & FORMA & 97 & 0,15 \\
\hline 62 & PARQUE & 97 & 0,15 \\
\hline 63 & TEM & 94 & 0,14 \\
\hline 64 & ATIVIDADES & 92 & 0,14 \\
\hline 65 & $\mathrm{BR}$ & 87 & 0,13 \\
\hline 66 & ATIVIDADE & 83 & 0,13 \\
\hline 67 & CABO & 82 & 0,13 \\
\hline 68 & SOCIAL & 82 & 0,13 \\
\hline 69 & ÁREA & 81 & 0,12 \\
\hline 70 & FRIO & 81 & 0,12 \\
\hline 71 & PANTANAL & 81 & 0,12 \\
\hline 72 & TRABALHO & 79 & 0,12 \\
\hline 73 & NATURAIS & 78 & 0,12 \\
\hline 74 & SEUS & 78 & 0,12 \\
\hline 75 & SETOR & 77 & 0,12 \\
\hline 76 & MUNDO & 76 & 0,12 \\
\hline 77 & PLANEJAMENTO & 76 & 0,12 \\
\hline 78 & PROJETOS & 76 & 0,12 \\
\hline 79 & ANOS & 75 & 0,12 \\
\hline 80 & USO & 74 & 0,11 \\
\hline 81 & POLÍTICAS & 73 & 0,11 \\
\hline 82 & SUAS & 73 & 0,11 \\
\hline 83 & ESTÁ & 72 & 0,11 \\
\hline 84 & AOS & 71 & 0,11 \\
\hline 85 & INTERNACIONAL & 70 & 0,11 \\
\hline 86 & ORG & 70 & 0,11 \\
\hline 87 & PROCESSO & 70 & 0,11 \\
\hline 88 & ALÉM & 69 & 0,11 \\
\hline 89 & FIECOTUR & 67 & 0,10 \\
\hline 90 & ECOLÓGICO & 66 & 0,10 \\
\hline 91 & GESTÃO & 66 & 0,10 \\
\hline 92 & HOMEM & 65 & 0,10 \\
\hline 93 & SOCIEDADE & 64 & 0,10 \\
\hline
\end{tabular}

\begin{tabular}{|c|c|c|c|}
\hline 42 & CADA & 160 & 0,23 \\
\hline 43 & PARQUE & 159 & 0,22 \\
\hline 44 & NOS & 157 & 0,22 \\
\hline 45 & UNIDADES & 148 & 0,21 \\
\hline 46 & SER & 147 & 0,21 \\
\hline 47 & ESTADUAL & 144 & 0,20 \\
\hline 48 & ÁREAS & 140 & 0,20 \\
\hline 49 & REGIÃO & 128 & 0,18 \\
\hline 50 & IMPACTOS & 125 & 0,18 \\
\hline 51 & MEIO & 125 & 0,18 \\
\hline 52 & NAS & 125 & 0,18 \\
\hline 53 & SOBRE & 122 & 0,17 \\
\hline 54 & PELA & 120 & 0,17 \\
\hline 55 & AMBIENTE & 119 & 0,17 \\
\hline 56 & SMA & 117 & 0,17 \\
\hline 57 & AÇÕES & 116 & 0,16 \\
\hline 58 & ENTRE & 112 & 0,16 \\
\hline 59 & NATURAIS & 112 & 0,16 \\
\hline 60 & AOS & 111 & 0,16 \\
\hline 61 & RECURSOS & 111 & 0,16 \\
\hline 62 & SUSTENTÁVEL & 109 & 0,15 \\
\hline 63 & SUA & 108 & 0,15 \\
\hline 64 & TAMBÉM & 108 & 0,15 \\
\hline 65 & GESTÃO & 104 & 0,15 \\
\hline 66 & LOCAIS & 103 & 0,15 \\
\hline 67 & PELO & 102 & 0,14 \\
\hline 68 & RESPONSABILIDADE & 99 & 0,14 \\
\hline 69 & $\mathrm{FOI}$ & 98 & 0,14 \\
\hline 70 & TURÍSTICO & 98 & 0,14 \\
\hline 71 & COMUNIDADES & 96 & 0,14 \\
\hline 72 & ESTRUTURA & 94 & 0,13 \\
\hline 73 & BRASIL & 93 & 0,13 \\
\hline 74 & REGIONAL & 93 & 0,13 \\
\hline 75 & ÁREA & 89 & 0,13 \\
\hline 76 & SETOR & 89 & 0,13 \\
\hline 77 & JÁ & 85 & 0,12 \\
\hline 78 & NESTE & 85 & 0,12 \\
\hline 79 & VISITANTES & 85 & 0,12 \\
\hline 80 & ALÉM & 84 & 0,12 \\
\hline 81 & GRANDE & 83 & 0,12 \\
\hline 82 & MUNICÍPIOS & 83 & 0,12 \\
\hline 83 & MERCADO & 82 & 0,12 \\
\hline 84 & IMPLANTAÇÃO & 81 & 0,11 \\
\hline 85 & NACIONAL & 81 & 0,11 \\
\hline 86 & SERVIÇOS & 81 & 0,11 \\
\hline 87 & USO & 81 & 0,11 \\
\hline 88 & Às & 80 & 0,11 \\
\hline 89 & SECRETARIA & 79 & 0,11 \\
\hline 90 & ANO & 78 & 0,11 \\
\hline 91 & EQUIPAMENTOS & 78 & 0,11 \\
\hline 92 & RIBEIRA & 78 & 0,11 \\
\hline 93 & FORMA & 77 & 0,11 \\
\hline
\end{tabular}




\begin{tabular}{|r|l|r|r|}
94 & PARTE & 78 & 0,10 \\
\hline 95 & TRILHAS & 78 & 0,10 \\
\hline 96 & ATRAVÉS & 76 & 0,09 \\
\hline 97 & MUITO & 76 & 0,09 \\
\hline 98 & NATURAL & 76 & 0,09 \\
\hline 99 & SUAS & 76 & 0,09 \\
\hline 100 & VISITANTES & 76 & 0,09 \\
\hline
\end{tabular}

\begin{tabular}{|r|l|r|r|}
94 & AMBIENTAIS & 63 & 0,10 \\
\hline 95 & APOIO & 63 & 0,10 \\
\hline 96 & NAS & 63 & 0,10 \\
\hline 97 & PODE & 63 & 0,10 \\
\hline 98 & QUALIDADE & 62 & 0,10 \\
\hline 99 & AINDA & 61 & 0,09 \\
\hline 100 & COMUNIDADE & 61 & 0,09 \\
\hline
\end{tabular}

\begin{tabular}{|r|l|r|r|}
94 & PLANEJAMENTO & 77 & 0,11 \\
\hline 95 & TEM & 77 & 0,11 \\
\hline 96 & PÚBLICA & 75 & 0,11 \\
\hline 97 & ATRAVÉS & 74 & 0,10 \\
\hline 98 & ATRATIVOS & 73 & 0,10 \\
\hline 99 & PROGRAMA & 73 & 0,10 \\
\hline 100 & TEXTOS & 73 & 0,10 \\
\hline
\end{tabular}

Como costuma acontecer em todos os corpora, os três apresentam certas características em comum: as primeiras palavras não são palavras relacionadas ao assunto, e sim palavras gramaticais, como artigos, preposições, pronomes pessoais e demonstrativos, entre outras, que não são de nosso interesse, uma vez que estamos buscando as palavras específicas relacionadas à área de ecoturismo em cada subcorpus.

Mesmo assim, podemos identificar, sem o recurso de uma ferramenta de análise lingüística, as palavras que retratam o tipo de corpus com o qual estamos trabalhando.

O corpus de agências de turismo em português, por exemplo, apresenta, nessa lista, palavras relacionadas ao tipo de experiência que o turista pode experimentar. Há palavras que indicam atividades e locais para essa prática, além daquelas que se relacionam à natureza:

- ecoturismo, turismo, atividades, naturais, aventura, natureza, atividade, cavernas, parques, praias, pantanal, trilha, trilhas, visitantes.

O corpus de entidades ambientalistas apresenta palavras voltadas à conservação e proteção ambiental:

- turismo, ecoturismo, desenvolvimento, sustentável, meio, ambiente, conservação, natureza, projeto, sustentabilidade, certificação, cultural, programa, comunidades, educação, parque, recursos, atividades, atividade, social, trabalho, naturais, planejamento, projetos, políticas, processo. 
Já o corpus de órgãos governamentais apresenta palavras ligadas à preocupação com a conservação de áreas naturais:

- turismo, ecoturismo, parque, atividades, projeto, desenvolvimento, estado, conservação, atividade, ambiental, aventura, visitação, parque, unidades, impactos, meio, ambiente, ações, naturais, recursos, sustentável, gestão, responsabilidade, turístico, comunidades, estrutura, visitantes, implantação, serviços, uso, secretaria, planejamento, atrativos, programa.

Vale ressaltar a presença da palavra "aventura", num corpus de ecoturismo. Isso acontece porque as atividades ligadas ao turismo de aventura ainda são divulgadas como parte de atividades ecoturísticas, uma vez que envolvem o contato com a natureza. Essa mesma palavra nos chama a atenção em um corpus do governo por ser uma palavra relacionada a outra forma de turismo e que não se enquadra nos objetivos do governo de proteger e conservar áreas ambientais.

Veremos agora o que ocorre na lista de freqüência do corpus em inglês.

\section{Lista de Palavras por ordem de freqüência - corpus em inglês}

Agências de turismo
\begin{tabular}{|r|l|r|r|}
\hline \multicolumn{1}{|c|}{ N } & Word & Freq. & $\%$ \\
\hline 1 & THE & 2.249 & 5,69 \\
\hline 2 & AND & 1.524 & 3,85 \\
\hline 3 & OF & 1.235 & 3,12 \\
\hline 4 & TO & 899 & 2,27 \\
\hline 5 & A & 818 & 2,07 \\
\hline 6 & IN & 692 & 1,75 \\
\hline 7 & IS & 503 & 1,27 \\
\hline 8 & NEW & 476 & 1,2 \\
\hline 9 & FOR & 413 & 1,04 \\
\hline 10 & ZEALAND & 395 & 1,0 \\
\hline 11 & ARE & 382 & 0,97 \\
\hline 12 & ON & 321 & 0,81 \\
\hline 13 & WITH & 301 & 0,76 \\
\hline 14 & YOU & 258 & 0,65 \\
\hline 15 & WE & 248 & 0,63 \\
\hline 16 & OUR & 224 & 0,57 \\
\hline
\end{tabular}

Entidades ambientalistas

\begin{tabular}{|c|l|r|c|}
\hline $\mathbf{N}$ & \multicolumn{1}{|c|}{ Word } & Freq. & $\%$ \\
\hline 1 & THE & 3.671 & 5,84 \\
\hline 2 & OF & 2.228 & 3,55 \\
\hline 3 & AND & 2.174 & 3,46 \\
\hline 4 & TO & 1.724 & 2,74 \\
\hline 5 & IN & 1.192 & 1,90 \\
\hline 6 & A & 988 & 1,57 \\
\hline 7 & IS & 802 & 1,28 \\
\hline 8 & FOR & 655 & 1,04 \\
\hline 9 & THAT & 600 & 0,95 \\
\hline 10 & ARE & 529 & 0,84 \\
\hline 11 & TOURISM & 523 & 0,83 \\
\hline 12 & ON & 421 & 0,67 \\
\hline 13 & AS & 405 & 0,64 \\
\hline 14 & BE & 402 & 0,64 \\
\hline 15 & BY & 330 & 0,53 \\
\hline 16 & THIS & 327 & 0,52 \\
\hline
\end{tabular}

Órgãos governamentais

\begin{tabular}{|r|l|r|c|}
\hline \multicolumn{1}{|c|}{$\mathbf{N}$} & Word & Freq. & $\%$ \\
\hline 1 & THE & 3.854 & 5,81 \\
\hline 2 & OF & 2.659 & 4,01 \\
\hline 3 & AND & 2.523 & 3,80 \\
\hline 4 & TO & 1.861 & 2,80 \\
\hline 5 & IN & 1.314 & 1,98 \\
\hline 6 & A & 1.059 & 1,60 \\
\hline 7 & FOR & 898 & 1,35 \\
\hline 8 & THAT & 849 & 1,28 \\
\hline 9 & IS & 739 & 1,11 \\
\hline 10 & ON & 650 & 0,98 \\
\hline 11 & BE & 521 & 0,79 \\
\hline 12 & ARE & 466 & 0,70 \\
\hline 13 & NEW & 438 & 0,66 \\
\hline 14 & AS & 407 & 0,61 \\
\hline 15 & THIS & 388 & 0,58 \\
\hline 16 & WITH & 365 & 0,55 \\
\hline
\end{tabular}




\begin{tabular}{|c|c|c|c|c|c|c|c|c|c|c|c|}
\hline 17 & AS & 217 & 0,55 & 17 & IT & 309 & 0,49 & 17 & FOREST & 337 & 0,51 \\
\hline 18 & THAT & 206 & 0,52 & 18 & FROM & 301 & 0,48 & 18 & BY & 332 & 0,50 \\
\hline 19 & FROM & 185 & 0,47 & 19 & WITH & 295 & 0,47 & 19 & FROM & 315 & 0,47 \\
\hline 20 & AT & 177 & 0,45 & 20 & NEW & 278 & 0,44 & 20 & IT & 312 & 0,47 \\
\hline 21 & $\mathrm{BE}$ & 169 & 0,43 & 21 & OR & 272 & 0,43 & 21 & NATIVE & 303 & 0,46 \\
\hline 22 & OR & 165 & 0,42 & 22 & NA & 254 & 0,40 & 22 & TOURISM & 297 & 0,45 \\
\hline 23 & AN & 164 & 0,41 & 23 & HAVE & 248 & 0,39 & 23 & ZEALAND & 296 & 0,45 \\
\hline 24 & IT & 160 & 0,40 & 24 & CONSERVATION & 220 & 0,35 & 24 & OR & 283 & 0,43 \\
\hline 25 & HAVE & 157 & 0,40 & 25 & AT & 215 & 0,34 & 25 & HAVE & 257 & 0,39 \\
\hline 26 & THIS & 157 & 0,40 & 26 & THEIR & 213 & 0,34 & 26 & CONSERVATION & 243 & 0,37 \\
\hline 27 & BY & 156 & 0,39 & 27 & ZEALAND & 206 & 0,33 & 27 & MANAGEMENT & 241 & 0,36 \\
\hline 28 & NZ & 152 & 0,38 & 28 & SPECIES & 197 & 0,31 & 28 & PLANTS & 222 & 0,33 \\
\hline 29 & CAN & 140 & 0,35 & 29 & HAS & 196 & 0,31 & 29 & FORESTS & 214 & 0,32 \\
\hline 30 & TOURS & 129 & 0,33 & 30 & NOT & 185 & 0,29 & 30 & NA & 213 & 0,32 \\
\hline 31 & ALL & 121 & 0,31 & 31 & THESE & 185 & 0,29 & 31 & SUSTAINABLE & 212 & 0,32 \\
\hline 32 & NATURAL & 114 & 0,29 & 32 & ECOTOURISM & 181 & 0,29 & 32 & WILL & 211 & 0,32 \\
\hline 33 & TOURISM & 114 & 0,29 & 33 & WAS & 181 & 0,29 & 33 & LAND & 208 & 0,31 \\
\hline 34 & HAS & 111 & 0,28 & 34 & WERE & 176 & 0,28 & 34 & HAS & 202 & 0,30 \\
\hline 35 & WWW & 109 & 0,28 & 35 & THEY & 169 & 0,27 & 35 & INDIGENOUS & 202 & 0,30 \\
\hline 36 & ISLAND & 107 & 0,27 & 36 & WHICH & 169 & 0,27 & 36 & RESEARCH & 199 & 0,30 \\
\hline 37 & WILL & 107 & 0,27 & 37 & WILL & 161 & 0,26 & 37 & AT & 197 & 0,30 \\
\hline 38 & $\mathrm{CO}$ & 106 & 0,27 & 38 & MORE & 157 & 0,25 & 38 & THEIR & 195 & 0,29 \\
\hline 39 & HTTP & 99 & 0,25 & 39 & CAN & 156 & 0,25 & 39 & PRODUCTS & 194 & 0,29 \\
\hline 40 & TRACK & 97 & 0,25 & 40 & ENVIRONMENTAL & 155 & 0,25 & 40 & 1 & 185 & 0,28 \\
\hline 41 & YOUR & 97 & 0,25 & 41 & LOCAL & 155 & 0,25 & 41 & WE & 182 & 0,27 \\
\hline 42 & NATIONAL & 94 & 0,24 & 42 & THERE & 153 & 0,24 & 42 & THESE & 180 & 0,27 \\
\hline 43 & ECOTOURISM & 93 & 0,24 & 43 & VISITORS & 149 & 0,24 & 43 & USE & 180 & 0,27 \\
\hline 44 & MANY & 93 & 0,24 & 44 & BEEN & 146 & 0,23 & 44 & ONE & 178 & 0,27 \\
\hline 45 & DAY & 92 & 0,23 & 45 & ALSO & 142 & 0,23 & 45 & SUBMITTER & 178 & 0,27 \\
\hline 46 & THERE & 92 & 0,23 & 46 & VISITOR & 141 & 0,22 & 46 & OUR & 177 & 0,27 \\
\hline 47 & NATURE & 90 & 0,23 & 47 & OTHER & 140 & 0,22 & 47 & NOT & 171 & 0,26 \\
\hline 48 & PARK & 90 & 0,23 & 48 & $S$ & 137 & 0,22 & 48 & $S$ & 170 & 0,26 \\
\hline 49 & ENVIRONMENT & 89 & 0,22 & 49 & DEVELOPMENT & 133 & 0,21 & 49 & ALSO & 163 & 0,25 \\
\hline 50 & ONE & 89 & 0,22 & 50 & BUT & 129 & 0,21 & 50 & TRADE & 162 & 0,24 \\
\hline 51 & ECO & 83 & 0,21 & 51 & MANAGEMENT & 127 & 0,20 & 51 & CAN & 160 & 0,24 \\
\hline 52 & THEIR & 81 & 0,20 & 52 & SUSTAINABLE & 125 & 0,20 & 52 & THEY & 158 & 0,24 \\
\hline 53 & AREA & 79 & 0,20 & 53 & ALL & 124 & 0,20 & 53 & OTHER & 155 & 0,23 \\
\hline 54 & WAS & 79 & 0,20 & 54 & MOST & 121 & 0,19 & 54 & NATURAL & 154 & 0,23 \\
\hline 55 & SOME & 78 & 0,20 & 55 & SOME & 117 & 0,19 & 55 & TIMBER & 149 & 0,22 \\
\hline 56 & WORLD & 78 & 0,20 & 56 & YOU & 107 & 0,17 & 56 & MORE & 147 & 0,22 \\
\hline 57 & EXPERIENCE & 77 & 0,19 & 57 & INDUSTRY & 101 & 0,16 & 57 & AREAS & 146 & 0,22 \\
\hline 58 & TOUR & 77 & 0,19 & 58 & ONE & 101 & 0,16 & 58 & THERE & 146 & 0,22 \\
\hline 59 & MORE & 76 & 0,19 & 59 & WE & 101 & 0,16 & 59 & WAS & 141 & 0,21 \\
\hline 60 & CONSERVATION & 74 & 0,19 & 60 & MANY & 100 & 0,16 & 60 & BIODIVERSITY & 140 & 0,21 \\
\hline 61 & WHICH & 74 & 0,19 & 61 & MAY & 100 & 0,16 & 61 & SUBMITTERS & 139 & 0,21 \\
\hline 62 & MOST & 73 & 0,18 & 62 & USE & 100 & 0,16 & 62 & ENVIRONMENT & 135 & 0,20 \\
\hline 63 & RIVER & 72 & 0,18 & 63 & NATIONAL & 99 & 0,16 & 63 & WHICH & 133 & 0,20 \\
\hline 64 & THEY & 71 & 0,18 & 64 & PEOPLE & 99 & 0,16 & 64 & INTERNATIONAL & 129 & 0,19 \\
\hline 65 & TIME & 71 & 0,18 & 65 & ABOUT & 98 & 0,16 & 65 & YOU & 129 & 0,19 \\
\hline 66 & NATIVE & 70 & 0,18 & 66 & AREAS & 98 & 0,16 & 66 & SOME & 126 & 0,19 \\
\hline 67 & SOUTH & 69 & 0,17 & 67 & ENVIRONMENT & 88 & 0,14 & 67 & ITS & 124 & 0,19 \\
\hline 68 & ALSO & 68 & 0,17 & 68 & $\mathrm{SUCH}$ & 88 & 0,14 & 68 & DEVELOPMENT & 122 & 0,18 \\
\hline
\end{tabular}




\begin{tabular}{|c|c|c|c|c|c|c|c|c|c|c|c|}
\hline 69 & DOLPHINS & 68 & 0,17 & 69 & NZ & 86 & 0,14 & 69 & BEEN & 118 & 0,18 \\
\hline 70 & THESE & 67 & 0,17 & 70 & THAN & 84 & 0,13 & 70 & SPECIES & 118 & 0,18 \\
\hline 71 & PEOPLE & 66 & 0,17 & 71 & ECONOMIC & 83 & 0,13 & 71 & ECOTOURISM & 111 & 0,17 \\
\hline 72 & ITS & 65 & 0,16 & 72 & ONLY & 83 & 0,13 & 72 & ECONOMIC & 108 & 0,16 \\
\hline 73 & OTHER & 65 & 0,16 & 73 & ISLAND & 82 & 0,13 & 73 & ALL & 105 & 0,16 \\
\hline 74 & SEE & 65 & 0,16 & 74 & ISSUES & 82 & 0,13 & 74 & PRIVATE & 105 & 0,16 \\
\hline 75 & NOT & 64 & 0,16 & 75 & PACIFIC & 82 & 0,13 & 75 & WOULD & 105 & 0,16 \\
\hline 76 & S & 64 & 0,16 & 76 & PARK & 82 & 0,13 & 76 & INTO & 103 & 0,16 \\
\hline 77 & ABOUT & 63 & 0,16 & 77 & AREA & 80 & 0,13 & 77 & ROLE & 103 & 0,16 \\
\hline 78 & MOUNTAIN & 63 & 0,16 & 78 & ITS & 80 & 0,13 & 78 & LOCAL & 102 & 0,15 \\
\hline 79 & BUT & 62 & 0,16 & 79 & RESEARCH & 80 & 0,13 & 79 & YOUR & 102 & 0,15 \\
\hline 80 & WALKING & 62 & 0,16 & 80 & DATA & 79 & 0,13 & 80 & GOVERNMENT & 101 & 0,15 \\
\hline 81 & WELL & 62 & 0,16 & 81 & INFORMATION & 79 & 0,13 & 81 & MANY & 99 & 0,15 \\
\hline 82 & TAKE & 61 & 0,15 & 82 & SOUTH & 77 & 0,12 & 82 & COUNTRIES & 98 & 0,15 \\
\hline 83 & UNIQUE & 61 & 0,15 & 83 & NATURAL & 76 & 0,12 & 83 & ABOUT & 95 & 0,14 \\
\hline 84 & GREAT & 58 & 0,15 & 84 & BUSINESS & 73 & 0,12 & 84 & BUT & 95 & 0,14 \\
\hline 85 & THROUGH & 58 & 0,15 & 85 & IF & 73 & 0,12 & 85 & SHOULD & 95 & 0,14 \\
\hline 86 & US & 58 & 0,15 & 86 & TIME & 73 & 0,12 & 86 & $\mathrm{SUCH}$ & 95 & 0,14 \\
\hline 87 & SEA & 57 & 0,14 & 87 & 1 & 72 & 0,11 & 87 & INFORMATION & 93 & 0,14 \\
\hline 88 & WALK & 56 & 0,14 & 88 & FOREST & 71 & 0,11 & 88 & IMPORTANT & 92 & 0,14 \\
\hline 89 & BIRD & 55 & 0,14 & 89 & CENTRE & 70 & 0,11 & 89 & COULD & 89 & 0,13 \\
\hline 90 & INTO & 55 & 0,14 & 90 & WORLD & 70 & 0,11 & 90 & COUNCIL & 89 & 0,13 \\
\hline 91 & ONLY & 55 & 0,14 & 91 & INTO & 69 & 0,11 & 91 & MAORI & 87 & 0,13 \\
\hline 92 & $\mathrm{SUCH}$ & 55 & 0,14 & 92 & YEAR & 69 & 0,11 & 92 & NON & 87 & 0,13 \\
\hline 93 & WILDLIFE & 55 & 0,14 & 93 & COAST & 68 & 0,11 & 93 & ENVIRONMENTAL & 86 & 0,13 \\
\hline 94 & WATER & 53 & 0,13 & 94 & HOWEVER & 68 & 0,11 & 94 & NEED & 86 & 0,13 \\
\hline 95 & COAST & 52 & 0,13 & 95 & INTERNATIONAL & 68 & 0,11 & 95 & THROUGH & 86 & 0,13 \\
\hline 96 & LOCAL & 52 & 0,13 & 96 & MARINE & 68 & 0,11 & 96 & INDUSTRY & 85 & 0,13 \\
\hline 97 & OUT & 52 & 0,13 & 97 & OUR & 68 & 0,11 & 97 & KNOWLEDGE & 85 & 0,13 \\
\hline 98 & WALKS & 52 & 0,13 & 98 & SITE & 68 & 0,11 & 98 & BEING & 83 & 0,13 \\
\hline 99 & COUNTRY & 51 & 0,13 & 99 & VALUES & 68 & 0,11 & 99 & FORESTRY & 82 & 0,12 \\
\hline 100 & TWO & 51 & 0,13 & 100 & THOSE & 66 & 0,11 & 100 & VALUE & 82 & 0,12 \\
\hline
\end{tabular}

Analisando as palavras dos corpora de cada uma das áreas em inglês, podemos notar que o corpus de agências de turismo também apresenta palavras relacionadas a atividades desenvolvidas, não havendo, no entanto, menção a "aventura" (adventure):

- tours, natural, tourism, track, ecotourism, nature, park, environment, eco, experience, tour, conservation, native, dolphins, walking, unique, walk, bird, wildlife, walks.

O corpus de entidades ambientalistas, como o corpus em português, também demonstra a preocupação com a preservação: 
- tourism, conservation, species, ecotourism, environmental, visitors, visitor, development, management, sustainable, industry, environment, economic, issues, park, research, data, information, natural, business, forest, values.

O mesmo ocorre com o corpus de órgãos governamentais. No entanto, este corpus não apresenta nenhuma palavra relacionada a atividades ou aventura, como no mesmo corpus em português.

- forest, native, tourism, conservation, management, forests, sustainable, indigenous, research, products, submitter, trade, natural, biodiversity, submitters, environment, development, species, ecotourism, economic, private, role, local, government, information, council, environmental, industry, knowledge, forestry, value.

Embora algumas conclusões possam ser tiradas por meio de uma análise das listas de palavras, a quantidade de dados é muito grande, o que torna uma análise minuciosa inviável.

Para solucionarmos esse problema, utilizamos a ferramenta KeyWords (palavras-chave), que apresenta a relação das palavras de freqüência mais significativa no corpus.

Nosso passo seguinte foi, então, a obtenção das listas de palavras-chave a partir do cruzamento de cada um dos subcorpus, tanto em português quanto em inglês, com o respectivo corpus de referência.

\subsection{KeyWords}

De acordo com o procedimento já apresentado anteriormente, o cruzamento entre duas listas de palavras resultou em uma lista com palavras positivas e negativas. As positivas referem-se às palavras que mais ocorreram no corpus de estudo e as negativas às que mais ocorreram no corpus de referência. Portanto, as primeiras palavras positivas são as que mais ocorreram no corpus de estudo, 
enquanto as últimas palavras negativas representam as palavras que mais ocorreram no corpus de referência.

Para a produção dessa lista, é possível estabelecer o número máximo de palavras que desejamos obter. Optamos por manter a freqüência máxima de palavras em 500, que é o valor básico apresentado no quadro de ajustes.

Uma das vantagens da utilização dessa ferramenta é a redução no número de palavras com a eliminação das palavras gramaticais que aparecem nas listas de palavras e quaisquer outras de freqüência relativamente semelhante. Quando a lista de palavras-chave ainda apresenta palavras gramaticais, é possível que elas façam parte de agrupamentos de palavras como "turismo de aventura", "estrutura dos parques", "impactos no meio ambiente".

O resultado completo do cruzamento dos subcorpora de estudo com o corpus de referência encontra-se nos Anexos B e C.

Ao verificarmos os resultados dessas listas de palavras-chave pudemos notar que muitas delas ainda poderiam ser excluídas para chegarmos a uma lista de palavras-chave com os dados que realmente nos interessam.

Nosso próximo passo, então, foi a eliminação de uma série de palavras que, a nosso ver, não estavam relacionados aos objetivos de nossa análise. Desse modo, optamos por eliminar:

- palavras gramaticais

- verbos de ligação

- nomes próprios em geral, como nomes de pessoas envolvidas em atividades apresentadas nos textos, entidades ambientalistas, órgãos do governo, nomes de agências, de lugares, cidades, estados e países.

- siglas (como WWF, World Wild Fund)

- referências a páginas da internet, como http, html etc.

- referências a cidades, estados e países em palavras como governo, governamental, município, municipal, estado, estadual, nacional, internacional, ministério, ministerial. 
- nomes de peixes, pássaros, árvores, montanhas, parques, etc. Porém, foram mantidas as palavras "whale" e "dolphins" no corpus em inglês, pois representam atividades ecoturísticas muito comuns na Nova Zelândia.

- medidas como metro, quilômetro, hectare, etc.

- menções a tempo como hoje, amanhã, ontem, dia, mês, ano.

- palavras como ruas, avenidas, pistas, rodovias, estradas.

- nomes de alimentos.

- direções: norte, sul, leste, oeste, etc.

- formações naturais: estalactite, estalagmite, rochas, baía, etc.

Além da eliminação desses dados, optamos ainda por agrupar algumas palavras. Nesses casos, os dados referentes ao número de ocorrências (freqüência) foram somados:

- palavras no singular e suas formas no plural;

- verbos e suas conjugações.

Quando iniciamos o processo de "limpeza" das listas, notamos que, nas listas em inglês, há uma freqüência muito grande de nomes de pássaros, peixes e plantas, muito diferente do corpus em português. No caso dos pássaros, por exemplo, isso se refere a uma atividade muito comum na Nova Zelândia, birdwatching (observação de pássaros), enquanto no Brasil se trata de uma atividade mais característica de estudiosos.

Com a limpeza das listas de palavras-chave, eliminamos as palavras que não eram de nosso interesse e passamos a ver mais claramente as palavras de conteúdo presentes nos três subcorpora de cada língua. $O$ resultado completo encontra-se nos Anexos D e E. Nesses anexos, as palavras que ocorrem em mais de uma lista foram destacadas com cores diferentes para que pudéssemos visualizar as semelhanças de vocabulário encontradas.

Devido ao tamanho das listas de palavras e à restrição quanto à extensão deste estudo, decidimos analisar apenas as primeiras dez palavras de cada lista, em cada uma das línguas. 
Iniciaremos com a análise das palavras em português.

\subsubsection{Palavras em Português}

O quadro abaixo apresenta as dez primeiras palavras de conteúdo das listas de palavras-chave do corpus em português. Essas palavras estão organizadas pela ordem de aparecimento na lista com o número de ocorrência (freqüência) no corpus.

\begin{tabular}{|l|l|l|l|l|l|l|}
\hline N.․․ & \multicolumn{1}{|c|}{ Ag } & freq. & \multicolumn{1}{c|}{ Amb } & freq. & \multicolumn{1}{c|}{ Gov } & \multicolumn{1}{c|}{ freq. } \\
\hline 1 & turismo & 885 & turismo & 558 & turismo & 463 \\
2 & ecoturismo & 696 & ecoturismo & 431 & ecoturismo & 327 \\
3 & ambiental & 374 & desenvolvimento & 290 & parques & 255 \\
4 & região & 371 & ambiental & 236 & atividade(s) & $247 / 196$ \\
5 & meio & 363 & sustentável & 221 & projeto & 245 \\
6 & desenvolvimento & 351 & meio & 215 & desenvolvimento & 217 \\
7 & sustentável & 338 & ambiente & 183 & conservação & 208 \\
8 & ambiente & 333 & conservação & 136 & ambiental & 169 \\
9 & atividades & 316 & natureza & 129 & aventura & 165 \\
10 & naturais & 316 & projeto & 119 & visitação & 161 \\
\hline
\end{tabular}

Analisando as listas, notamos que algumas palavras ocorrem em mais de um subcorpus:

- palavras que ocorrem nos três subcorpora, sendo que as duas primeiras ocorrem na mesma posição nas três listas: turismo, ecoturismo, desenvolvimento e ambiental.

- palavras que ocorrem nos corpora de agências e ambientalistas: meio, sustentávele ambiente.

- palavras que ocorrem nos corpora de agências e governo: atividades.

- palavras que ocorrem nos corpora de ambientalistas e governo: conservação e projeto.

As palavras que só ocorrem em um dos subcorpora são:

- Ag: região e naturais.

- Amb: natureza.

- Gov: parques, visitação e aventura. 
É interessante observar as palavras que ocorrem em apenas um dos corpora e a relação delas com o corpus a que pertencem.

As agências de turismo costumam trabalhar com pacotes por "região" do país e se preocupam em divulgar as belezas "naturais" que o turista vai encontrar, o que pode justificar o fato de essas palavras só aparecerem nesse corpus.

As entidades ambientalistas se preocupam, de modo geral, com a "natureza", enquanto o governo tem interesse na divulgação de locais ("parques") que possam ser visitados ("visitados") por turistas.

Em seguida, investigamos os colocados dessas palavras, ou seja, as palavras que mais ocorrem junto às palavras selecionadas. As primeiras palavras a serem apresentadas são as que ocorreram nos três corpora: "turismo", "ecoturismo" e "ambiental".

\section{Turismo}

A palavra "turismo" é a primeira nos três subcorpora. Analisando os colocados dessa palavra, verificamos que a maioria se refere a formas de nomear a atividade turística. No quadro abaixo, apresentamos as formas de turismo encontradas em cada subcorpus com a freqüência com que ocorreram.

\begin{tabular}{|l|l|l|}
\hline \multicolumn{1}{|c|}{ Ag } & \multicolumn{1}{|c|}{ Amb } & \multicolumn{1}{c|}{ Gov } \\
\hline turismo sustentável (155) & turismo sustentável (96) & turismo de aventura (137) \\
turismo ecológico (52) & turismo ecológico (40) & tustentável (36) \\
turismo rural (10) \\
turismo de aventura (50) & turismo comonnanável (18) & turismo ecológico (8) \\
turismo de massa (23) & turismo rural (6) & turismo eqüestre (3) \\
turismo responsável (18) & turismo de base comunitária (3) \\
turismo de base comunitária (9) & turismo cultural (5) & turismo receptivo (3) \\
turismo alternativo (7) & turismo de aventura (4) & turismo responsável (3) \\
turismo especializado (6) & turismo de base comunitária (3) & turismo alternativo (2) \\
turismo local (5) & turismo convencional (2) & turismo de massa (2) \\
turismo solidário (4) & turismo de lazer e incentivo (2) & turismo náutico (3) \\
turismo rural (4) & turismo científico (1) & turismo esotérico (2) \\
turismo convencional (3) & turismo receptivo (1) & turismo de curta/média/longa \\
turismo ambiental (3) & turismo de pesca (1) & distância (2) \\
turismo tradicional (3) & turismo comercial convencional & turismo de campo (1) \\
turismo de pesca (3) & (1) & turismo interno (1) \\
turismo ecológico sustentável & turismo para a 3a. idade (1) & turismo de negócios (1) \\
(3) & turismo especializado(1) & turismo verde (1) \\
turismo em cavernas (3) & turismo ambiental (1) \\
turismo comunitário (3) & turismo local (1) &
\end{tabular}




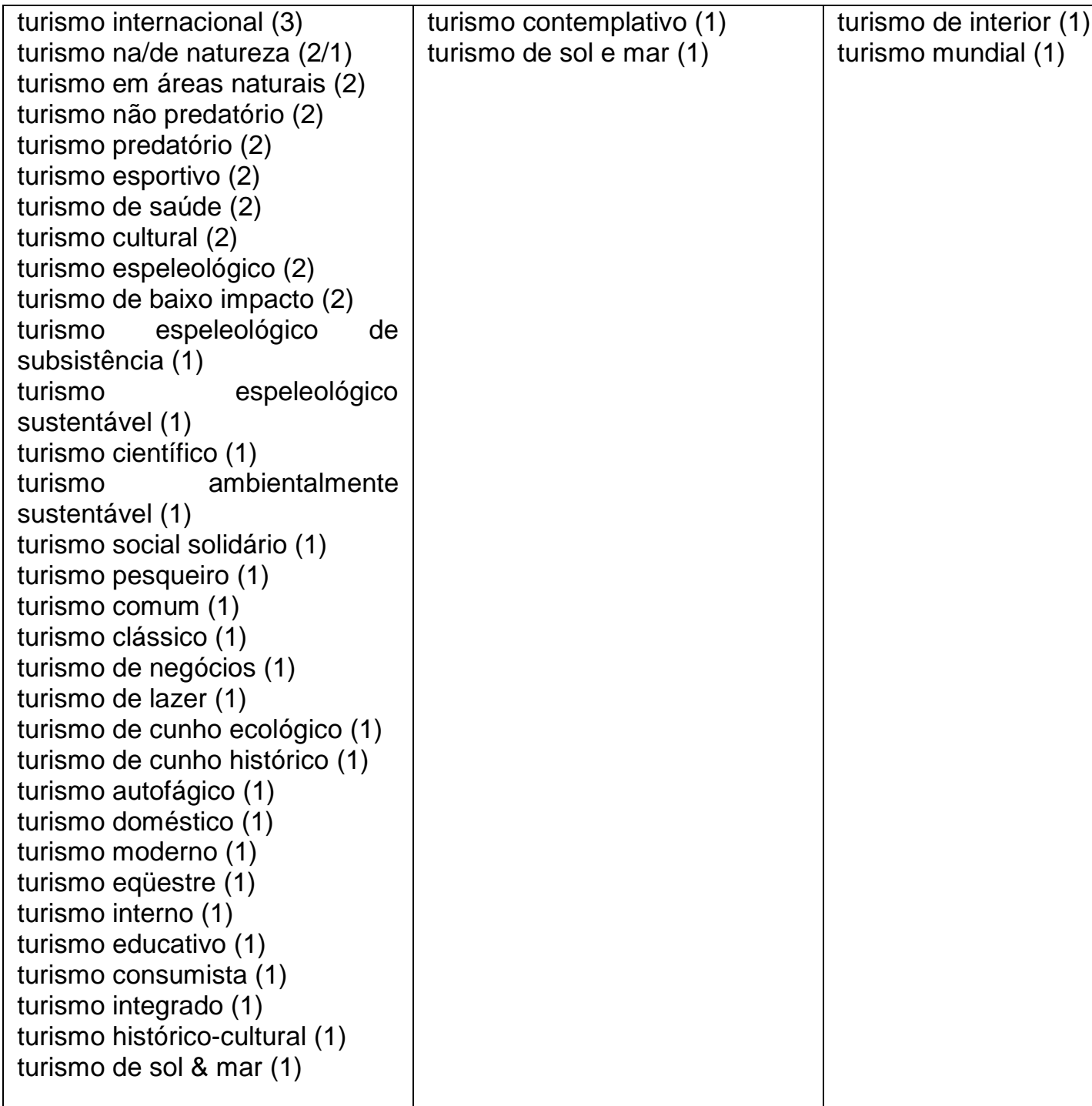

Podemos observar que há uma grande diferença entre as formas como as agências de turismo nomeiam os tipos de turismo, valendo-se, inclusive, de várias formas para designar, por exemplo, turismo de massa: "turismo comum", "turismo clássico", "turismo convencional". As agências têm a necessidade de apresentar produtos diferenciados e, para isso, criam neologismos como se fossem novas formas de turismo.

As agências de turismo têm como objetivo a venda de pacotes turísticos. Para isso, utilizam-se de formas variadas para atrair uma clientela ávida por novas atividades. Isso já não acontece com as entidades ambientalistas e com o governo, que apresentam um número menor de tipos de turismo. 
É importante ressaltar o número de ocorrências da forma "turismo de aventura" no corpus do governo. Embora 46 dessas ocorrências sejam devidas ao agrupamento "I Seminário Regional de Turismo de Aventura", evento realizado em diversos locais do país por iniciativa do Ministério do Turismo, o número ainda é muito alto, com outras 91 ocorrências.

Isso nos levou a uma análise das ocorrências da palavra "aventura" para verificarmos as concordâncias. Além das 137 ocorrências do agrupamento "turismo de aventura", temos ainda mais 28 ocorrências, sendo que as mais significativas são: 3 com a palavra "atividades"; 6 com "corrida(s)" e 6 com "esporte(s)". A leitura de alguns trechos dos textos nos mostra que parece não haver uma distinção muito clara entre as duas formas de turismo, pois algumas atividades de aventura são, às vezes, descritas como atividades turísticas.

Exemplos de concordâncias da palavra "aventura" do subcorpus do governo:

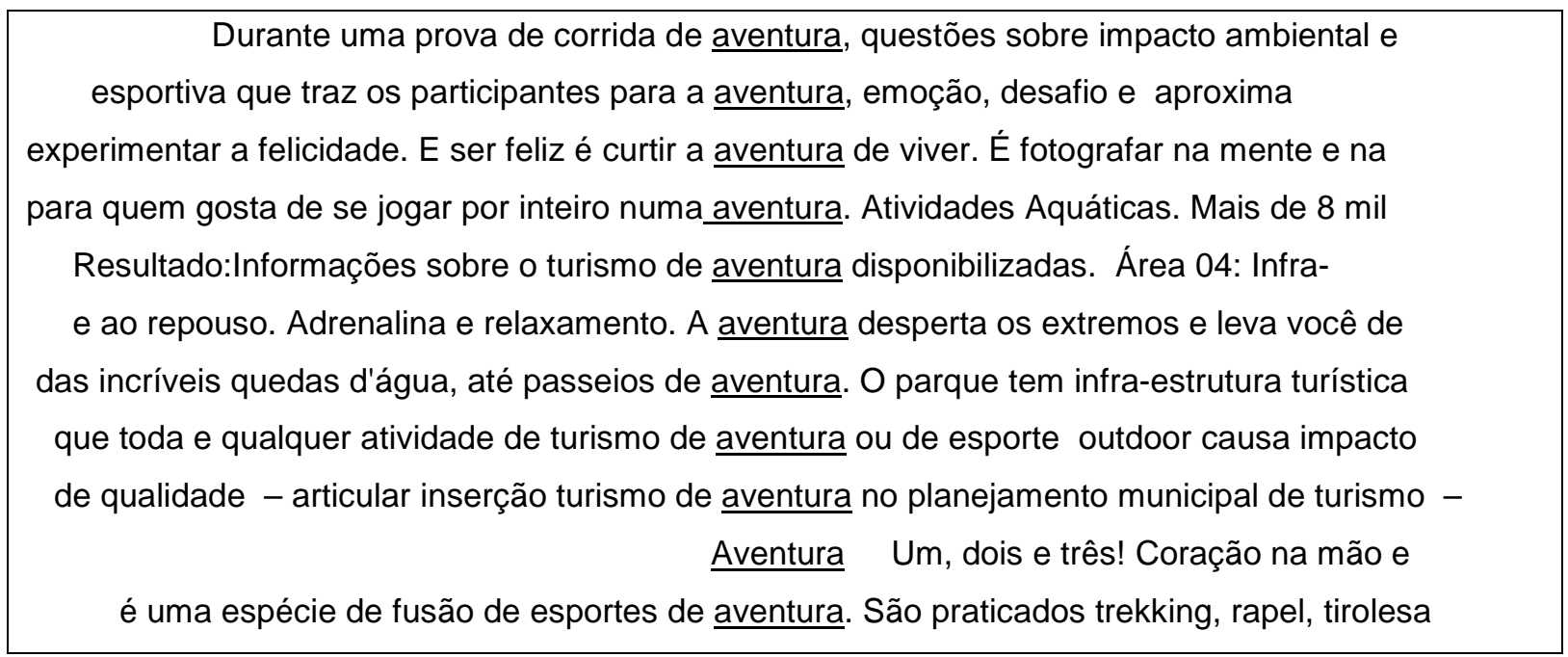

Além dos tipos de turismo apresentados acima, encontramos também uma série de agrupamentos (clusters) que ocorrem com bastante freqüência no corpus. Em uma pesquisa para a elaboração de um glossário de ecoturismo, a utilização da lista de palavras-chave é uma forma de descobrirmos os candidatos a termo. Os cruzamentos dos agrupamentos encontrados em português e em inglês podem ser 
de grande valia para o tradutor, que pode verificar como um determinado termo é utilizado na outra língua.

A lista abaixo não apresenta os termos do quadro anterior.

\begin{tabular}{|c|c|c|}
\hline $\begin{array}{l}\text { certificação do/em/de } \sim(45) \\
\text { desenvolvimento do } \sim(21) \\
\text { conselho brasileiro de } \sim(19) \\
\text { programa de certificação em } \sim(14) \\
\text { prática(s) do } \sim(12) \\
\text { modelo de } \sim(10) \\
\text { indústria do } \sim(10) \\
\text { tipos de } \sim(10) \\
\text { atividade(s) de } \sim(9) \\
\text { modalidade }(\text { s) de } \sim(8) \\
\text { área(s) de } \sim(7) \\
\text { guia de } \sim(7) \\
\text { plano diretor de } \sim(7) \\
\text { organização mundial de } \sim(7) \\
\text { meio ambiente e } \sim(6) \\
\text { ministério do } \sim(6) \\
\text { segmento(s) de/do } \sim(6) \\
\text { conceito de } \sim(6) \\
\text { desenvolvimento sustentável do } \sim(6) \\
\text { mercado de } \sim(4) \\
\text { conselho municipal de } \sim(4) \\
\text { operadora de } \sim(4) \\
\text { processo de certificação em } \sim(4) \\
\sim \text { e planejamento }(4) \\
\text { câmara brasileira de } \sim(4) \\
\text { instituto brasileiro de } \sim(4) \\
\text { diretor de } \sim(4) \\
\text { viagens de } \sim(3) \\
\text { empresas de } \sim(3) \\
\text { profissionais de } \sim(3) \\
\text { agências de } \sim(3) \\
\text { centro de } \sim(3) \\
\text { congresso brasileiro de } \sim(2) \\
\sim \text { e desenvolvimento sustentável (2) } \\
\text { programa de } \sim(2) \\
\text { secretaria do } \sim(1)\end{array}$ & $\begin{array}{l}\text { certificação do/em/de (37) } \\
\sim \text { e meio ambiente }(19) \\
\text { conselho brasileiro de } \sim(18) \\
\text { desenvolvimento do } \sim(13) \\
\text { ministério do } \sim(12) \\
\text { organização mundial de } \sim(12) \\
\text { programa de } \sim(12) \\
\text { sustentabilidade do } \sim(11) \\
\text { associação de } \sim(8) \\
\text { atividade }(\text { s) de } \sim(6) \\
\text { política nacional de } \sim(4) \\
\text { meio ambiente e } \sim(4) \\
\sim \text { e conservação }(4) \\
\text { prática(s) de } \sim(4) \\
\text { planejamento do } \sim(3) \\
\text { projetos de } \sim(3) \\
\text { indústria do } \sim(3) \\
\text { mercado de } \sim(3) \\
\text { agenda } 21 \text { do } \sim(3) \\
\text { área de } \sim(3) \\
\text { educação e } \sim(3) \\
\text { gestão do } \sim(3) \text { conceito de } \sim(3) \\
\text { viagens de } \sim(2) \\
\text { projeto de } \sim(2) \\
\text { profissionais de } \sim(2) \\
\text { empresas de } \sim(1)\end{array}$ & $\begin{array}{l}\text { seminário regional de } \sim(46) \\
\text { desenvolvimento do } \sim(23) \\
\text { atividade(s) de } \sim(14) \\
\text { mercado de } \sim(11) \\
\text { ministério do } \sim(9) \\
\text { modalidade(s) de } \sim(9) \\
\text { conselho (brasileiro) de } \sim(7) \\
\text { setor de } \sim(6) \\
\text { programa(s) de } \sim(5) \\
\text { indústria do } \sim(5) \\
\text { operador(es) de } \sim(4) \\
\text { instituto brasileiro de } \sim(4) \\
\text { consolidar o } \sim(4) \\
\text { promoção do } \sim(4) \\
\text { secretaria de } \sim(4) \\
\text { área de } \sim(3) \\
\text { segmento do } \sim(3) \\
\text { guia(s) de } \sim(3) \\
\text { princípios do } \sim(2) \\
\text { agentes de } \sim(2) \\
\text { associação brasileira de } \sim(2) \\
\sim \text { e planejamento }(2) \\
\sim \text { e meio ambiente }(2)\end{array}$ \\
\hline
\end{tabular}

\section{Ecoturismo}

A palavra "ecoturismo", além de aparecer nos três subcorpora, também ocorre na mesma posição, como segunda palavra em número de ocorrências. A partir dessa lista, apresentamos todos os agrupamentos encontrados. Nosso estudo busca 
verificar as ocorrências nos subcorpora, porém essas listas de agrupamentos são muito úteis para a identificação dos possíveis termos da área de ecoturismo.

\begin{tabular}{|c|c|c|}
\hline $\mathbf{A g}$ & Amb & Gov \\
\hline $\begin{array}{l}\text { prática(s) de } \sim(27) \\
\text { desenvolvimento do } \sim(20) \\
\text { instituto de } \sim(11) \\
\text { fórum de } \sim(10) \\
\text { pólo(s) de } \sim(9) \\
\text { guia(s) de } \sim(9) \\
\text { projeto(s) de } \sim(9) \\
\text { viagem(ns) de } \sim(8) \\
\text { atividade(s) de } \sim(8) \\
\text { política (nacional) de } \sim(7) \\
\text { monitor(es) de } \sim(7) \\
\text { empresa(s) de } \sim(6) \\
\text { programa(s) de } \sim(5) \\
\text { roteiros de } \sim(5) \\
\text { educação para o } \sim(5) \\
\text { mercado de } \sim(4) \\
\text { impacto(s) do } \sim(4) \\
\text { operadora(s) de } \sim(4) \\
\sim \text { brasileiro }(4) \\
\text { área de } \sim(3) \\
\sim \text { na região }(3) \\
\text { segmento de } \sim(2) \\
\sim \text { responsável }(2) \\
\text { produto(s) de } \sim(2) \\
\text { incentivo ao } \sim(2) \\
\text { princípios do } \sim(2) \\
\text { importância do } \sim(2) \\
\sim \text { mundial }(2) \\
\sim \text { empresarial }(1) \\
\sim \text { e ética }(1)\end{array}$ & $\begin{array}{l}\text { desenvolvimento do } \sim(28) \\
\sim \text { de base comunitária }(20) \\
\text { manual de } \sim(16) \\
\text { política nacional de } \sim(13) \\
\text { atividade }(\text { s) de } \sim(13) \\
\text { pólos de } \sim(10) \\
\text { políticas de } \sim(6) \\
\text { instituto brasileiro de } \sim(5) \\
\text { princípios do } \sim(4) \\
\text { projeto(s) de } \sim(4) \\
\text { mercado de } \sim(4) \\
\text { crescimento do } \sim(3) \\
\text { desenvolver o } \sim(3) \\
\text { benefícios do } \sim(3) \\
\text { locais de } \sim(3) \\
\text { planejamento do } \sim(3) \\
\text { empreendimentos em } \sim(3) \\
\text { certificação em } \sim(2) \\
\text { agências de } \sim(2) \\
\sim \text { e conservação }(2) \\
\text { implementação de } \sim(1) \\
\text { segmento do } \sim(1)\end{array}$ & $\begin{array}{l}\text { desenvolvimento do } \sim(23) \\
\text { atividade(s) de } \sim(19) \\
\text { política (nacional) de } \sim(16) \\
\sim \text { na região }(10) \\
\text { gestão do } \sim(9) \\
\text { agenda de } \sim(7) \\
\text { pólos de } \sim(6) \\
\text { produtos de } \sim(5) \\
\text { segmento de } \sim(5) \\
\sim \text { e educação ambiental } \sim(4) \\
\text { projeto(s) de } \sim(4) \\
\text { mercado de } \sim(4) \\
\text { instituto de } \sim(4) \\
\text { planejamento do } \sim(3) \\
\text { regulamentação do } \sim(3) \\
\text { informação sobre } \sim(3) \\
\text { programa }(\text { nacional) de } \sim(3) \\
\text { impactos do } \sim(2) \\
\sim \text { sustentável }(1) \\
\text { promover o } \sim(1)\end{array}$ \\
\hline
\end{tabular}

Um dos itens que mais aparecem é o "desenvolvimento do ecoturismo". As três áreas, cada uma de acordo com seus objetivos, têm interesse nesse tipo de desenvolvimento.

Nas ocorrências do corpus de agências, destacamos algumas palavras que refletem as características da área: "viagem(ns)", "roteiro(s)", "prática(s)", "monitor(es)", "operadora(s)", "incentivo", "guia".

As palavras do corpus de entidades ambientalistas mostram uma preocupação com a comunidade e a implantação de um modelo, com desenvolvimento de modo organizado e orientado: "base comunitária", 
"planejamento”, “conservação”, “implementação”, “desenvolver”, “certificação”, "benefícios".

O governo tem interesse tanto no desenvolvimento e crescimento da área quanto na educação. Podemos dizer que seus objetivos ficam entre as duas outras áreas: a promoção e desenvolvimento do turismo e a preocupação com o desenvolvimento de projetos e educação ambiental. Como exemplo, podemos destacar as seguintes palavras: "atividades", "gestão”, "desenvolvimento", "educação ambiental", "projetos", "planejamento", "sustentável", "promover".

\section{Ambiental}

A palavra "ambiental" é a terceira palavra em comum entre os subcorpora. Os agrupamentos encontrados encontram-se no quadro abaixo.

\begin{tabular}{|c|c|c|}
\hline $\mathbf{A g}$ & Amb & Gov \\
\hline 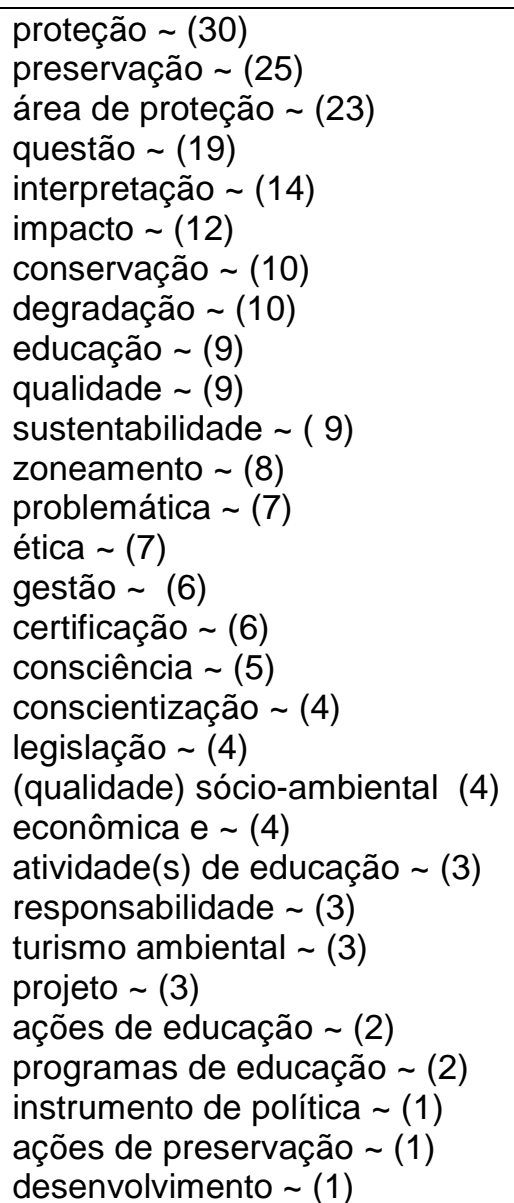 & $\begin{array}{l}\text { educação (68) } \\
\text { gestão (14) } \\
\text { questão (11) } \\
\text { interpretação (10) } \\
\text { proteção } \sim(10) \\
\text { preservação } \sim(9) \\
\text { sustentabilidade } \sim(7) \\
\text { qualidade } \sim(5) \\
\text { conservação } \sim(5) \\
\text { impacto } \sim(5) \\
\text { monitoramento } \sim(4) \\
\text { projeto } \sim(2) \\
\text { legislação } \sim(2)\end{array}$ & $\begin{array}{l}\text { educação (39) } \\
\text { gestão (15) } \\
\text { interpretação (14) } \\
\text { proteção (12) } \\
\text { impacto (12) } \\
\text { conservação (10) } \\
\text { monitor (7) } \\
\text { patrimônio (5) } \\
\text { monitoria (5) } \\
\text { sustentabilidade (4) } \\
\text { planejamento (2) }\end{array}$ \\
\hline
\end{tabular}


instrumento de preservação (1)

instrumento de degradação (1)

instrumento para educação (1)

atividade de gerenciamento $\sim(1)$

atividade de zoneamento (1)

Assim como foi observado nas outras palavras, as agências apresentam um número bem mais alto de ocorrências (374) e de agrupamentos com a palavra "ambiental", sendo que as palavras que mais ocorrem nesse subcorpus são "proteção" e "preservação". Na divulgação de seus pacotes, mostrar uma preocupação ambiental é muito importante para atrair turistas.

Os ambientalistas apresentam como ponto principal a questão da educação ambiental, uma forma não apenas de preservar o meio ambiente, mas também de preparar as futuras gerações para a questão da conservação. As palavras "educação", "sustentabilidade", "preservação" e "monitoramento" são exemplos dessa preocupação.

A preocupação do governo vai ao encontro da dos ambientalistas, tendo como foco principal a educação "ambiental". A ocorrência das palavras "monitor" e "monitoria" entre as palavras do subcorpus pode ter relação com a importância de uma visitação orientada, o que indica a preocupação com a preservação e com a educação, no qual o monitor tem o papel de passar informações sobre a área preservada e os projetos desenvolvidos.

Exemplos de concordâncias das palavras "monitor" e 'monitoria do subcorpus do governo:

\footnotetext{
Critérios para candidato a Monitor Ambiental, para ecoturismo e educação

Os candidatos a aluno para o curso de Monitor Ambiental deverão passar por uma sele

trata das normas de conduta do monitor ambiental nas unidades da SMA-SP.

de avaliação dos alunos no curso de Monitor Ambiental serão feitos após cada

de credenciamento provisório, o monitor deve freqüentar curso com pelo menos

centros de informações turísticas. Monitor ou Condutor local Profissional, preferencialmente conservação da SMA-SP) do curso de Monitor Ambiental, deverá ser entregue pelos

loja, uma base para serviços de monitoria ambiental e estacionamento. As fichas pretenderam regular a atividade de monitoria ambiental nas unidades de conservação Pode-se notar que a monitoria ambiental é uma atividade que envolve
} 
capacitação para que a atividade de monitoria seja desenvolvida. Contudo, a questão desenvolvida. Contudo, a questão da monitoria ainda é controversa, de modo que as acompanhar os visitantes. O tema monitoria ambiental vem sendo trabalhado na

\section{Desenvolvimento}

A palavra "desenvolvimento" é a última das palavras que ocorreram nos três subcorpora.

\begin{tabular}{|c|c|c|}
\hline $\mathrm{Ag}$ & Amb & Gov \\
\hline 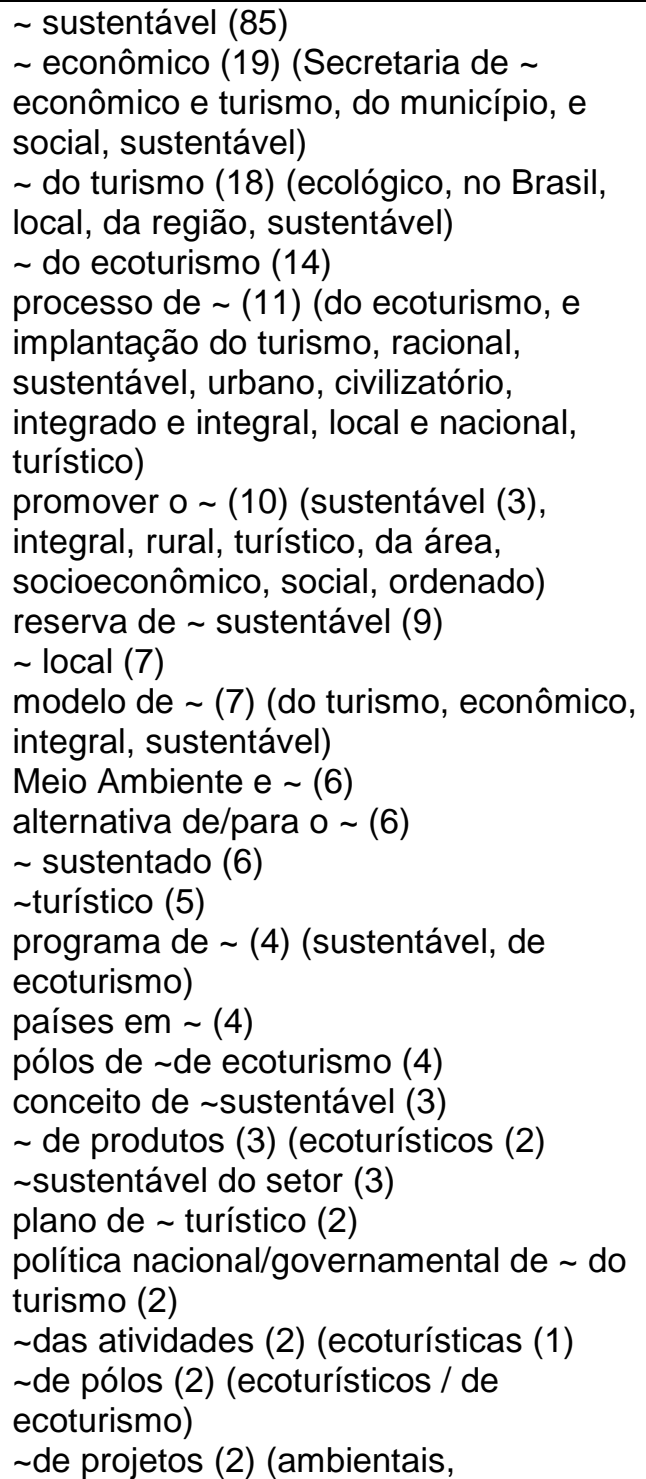 & $\begin{array}{l}\text { sustentável }(76) \\
\sim \text { do ecoturismo }(28) \\
\sim \text { econômico }(15) \\
\sim \text { do turismo }(13) \\
\sim \text { sustentado }(7) \\
\sim \text { turístico }(7) \\
\text { processo de } \sim(7) \\
\text { modelo de } \sim(6) \\
\text { conceito de } \sim(6) \\
\text { diretor de } \sim(5) \\
\text { contribuir para o } \sim(5) \\
\text { meio ambiente e } \sim(5) \\
\text { conservação e } \\
\sim(\text { local/sustentado })(4) \\
\sim \text { de projetos }(4) \\
\text { promoção de } \sim(4) \\
\sim \text { de políticas }(3) \\
\text { apoio ao } \sim(3) \\
\sim \text { regional }(3) \\
\sim \text { responsável }(2) \\
\sim \text { local }(2)\end{array}$ & $\begin{array}{l}\sim \text { sustentável }(41) \\
\sim \text { do turismo }(23) \\
\sim \text { do ecoturismo }(22) \\
\text { projeto de } \sim(11) \\
\sim \text { econômico }(10) \\
\sim \text { de atividades de aventura } \\
\text { (8) } \\
\sim \text { regional }(6) \\
\text { programa de } \sim(6) \\
\sim \text { turístico }(6) \\
\text { promover } 0 \sim(5) \\
\text { estratégia de } \sim(4) \\
\sim \text { de atividade }(5)(4) \\
\sim \text { da Amazônia }(3) \\
\text { apoio ao } \sim(3) \\
\text { plano de } \sim(2) \\
\text { potencial de } \sim(2) \\
\sim \text { local }(2)\end{array}$ \\
\hline
\end{tabular}


ecoturísticos)

projeto de de pólos ecoturísticos (2)

$\sim$ do setor (2)

$\sim$ do município (2)

$\sim$ de/das atividades sustentáveis (2)

$\sim$ das atividades ecoturísticas (1)

$\sim$ de atividades (2)

A palavra "sustentável" foi a que apareceu o maior número de vezes junto à palavra "desenvolvimento", nos três subcorpora.

O subcorpus de agências mais uma vez apresentou um grande número de agrupamentos diferentes com a palavra "desenvolvimento". Entre os colocados, podemos destacar "promover", "pólos", "produtos" e "atividades", que se enquadram nos objetivos das agências.

A preocupação maior dos ambientalistas é com a questão da sustentabilidade, que fica clara com os colocados "sustentável", "sustentado", "econômico", o que também vai ao encontro de seus objetivos.

O governo, além de se preocupar com o "desenvolvimento" "sustentável" e "econômico" como as entidades ambientalistas, mostra também uma preocupação com o "desenvolvimento" de "atividades", inclusive de "aventura", o que o aproxima das agências de turismo. A ocorrência de duas concordâncias encontradas associa a idéia de "desenvolvimento sustentável" com "turismo de aventura".

Exemplo de concordâncias das palavras "desenvolvimento" e "aventura" do subcorpus do governo:

ESTADUAL PARA O DESENVOLVIMENTO SUSTENTÁVEL DO TURISMO DE AVEN PLANEJAMENTO Plano Nacional de Desenvolvimento Sustentável TURISMO DE AVENTURA

As próximas três palavras ocorreram apenas em dois subcorpora, agências e ambientalistas.

\section{Meio}


Embora só tenha ocorrido em dois subcorpora, a palavra "meio" forma com "ambiente" uma colocação muito forte, como podemos observar nas ocorrências encontradas.

\begin{tabular}{|l|l|}
\hline \multicolumn{1}{|c|}{ Ag } & \multicolumn{1}{|c|}{ Amb } \\
\hline meio ambiente (242) & meio ambiente (154) \\
ministério do meio ambiente (17) & ministério do meio ambiente (20) \\
preservação do meio ambiente (12) & turismo e meio ambiente (19) \\
turismo e meio ambiente (7) & secretaria do meio ambiente (10) \\
preservar o meio ambiente (6) & conservação do meio ambiente (8) \\
estudo do meio (6) & pesca e meio ambiente (5) \\
conservação do meio ambiente (5) & respeito ao meio ambiente (5) \\
impactos no meio ambiente (5) & ecoturismo e meio ambiente (4) \\
meio físico (5) & \\
instituto (brasileiro) do meio ambiente (5) & \\
secretaria do meio ambiente (4) & \\
sustentabilidade do meio ambiente (3) & \\
meio rural (3) & \\
estudos do e vivência ambiental (3) & \\
meio natural (3) & \\
meio dia (3) & \\
meio ambiente natural (2) & \\
áreas de meio ambiente (2) & \\
meio social (1) & \\
planejamento do meio ambiente (1) & \\
meio biofísico e natural (1) & \\
\hline
\end{tabular}

Todos os agrupamentos encontrados no subcorpus das entidades ambientalistas se referiam ao termo "meio ambiente", enquanto as agências também apresentam colocações diferentes como "meio físico", "meio social", "meio biofísico e natural", "estudos do ambiente e vivência ambiental", entre outras, sendo que a única colocação que foge ao assunto principal é "meio dia".

\section{Sustentável}

\begin{tabular}{|l|l|}
\hline \multicolumn{1}{|c|}{ Ag } & \multicolumn{1}{c|}{ Amb } \\
\hline turismo $~(154)$ & turismo $\sim(92)$ \\
$\sim$ sustentável (86) & desenvolvimento $\sim(76)$ \\
ecoturismo e desenvolvimento $\sim(25)$ & certificação de t. sustentável (25) \\
certificação de turismo (250 & utilizar de forma $\sim(7)$ \\
uso sustentável (14) (conservacaão e uso & conceito de turismo $\sim(6)$ \\
$\sim$ dos recursos naturais, uso da & uso $\sim(5)$ \\
biodiversidade, das águas brasileiras, de & ecológico $\sim(3)$ \\
atrativos) & \\
utilizar de forma $\sim(10)$ & \\
conceito de turismo $\sim(5)$ & \\
\hline
\end{tabular}


turismo e planejamento (4)

ecoturismo (4)

ecológico (3)

fórum de desenvolvimento $\sim(3)$

de maneira (3)

tornar-se efetivamente $\sim(3)$

gestão (3) (dos recursos naturais, dos

espaços naturais, das atividades turísticas

prática (1)

desenvolvimento de maneira (1)

Embora as agências de turismo apresentem mais agrupamentos com a palavra "sustentável", não há muitas diferenças entre as colocações. As questões relacionadas à sustentabilidade da população local e à forma de utilização dos recursos naturais fica marcada pelas formas "uso sustentável" e "utilizar de forma sustentável". A "sustentabilidade" é um dos tópicos mais importantes dos projetos de desenvolvimento turístico das entidades ambientalistas. As agências, por sua vez, não podem ignorar essas questões.

Exemplo de concordâncias dos agrupamentos "uso sustentável" e "utilizar de forma sustentável" nos subcorpora de agências e ambientalistas:

\section{Agências}

e possam promover a conservação e o uso sustentável dos recursos naturais e cultura institucional de conservar e dar uso sustentável à biodiversidade e com o propósito de desenvolvimento compatíveis com o uso sustentável dos recursos naturais, o turismo a conservação e a otimização do uso sustentável das águas brasileiras, ecossistemas de turismo mundial que aponta para o uso sustentável de atrativos no meio ambiente

O turismo de aventura utiliza de forma sustentável o patrimônio natural e cultural dos áreas naturais, que se utiliza de forma sustentável dos patrimônios natural e cultural,

"um segmento que utiliza de forma sustentável o patrimônio natural e cultural, inc em ecossistemas, utilizando-se de forma sustentável dos patrimônios naturais e cultura

\section{Ambientalistas}

de Conservação de Uso Direto ou Uso Sustentável, destinadas à conservação da institucional de conservar e dar uso sustentável à biodiversidade e com o prop de proteção integral ou de uso sustentável, públicas ou privadas, prevista turismo mundial, que aponta para o uso sustentável de atrativos no meio-ambiente que são áreas destinadas ao uso sustentável dos recursos naturais. As com 
o patrimônio natural $\S \quad$ utilizar de forma sustentável o patrimônio cultural $\S$ incentivar se permite utilizar os recursos naturais de forma sustentável, estabelecendo atividade turística que utiliza, de forma sustentável, o patrimônio natural e cultural, incen

\section{Ambiente}

Já foi mostrada a forte colocação entre as palavras "meio" e "ambiente". No entanto, aqui podemos notar as palavras que ocorrem junto dessa colocação.

\begin{tabular}{|l|l|}
\hline \multicolumn{1}{|c|}{ Ag } & \multicolumn{1}{c|}{ Amb } \\
\hline meio ambiente (244) & meio ambiente (154) \\
$\sim$ natural (18) & $\sim$ urbano (4) \\
ministério do meio ambiente (17) & $\sim$ visitado (2) \\
preservação do meio ambiente (12) & $\sim$ marinho (2) \\
meio ambiente e desenvolvimento (6) & degradar, destruição do (1) \\
secretaria do meio ambiente (4) & $\sim$ saudável, sanitário, natural, humano, rústico (1) \\
interpretação do (6) & \\
preservar o meio ambiente (5) & \\
preservar o natural (1) & \\
proteção do meio ambiente (5) & \\
proteção do (1) & \\
$\sim$ rural (2) & \\
visitante a um agradável (1) & \\
\hline
\end{tabular}

Embora a maioria das ocorrências se relacione ao agrupamento "meio ambiente", a ocorrência, embora única, de "visitante a um ambiente agradável", evidencia o interesse das agências em destacar o local a ser visitado, funcionando como um chamariz.

As entidades também falam de diferentes "ambientes", mas levantam a questão da "degradação" e "destruição" dessas áreas, além de apresentar novas colocações: "ambiente urbano", "ambiente visitado", "ambiente marinho".

\section{Atividades}

A palavra "atividades" é a única que aparece nos subcorpora de agências e governo. 


\begin{tabular}{|c|c|}
\hline $\mathbf{A g}$ & Gov \\
\hline $\begin{array}{l}\text { atividades de aventura (14) } \\
\sim \text { econômicas }(11) \\
\text { outras } \sim(11) \\
\sim \text { relacionadas }(8) \\
\sim \text { ecoturísticas }(7) \\
\sim \text { culturais }(7) \\
\text { realização das } \sim(7) \\
\sim \text { turísticas }(7) \\
\text { todas as } \sim(6) \\
\sim \text { esportivas }(6) \\
\text { I de turismo }(5) \\
\text { ocal das } \sim(5) \\
\text { principais } \sim(5) \\
\text { desenvolvimento de } \sim(4) \\
\text { ecoturismo e } \sim(4) \\
\sim \text { realizadas }(4) \\
\text { prática de } \sim(4) \\
\text { atividades de ed. ambiental }(3) \\
\text { diversas } \sim(3) \\
\text { viagens de } \sim \text { de aventura (3) } \\
\sim \text { de arvorismo }(3) \\
\text { seguintes } \sim(3) \\
\text { atividades e produtos ecoturísticos (2) } \\
\text { promover } \sim(2) \\
\sim \text { desenvolvidas }(2) \\
\text { viagens de } \sim(2) \\
\sim \text { recreativas }(2)\end{array}$ & $\begin{array}{l}\text { turísticas }(40) \\
\sim \text { de ecoturismo }(20) \\
\text { prática(s) de } \sim(20) \\
\sim \text { de turismo }(15) \\
\sim \text { econômicas } \sim(13) \\
\text { regulamentação de } \sim(11) \\
\sim \text { relacionadas }(10) \\
\sim \text { ilegais }(9) \\
\text { gestão de } \sim(6) \\
\text { segurança nas/das } \sim(6) \\
\sim \text { de visitação }(5) \\
\text { execução das } \sim(4) \\
\sim \text { previstas }(4) \\
\text { acompanhamento das } \sim(4) \\
\sim \text { de aventura }(3) \\
\sim \text { rafting }(3) \\
\sim \text { esportiva }(3) \\
\sim \text { de lazer }(2) \\
\sim \text { montanhismo }(2) \\
\sim \text { de cavalgada }(2) \\
\sim \text { de mergulho }(2) \\
\text { desenvolvimento de } \sim(2) \\
\sim \text { de planejamento }(2)\end{array}$ \\
\hline
\end{tabular}

O subcorpus de agências apresenta diversas formas de "atividades" de uma maneira mais ampla, sem descrevê-las: "de aventura", "culturais", "esportivas", "recreativas", "culturais". Elas estão organizadas de uma forma mais geral, referindose aos tipos de atividade (superordenação). A única exceção é "atividades de arvorismo", que é um subordinado de "atividades de aventura".

O governo, por sua vez, apresenta diversas formas de "atividades" de modo subordinado, ou seja, listando as atividades que fazem parte do grupo "atividades de aventura": "atividades de montanhismo", "de mergulho" e "de rafting", por exemplo. Além disso, o governo mostra o interesse no desenvolvimento e planejamento das atividades com as palavras "regulamentação", "gestão", "segurança", "visitação", "execução", "acompanhamento", "planejamento".

Isso não significa que palavras como "rafting", "rapel", "montanhismo", entre outras, não ocorram no subcorpus das agências. Apenas indica que essas ocorrências aparecem diluídas nos textos. 
As próximas três palavras foram encontradas entre as primeiras nos subcorpora de ambientalistas e do governo.

\section{Conservação}

A ocorrência da palavra "conservação" entre as primeiras dez palavras-chave evidencia a preocupação dos ambientalistas e do governo de exercer seu papel, que é o de conservação das áreas naturais.

\begin{tabular}{|c|c|}
\hline Amb & Gov \\
\hline $\begin{array}{l}\text { unidades de } \sim(34) \\
\sim \text { da biodiversidade }(13) \\
\sim \text { das áreas naturais }(10) \\
\sim \text { do meio ambiente }(8) \\
\sim \text { da natureza }(8) \\
\sim \text { dos recursos naturais }(8) \\
\sim \text { ambiental }(5) \\
\sim \text { e desenvolvimento }(4) \\
\sim \text { do patrimônio }(3) \\
\sim \text { e uso }(3) \\
\text { atividades de } \sim(2) \\
\text { ecoturismo e } \sim(2)\end{array}$ & $\begin{array}{l}\text { unidade }(\mathrm{s}) \text { de } \sim(136) \\
\text { unidades de } \sim \text { do estado (13) } \\
\sim \text { ambiental }(9) \\
\sim \text { da mata atlântica }(8) \\
\sim \text { das áreas }(6) \\
\sim \text { da natureza }(6) \\
\sim \text { da biodiversidade }(5) \\
\sim \text { dos recursos ambientais }(4) \\
\sim \text { do meio ambiente }(3) \\
\sim \text { e uso }(3) \\
\sim \text { do patrimônio }(2) \\
\sim \text { dos parques }(1)\end{array}$ \\
\hline
\end{tabular}

As unidades encontradas mostram uma sintonia entre os interesses das entidades ambientalistas e o governo. As maiores ocorrências se referem ao agrupamento "unidade(s) de conservação".

Se analisarmos o subcorpus de agências, certamente encontraremos a ocorrência da palavra conservação, porém a freqüência não é significativa a ponto de aparecer entre as primeiras palavras-chave, o que pode indicar que "conservação" não é um dos objetivos das agências.

\section{Projeto}

O desenvolvimento de "projetos" é uma das principais atividades das entidades ambientalistas e também do governo, o que é comprovado pela ocorrência dessa palavra nesses dois subcorpora entre as primeiras dez palavraschave. 


\begin{tabular}{|c|c|}
\hline Amb & Gov \\
\hline $\begin{array}{l}\text { tamar }(7) \\
\sim \text { de ecoturismo }(4) \\
\sim \text { ecoturístico }(3) \\
\sim \text { ambiental }(2) \\
\text { descrição do } \sim(2)\end{array}$ & $\begin{array}{l}\text { componentes do (9) } \\
\text { execução do/de } \sim(9) \\
\sim \text { de desenvolvimento }(7) \\
\text { gestão ambiental do (6) } \\
\sim \text { de lei (5) } \\
\text { atividades e (4) } \\
\text { implantação do (4) } \\
\text { descrição do (4) } \\
\text { impactos do (3) } \\
\sim \text { de ecoturismo (3) } \\
\text { pilotos do (3) } \\
\text { resultados do (2) } \\
\sim \text { de elaboração (2) } \\
\text { avaliação do (2) } \\
\text { sustentabilidade do (2) } \\
\text { benefícios do (1) }\end{array}$ \\
\hline
\end{tabular}

Embora a preocupação com "projeto" seja importante nos dois subcorpora, o governo vai além ao destacar questões relacionadas às leis, implantação, execução, avaliação e resultados, o que está dentro de seu papel de desenvolver e implantar projetos e avaliar os resultados e os impactos causados. A meta do governo é mais administrativa e burocrática.

As palavras a seguir foram encontradas em apenas um dos subcorpora. Iniciaremos com as palavras que ocorreram entre as primeiras no subcorpus das agências de turismo

\section{Região}

\begin{tabular}{|l|}
\hline \multicolumn{1}{|c|}{ Ag } \\
\hline papel do MPE na $\sim(10)$ \\
desenvolvimento da $\sim(4)$ \\
(recursos) naturais da $\sim(6)$ \\
turismo na $\sim(5)$ \\
clima da $\sim(5)$ \\
flora da $\sim(5)$ \\
fauna da $\sim(4)$ \\
produto $($ s) da $\sim(4)$ \\
moradores da $\sim(4)$ \\
ecoturismo na $\sim(3)$ \\
potencialidades da $\sim(3)$ \\
recursos da região $(3)$ \\
patrimônio natural da região (2) \\
biodiversidade da $\sim(2)$ \\
patrimônio natural e cultural da $\sim(2)$ \\
\hline
\end{tabular}

\section{Naturais}

\begin{tabular}{|l|}
\hline \multicolumn{1}{|c|}{ Ag } \\
\hline recursos $\sim(104)$ \\
áreas $\sim(35)$ \\
ambientes $\sim(31)$ \\
belezas $\sim(19)$ \\
atrativos $\sim(16)$ \\
$\sim$ e culturais $(15)$ \\
paisagens $\sim(7)$ \\
processos $\sim(7)$ \\
piscinas $\sim(7)$ \\
reservas $\sim(6)$ \\
recursos $\sim$ renováveis $(5)$ \\
$\sim$ e históricos (5) \\
condições $\sim(3)$ \\
ecossistemas $\sim(2)$ \\
valores $\sim(2)$ \\
\hline
\end{tabular}


desenvolvimento sustentável da (2)

conservação da (2)

viabilidade econômica da (2)

pesca econômica da região (1)

atividade econômica da (1)

economia sustentável da (1)

desenvolvimento econômico da (1) conservação dos recursos (1)

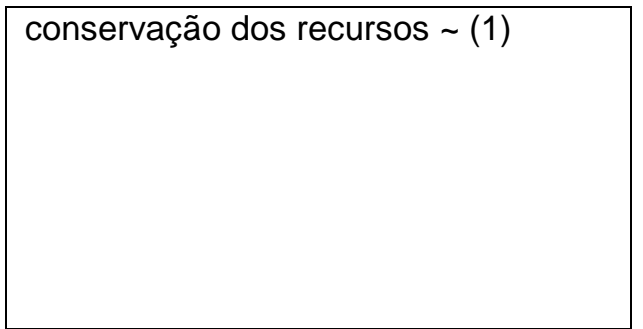

Como já foi mencionado anteriormente, as agências de turismo têm o interesse de divulgar formas variadas que possam tornar seu produto mais interessante. A divulgação das "belezas", "atrativos" e "paisagens" "naturais" é muito importante para atrair turistas. Além disso, os pacotes são apresentados por região e a descrição do que se pode encontrar em cada uma delas é fundamental para as agências. Os agrupamentos encontrados deixam clara a intenção de valorização, tanto das diversas "regiões", quanto dos recursos "naturais", no sentido de tornar o produto ecoturístico único e especial.

A única palavra que apareceu somente no subcorpus das entidades ambientalistas foi "natureza".

\section{Natureza}

\begin{tabular}{|l|}
\hline \multicolumn{1}{|c|}{ Amb } \\
\hline homem c/ a $\sim(\mathrm{e} a \sim)(9)$ \\
conservação da $\sim(8)$ \\
respeito pela $\sim(5)$ \\
consumo da $\sim(3)$ \\
turismo na $\sim(3)$ \\
\hline
\end{tabular}

Essa única palavra mostra o tema central da preocupação que as entidades têm: a "natureza", com as questões que são importantes para elas, como o "respeito pela natureza", a "conservação da natureza", a interação do "homem com a natureza" e o resultado das atividades ecoturísticas com o "consumo da natureza".

Três palavras ocorreram entre as primeiras no subcorpus dos órgãos governamentais.

\section{Parques}

Visitação

Aventura 

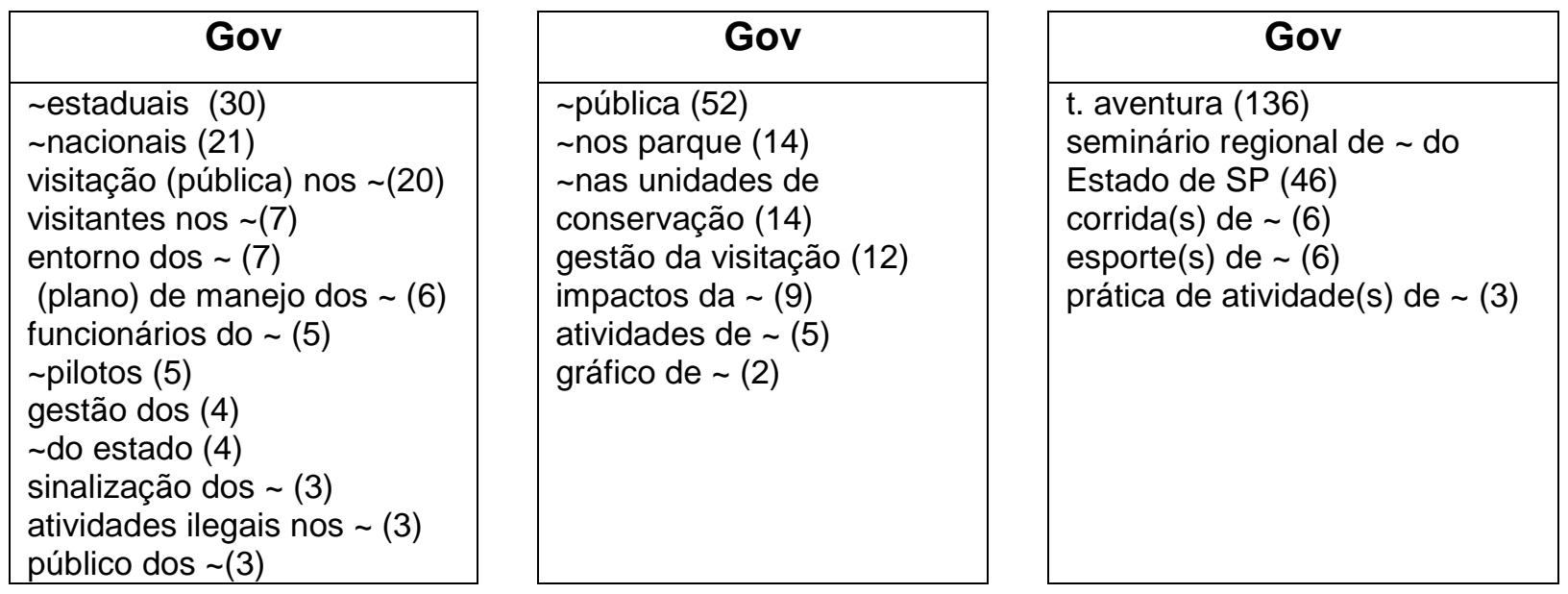

O governo tem o objetivo de cuidar das áreas protegidas e incentivar e administrar a visitação nessas áreas. As ocorrências vão ao encontro do papel do governo. No entanto, era de se esperar que a palavra "aventura" ocorresse no subcorpus das agências, e não no do governo.

Já foi mencionado que uma parte dessas ocorrências refere-se ao "Seminário Regional de Aventura do Estado de São Paulo", uma iniciativa do governo com o objetivo de divulgar a prática dessas atividades e a necessidade de uma consciência com relação à segurança que elas requerem. $O$ interesse do governo em divulgar atividades de aventura pode justificar-se pelo fato de que, no Brasil, muitas pessoas não consideram interessante a viagem a um local para simples observação e contato com a natureza.

A palavra "visitação" dá mais formalidade ao termo e aparece em agrupamentos que demonstram a preocupação com o impacto causado às áreas naturais pelos visitantes, tanto que há um cuidado com a "gestão da visitação", os "impactos da visitação" e até mesmo "os gráficos de visitação", que indicam a necessidade de um controle de visitas nos parques e unidades de conservação.

É interessante notar que as listas de ocorrências das agências de turismo, quando comparadas com as outras, sempre oferecem um número maior de agrupamentos, o que faz supor a necessidade de divulgar um grande volume de informações e de inovar para atrair cada vez mais turistas. 
As primeiras palavras das listas de palavras-chave são realmente representantes das idéias e objetivos de cada área com relação ao assunto ecoturismo, com a exceção da palavra "aventura" no subcorpus do governo, o que pode indicar a falta de uma clareza maior com relação ao que são atividades ecoturísticas e atividades de aventura. O simples fato de uma atividade ser desenvolvida em uma área natural não significa que ela seja ecoturística, até mesmo porque os impactos que as atividades de aventura causam fogem do conceito de ecoturismo e preservação ambiental.

O governo parece estar dividido entre as duas áreas, de um lado precisa se preocupar com a conservação e preservação do ambiente, o que vai ao encontro dos objetivos dos ambientalistas, por outro, precisa do turismo, uma indústria altamente rentável, para trazer mais divisas para o país.

Apresentaremos agora o mesmo processo com as palavras em inglês.

\subsubsection{Palavras em inglês}

As palavras abaixo foram extraídas da lista de palavras-chave com o número de ocorrências de cada uma no corpus em inglês.

\begin{tabular}{|l|l|l|l|l|l|l|}
\hline No. & \multicolumn{1}{|c|}{ Ag } & freq. & \multicolumn{1}{c|}{ Amb } & freq. & \multicolumn{1}{c|}{ Gov } & \multicolumn{1}{c|}{ freq. } \\
\hline 1 & ecotourism & 93 & tourism & 523 & tourism & 297 \\
2 & tours & 129 & ecotourism & 181 & $\begin{array}{l}\text { submitter } \\
\text { (submitters) }\end{array}$ & 178 \\
& & & & & 139 \\
3 & tourism & 114 & conservation & 220 & native & 303 \\
4 & eco & 83 & sustainable & 125 & forest/forests & $337 / 214$ \\
5 & ecotours & 47 & visitor (visitors) & $141 / 149$ & sustainable & 212 \\
6 & dolphins & 68 & species & 197 & indigenous & 202 \\
7 & track & 97 & environmental & 155 & biodiversity & 140 \\
8 & natural & 114 & sustainability & 50 & conservation & 243 \\
9 & native & 70 & overfished & 33 & ecotourism & 111 \\
10 & conservation & 74 & tours & 64 & plants & 222 \\
\hline
\end{tabular}

Como aconteceu no corpus em português, há palavras que ocorreram em mais de um subcorpus. No entanto, o número de ocorrências iguais é bastante diferente do que ocorreu em português, com um número maior de palavras únicas 
de cada subcorpus. A lista não apresenta casos de palavras que ocorreram nos três subcorpora na mesma posição.

Palavras que ocorreram nos três subcorpora: ecotourism, tourism, conservation.

- Palavras que ocorreram em agências e ambientalistas: tours.

- Palavras que ocorreram em agências e governo: native.

- Palavras que ocorreram em ambientalistas e governo: sustainable.

As palavras que ocorrem em apenas um dos subcorpora são:

- Ag: eco, ecotours, dolphins, track, natural.

- Amb: visitor/visitors, species, environmental, overfished, sustainability.

- Gov: submitter/submitters, forest/forests, indigenous, biodiversity, plants.

Iniciaremos com as palavras que ocorreram nos três subcorpora: ecotourism, tourism e conservation.

\section{Ecotourism}

\begin{tabular}{|c|c|c|}
\hline $\mathbf{A g}$ & Amb & Gov \\
\hline $\begin{array}{l}\sim \text { operators } 6 \\
\sim \text { destination(s) } 4 \\
\sim \text { policies } 4 \\
\sim \text { activities } 2 \\
\sim \text { attractions } 2 \\
\text { local } ~ \text { guides } 1 \\
\sim \text { benefits } 1 \\
\sim \text { adventure } 1 \\
\sim \text { industry } 1 \\
\sim \text { principles } 1 \\
\sim \text { programme } 1 \\
\sim \text { wilderness areas } 1 \\
\sim \text { travellers } 1 \\
\sim \text { businesses } 1\end{array}$ & $\begin{array}{l}\text { operations } 12 \\
\sim \text { visitor } 9 \\
\sim \text { development } 7 \\
\sim \text { sites } 4 \\
\sim \text { experiences } 3 \\
\sim \text { discourse } 1 \\
\sim \text { attractions } 1\end{array}$ & $\begin{array}{l}\sim \text { sector } 8 \\
\sim \text { businesses } 7 \\
\text { successful } 5 \\
\sim \text { ventures } 5 \\
\text { international } \sim 2\end{array}$ \\
\hline
\end{tabular}

Assim como em português, as agências também apresentam uma preocupação em divulgar as atrações e as possibilidades de atividades no local 
(ecotourism activities, ecotourism attractions, ecotourism adventure, ecotourism wilderness áreas). No entanto, essas atividades não se relacionam obrigatoriamente ao turismo de aventura, cujo termo ocorreu apenas uma vez junto da palavra ecotourism.

No entanto, o número de ocorrências foi bem menor quando comparado às ocorrências em português.

\section{Tourism}

A palavra tourism também apareceu nos três subcorpora, não apenas em inglês, mas também e português ("turismo").

\begin{tabular}{|c|c|c|}
\hline $\mathbf{A g}$ & Amb & Gov \\
\hline $\begin{array}{l}\text { eco- } 37 \\
\text { adventure } ~ 20 \\
\text { in NZ } 14 \\
\text { sustainable } \sim 6 \\
\text { impacts of } \sim 5\end{array}$ & 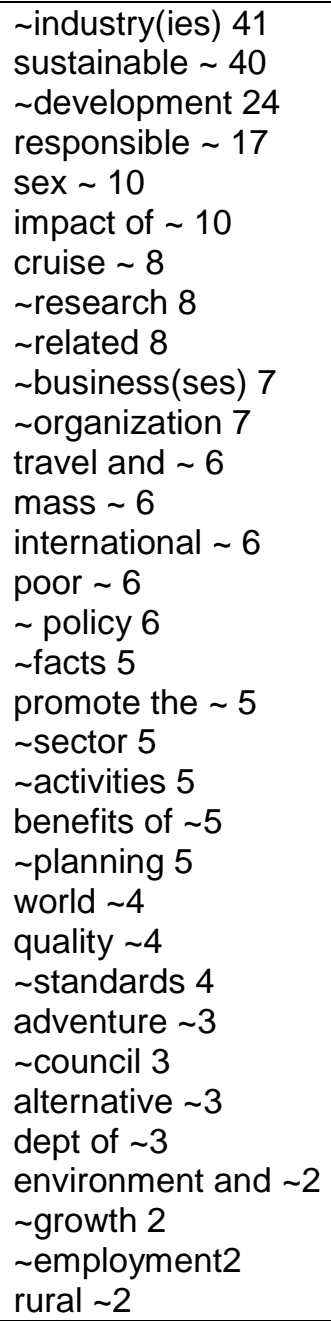 & $\begin{array}{l}\text { industry } 25 \\
\text { sustainable } \sim 19 \\
\sim \text { strategy } 19 \\
\sim \text { research } 16 \\
\sim \text { sector } 14 \\
\text { ministry of } \sim 13 \\
\sim \text { operators } 8 \\
\sim \text { products } 7 \\
\text { adventure } \sim 6 \\
\text { eco } \sim 6 \\
\sim \text { activity } 5 \\
\text { minister of } \sim 4 \\
\text { international } ~ 4 \\
\sim \text { minister } 3 \\
\sim \text { growth } 3 \\
\text { benefits of } \sim 3 \\
\text { regional } \sim 3 \\
\sim \text { business } 3 \\
\text { conservation } \sim 2 \\
\sim \text { organization } 3 \\
\sim \text { projects } 3 \\
\text { quality } \sim 2 \\
\text { success of } \sim 2 \\
\text { world } \sim 2 \\
\sim \text { certification } 2 \\
\sim \text { policy } 1 \\
\sim \text { services } 1\end{array}$ \\
\hline
\end{tabular}




\begin{tabular}{|l|l|l|}
\hline & $\begin{array}{l}\text { cultural } ~ 1 \\
\sim \text { management 1 } \\
\text { environmental } \sim 1 \\
\\
\sim \text { project 1 }\end{array}$ & \\
\hline
\end{tabular}

As agências de turismo apresentaram poucas ocorrências com a palavra "turismo". Uma análise das ocorrências da forma adventure tourism mostrou que atividades como whale watching (observação de baleias) e hiking aparecem como formas de turismo de aventura.

Parece haver diferenças mais claras entre ecotourism e adventure tourism.Ao contrário do português, as entidades ambientalistas apresentaram um número bem maior de agrupamentos com a palavra tourism. No entanto, nem todas indicam tipos de turismo.

Destacamos aqui o aparecimento de duas formas de turismo - sex tourism e poor tourism - que fogem do assunto ecoturismo. A primeira forma aparece em textos que, além de falar sobre ecoturismo, buscam divulgar os problemas causados em certas regiões do mundo com formas de turismo inadequadas, como o turismo sexual.

Exemplo de concordâncias do agrupamento sex tourism no subcorpus de ambientalistas:

bars, restaurants and on the streets. 6 Sex tourism results in high rates of sexually million children are exploited through child sex tourism each year. In a study of 100 school

However, tourism (such as sex tourism and war tourism) can also have a negative of children and is illegal. Although child sex tourism mainly occurs in developing countries (such ignore, or even covertly promote, sex tourism. Child sex tourism: Child sex tourism exploit STDs (including HIV/AIDS) internationally. Sex Tourism can lead to the trafficking of women and from local women, men, and children. Sex tourism takes advantage of the fact that in some

A outra forma denomina uma atividade relacionada ao desenvolvimento do turismo e sustentabilidade. O objetivo do poor tourism é diminuir a pobreza das populações próximas a áreas turísticas, buscando envolvê-las em atividades que possam melhorar a condição de vida dessas pessoas, como produção de 
artesanato, comidas típicas e transporte, e a contratação delas em pousadas, hotéis, restaurantes e outras empresas ligadas ao setor de turismo.

Exemplo de concordâncias do agrupamento poor tourism no subcorpus de ambientalistas:

tourism development. The aims of pro poor tourism range from increasing local employment continue making money. Pro Poor Tourism: Pro poor tourism is set up in developing making processes. The focus of pro poor tourism is on ensuring that poor people cultural tourism, and ecotourism (including pro poor tourism, agro tourism, community based tourism, and

Do mesmo modo como foi apresentado em português, optamos por apresentar as colocações com a palavra tourism que indiquem formas de turismo.

\begin{tabular}{|c|c|c|}
\hline $\mathrm{Ag}$ & Amb & Gov \\
\hline $\begin{array}{l}\text { eco-tourism } \\
\text { adventure tourism } \\
\text { sustainable tourism }\end{array}$ & $\begin{array}{l}\text { sustainable tourism } \\
\text { responsible tourism } \\
\text { sex tourism } \\
\text { cruise tourism } \\
\text { mass tourism } \\
\text { international tourism } \\
\text { poor tourism } \\
\text { world tourism } \\
\text { adventure tourism } \\
\text { alternative tourism } \\
\text { rural tourism } \\
\text { environmental tourism } \\
\text { cultural tourism }\end{array}$ & $\begin{array}{l}\text { sustainable tourism } \\
\text { adventure tourism } \\
\text { eco tourism } \\
\text { international tourism } \\
\text { world tourism }\end{array}$ \\
\hline
\end{tabular}

Podemos notar que há uma grande diferença entre as colocações encontradas em português e em inglês, principalmente com relação às agências de turismo, que apresentam apenas três colocações em inglês: eco-tourism, adventure tourism e sustainable tourism.

A última palavra que apareceu nos três subcorpora foi conservation, que, em português, não fazia parte das palavras das agências.

\section{Conservation}




\begin{tabular}{|c|c|c|}
\hline $\mathrm{Ag}$ & Amb & Gov \\
\hline $\begin{array}{l}\text { Dept of } \sim 9 \\
\sim \text { of the environment } 3 \\
\sim \text { project(s) } 3 \\
\sim \text { group } 2 \\
\sim \text { programme } \\
\sim \text { education } 1\end{array}$ & $\begin{array}{l}\text { dept of } \sim 6 \\
\sim \text { management } 7 \\
\text { biodiversity } \sim \\
\text { whale } \sim \\
\text { nature } \sim \\
\sim \text { advocacy } 3 \\
\sim \text { project } 3 \\
\sim \text { volunteers } 3 \\
\sim \text { area(s) } 2 \\
\text { national } \sim 2 \\
\sim \text { issues } 2 \\
\text { wildlife } \sim 1 \\
\text { environmental } \sim 1\end{array}$ & $\begin{array}{l}\text { dept of } \sim 34 \\
\sim \text { act } 13 \\
\text { forest } \sim 12 \\
\sim \text { of biodiversity } 11 \\
\sim \text { of sustainable } 8 \\
\sim \text { estate } 8 \\
\sim \text { and preservation } 7 \\
\sim \text { work } 7 \\
\sim \text { value(s) } 6 \\
\text { biodiversity } \sim 5 \\
\text { contribute(ing) to } \sim 5 \\
\text { management of } \sim 5 \\
\text { involved in } \sim 4 \\
\sim \text { issues } 4 \\
\sim \text { land } 3 \\
\text { nature } \sim 2 \\
\text { local } \sim 2\end{array}$ \\
\hline
\end{tabular}

Neste caso, encontramos basicamente o mesmo interesse com relação à conservação. As agências falam do assunto mais superficialmente, com um número baixo de ocorrências, com exceção de Department of Conservation, que aparece em primeiro lugar nos três subcorpora.

As entidades ambientalistas e o governo, que são responsáveis pela conservação, apresentam um número maior de ocorrências e de colocações diferentes.

A próxima palavra, tours, apareceu em dois subcorpora, sendo a única palavra comum entre as agências e os ambientalistas.

\section{Tours}

\begin{tabular}{|l|l|}
\hline \multicolumn{1}{|c|}{ Ag } & \multicolumn{1}{c|}{ Amb } \\
\hline tours in NZ 14 & nature 6 \\
eco 10 & Garden tours 5 \\
wildlife 7 & wildlife 2 \\
guided (birdwatching) 7 & \\
birdwatching 4 & \\
nature 3 & \\
personalized 3 & \\
day 3 & \\
kiwi 2 & \\
watching 2 & \\
\hline
\end{tabular}


As agências destacam algumas atividades importantes da Nova Zelândia, como a observação de pássaros, incluindo o kiwi, que é o pássaro-símbolo do país.

Podemos notar que há um detalhamento maior das atividades com as palavras: personalized tour, kiwi tour, watching tour, birdwatching tour, guided birdwatching tour, wildlife tour. Esse detalhamento resulta do interesse das agências em exibir seus produtos para chamar a atenção do turista.

A palavra native ocorreu apenas nos subcorpora das agências e do governo.

\section{Native}

\begin{tabular}{|c|c|}
\hline $\mathbf{A g}$ & Gov \\
\hline $\begin{array}{l}\text { forest(s) } 7 \\
\sim \text { flora and fauna } 7 \\
\sim \text { birds } 6 \\
\sim \text { bush } 6 \\
\sim \text { species } 5 \\
\sim \text { trees } 5 \\
\sim \text { plants } 4 \\
\sim \text { wildlife } 4\end{array}$ & $\begin{array}{l}\sim \text { plants } 173 \\
\text { use }(\text { s/ing) } \sim \text { plants } 29 \\
\text { role(s) of } \sim 19 \\
\sim \text { vegetation } 17 \\
\sim \text { trees } 16 \\
\sim \text { species } 15 \\
\sim \text { plant } 15 \\
\sim \text { forest(s) } 13 \\
\sim \text { bush } 11 \\
\text { planting } \sim \text { the planting of } \sim 7 \\
\text { areas of } \sim 7 \\
\text { value of } \sim 7 \\
\text { protect } \sim 5 \\
\sim \text { timber } 5 \\
\text { growing (of) } \sim 4 \\
\text { management of } \sim 4 \\
\text { managing } \sim 4 \\
\text { establishment of } \sim 3 \\
\sim \text { ecosystems } 3 \\
\text { promote } \sim 3 \\
\sim \text { planting } 3 \\
\text { protection of } \sim 3 \\
\sim \text { products } 3 \\
\sim \text { forestry } 1\end{array}$ \\
\hline
\end{tabular}

As agências buscam mostrar a diversidade e riqueza do país em todas as colocações, divulgando as maravilhas do lugar, enquanto o governo busca, além de promover a diversidade, tratar do seu gerenciamento e proteção, o que é parte do seu papel.

\section{Sustainable}


Sustainable ocorreu nos subcorpora de ambientalistas e do governo. Essa palavra reflete a preocupação que as duas áreas têm com a questão da sustentabilidade.

\begin{tabular}{|c|c|}
\hline Amb & Gov \\
\hline $\begin{array}{l}\text { tourism } 36 \\
\sim \text { development } 13 \\
\sim \text { use } 8 \\
\sim \text { business } 5 \\
\text { principles of } \sim \text { development } 4 \\
\text { industries } 1\end{array}$ & $\begin{array}{l}\sim \text { (tourism) management83 } \\
\sim \text { forest } 52 \\
\sim \text { tourism } 19 \\
\sim \text { use } 19 \\
\sim \text { development } 18 \\
\text { ecologically } \sim 16 \\
\text { promote(ing) } \sim 12 \\
\sim \text { land } 10 \\
\text { achieve }(\text { ing) } \sim 8 \\
\text { conservation of } \sim 8 \\
\sim \text { indigenous } 6 \\
\sim \text { tourism industry } 5 \\
\sim \text { harvesting } 5 \\
\sim \text { production4 } \\
\sim \text { resource }(s) 4 \\
\sim \text { uses } 4 \text { (s) } \\
\sim \text { timber } 2 \\
\sim \text { natural } 2 \\
\sim \text { industry } 2 \\
\end{array}$ \\
\hline
\end{tabular}

Assim como revela a palavra native, o governo se preocupa com a proteção, o gerenciamento e a conservação da natureza de modo sustentável, apresentando, por isso, um vocabulário mais amplo do que as entidades ambientalistas, mais focadas na questão do turismo e desenvolvimento.

A partir deste ponto apresentaremos as palavras que ocorreram em um só subcorpus. Das dez palavras de cada lista, cinco (50\%) foram exclusivas de cada subcorpus.

Iniciaremos com as palavras que ocorreram apenas no subcorpus das agências de viagens: eco, ecotorus, natural, track e dolphins.

\section{Eco}

\begin{tabular}{|l|}
\hline \multicolumn{1}{|c|}{$\mathbf{A g}$} \\
\hline tourism 24 \\
nz eco tourism 10 \\
eco-tours 17 \\
eco-friendly (transport, business, \\
products, outboard motor) 6 \\
\hline
\end{tabular}

Ecotours

\begin{tabular}{|l|}
\hline \multicolumn{1}{|c|}{ Ag } \\
\hline$\sim$ prices 1 \\
local $\sim$ guides 1 \\
variety of $\sim$ available 1 \\
wildlife $\sim 1$
\end{tabular}

Natural

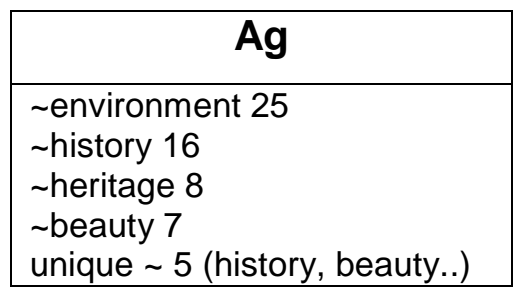


eco-cruises 2

eco-sustainable practice 1

eco strategy 1

eco system 1

Track

\begin{tabular}{|l|}
\hline \multicolumn{1}{|c|}{$\mathbf{A g}$} \\
\hline Inland Pack $\sim 10$ \\
walking along the $\sim 9$ \\
distance of the $\sim 9$ \\
Pororari River $\sim 5$ \\
the sealed $\sim 1$ \\
walking $\sim 2$ \\
\hline
\end{tabular}

Dolphins

\begin{tabular}{|l|}
\hline \multicolumn{1}{|c|}{$\mathbf{A g}$} \\
\hline swim $($ ming) with $\sim 6$ \\
dusky $\sim 4$ \\
common $\sim 4$ \\
bottlenose $\sim 3$ \\
seals and $\sim 2$ \\
\hline
\end{tabular}

Além de aparecer com tourism, a palavra eco é também utilizada para divulgar práticas e designar atividades como eco-friendly, eco-cruise, ecosustainable practice, eco-strategy.

As palavras que aparecem somente na lista das agências mostram a preocupação em divulgar as possibilidades de atividades ecoturísticas que podem ser desenvolvidas na Nova Zelândia. A palavra natural ("natural") também só apareceu na lista de agências em português, com o mesmo objetivo de destacar as belezas e a riqueza natural da região e, conseqüentemente, atrair turistas que se interessem em conhecer e experienciar atividades únicas no país. A utilização das palavras beauty, unique, heritage, phenomena, history reforça essa idéia.

As ocorrências das palavras track e dolphins estão ligadas às atividades que podem ser desenvolvidas na região. Mais uma vez, estão relacionadas à divulgação, para o turista, das diversas atividades ligadas à natureza que podem ser desenvolvidas. A palavra dolphin aparece com o verbo swim, designando uma importante atividade ecoturística.

As palavras visitor(s), species, environmental, overfished e sustainability apareceram apenas no subcorpus das entidades ambientalistas.

Visitor/visitors

\section{Species}




\begin{tabular}{|l|}
\hline \multicolumn{1}{|c|}{ Amb } \\
\hline experience(s) 38 \\
ecotourism 9 \\
international 9 \\
$\sim$ expenditure 8 \\
$\sim$ interpretation 7 \\
overseas 6 \\
$\sim$ numbers 5 \\
information 3 \\
$\sim$ behaviour 3 \\
$\sim$ centres 3 \\
$\sim$ values 2 \\
domestic $~ 2$ \\
environmental $~ 1$ \\
\hline
\end{tabular}

\section{Environmental}

\begin{tabular}{|c|}
\hline Amb \\
\hline $\begin{array}{l}\text { issues } 21 \\
\sim \text { values } 19 \\
\sim \text { care } 7 \\
\sim \text { education } 6 \\
\sim \text { groups } \sim 5 \\
\text { pro } \\
\sim \text { behavior/attitudes/outcomes } 5 \\
\text { challenging (the) } \sim \text { values } 5 \\
\sim \text { management } \sim 4 \\
\sim \text { code } 4 \\
\sim \text { sustainability } 4 \\
\sim \text { behavior } 3 \\
\text { conservation } \sim 2\end{array}$ \\
\hline
\end{tabular}

\begin{tabular}{|c|}
\hline Amb \\
\hline $\begin{array}{l}\text { migratory } \sim 7 \\
\text { introduced } \sim 5 \\
\text { marine } \sim 5 \\
\text { bird } \sim 4 \\
\text { reef } \sim 4 \\
\text { sedentary } \sim 3 \\
\text { Atlantic } \sim 2 \\
\text { native } \sim 2 \\
\text { pelagic } \sim 2 \\
\sim \text { lists 1 } \\
\text { benefit the } \sim 1 \\
\sim \text { movement } 1\end{array}$ \\
\hline
\end{tabular}

\begin{tabular}{|c|c|}
\hline Overfished & Sustainability \\
\hline Amb & Amb \\
\hline $\begin{array}{l}\text { considered } \sim 7 \\
\text { stocks are/were } \sim 7 \\
\text { the } \sim \text { stock } 3\end{array}$ & $\begin{array}{l}\text { environmental } \sim 4 \\
\text { attitudes towards } \sim 4 \\
\text { sustainability issues } 3 \\
\text { social } \sim 3\end{array}$ \\
\hline
\end{tabular}

No corpus em português, a palavra "visitação" apareceu no subcorpus do governo voltada para a questão do controle e freqüência das visitas às unidades de conservação. Em inglês, temos a presença de visitor e sua forma no plural, visitors, entre as primeiras dez palavras do subcorpus das entidades ambientalistas. Além de falar das experiências que o visitante vai vivenciar, há a preocupação com o comportamento e o número de visitantes nas áreas naturais, demonstrando um cuidado com o meio ambiente.

As entidades ambientalistas também mostram a preocupação com o meio ambiente ao falar das espécies, do comportamento e da educação das pessoas, dos problemas com a pesca predatória, do equilíbrio da natureza e da necessidade de uma atitude voltada para a sustentabilidade, o que resulta em proteção para as 
áreas e desenvolvimento social. Todas as palavras refletem bem os objetivos dos ambientalistas.

Apresentaremos, agora, as últimas cinco palavras, que ocorreram apenas no subcorpus dos órgãos governamentais.

Submitter/submitters

\begin{tabular}{|c|}
\hline Gov \\
\hline $\begin{array}{l}\text { (a number of ) } \\
\sim \text { stated } 29 \\
\sim \text { expressed } 31 \\
\sim \text { discussed } 21 \\
\sim \text { commented } 17 \\
\sim \text { suggested } 14 \\
\sim \text { pointed } 12 \\
\sim \text { proposed } 10 \\
\sim \text { raised } 8 \\
\sim \text { concluded } 8 \\
\sim \text { considered } 6 \\
\sim \text { continued } 6 \\
\sim \text { questioned } 6 \\
\sim \text { noted } 5\end{array}$ \\
\hline
\end{tabular}

Forest/forests

\begin{tabular}{|l|}
\hline \multicolumn{1}{|c|}{ Gov } \\
\hline$\sim$ products 94 \\
$\sim$ management 73 \\
sustainable $~ 52$ \\
natural $\sim 39$ \\
indigenous $\sim 34$ \\
trade of $\sim$ products 32 \\
$\sim$ principle(s) 18 \\
tropical $\sim 18$ \\
native $\sim 13$ \\
$\sim$ conservation 12 \\
competitiveness of (temperate) $\sim$ products 10 \\
temperate $\sim 10$ \\
managed $\sim 10$ \\
value of $\sim 6$ \\
$\sim$ research 6 \\
promoting the $\sim 5$ \\
access to $\sim 4$ \\
promote sustainable $\sim 4$ \\
$\sim$ certification 4 \\
ecosystems $\sim 4$ \\
$\sim$ parks 3 \\
$\sim$ harvesting 2 \\
labeling the $\sim 2$ \\
wood $\sim 2$ \\
processed $\sim 2$ \\
environment of $\sim 2$ \\
\hline
\end{tabular}

\section{Plants}

\begin{tabular}{|l|}
\hline \multicolumn{1}{|c|}{ Gov } \\
\hline native plants 173 \\
indigenous $\sim 13$ \\
exotic $\sim 5$ \\
protect $X \sim 5$ \\
\\
\end{tabular}

\begin{tabular}{|l|}
\hline \multicolumn{1}{|c|}{ Gov } \\
\hline forest 44 \\
$\sim$ forestry 29 \\
$\sim$ species 21 \\
$\sim$ biodiversity21 \\
$\sim$ vegetation 19 \\
$\sim$ plant(s) 18 \\
$\sim$ flora 14 \\
research of $\sim 8$ \\
$\sim$ ecosystems 7 \\
\hline
\end{tabular}

\begin{tabular}{|l|}
\hline \multicolumn{1}{|c|}{ Gov } \\
\hline indigenous $\sim 21$ \\
conservation of $\sim 11$ \\
$\sim$ conservation 7 \\
$\sim$ strategy 7 \\
$\sim$ management 4 \\
$\sim$ goals 3 \\
quality of $\sim 3$ \\
$\sim$ landscape2 \\
protection of $\sim 2$ \\
\hline
\end{tabular}


sustainable $\sim 6$

$\sim$ ecology 4

timber 2

protection of $\sim 2$

values of $\sim 2$
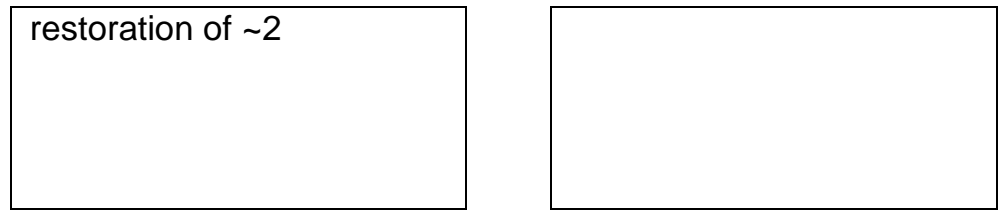

A palavra submitter e sua forma no plural, submitters, provavelmente aparecem entre as primeiras devido ao possível envolvimento da comunidade em relação às questões ecoturística. As colocações indicam as atitudes dessas pessoas ao expressar, discutir, comentar, propor, levantar questões, questionar, considerar e concluir, que reforçam a idéia de participação.

As outras palavras mostram a grande preocupação com o ambiente e estão fortemente relacionadas umas com as outras. Há um grande interesse em divulgar a biodiversidade da Nova Zelândia, sua vegetação nativa e a necessidade de proteção dessa diversidade.

Pudemos perceber que as palavras de cada lista, nas duas línguas, são representantes dos objetivos e interesses de cada uma das áreas - agências de turismo, entidades ambientalistas e órgãos governamentais.

Quando uma palavra resulta em colocados e clusters diferentes do esperado, podemos recorrer às concordâncias, que nos oferecem o contexto e esclarecem nossas dúvidas quanto ao seu significado e uso.

Os resultados obtidos nos oferecem um panorama da forma como cada uma das áreas divulga não apenas as suas idéias com relação ao ecoturismo, mas também o seu papel de atuação, como no caso do governo e dos ambientalistas.

Além disso, o levantamento das ocorrências e a lista de colocados e agrupamentos (clusters) são uma forma de extrair os candidatos a termo da área de ecoturismo, sendo muito útil na produção de um glossário, o que abre as portas para uma continuação da pesquisa em busca da obtenção e extração desses termos.

Nosso próximo passo é o cruzamento das listas de palavras-chave de cada uma das áreas envolvidas, para obtermos as palavras mais significativas entre elas.

As listas completas desse cruzamento estão nos Anexos G e H. 


\subsection{Keywords entre os subcorpora}

O Anexo $G$ contém a lista completa de palavras resultantes do cruzamento das palavras-chave entre os subcorpora em português, enquanto $\circ$ Anexo $\mathrm{H}$ apresenta as listas em inglês.

No capítulo 2, Metodologia, apresentamos como as listas de palavras-chave foram nomeadas:

pag_amb - português / agências de turismo $x$ entidades ambientalistas

pag_gov - português / agências de turismo x órgãos governamentais

pamb_gov - português / entidades ambientalistas $x$ órgãos governamentais

iag_amb - inglês / agências de turismo $x$ entidades ambientalistas

iag_gov - inglês / agências de turismo x órgãos governamentais

iamb_gov - inglês / agências de turismo $\mathrm{x}$ entidades ambientalistas

Nosso interesse aqui é destacar as palavras mais importantes em cada um desses cruzamentos e como elas representam as idéias de cada um dos setores já mencionados.

A primeira lista de palavras-chave vem do cruzamento das listas de agências e ambientalistas. As primeiras palavras, em preto, são as mais representativas do corpus das agências de turismo. Em seguida, em cinza, temos as palavras mais representativas das entidades ambientalistas. Vale lembrar que a leitura da segunda parte da lista deve ser feita de baixo para cima, ou seja, as últimas palavras da lista referem-se às mais importantes do segundo corpora.

\subsubsection{Português}

\section{p_ag x amb (português/ agências de turismo x entidades ambientalistas)}

\begin{tabular}{|r|l|r|r|r|r|r|}
\hline $\mathbf{N}$ & WORD & FREQ. & WLP_AG2.LST \% & FREQ. & WLP_AMB.LST \% & KEYNESS \\
\hline 4 & AVENTURA & 139 & 0,17 & 11 & 0,02 & 102,1 \\
\hline 6 & CAVERNAS & 84 & 0,1 & 0 & 98,4 & 0 \\
\hline 7 & RIOS & 115 & 0,14 & 7 & 0,01 & 92,5 \\
\hline
\end{tabular}




\begin{tabular}{|c|c|c|c|c|c|c|}
\hline 15 & ESPORTE & 59 & 0,07 & 2 & 54,8 & 0 \\
\hline 16 & SEGURANÇA & 67 & 0,08 & 4 & 54,2 & 0 \\
\hline 17 & ÁGUA & 93 & 0,11 & 13 & 0,02 & 51,2 \\
\hline 24 & CACHOEIRA & 51 & 0,06 & 2 & 46 & 0 \\
\hline 26 & ÁGUAS & 55 & 0,07 & 3 & 45,7 & 0 \\
\hline 27 & DESCIDA & 39 & 0,05 & 0 & 45,7 & 0 \\
\hline 28 & ARVORISMO & 38 & 0,05 & 0 & 44,5 & 0 \\
\hline 29 & PERCURSO & 49 & 0,06 & 2 & 43,8 & 0 \\
\hline 30 & PRAIA & 87 & 0,11 & 14 & 0,02 & 43,4 \\
\hline 31 & MAR & 63 & 0,08 & 6 & 42,8 & 0 \\
\hline 32 & CAVERNA & 36 & 0,04 & 0 & 42,2 & 0 \\
\hline 34 & FAUNA & 88 & 0,11 & 15 & 0,02 & 42 \\
\hline 35 & CLIMA & 42 & 0,05 & 1 & 41,3 & 0 \\
\hline 36 & TRILHA & 79 & 0,1 & 12 & 0,02 & 41,1 \\
\hline 37 & EQUIPAMENTOS & 75 & 0,09 & 11 & 0,02 & 40 \\
\hline 40 & VEGETAÇÃO & 48 & 0,06 & 3 & 38,3 & 0 \\
\hline 42 & RAFTING & 31 & 0,04 & 0 & 36,3 & 0 \\
\hline 44 & CACHOEIRAS & 48 & 0,06 & 4 & 34,5 & 0 \\
\hline 46 & CORREDEIRAS & 28 & 0,03 & 0 & 32,8 & 0 \\
\hline 49 & PRAIAS & 57 & 0,07 & 8 & 0,01 & 31,3 \\
\hline 53 & CORDA & 26 & 0,03 & 0 & 30,5 & 0 \\
\hline 54 & TREKKING & 26 & 0,03 & 0 & 30,5 & 0 \\
\hline 55 & RAPEL & 26 & 0,03 & 0 & 30,5 & 0 \\
\hline 57 & ESCALADA & 32 & 0,04 & 1 & 30,1 & 0 \\
\hline 58 & BÓIA & 25 & 0,03 & 0 & 29,3 & 0 \\
\hline 70 & TRAVESSIA & 21 & 0,03 & 0 & 24,6 & $1 \mathrm{E}-06$ \\
\hline 71 & CANYONING & 21 & 0,03 & 0 & 24,6 & $1 \mathrm{E}-06$ \\
\hline 72 & OUTDOOR & 21 & 0,03 & 0 & 24,6 & $1 \mathrm{E}-06$ \\
\hline 73 & CROSS & 21 & 0,03 & 0 & 24,6 & $1 \mathrm{E}-06$ \\
\hline 74 & PROVA & 21 & 0,03 & 0 & 24,6 & $1 \mathrm{E}-06$ \\
\hline 76 & ESPORTES & 41 & 0,05 & 5 & 24,5 & $1 \mathrm{E}-06$ \\
\hline 78 & MARINHO & 2 & 22 & 0,03 & 24,4 & $1 \mathrm{E}-06$ \\
\hline 80 & INTEGRADO & 2 & 22 & 0,03 & 24,4 & $1 \mathrm{E}-06$ \\
\hline 84 & SOCIAIS & 20 & 0,02 & 55 & 0,08 & 26 \\
\hline 91 & RECREATIVO & 1 & 21 & 0,03 & 27,2 & 0 \\
\hline 97 & ECOGÊNESE & 0 & 18 & 0,03 & 29,3 & 0 \\
\hline 100 & ORGANIZAÇÃO & 14 & 0,02 & 51 & 0,08 & 31,7 \\
\hline 104 & PROJETO & 62 & 0,08 & 119 & 0,18 & 33,7 \\
\hline 106 & COMUNITÁRIA & 1 & 26 & 0,04 & 34,9 & 0 \\
\hline 108 & PROCESSO & 24 & 0,03 & 70 & 0,11 & 35,3 \\
\hline 111 & AGENDA & 0 & 23 & 0,04 & 37,4 & 0 \\
\hline 112 & QUESTÃO & 5 & 39 & 0,06 & 38,2 & 0 \\
\hline 113 & HOMEM & 19 & 0,02 & 65 & 0,1 & 38,2 \\
\hline 114 & POLÍTICA & 13 & 0,02 & 55 & 0,08 & 38,4 \\
\hline 115 & CONSUMO & 2 & 32 & 0,05 & 39,2 & 0 \\
\hline 116 & DIRETRIZES & 6 & 42 & 0,06 & 39,2 & 0 \\
\hline 119 & ALDEIA & 1 & 30 & 0,05 & 41,2 & 0 \\
\hline 120 & GESTÃO & 18 & 0,02 & 66 & 0,1 & 41,2 \\
\hline 121 & AMBIENTE & 107 & 0,13 & 183 & 0,28 & 41,3 \\
\hline
\end{tabular}




\begin{tabular}{|r|l|r|r|r|r|r|}
\hline 122 & MARKETING & 4 & 39 & 0,06 & 41,6 & 0 \\
\hline 123 & SETOR & 24 & 0,03 & 77 & 0,12 & 42,7 \\
\hline 124 & ENTIDADES & 31 & 0,05 & 42,7 & 0 \\
\hline 125 & SOCIEDADE & 16 & 0,02 & 64 & 0,1 & 42,9 \\
\hline 126 & PROGRAMA & 42 & 0,05 & 104 & 0,16 & 43,3 \\
\hline 128 & MANUAL & 28 & 0,04 & 45,6 & 0 \\
\hline 132 & ECOTURISMO & 325 & 0,4 & 431 & 0,66 & 49,2 \\
\hline 133 & MEIO & 120 & 0,15 & 215 & 0,33 & 53,5 \\
\hline 136 & PROJETOS & 17 & 0,02 & 76 & 0,12 & 55,2 \\
\hline 137 & lULTURAL & 33 & 0,04 & 104 & 0,16 & 56,7 \\
\hline 138 & SOCIAL & 0,02 & 82 & 0,13 & 58,1 \\
\hline 140 & COMUNIDADES & 28 & 0,03 & 100 & 0,15 & 61,1 \\
\hline 141 & EDUCAÇÃO & 24 & 0,03 & 99 & 0,15 & 67,9 \\
\hline 143 & AMBIENTAL & 118 & 0,14 & 236 & 0,36 & 71,8 \\
\hline 148 & SUSTENTABILIDA+ & 17 & 0,02 & 111 & 0,17 & 100,4 \\
\hline 150 & POLITICAS & 1 & 73 & 0,11 & 109,4 & 0 \\
\hline 151 & CERTIFICAÇÃO & 10 & 0,01 & 109 & 0,17 & 120,5 \\
\hline 152 & DESENVOLVIMENT + & 94 & 0,12 & 290 & 0,45 & 155 \\
\hline 153 & SUSTENTÁVEL & 43 & 0,05 & 221 & 0,34 & 175,7 \\
\hline 155 & TURISMO & 201 & 0,25 & 558 & 0,86 & 267,4 \\
\hline
\end{tabular}

O cruzamento entre esses dois subcorpora deixa clara a intenção das agências de turismo em divulgar o que pode ser encontrado nas diversas regiões: "cavernas", "cachoeira", "vegetação", "praia", "corredeiras", entre outras atrações, e as atividades que podem ser realizadas, com ênfase nas de aventura: "aventura", "arvorismo", "rapel”, "rafting", "trekking". Praticamente todas as palavras são um convite a uma viagem cheia de aventura e desafios em lugares naturais.

Já as palavras do subcorpus das entidades ambientalistas têm como foco principal o turismo sustentável e os projetos de sustentabilidade, desenvolvimento e educação dos turistas e das comunidades envolvidas, descrevendo bem qual o papel dessas entidades. As palavras de maior ocorrência são: "turismo", "sustentável”, “desenvolvimento", “certificação", "políticas", "sustentabilidade", "educação", "ambiental” e "comunidades", entre outras.

p_ag x gov (português / agências de turismo x órgãos governamentais)

\begin{tabular}{|r|l|r|r|r|r|r|}
\hline N & WORD & FREQ. & WLP_AG2.LST \% & FREQ. & WLP_GOV.LST \% & KEYNESS \\
\hline 11 & PANTANAL & 91 & 0,11 & 7 & 74,3 & 0 \\
\hline
\end{tabular}




\begin{tabular}{|c|c|c|c|c|c|c|}
\hline 12 & PRAIA & 87 & 0,11 & 6 & 73,7 & 0 \\
\hline 21 & TRILHA & 79 & 0,1 & 11 & 0,02 & 48,9 \\
\hline 22 & PEIXE & 39 & 0,05 & 0 & 48,8 & 0 \\
\hline 23 & RIOS & 115 & 0,14 & 27 & 0,04 & 47,2 \\
\hline 24 & PÓLO & 68 & 0,08 & 9 & 0,01 & 43,4 \\
\hline 27 & ARVORISMO & 38 & 0,05 & 2 & 34,8 & 0 \\
\hline 30 & ECO & 41 & 0,05 & 3 & 34 & 0 \\
\hline 34 & PRAIAS & 57 & 0,07 & 9 & 0,01 & 32,6 \\
\hline 35 & MARGENS & 26 & 0,03 & 0 & 32,6 & 0 \\
\hline 39 & LUGAR & 43 & 0,05 & 5 & 29,4 & 0 \\
\hline 42 & CACHOEIRA & 51 & 0,06 & 8 & 0,01 & 29,3 \\
\hline 46 & CLIMA & 42 & 0,05 & 5 & 28,4 & 0 \\
\hline 47 & NATUREZA & 115 & 0,14 & 40 & 0,06 & 28,2 \\
\hline 51 & PERCURSO & 49 & 0,06 & 8 & 0,01 & 27,4 \\
\hline 52 & ÁGUA & 93 & 0,11 & 29 & 0,04 & 27 \\
\hline 54 & ROTEIROS & 58 & 0,07 & 12 & 0,02 & 26,9 \\
\hline 61 & FAUNA & 88 & 0,11 & 28 & 0,04 & 24,8 \\
\hline 62 & PROMOVER & 18 & 0,02 & 54 & 0,08 & 24,2 \\
\hline 67 & INVESTIMENTOS & 9 & 0,01 & 39 & 0,06 & 24,6 \\
\hline 72 & AVALIAÇÃO & 6 & 34 & 0,05 & 25,7 & 0 \\
\hline 73 & PLANOS & 10 & 0,01 & 42 & 0,06 & 25,9 \\
\hline 78 & ESPAÇOS & 0 & 18 & 0,03 & 27,5 & 0 \\
\hline 79 & APOIAR & 0 & 18 & 0,03 & 27,5 & 0 \\
\hline 85 & (PÁRA) QUEDISMO & 1 & 23 & 0,03 & 28,1 & 0 \\
\hline 87 & DIRETRIZES & 6 & 36 & 0,05 & 28,1 & 0 \\
\hline 88 & PARTICIPAÇÃO & 17 & 0,02 & 57 & 0,08 & 28,7 \\
\hline 89 & MERCADO & 33 & 0,04 & 82 & 0,12 & 28,9 \\
\hline 91 & TURISTA & 18 & 0,02 & 59 & 0,08 & 29,1 \\
\hline 93 & TURÍSTICA & 21 & 0,03 & 64 & 0,09 & 29,2 \\
\hline 94 & TURÍSTICOS & 19 & 0,02 & 61 & 0,09 & 29,4 \\
\hline 97 & ÓRGÃOS & 10 & 0,01 & 46 & 0,06 & 30,4 \\
\hline 104 & TURÍSTICO & 42 & 0,05 & 98 & 0,14 & 31,5 \\
\hline 105 & SEGMENTO & 17 & 0,02 & 60 & 0,08 & 31,8 \\
\hline 109 & ENTORNO & 9 & 0,01 & 46 & 0,06 & 32,6 \\
\hline 116 & PROJETOS & 17 & 0,02 & 64 & 0,09 & 36 \\
\hline 118 & IMPLANTAÇÃO & 27 & 0,03 & 81 & 0,11 & 36,3 \\
\hline 121 & CAPACITAÇÃO & 13 & 0,02 & 59 & 0,08 & 38,6 \\
\hline 122 & ATIVIDADES & 151 & 0,19 & 247 & 0,35 & 38,7 \\
\hline 125 & SUSTENTÁVEL & 43 & 0,05 & 109 & 0,15 & 39,6 \\
\hline 126 & RALLY & 0 & 26 & 0,04 & 39,8 & 0 \\
\hline 131 & ESTRATÉGIA & 6 & 48 & 0,07 & 43,3 & 0 \\
\hline 132 & ESTRATÉGIAS & 2 & 37 & 0,05 & 43,3 & 0 \\
\hline 136 & CONSERVAÇÃO & 107 & 0,13 & 208 & 0,29 & 48,6 \\
\hline 137 & SETOR & 24 & 0,03 & 89 & 0,13 & 49,4 \\
\hline 138 & COMUNIDADES & 28 & 0,03 & 96 & 0,14 & 49,5 \\
\hline 141 & ORGANIZAÇÃO & 14 & 0,02 & 72 & 0,1 & 51,3 \\
\hline 146 & ATIVIDADE & 91 & 0,11 & 196 & 0,28 & 55,4 \\
\hline 148 & REGULAMENTAÇÃO & 3 & 49 & 0,07 & 55,8 & 0 \\
\hline 150 & FLORESTAL & 7 & 63 & 0,09 & 59,7 & 0 \\
\hline
\end{tabular}




\begin{tabular}{|r|l|r|r|r|r|r|}
\hline 151 & IMPACTOS & 36 & 0,04 & 125 & 0,18 & 65,3 \\
\hline 153 & DESENVOLVIMENT+ & 94 & 0,12 & 217 & 0,31 & 68,7 \\
\hline 154 & REGIONAL & 17 & 0,02 & 93 & 0,13 & 68,9 \\
\hline 157 & GESTÃO & 18 & 0,02 & 104 & 0,15 & 79,6 \\
\hline 161 & ENTIDADES & 1 & 63 & 0,09 & 87,4 & 0 \\
\hline 162 & UNIDADES & 37 & 0,05 & 148 & 0,21 & 87,7 \\
\hline 166 & AÇÕES & 19 & 0,02 & 116 & 0,16 & 91,6 \\
\hline 167 & RESPONSABILIDA+ & 10 & 0,01 & 99 & 0,14 & 97,2 \\
\hline 169 & VISITAÇÃO & 36 & 0,04 & 161 & 0,23 & 104,2 \\
\hline 170 & PROJETO & 62 & 0,08 & 245 & 0,35 & 143,8 \\
\hline 171 & TURISMO & 201 & 0,25 & 463 & 0,65 & 146,4 \\
\hline 173 & PARQUES & 20 & 0,02 & 255 & 0,36 & 272,2 \\
\hline
\end{tabular}

É interessante notar os resultados do cruzamento das listas de palavraschave das agências com o governo. A lista das agências apresenta palavras relacionadas a lugares como "rios", "cachoeiras", "praia", a natureza, como "natureza", "águas", "peixe”, "fauna”, entre outras, e apenas uma palavra relacionada a atividades: "arvorismo".

Já a lista do governo nos oferece palavras relacionadas ao seu papel de administrador de parques e unidades de conservação e desenvolvimento e implantação de projetos, mas também apresenta palavras relacionadas a atividades como "rally" e "pára-quedismo", além da palavra "atividades", que aproxima seus interesses aos dos das agências de turismo.

p_amb $x$ gov (português entidades ambientalistas $x$ órgãos governamentais)

\begin{tabular}{|r|l|l|r|r|r|r|}
\hline $\mathbf{N}$ & WORD & FREQ. & WLP_AMB.LST \% & FREQ. & WLP_GOV.LST \% & KEYNESS \\
\hline 2 & CERTIFICAÇÃO & 109 & 0,17 & 3 & 137,4 & 0 \\
\hline 9 & PANTANAL & 81 & 0,12 & 7 & 80 & 0 \\
\hline 14 & SUSTENTABILIDA+ & 111 & 0,17 & 25 & 0,04 & 66,8 \\
\hline 16 & NATUREZA & 129 & 0,2 & 40 & 0,06 & 57,7 \\
\hline 20 & SUSTENTÁVEL & 221 & 0,34 & 109 & 0,15 & 49,6 \\
\hline 21 & SOCIAL & 82 & 0,13 & 19 & 0,03 & 48,2 \\
\hline 22 & POLÍTICAS & 73 & 0,11 & 15 & 0,02 & 47 \\
\hline 25 & ALDEIA & 30 & 0,05 & 0 & 44,3 & 0 \\
\hline 33 & MEIO & 215 & 0,33 & 125 & 0,18 & 32,9 \\
\hline 34 & CULTURAL & 104 & 0,16 & 43 & 0,06 & 31,9 \\
\hline 39 & ECOLÓGICO & 66 & 0,1 & 21 & 0,03 & 28,7 \\
\hline 42 & ECOGÉNESE & 18 & 0,03 & 0 & 26,6 & 0 \\
\hline 48 & ECOTURISMO & 431 & 0,66 & 327 & 0,46 & 25,3 \\
\hline
\end{tabular}




\begin{tabular}{|r|l|r|r|r|r|r|}
\hline 52 & TURISTA & 15 & 0,02 & 59 & 0,08 & 24,2 \\
\hline 56 & NÚCLEOS & 0 & 19 & 0,03 & 24,7 & 0,000001 \\
\hline 59 & ESTRUTURA & 33 & 0,05 & 94 & 0,13 & 25,4 \\
\hline 60 & ESTRUTURAÇÃO & 0 & 20 & 0,03 & 26 & 0 \\
\hline 61 & CAVALGADA & 0 & 20 & 0,03 & 26 & 0 \\
\hline 63 & LITORAL & 5 & 39 & 0,06 & 26,9 & 0 \\
\hline 67 & QUEDISMO & 0 & 23 & 0,03 & 29,9 & 0 \\
\hline 68 & NÚCLEO & 4 & 39 & 0,06 & 30 & 0 \\
\hline 71 & MERGULHO & 8 & 0,01 & 50 & 0,07 & 30,2 \\
\hline 72 & LIVRE & 2 & 33 & 0,05 & 30,5 & 0 \\
\hline 73 & ATRATIVOS & 18 & 0,03 & 73 & 0,1 & 30,9 \\
\hline 76 & RALLY & 0 & 26 & 0,04 & 33,8 & 0 \\
\hline 79 & PROJETO & 119 & 0,18 & 245 & 0,35 & 34,1 \\
\hline 81 & RAFTING & 0 & 27 & 0,04 & 35,1 & 0 \\
\hline 82 & MODALIDADES & 2 & 37 & 0,05 & 35,2 & 0 \\
\hline 87 & REGIONAL & 24 & 0,04 & 93 & 0,13 & 37,6 \\
\hline 88 & ATIVIDADE & 83 & 0,13 & 196 & 0,28 & 37,6 \\
\hline 90 & VÔO & 0 & 29 & 0,04 & 37,7 & 0 \\
\hline 95 & ETAPAS & 2 & 43 & 0,06 & 42,5 & 0 \\
\hline 97 & CAVERNAS & 0 & 35 & 0,05 & 45,5 & 0 \\
\hline 99 & RESPONSABILIDA+ & 21 & 0,03 & 99 & 0,14 & 48,4 \\
\hline 101 & SEGURANÇA & 4 & 57 & 0,08 & 50,4 & 0 \\
\hline 102 & EQUIPAMENTOS & 11 & 0,02 & 78 & 0,11 & 51 \\
\hline 103 & IMPACTOS & 31 & 0,05 & 125 & 0,18 & 52,7 \\
\hline 104 & PÁRA & 0 & 41 & 0,06 & 53,3 & 0 \\
\hline 105 & FLORESTAL & 4 & 63 & 0,09 & 57,5 & 0 \\
\hline 107 & ATIVIDADES & 92 & 0,14 & 247 & 0,35 & 60,5 \\
\hline 111 & UNIDADES & 31 & 0,05 & 148 & 0,21 & 73,1 \\
\hline 112 & VISITAÇÃO & 37 & 0,06 & 161 & 0,23 & 73,2 \\
\hline 119 & AVENTURA & 11 & 0,02 & 165 & 0,23 & 148,4 \\
\hline 121 & PARQUES & 0,03 & 255 & 0,36 & 225,5 \\
\hline
\end{tabular}

O cruzamento das listas de palavras das entidades ambientalistas com a lista dos órgãos governamentais nos mostra as entidades exercendo seu papel no que diz respeito à "sustentabilidade" e cuidados com a "natureza". Por outro lado, o governo tem como palavras de maior importância aquelas relativas a "aventura" e "atividades", com a descrição de várias atividades como "vôo", "rafting", "mergulho" e atividades de "visitação" dos "parques" e "unidades de conservação".

Esse tipo de cruzamento evidencia o papel de cada uma das áreas mencionadas. As agências de turismo têm a preocupação com a divulgação das belezas naturais e dos atrativos que possam levar a uma maior procura por pacotes turísticos. As entidades ambientalistas evidenciam a preocupação com a conservação da natureza e a sustentabilidade da região e das comunidades locais. 
Já o governo, por um lado, exerce seu papel de administrador, que precisa cuidar da preservação e conservação das áreas naturais, por outro, preocupa-se em divulgar as possibilidades de atividades de aventura, o que faz com que seus objetivos se aproximem dos objetivos das agências, ou seja, atrair turistas.

\subsubsection{Inglês}

\section{ag $x$ amb (inglês / agências $x$ ambientalistas)}

\begin{tabular}{|c|c|c|c|c|c|c|}
\hline No. & WORD & FREQ. & WLI_AG.LST \% & FREQ. & WLI_AMB.LST \% & KEYNESS \\
\hline 6 & TRACK & 97 & 0,25 & 17 & 0,03 & 105,2 \\
\hline 8 & MOUNTAIN & 63 & 0,16 & 5 & 89,1 & 0 \\
\hline 9 & ECOTOURS & 47 & 0,12 & 1 & 80,7 & 0 \\
\hline 11 & RIVER & 72 & 0,18 & 12 & 0,02 & 79,8 \\
\hline 12 & DOLPHINS & 68 & 0,17 & 12 & 0,02 & 73,5 \\
\hline 13 & ECO & 83 & 0,21 & 22 & 0,04 & 71,6 \\
\hline 14 & TOURS & 129 & 0,33 & 64 & 0,1 & 62,8 \\
\hline 16 & UNIQUE & 61 & 0,15 & 14 & 0,02 & 57,5 \\
\hline 17 & HIKING & 35 & 0,09 & 2 & 53 & 0 \\
\hline 19 & TOUR & 77 & 0,19 & 30 & 0,05 & 48,8 \\
\hline 20 & ADVENTURE & 47 & 0,12 & 9 & 0,01 & 48,8 \\
\hline 21 & WALKS & 52 & 0,13 & 13 & 0,02 & 46,6 \\
\hline 23 & SEA & 57 & 0,14 & 17 & 0,03 & 45,3 \\
\hline 24 & WALKING & 62 & 0,16 & 21 & 0,03 & 44,6 \\
\hline 25 & BIKING & 30 & 0,08 & 2 & 44,1 & $\underline{0}$ \\
\hline 27 & KAYAKING & 29 & 0,07 & 2 & 42,3 & 0 \\
\hline 29 & LAKE & 34 & 0,09 & 5 & 39,7 & 0 \\
\hline 30 & WALK & 56 & 0,14 & 20 & 0,03 & 38,5 \\
\hline 32 & RAFTING & 29 & 0,07 & 3 & 38,2 & 0 \\
\hline 33 & GUIDED & 47 & 0,12 & 14 & 0,02 & 37,4 \\
\hline 34 & CREEK & 19 & 0,05 & 0 & 36,1 & 0 \\
\hline 36 & NATURAL & 114 & 0,29 & 76 & 0,12 & 35,4 \\
\hline 37 & SOUNDS & 25 & 0,06 & 2 & 35,3 & 0 \\
\hline 38 & WATCHING & 38 & 0,1 & 9 & 0,01 & 35,2 \\
\hline 40 & STUNNING & 18 & 0,05 & 0 & 34,2 & 0 \\
\hline 43 & TRIPS & 40 & 0,1 & 11 & 0,02 & 33,7 \\
\hline 47 & NATURE & 90 & 0,23 & 57 & 0,09 & 30,6 \\
\hline 48 & SCENERY & 31 & 0,08 & 7 & 0,01 & 29,5 \\
\hline 50 & SWIM & 15 & 0,04 & 0 & 28,5 & 0 \\
\hline 51 & BEACHES & 23 & 0,06 & 3 & 28,1 & 0 \\
\hline 52 & BEAUTIFUL & 31 & 0,08 & 8 & 0,01 & 27,2 \\
\hline 53 & COASTLINE & 26 & 0,07 & 5 & 27 & 0 \\
\hline 54 & TRIP & 39 & 0,1 & 14 & 0,02 & 26,7 \\
\hline 57 & SEALS & 20 & 0,05 & 2 & 26,6 & 0 \\
\hline
\end{tabular}




\begin{tabular}{|r|l|r|r|r|r|r|}
58 & AMAZING & 22 & 0,06 & 3 & 26,4 & 0 \\
\hline 59 & VALLEY & 37 & 0,09 & 13 & 0,02 & 25,8 \\
\hline 66 & WHITEWATER & 13 & 0,03 & 0 & 24,7 & 0,000001 \\
\hline 68 & CONSERVATION & 74 & 0,19 & 220 & 0,35 & 23,9 \\
\hline 70 & BUSINESSES & 3 & 42 & 0,07 & 24,7 & 0,000001 \\
\hline 71 & OPERATIONS & 5 & 0,01 & 50 & 0,08 & 24,8 \\
\hline 76 & VOLUNTEERS & 0 & 27 & 0,04 & 26,4 & 0 \\
\hline 77 & VISITORS & 40 & 0,1 & 149 & 0,24 & 26,5 \\
\hline 85 & COUNCIL & 1 & 37 & 0,06 & 28,8 & 0 \\
\hline 86 & SOCIAL & 3 & 47 & 0,07 & 28,9 & 0 \\
\hline 87 & ISSUES & 13 & 0,03 & 82 & 0,13 & 29 \\
\hline 89 & VALUES & 8 & 0,02 & 68 & 0,11 & 30,5 \\
\hline 90 & HORTICULTURE & 0 & 32 & 0,05 & 31,3 & 0 \\
\hline 92 & OVERFISHED & 0 & 33 & 0,05 & 32,2 & 0 \\
\hline 98 & ENVIRONMENTAL & 35 & 0,09 & 155 & 0,25 & 36,5 \\
\hline 99 & RESEARCH & 9 & 0,02 & 80 & 0,13 & 37 \\
\hline 103 & USE & 14 & 0,04 & 100 & 0,16 & 39,4 \\
\hline 104 & STRATEGIES & 0 & 41 & 0,07 & 40,1 & 0 \\
\hline 105 & SUSTAINABLE & 21 & 0,05 & 125 & 0,2 & 41,8 \\
\hline 106 & ECONOMIC & 8 & 0,02 & 83 & 0,13 & 42,1 \\
\hline 107 & INDUSTRY & 13 & 0,03 & 101 & 0,16 & 42,5 \\
\hline 109 & STOCK & 1 & 56 & 0,09 & 46,5 & 0 \\
\hline 111 & STOCKS & 0 & 50 & 0,08 & 48,8 & 0 \\
\hline 112 & MANAGEMENT & 16 & 0,04 & 127 & 0,2 & 54,3 \\
\hline 115 & SPECIES & 35 & 0,09 & 197 & 0,31 & 62,3 \\
\hline 116 & VISITOR & 16 & 0,04 & 141 & 0,22 & 64,8 \\
\hline 118 & DEVELOPMENT & 12 & 0,03 & 133 & 0,21 & 70 \\
\hline 119 & TOURISM & 114 & 0,29 & 523 & 0,83 & 129,8 \\
\hline & & & & & \\
\hline
\end{tabular}

Embora as agências de turismo da Nova Zelândia também tenham a intenção de atrair turistas e divulgar as belezas e atividades que podem ser realizadas nas diversas regiões, há uma ênfase em atividades ecoturísticas, como a observação de baleias, golfinhos e focas, além das belezas naturais que podem ser admiradas.

As entidades, por sua vez, confirmam, como em português, a preocupação com o turismo, o desenvolvimento da região, a sustentabilidade e a preservação da natureza.

\section{i_ag x gov (inglês / agências x governo)}

\begin{tabular}{|r|l|r|r|r|r|r|}
\hline N & WORD & FREQ. & WLI_AG.LST \% & FREQ. & WLI_GOV.LST \% & KEYNESS \\
\hline 1 & TOURS & 129 & 0,33 & 12 & 0,02 & 183,5 \\
\hline 6 & TRACK & 97 & 0,25 & 14 & 0,02 & 120,2 \\
\hline 7 & TOUR & 77 & 0,19 & 6 & 114,3 & 0 \\
\hline
\end{tabular}




\begin{tabular}{|c|c|c|c|c|c|c|}
\hline 9 & PARK & 90 & 0,23 & 14 & 0,02 & 108,3 \\
\hline 11 & RIVER & 72 & 0,18 & 6 & 105,2 & 0 \\
\hline 12 & DOLPHINS & 68 & 0,17 & 5 & 102,2 & 0 \\
\hline 13 & WALK & 56 & 0,14 & 1 & 101,2 & 0 \\
\hline 14 & ECO & 83 & 0,21 & 13 & 0,02 & 99,6 \\
\hline 15 & WALKING & 62 & 0,16 & 5 & 91,3 & 0 \\
\hline 16 & MOUNTAIN & 63 & 0,16 & 6 & 89 & 0 \\
\hline 18 & ECOTOURS & 47 & 0,12 & 1 & 83,8 & 0 \\
\hline 22 & HIKING & 35 & 0,09 & 0 & 69 & 0 \\
\hline 23 & GUIDED & 47 & 0,12 & 4 & 68,3 & $\underline{0}$ \\
\hline 24 & BIRD & 55 & 0,14 & 10 & 0,02 & 61,9 \\
\hline 25 & TRIPS & 40 & 0,1 & 3 & 59,9 & 0 \\
\hline 26 & COAST & 52 & 0,13 & 9 & 0,01 & 59,8 \\
\hline 29 & WATCHING & 38 & 0,1 & 3 & 56,2 & 0 \\
\hline 31 & SEA & 57 & 0,14 & 14 & 0,02 & 54,9 \\
\hline 32 & BIKING & 30 & 0,08 & 1 & 51,2 & 0 \\
\hline 33 & WALKS & 52 & 0,13 & 13 & 0,02 & 49,6 \\
\hline 34 & LAKE & 34 & 0,09 & 3 & 49 & 0 \\
\hline 37 & SPECTACULAR & 31 & 0,08 & 2 & 47,9 & 0 \\
\hline 38 & VALLEY & 37 & 0,09 & 5 & 46,9 & 0 \\
\hline 41 & BEACHES & 23 & 0,06 & 0 & 45,3 & 0 \\
\hline 42 & BOAT & 23 & 0,06 & 0 & 45,3 & 0 \\
\hline 43 & ADVENTURE & 47 & 0,12 & 12 & 0,02 & 44,2 \\
\hline 44 & KAYAKING & 29 & 0,07 & 2 & 44,2 & 0 \\
\hline 46 & SCENERY & 31 & 0,08 & 3 & 43,6 & 0 \\
\hline 47 & BEAUTIFUL & 31 & 0,08 & 3 & 43,6 & 0 \\
\hline 49 & SOUNDS & 25 & 0,06 & 1 & 41,7 & 0 \\
\hline 52 & RAFTING & 29 & 0,07 & 3 & 40 & 0 \\
\hline 53 & UNIQUE & 61 & 0,15 & 25 & 0,04 & 39,9 \\
\hline 55 & BIRDS & 45 & 0,11 & 13 & 0,02 & 39,1 \\
\hline 56 & COASTLINE & 26 & 0,07 & 2 & 38,7 & 0 \\
\hline 58 & CREEK & 19 & 0,05 & 0 & 37,4 & 0 \\
\hline 59 & NATURE & 90 & 0,23 & 54 & 0,08 & 37,3 \\
\hline 61 & AMAZING & 22 & 0,06 & 1 & 36 & 0 \\
\hline 62 & STUNNING & 18 & 0,05 & 0 & 35,5 & 0 \\
\hline 64 & BUNGY & 18 & 0,05 & 0 & 35,5 & 0 \\
\hline 65 & BIRDING & 18 & 0,05 & 0 & 35,5 & 0 \\
\hline 69 & BEACH & 21 & 0,05 & 1 & 34,2 & 0 \\
\hline 71 & JUMPING & 17 & 0,04 & 0 & 33,5 & 0 \\
\hline 73 & SEALS & 20 & 0,05 & 1 & 32,3 & 0 \\
\hline 74 & BAY & 28 & 0,07 & 5 & 31,8 & 0 \\
\hline 75 & OCEAN & 16 & 0,04 & 0 & 31,5 & 0 \\
\hline 78 & BIRDWATCHING & 16 & 0,04 & 0 & 31,5 & 0 \\
\hline 82 & WILDLIFE & 55 & 0,14 & 26 & 0,04 & 31 \\
\hline 84 & EXPERIENCE & 77 & 0,19 & 48 & 0,07 & 30,1 \\
\hline 85 & SCENIC & 25 & 0,06 & 4 & 29,7 & 0 \\
\hline 88 & ROCKS & 15 & 0,04 & 0 & 29,5 & 0 \\
\hline 89 & SWIM & 15 & 0,04 & 0 & 29,5 & 0 \\
\hline 90 & CRUISE & 15 & 0,04 & 0 & 29,5 & 0 \\
\hline
\end{tabular}




\begin{tabular}{|c|c|c|c|c|c|c|}
\hline 103 & TRIP & 39 & 0,1 & 15 & 0,02 & 27 \\
\hline 107 & LAKES & 28 & 0,07 & 7 & 0,01 & 26,7 \\
\hline 108 & SWIMMING & 19 & 0,05 & 2 & 26,1 & 0 \\
\hline 110 & WHITEWATER & 13 & 0,03 & 0 & 25,6 & 0 \\
\hline 115 & WILDERNESS & 30 & 0,08 & 9 & 0,01 & 25,4 \\
\hline 117 & PENGUINS & 16 & 0,04 & 1 & 24,8 & 0,000001 \\
\hline 123 & RAINFOREST & 18 & 0,05 & 2 & 24,3 & 0,000001 \\
\hline 124 & ENCOUNTER & 18 & 0,05 & 2 & 24,3 & 0,000001 \\
\hline 128 & LANDOWNER & 0 & 26 & 0,04 & 24,3 & 0,000001 \\
\hline 129 & MANAGED & 4 & 0,01 & 48 & 0,07 & 24,6 \\
\hline 135 & PLANTATION & 3 & 46 & 0,07 & 26,4 & 0 \\
\hline 139 & USES & 2 & 42 & 0,06 & 27 & 0 \\
\hline 140 & RULES & 0 & 29 & 0,04 & 27,1 & 0 \\
\hline 143 & PRODUCTION & 2 & 43 & 0,06 & 27,8 & 0 \\
\hline 144 & GROWTH & 3 & 48 & 0,07 & 28 & 0 \\
\hline 148 & INDUSTRY & 13 & 0,03 & 85 & 0,13 & 28,4 \\
\hline 150 & DEVELOPING & 9 & 0,02 & 72 & 0,11 & 28,6 \\
\hline 151 & CONSERVATION & 74 & 0,19 & 243 & 0,37 & 28,6 \\
\hline 152 & RELATIONSHIP & 0 & 33 & 0,05 & 30,9 & 0 \\
\hline 159 & EXOTIC & 1 & 44 & 0,07 & 33,5 & 0 \\
\hline 161 & ECOSYSTEMS & 2 & 52 & 0,08 & 35,5 & 0 \\
\hline 164 & STRATEGY & 2 & 54 & 0,08 & 37,2 & 0 \\
\hline 165 & VALUE & 8 & 0,02 & 82 & 0,12 & 38,5 \\
\hline 167 & PLANTING & 0 & 44 & 0,07 & 41,2 & 0 \\
\hline 171 & POTENTIAL & 4 & 0,01 & 75 & 0,11 & 46,4 \\
\hline 175 & SECTOR & 2 & 73 & 0,11 & 53,8 & 0 \\
\hline 176 & CERTIFICATION & 0 & 58 & 0,09 & 54,3 & 0 \\
\hline 177 & FORESTS & 42 & 0,11 & 214 & 0,32 & 54,4 \\
\hline 180 & FORESTRY & 3 & 82 & 0,12 & 56,7 & 0 \\
\hline 181 & DEVELOPMENT & 12 & 0,03 & 122 & 0,18 & 57 \\
\hline 184 & ECONOMIC & 8 & 0,02 & 108 & 0,16 & 58,6 \\
\hline 185 & NATIVE & 70 & 0,18 & 303 & 0,46 & 61,3 \\
\hline 191 & PRODUCTS & 26 & 0,07 & 194 & 0,29 & 72,9 \\
\hline 192 & COUNCIL & 1 & 89 & 0,13 & 74,3 & 0 \\
\hline 195 & PLANTS & 27 & 0,07 & 222 & 0,33 & 90 \\
\hline 196 & USE & 14 & 0,04 & 180 & 0,27 & 95,5 \\
\hline 198 & SUSTAINABLE & 21 & 0,05 & 212 & 0,32 & 98,7 \\
\hline 199 & BIODIVERSITY & 3 & 140 & 0,21 & 107,8 & 0 \\
\hline 200 & FOREST & 47 & 0,12 & 337 & 0,51 & 122,7 \\
\hline 201 & RESEARCH & 9 & 0,02 & 199 & 0,3 & 129,9 \\
\hline 202 & SUBMITTERS & 0 & 139 & 0,21 & 130,1 & 0 \\
\hline 203 & MANAGEMENT & 16 & 0,04 & 241 & 0,36 & 137,3 \\
\hline 205 & INDIGENOUS & 5 & 0,01 & 202 & 0,3 & 151,9 \\
\hline 207 & SUBMITTER & 0 & 178 & 0,27 & 166,6 & 0 \\
\hline
\end{tabular}


Ao compararmos os resultados encontrados nessa lista, observamos que as agências, além das atividades ecoturísticas, também divulgam atividades de aventura.

As palavras que aparecem como mais importantes para o governo não mencionam atividades e sim a preocupação com a biodiversidade e a sustentabilidade da região, além do papel que as pessoas da comunidade podem exercer ao participarem ativamente da conservação.

\section{i_amb x gov (inglês / ambientalistas x governo)}

\begin{tabular}{|r|l|r|r|r|r|r|}
\hline no. & WORD & FREQ. & WLI_AMB.LST \% & FREQ. & WLI_GOV.LST \% & KEYNESS \\
\hline 1 & TOURISM & 523 & 0,83 & 297 & 0,45 & 76,5 \\
\hline 2 & STOCKS & 50 & 0,08 & 0 & 72,1 & 0 \\
\hline 4 & VISITOR & 141 & 0,22 & 43 & 0,06 & 60,6 \\
\hline 6 & PARK & 02 & 0,13 & 14 & 0,02 & 57,1 \\
\hline 8 & COAST & 0,11 & 9 & 0,01 & 54,5 \\
\hline 15 & OVERFISHED & 33 & 0,05 & 0 & 47,6 & 0 \\
\hline 16 & TOURIST & 01 & 0,1 & 9 & 0,01 & 46,2 \\
\hline 18 & STOCK & 56 & 0,09 & 7 & 0,01 & 46,1 \\
\hline 19 & TOURISTS & 0,1 & 11 & 0,02 & 44,4 \\
\hline 20 & TRAVEL & 53 & 0,08 & 7 & 0,01 & 42,5 \\
\hline 22 & TOURS & 64 & 0,1 & 12 & 0,02 & 42 \\
\hline 31 & CRUISE & 24 & 0,04 & 0 & 34,6 & 0 \\
\hline 33 & HORTICULTURE & 32 & 0,05 & 2 & 33,6 & 0 \\
\hline 36 & BEHAVIOUR & 30 & 0,05 & 2 & 31 & 0 \\
\hline 37 & SANCTUARY & 47 & 0,07 & 9 & 0,01 & 30,4 \\
\hline 39 & RESERVE & 29 & 0,05 & 2 & 29,6 & 0 \\
\hline 42 & STRATEGIES & 41 & 0,07 & 7 & 0,01 & 28,6 \\
\hline 44 & VISITORS & 149 & 0,24 & 77 & 0,12 & 27,5 \\
\hline 46 & EXPERIENCES & 54 & 0,09 & 14 & 0,02 & 27,4 \\
\hline 53 & SPECIES & 197 & 0,31 & 118 & 0,18 & 24,6 \\
\hline 56 & OVERFISHING & 17 & 0,03 & 0 & 24,5 & 0,000001 \\
\hline 57 & HABITAT & 49 & 0,08 & 13 & 0,02 & 24,3 \\
\hline 59 & ENVIRONMENTAL & 155 & 0,25 & 86 & 0,13 & 24 \\
\hline 60 & HARVESTING & 2 & 27 & 0,04 & 24,3 & 0,000001 \\
\hline 62 & LANDSCAPE & 12 & 0,02 & 52 & 0,08 & 24,8 \\
\hline 69 & VEGETATION & 8 & 0,01 & 46 & 0,07 & 27,5 \\
\hline 72 & SUSTAINABLY & 0 & 21 & 0,03 & 28 & 0 \\
\hline 74 & STRATEGY & 11 & 0,02 & 54 & 0,08 & 28,7 \\
\hline 75 & MANAGING & 1 & 0,04 & 28,8 & 0 \\
\hline 76 & MANAGEMENT & 127 & 0,01 & 48 & 0,36 & 30,1 \\
\hline 79 & RAISED & 0 & & & 0,7 & 0 \\
\hline 83 & SECTION & 7 & 0,07 & 32,1 \\
\hline & & & 0,2 & & \\
\hline
\end{tabular}




\begin{tabular}{|r|l|r|r|r|r|r|}
\hline 85 & TROPICAL & 9 & 0,01 & 54 & 0,08 & 33,3 \\
\hline 90 & FARMERS & 2 & 36 & 0,05 & 35,2 & 0 \\
\hline 91 & PRODUCTIVE & 0 & 28 & 0,04 & 37,3 & 0 \\
\hline 96 & AQUACULTURE & 0 & 30 & 0,05 & 40 & 0 \\
\hline 97 & EXOTIC & 44 & 0,07 & 40,7 & 0 \\
\hline 98 & USES & 3 & 42 & 0,06 & 42,6 & 0 \\
\hline 104 & RESEARCH & 2 & 0,13 & 199 & 0,3 & 46,2 \\
\hline 106 & PLANTATION & 46 & 0,07 & 47,6 & 0 \\
\hline 107 & ROLE & 24 & 0,04 & 103 & 0,16 & 48,8 \\
\hline 108 & BIODIVERSITY & 40 & 0,06 & 140 & 0,21 & 53,6 \\
\hline 109 & CERTIFICATION & 58 & 0,09 & 57,7 & 0 \\
\hline 112 & FORESTRY & 3 & 0,01 & 82 & 0,12 & 70,4 \\
\hline 115 & FORESTS & 3 & 0,06 & 214 & 0,32 & 133,7 \\
\hline 116 & INDIGENOUS & 19 & 0,03 & 202 & 0,3 & 167,3 \\
\hline 117 & NATIVE & 58 & 0,09 & 303 & 0,46 & 169,6 \\
\hline 119 & FOREST & 71 & 0,11 & 337 & 0,51 & 174,8 \\
\hline 120 & PRODUCTS & 0,02 & 194 & 0,29 & 180,4 \\
\hline 121 & SUBMITTERS & 13 & 139 & 0,21 & 185,4 & 0 \\
\hline 123 & PLANTS & 19 & 0,03 & 222 & 0,33 & 190,5 \\
\hline 124 & SUBMITTER & 0 & 178 & 0,27 & 237,4 & 0 \\
\hline
\end{tabular}

As palavras encontradas no cruzamento da lista de palavras-chave das entidades ambientalistas com a lista do governo nos mostram uma sintonia com relação ao papel que ambos desempenham, voltado à proteção e preservação do meio ambiente e das espécies nativas e ao comportamento do turista nas áreas visitadas.

Essas listas, embora possam trazer resultados já mostrados nos agrupamentos de palavras, apresentam de forma mais clara toda uma relação de palavras importantes em cada um dos subcorpora, o que nos permite confirmar os dados que já haviam sido encontrados e comentados. 


\section{CONSIDERAÇÕES FINAIS}

Neste trabalho pretendíamos analisar o modo como três áreas distintas - as agências de viagens, as entidades ambientalistas e os órgãos governamentais -lidam com o tema ecoturismo. A compilação do corpus foi a base para todo o seu desenvolvimento da pesquisa. Para isso foi feita uma busca na internet em sites brasileiros e neozelandeses dessas áreas dos quais foram extraídos os textos que integram nosso corpus. A compilação criteriosa foi fundamental para obtermos os dados relevantes deste trabalho.

O computador exerceu um papel fundamental na compilação do corpus, assim como a internet. $O$ primeiro, por ter possibilitado a análise de uma grande quantidade de material de forma confiável, permitindo-nos ter mais acesso a detalhes do corpus, que poderiam não ser notados manualmente, ampliando os horizontes de pesquisa.

A internet, por outro lado, com a grande disponibilização de material on-line, tornou a compilação rápida e eficiente. Teria sido muito difícil a compilação de textos da Nova Zelândia se não tivéssemos esse recurso.

Além disso, a ferramenta WordSmith Tools permitiu a obtenção de uma lista de palavras a partir dos textos do nosso corpus, com dados que seriam dificilmente manipulados manualmente. O programa ainda possibilitou o cruzamento dessas listas de palavras, o que eliminou grande parte do vocabulário que não era útil, uma vez que estávamos em busca das palavras de conteúdo de cada um dos subcorpora.

Um dos objetivos deste trabalho era a identificação do vocabulário específico de ecoturismo a partir do corpus compilado.

Como a análise de toda a lista tornava o trabalho muito extenso, e, portanto, inviável, partimos para a análise das dez primeiras palavras de cada lista de palavras-chave de cada uma das línguas. Cada dado pode ser levantado com relação às colocações, ou seja, às palavras próximas ao termo pesquisado e o 
acesso às linhas de concordância para analisarmos o contexto, a partir das quais as dúvidas sobre a utilização do termo foram sanadas.

Em nossa análise, pudemos observar que as agências de viagens em português apresentaram uma grande variedade de colocações com relação aos outros subcorpora. Além disso, as agências utilizaram um grande número de termos para descrever modalidades de turismo. Fizeram uso, inclusive, de termos diferentes para se referirem a uma mesma forma de turismo, como "turismo de massa", "turismo convencional", "turismo comum" e "turismo clássico", além de inúmeras formas para se referir a viagens a regiões naturais como "ecoturismo", "turismo ecológico", "turismo responsável", "turismo alternativo", "turismo ambiental", "turismo de/na natureza", "turismo em áreas naturais", "turismo não predatório", "turismo ambientalmente sustentável", "turismo de baixo impacto" e "turismo de cunho ecológico".

Isso vai ao encontro dos objetivos das agências de mostrar produtos diferenciados, inovadores, que possam ser mais atraentes e mais facilmente comercializados, uma vez que as pessoas, de modo geral, se interessam por novidades e têm motivação para experimentá-las.

Essa necessidade de atrair clientes a partir de novidades também ficou clara ao notarmos que o vocabulário encontrado no subcorpus de agências em português foi muito maior que o vocabulário dos demais subcorpora, o que confirma a necessidade de inovar.

Embora a variedade de formas encontradas em inglês não fosse tão significativa quanto em português, notamos a menção a um grande número de pássaros, peixes e plantas como forma de atrair o turista pela grande diversidade desses elementos encontrada na Nova Zelândia.

Pudemos notar também a importância de atividades de observação (de pássaros ou baleias), como uma atividade tipicamente ecoturística daquele país, ao contrário do que ocorre no Brasil, onde esse tipo de atividade é realizado principalmente por pesquisadores. Embora alguns sites em português já venham oferecendo esse tipo de atividade, isso ainda não faz parte da nossa cultura, que busca diferentes práticas em locais onde há riqueza natural. 
As entidades ambientalistas, por sua vez, deixam clara a preocupação com a preservação e a conservação, levantando sempre a questão da sustentabilidade, que é um item cada vez mais importante em projetos de desenvolvimento do ecoturismo.

As preocupações das entidades brasileiras e neozelandesas são similares, embora tenhamos encontrado uma maior menção à diversidade da Nova Zelândia nesse subcorpus.

Os órgãos governamentais revelaram algumas diferenças entre os dois países.

Sabe-se que o governo tem como objetivo principal a preservação e conservação das áreas naturais do país. Isso é feito através da criação de parques, reservas e unidades de conservação, visando a sobrevivência das diversas espécies de cada ecossistema.

Essa preocupação fica evidente pela utilização do vocabulário encontrado no subcorpus do governo: a necessidade de proteção, preservação, desenvolvimento de projetos, gestão das áreas preservadas, preocupação com a visitação e com os impactos que essas visitas podem causar. Isso os aproxima das entidades ambientalistas e suas metas.

No entanto, o turismo é, atualmente, a maior indústria do mundo, com crescimento estável e garantido, em parte, pelo sucesso na divulgação de roteiros, pacotes e atividades por parte das agências de turismo. O governo não pode ignorar o turismo, principalmente pela da renda gerada por essa atividade, principalmente com o crescimento do ecoturismo.

Nesse ponto o governo se vê diante de duas questões: proteger as áreas naturais e expandir a atividade turística nessas mesmas áreas, o que faz com que fique dividido e não tenha uma posição clara quanto ao quê fazer. Um exemplo disso é a divulgação de atividades de aventura como sendo atividades ecoturísticas. Há a necessidade de revisão dos conceitos de ecoturismo e turismo de aventura e da divulgação desse conceito de forma mais coerente por parte do governo.

Essa confusão não ocorre nos subcorpora do governo em inglês. Há uma definição mais clara quanto às diferenças entre as duas formas de turismo e as atividades de cada uma. 
A importância da observação de pássaros e baleias se faz presente nos três subcorpora em inglês, o que indica uma uniformidade de idéias quanto às atividades ecoturísticas.

Assim com o corpus das agências e dos ambientalistas, o governo também menciona locais, pássaros, peixes e plantas, o que também mostra a uniformidade quanto à valorização das riquezas naturais do país.

Os subcorpora em português fazem pouca menção à grande biodiversidade e maravilhas naturais que o Brasil possui, concentrando-se mais nas atividades.

Parece haver uma maior participação da comunidade com o aparecimento da palavra submitter(s) no subcorpus do governo da Nova Zelândia. No Brasil, isso ainda faz parte das atividades dos ambientalistas, que têm que fazer um trabalho de conscientização das comunidades. Embora isso possa resultar em melhorias, ainda não vemos essa participação ativa da comunidade no Brasil.

A Lingüística de Corpus vem se firmando cada vez mais como uma forma de análise de dados lingüísticos e compilação de dados para estudos diversos. Os trabalhos desenvolvidos no Brasil ainda são incipientes, até mesmo porque as próprias universidades ainda não trabalham sistematicamente com essa abordagem em seus cursos.

A descoberta da viabilidade da utilização da Lingüística de Corpus é útil não apenas aos pesquisadores da língua, mas também a todos os profissionais que necessitem fazer um levantamento de vocabulário especifico, por exemplo. Esse tipo de trabalho poderia se desenvolver, por exemplo, nos cursos de turismo, levando os alunos a aprender a lidar com a compilação de material em português ou outra língua que possa familiarizá-los com a linguagem específica de sua área.

Além disso, esse levantamento é de grande valia na produção de glossários para as mais diversas áreas, o que torna a Lingüística de Corpus uma ferramenta imprescindível nos trabalhos da Terminologia, pois além, da facilidade de manipulação dos dados, permite o desenvolvimento do trabalho a partir de textos autênticos.

Acreditamos, de modo geral, ter atingido os objetivos estabelecidos ao analisarmos as diferenças no modo como as três áreas - agências de turismo, entidades ambientalistas e órgãos governamentais - lidam com 0 assunto 
ecoturismo e como o vocabulário específico se comporta em cada uma dessas áreas. Além disso, mostramos como a Lingüística de Corpus pode ajudar na compilação de material e análise de vocabulário, abrindo possibilidade para novas pesquisas.

Entre os possíveis aspectos, sugerimos:

- a comprovação da metodologia apresentada a partir da sua aplicação em outros corpora, permitindo análises e comparações sobre a validade do processo empregado;

- a identificação, a partir dos agrupamentos de palavras levantados, dos termos que realmente poderiam ser considerados como da área de ecoturismo;

- a elaboração, a partir do levantamento desses agrupamentos, de um glossário de ecoturismo, útil não apenas para o público em geral, mas principalmente para tradutores e profissionais de ensino. 


\section{BIBLIOGRAFIA}

ALMEIDA, Gladis Maria de Barcellos; OLIVEIRA, Leandro Henrique Mendonça de y ALUISIO, Sandra Maria. A terminologia na era da informática. Ciência e Cultura, vol. 58 , n. 2, 2006, p. 42-45.

ALVES, leda Maria. A delimitação da unidade lexical nas línguas de especialidade. Revista Palavra, Departamento de Letras, PUC-Rio, 1999.

ALVES, leda Maria. A Constituição da Normalização Terminológica no Brasil. 2. ed. São Paulo: Humanitas Publicações - FFLCH/USP, 2001.

ANDRADE, J.V. Turismo: fundamentos e dimensões. São Paulo: Ática, 1995.

AUBERT, Francis Henrik. Introdução à metodologia da pesquisa terminológica bilíngüe. 2. ed. Cadernos de Terminologia. São Paulo: Humanitas Publicações FFLCH/USP, 2001.

BARROS, Lídia Almeida. Aspectos epistemológicos e perspectivas científicas da terminologia. Ciência e Cultura [online], vol. 58, n. 2, 2006, p.22-26. Disponível em $<$ http://cienciaecultura.bvs.br/scielo.php?script=sci_arttext\&pid=S0009-

$67252006000200011 \&$ Ing=es\& $n r m=i s o>$. ISSN 0009-6725.

BARROS, M. I. A. de. Outdoor Education: uma alternativa para a educação ambiental através do turismo de aventura. In: SERRANO, C. (Org.). A educação pelas pedras: ecoturismo e educação ambiental. São Paulo: Chronos, 2000.

; DINES, M. Mínimo impacto em áreas naturais: uma mudança de atitude. In: SERRANO, C. (Org). A educação pelas pedras: ecoturismo e educação ambiental. Coleção Tours. São Paulo: Chronos, 2000.

BECKER MACIEL, Anna Maria. Terminologia, linguagem de especialidade e dicionários. In: KRIEGER, Maria da Graça; MACIEL, Anna Maria B. (Org.). Temas de terminologia. Porto Alegre/São Paulo: Ed. Universidade/UFRGS/Humanitas/USP, 2001.

BENI, Mário Carlos. Análise Estrutural do Turismo. São Paulo: Editora Senac, 1998.

BERBER SARDINHA, Tony. Usando WordSmithTools na pesquisa lingüística. São Paulo/Liverpool: DIRECT Paper 40, 1999.

2000 .

. O que é um corpus representativo? São Paulo/Liverpool, DIRECT Paper 44

. Linguística de Corpus: histórico e problemática. D.E.L.T.A., São Paulo, v. 16, n. 2, 2000, p. 323-367

. Lingüística de Corpus. São Paulo: Manole, 2004.

BIBER, D.; CONRAD, S.; REPPEN, R. Corpus Linguistics: investigating language structure and use. Cambridge: Cambridge University Press, 1998. 
BIDERMAN, Maria Tereza Camargo. As Ciências do Léxico. In: OLIVEIRA, Ana Maria P. Pires; ISQUERDO, Aparecida Negri (Org). As Ciências do Léxico: Lexicologia, Lexicografia,Terminologia. Campo Grande: Editora UFMS, 1998.

$\mathrm{BOO}$, Elizabeth. O Planejamento do Ecoturismo para áreas protegidas. In: LINDBERG, Kreg \& HAWKINGS, Donald. Ecoturismo - um guia para planejamento e gestão. São Paulo: SENAC, 1993.

CABRÉ, M. T. Una nueva teoria de la Terminología: de la denominación a la comunicación. Actas do VI Simposio Ibero-americano de Terminología, Cuba, 1998.

. La terminología: representación y comunicación: elementos para una teoría de base comunicativa y otros artículos. Barcelona: IULA, Documenta Universitária, 1999.

. Cientificismo y pragmatismo em el campo de la Terminología. In: KRIEGER, Maria da Graça \& BECKER MACIEL, Anna Maria. Temas de terminologia. Porto Alegre/São Paulo: Ed. Universidade/Humanitas, 2001.

CAMARGO, Rosana et al. Como fazer turismo em uma cidade tão violenta como São Paulo. Revista Sinergia, vol. 3, n. 2, 2002.

CEBALLOS-LASCURÁIN, H. Ecoturismo, naturaleza y desarrollo sostenible. Ciudad de Mexico: Editorial Diana, 1998.

. O Ecoturismo como fenômeno mundial. In: LINDBERG, K.; COMISSÃO MUNDIAL SOBRE O MEIO AMBIENTE E DESENVOLVIMENTO (CMMAD). NosSO futuro comum. 2. ed. Rio de Janeiro: FGV, 1991.

CRUZ, Rita de Cássia. Introdução à Geografia do Turismo. São Paulo: Rocco, 2001.

DARIO, Aline Silviera. Avaliação de ações de empreendimentos ecoturísticos considerando a integração das dimensões conceituais do ecodesenvolvimento e do ecoturismo. Dissertação de Mestrado, Universidade Federal de Santa Catarina, Florianópolis, 2003.

DELGADO, J. A interpretação ambiental como instrumento para o ecoturismo. In: SERRANO, C. (Org). A Educação pelas pedras: ecoturismo e educação ambiental. Coleção Tours. São Paulo: Chronos, 2000.

EMBRATUR. Diretrizes para uma política nacional de ecoturismo. Brasília, 1994.

FAULSTICH, Enilde. Socioterminologia: mais que um método de pesquisa, uma disciplina. Ciência da Informação, Brasília, vol. 24, n. 3, 1995.

FENNEL, D. Ecoturismo: uma introdução. São Paulo: Contexto, 2002.

FILHO, João. Embratur. Da euforia ao esquecimento: o retorno às suas raízes quando serviu a ditadura militar. Revista turismo, maio, 2004.

GAMBIER, Y. Travail et vocabulaires spécialisés: prolégomènes à une socioterminologie. Meta, Montreal, v. 36, n. 1, 1991.

HARTMANN, F. Ecoturismo: uma alternativa para a Educação Ambiental. In : MATA, S. F.; GAVAZZA, S.; ALMEIDA, M. C. M. de; OLIVEIRA, C. L. de ; BARROS, R. 
(Orgs). Educação Ambiental: compromisso com a sociedade. Rio de Janeiro: MZ Editora, 1999.

HOEY, Michael. From concordance to text structure: new uses for computer corpora. In: LEWANDOWSKA-TOMASZCZYK, Barbara; MELIA, Patrick James (Eds.) International conference on practical applications in language corpora. Lódz: Lódz University Press, 1997.

HOEY, Martha. Patterns of Lexis in Text. Oxford: Oxford University Press, 1991. 1999. . Ecotourism and Sustained Development. Who Owns Paradise? Island Press,

KENNEDY, Graeme. An Introduction to Corpus Linguistics. London: Longman, 1998. KINKER, Sônia. Ecoturismo e Conservação da Natureza em Parques Nacionais. Campinas, SP: Papirus, 2002.

KRIEGER, Maria da Graça; BEVILACQUA, Cleci. A pesquisa terminológica no Brasil: uma contribuição para a consolidação da área. Revista debate terminológico, n. 1, 03/2005, 2004. Disponível em <www.riterm.net/revista/n_1/kriger.pdf>.

; FINATTO, Maria José B. Introdução à terminologia: Teoria \& Prática. São Paulo: Contexto.

; ARAÚJO, Luzia. A Terminologia em Foco. Cadernos de Tradução, n. 17, Porto Alegre, 2004.

LEECH, Geoffrey. Corpora and theories of linguistic performance. In: SVARTVIK, Jan. (Ed.). Directions in Corpus Linguistics. The Hague: Mouton the Gruyten, 1992.

McENERY, Tony; WILSON, Andrew. Corpus Linguistics. Edinburgh: Edinburgh University Press, 1997.

PASSOS, Deusa Maria de Souza-Pinheiro. Linguagem, Política e Ecologia. Uma análise do discurso de partidos verdes. São Paulo: Pontes, 2006.

PEARSON, Jennifer. Terms in Context. Amsterdan/Philadelphia: John Benajmins, 1998.

PIRES, P. dos S. Dimensões do ecoturismo. São Paulo: Editora SENAC, 2002.

PIRES, Mario Jorge. Raízes do Turismo no Brasil. 2. ed. São Paulo: Manole. 2001.

REJOWSKI, Mirian. Turismo e Pesquisa Científica. 3. ed. Campinas: Papirus, 1996.

RUSCHMANN, D. van de M. Turismo e planejamento sustentável: a proteção do meio ambiente. 6. ed. Campinas, SP: Papirus, 2000.

SACHS, Ignacy. Estratégias de transição para o século XXI: desenvolvimento e meio ambiente. São Paulo: Studio Nobel, 1993.

SALlOUTI-ALLEGRINI, Claudia Q. Gestão do Programa de Uso Público no Parque Estadual Turístico do Alto Ribeira: um Estudo de Caso de Implantação de Sistemas de Cobranças de Ingressos e Serviços. Dissertação (Mestrado em Ciência Ambiental). PROCAM-USP, São Paulo, 1999. 
SANABRIA, R. Exploring ecotourism certification: creating a conceptual framework for the Rainforest Alliance. JP Morgan Internship at the Rainforest Alliance, 1999. Disponível em: <www.rainforest.org>. Acesso em: 26 ago. 2004.

SANTOS, Raquel do Carmo. O uso da mulher na propaganda e o crescimento do turismo sexual. Jornal da Unicamp, n. 319, 17 a 23 de abril de 2006.

SERRANO, C. (Coord). Diretrizes para uma política estadual de ecoturismo. São Paulo: Governo do Estado de São Paulo: SMA, 1997.

SPINZI, Cinzia Giacinta. Travelling without a trace: a corpus study of the communicative process of 'eco-speaking'. ESP Across Cultures, Edizioni B.A. Graphis, 2004.

SWARBROOKE, J. Turismo sustentável: conceitos e impacto ambiental. Trad. de M. D. Pulido. São Paulo: Aleph, 2000. v. 1.

TAGNIN, Stella E. O. O jeito que a gente diz. Expressões convencionais e idiomáticas. São Paulo: Disal Editora, 2005.

TOGNINI-BONELLI, Elena. Corpus Linguistics at work. Amsterdam/ Philadelphia: John Benjamins, 2001.

WEARING, S.; NIEL, J. Ecoturismo: impactos, potencialidades e possibilidades. Barueri: Manole, 2001.

WAHAB, Salah-Eloi Abdel. Introdução à administração do turismo. 3. ed. São Paulo: Pioneira, 1991.

WESTERN, D. Definindo o ecoturismo. In: LINDEBERG, Kreg; HAWKINS, Donald E. (org.). Ecoturismo: um guia para planejamento e gestão. São Paulo: SENAC, 1999.

\section{Ferramenta de busca}

GOOGLE. Disponível em <http://www.google.com.br>.

WebCorp. Disponível em <http://www.webcorp.org.uk>.

\section{Software}

SCOTT, Mike. 1999, Wordsmith Tools version 3. Oxford: Oxford University Press. ISBN 0-19-459289-8.

\section{Sites}

Ministério do Turismo - www.mtur.gov.br

Organização Mundial de Turismo - www.wto.org

IBAMA - www.ibama.gov.br

Fundação Procon - www. http://www.procon.sp.gov.br/texto.asp?id=732 


\section{ANEXOS}

\section{ANEXO A - MAPA DO CORPUS}

\section{Ecoturismo}

\section{Agências de Turismo}

\section{Português}

\begin{tabular}{|l|l|l|l|l|}
\hline AgP001 & AgP023 & AgP045 & AgP067 & AgP089 \\
AgP002 & AgP024 & AgP046 & AgP068 & AgP090 \\
AgP003 & AgP025 & AgP047 & AgP069 & AgP091 \\
AgP004 & AgP026 & AgP048 & AgP070 & AgP092 \\
AgP005 & AgP027 & AgP049 & AgP071 & AgP093 \\
AgP006 & AgP028 & AgP050 & AgP072 & AgP094 \\
AgP007 & AgP029 & AgP051 & AgP073 & AgP095 \\
AgP008 & AgP030 & AgP052 & AgP074 & AgP096 \\
AgP009 & AgP031 & AgP053 & AgP075 & AgP097 \\
AgP010 & AgP032 & AgP054 & AgP076 & AgP098 \\
AgP011 & AgP033 & AgP055 & AgP077 & AgP099 \\
AgP012 & AgP034 & AgP056 & AgP078 & AgP100 \\
AgP013 & AgP035 & AgP057 & AgP079 & AgP101 \\
AgP014 & AgP036 & AgP058 & AgP080 & AgP102 \\
AgP015 & AgP037 & AgP059 & AgP081 & AgP103 \\
AgP016 & AgP038 & AgP060 & AgP082 & AgP104 \\
AgP017 & AgP039 & AgP061 & AgP083 & AgP105 \\
AgP018 & AgP040 & AgP062 & AgP084 & AgP106 \\
AgP019 & AgP041 & AgP063 & AgP085 & AgP107 \\
AgP020 & AgP042 & AgP064 & AgP086 & AgP108 \\
AgP021 & AgP043 & AgP065 & AgP087 & AgP109 \\
AgP022 & AgP044 & AgP066 & AgP088 & \\
\hline
\end{tabular}

\section{Inglês}

\begin{tabular}{|c|c|c|c|c|}
\hline Agl001 & $\mathrm{AgI021}$ & Agl041 & Agl061 & $\mathrm{Agl081}$ \\
\hline Agl002 & Agl022 & Agl042 & Agl062 & Agl082 \\
\hline Agl003 & Agl023 & Agl043 & Agl063 & Agl083 \\
\hline Agl004 & Agl024 & Agl044 & Agl064 & Agl084 \\
\hline Agl005 & Agl025 & Agl045 & Agl065 & Agl085 \\
\hline Agl006 & Agl026 & Agl046 & Agl066 & Agl086 \\
\hline Agl007 & Agl027 & Agl047 & Agl067 & Agl087 \\
\hline Agl008 & Agl028 & Agl048 & Agl068 & Agl088 \\
\hline Agl009 & Agl029 & Agl049 & Agl069 & Agl089 \\
\hline Agl010 & Agl030 & Agl050 & Agl070 & Agl090 \\
\hline Agl011 & Agl031 & Agl051 & Agl071 & Agl091 \\
\hline Agl012 & Agl032 & Agl052 & Agl072 & Agl092 \\
\hline Agl013 & Agl033 & Agl053 & Agl073 & Agl093 \\
\hline Agl014 & Agl034 & Agl054 & Agl074 & Agl094 \\
\hline Agl015 & Agl035 & Agl055 & Agl075 & Agl095 \\
\hline Agl016 & Agl036 & Agl056 & Agl076 & Agl096 \\
\hline Agl017 & Agl037 & Agl057 & Agl077 & Agl097 \\
\hline Agl018 & Agl038 & Agl058 & Agl078 & Agl098 \\
\hline Agl019 & Agl039 & Agl059 & Agl079 & Agl099 \\
\hline Agl020 & Agl040 & Agl060 & Agl080 & Agl100 \\
\hline
\end{tabular}




\section{Entidades Ambientalistas (AMB)}

\section{Português}

\begin{tabular}{|l|l|l|l|l|}
\hline AmbP001 & AmbP012 & AmbP023 & AmbP034 & AmbP045 \\
AmbP002 & AmbP013 & AmbP024 & AmbP035 & AmbP046 \\
AmbP003 & AmbP014 & AmbP025 & AmbP036 & AmbP047 \\
AmbP004 & AmbP015 & AmbP026 & AmbP037 & AmbP048 \\
AmbP005 & AmbP016 & AmbP027 & AmbP038 & AmbP049 \\
AmbP006 & AmbP017 & AmbP028 & AmbP039 & AmbP050 \\
AmbP007 & AmbP018 & AmbP029 & AmbP040 & AmbP051 \\
AmbP008 & AmbP019 & AmbP030 & AmbP041 & \\
AmbP009 & AmbP020 & AmbP031 & AmbP042 & \\
AmbP010 & AmbP021 & AmbP032 & AmbP043 & \\
AmbP011 & AmbP022 & AmbP033 & AmbP044 & \\
\hline
\end{tabular}

\section{Inglês}

\begin{tabular}{|c|c|c|c|}
\hline Ambl001 & Ambl011 & Ambl021 & Ambl031 \\
Ambl002 & Ambl012 & Ambl022 & Ambl032 \\
Ambl003 & Ambl013 & Ambl023 & Ambl033 \\
Ambl004 & Ambl014 & Ambl024 & Ambl034 \\
Ambl005 & Ambl015 & Ambl025 & Ambl035 \\
Ambl006 & Ambl016 & Ambl026 & Ambl036 \\
Ambl007 & Ambl017 & Ambl027 & Ambl037 \\
Ambl008 & Ambl018 & Ambl028 & Ambl038 \\
Ambl009 & Ambl019 & Ambl029 & Ambl039 \\
Ambl010 & Ambl020 & Ambl030 & \\
\hline
\end{tabular}

\section{Órgãos Governamentais}

\section{Português}

\begin{tabular}{|l|l|l|l|}
\hline GovP001 & GovP008 & GovP015 & GovP022 \\
GovP002 & GovP009 & GovP016 & GovP023 \\
GovP003 & GovP010 & GovP017 & GovP024 \\
GovP004 & GovP011 & GovP018 & GovP025 \\
GovP005 & GovP012 & GovP019 & GovP026 \\
GovP006 & GovP013 & GovP020 & GovP027 \\
GovP007 & GovP014 & GovP021 & GovP028 \\
\hline
\end{tabular}

\section{Inglês}

\begin{tabular}{|l|l|l|l|l|}
\hline Govl001 & Govl007 & Govl013 & Govl019 & Govl025 \\
Govl002 & Govl008 & Govl014 & Govl020 & Govl026 \\
Govl003 & Govl009 & Govl015 & Govl021 & Govl028 \\
Govl004 & Govl010 & Govl016 & Govl022 & Govl029 \\
Govl005 & Govl011 & Govl017 & Govl023 & Govl030 \\
Govl006 & Govl012 & Govl018 & Govl024 &
\end{tabular}




\section{ANEXO B - KEYWORDS: RESULTADO DO CRUZAMENTO DAS LISTAS DOS SUBCORPORA DE ESTUDO EM PORTUGUÊS COM O RESPECTIVO CORPUS DE REFERÊNCIA}

Optamos por apresentar apenas a relação das palavras.

\begin{tabular}{|c|c|c|c|c|c|}
\hline \multicolumn{3}{|c|}{ Agências de turismo } & \multicolumn{2}{|c|}{ Entidades ambientalistas } & $\begin{array}{c}\text { Órgãos } \\
\text { governamentais }\end{array}$ \\
\hline $\mathbf{N}$ & WORD & $\mathbf{N}$ & WORD & $\mathbf{N}$ & WORD \\
\hline 1 & $\mathrm{DE}$ & 1 & $\mathrm{DE}$ & 1 & $\mathrm{DE}$ \\
\hline 2 & $E$ & 2 & $E$ & 2 & $E$ \\
\hline 3 & $A$ & 3 & $A$ & 3 & $\mathrm{~A}$ \\
\hline 4 & 0 & 4 & 0 & 4 & DO \\
\hline 5 & $\mathrm{DO}$ & 5 & $\mathrm{DO}$ & 5 & 0 \\
\hline 6 & $\mathrm{DA}$ & 6 & $\mathrm{DA}$ & 6 & DA \\
\hline 7 & QUE & 7 & QUE & 7 & PARA \\
\hline 8 & EM & 8 & PARA & 8 & QUE \\
\hline 9 & PARA & 9 & EM & 9 & EM \\
\hline 10 & $\mathrm{COM}$ & 10 & $\mathrm{COM}$ & 10 & os \\
\hline 11 & É & 11 & UM & 11 & NO \\
\hline 12 & UM & 12 & TURISMO & 12 & COM \\
\hline 13 & OS & 13 & NO & 13 & DOS \\
\hline 14 & SE & 14 & os & 14 & AS \\
\hline 15 & UMA & 15 & UMA & 15 & DAS \\
\hline 16 & NO & 16 & DOS & 16 & TURISMO \\
\hline 17 & AS & 17 & ECOTURISMO & 17 & SÃO \\
\hline 18 & DOS & 18 & $\mathrm{SE}$ & 18 & SE \\
\hline 19 & COMO & 19 & COMO & 19 & COMO \\
\hline 20 & NA & 20 & AS & 20 & É \\
\hline 21 & POR & 21 & É & 21 & UMA \\
\hline 22 & TURISMO & 22 & NA & 22 & UM \\
\hline 23 & MAIS & 23 & DAS & 23 & NA \\
\hline 24 & SÃO & 24 & DESENVOLVIMENT+ & 24 & ECOTURISMO \\
\hline 25 & DAS & 25 & POR & 25 & $\mathrm{AO}$ \\
\hline 26 & NÃO & 26 & $\mathrm{AO}$ & 26 & POR \\
\hline 27 & $\mathrm{AO}$ & 27 & AMBIENTAL & 27 & OU \\
\hline 28 & ECOTURISMO & 28 & BRASIL & 28 & PARQUES \\
\hline 29 & $\mathrm{OU}$ & 29 & NÃO & 29 & ATIVIDADES \\
\hline 30 & SER & 30 & SUSTENTÁVEL & 30 & À \\
\hline 31 & À & 31 & MEIO & 31 & PROJETO \\
\hline 32 & SUA & 32 & SÃO & 32 & ESTADO \\
\hline 33 & $\mathrm{RIO}$ & 33 & À & 33 & DESENVOLVIMENT+ \\
\hline 34 & AMBIENTAL & 34 & $\mathrm{OU}$ & 34 & CONSERVAÇÃO \\
\hline 35 & REGIÃO & 35 & AMBIENTE & 35 & NÃO \\
\hline 36 & PELA & 36 & MAIS & 36 & ATIVIDADE \\
\hline 37 & MEIO & 37 & SER & 37 & MAIS \\
\hline
\end{tabular}




\begin{tabular}{|r|l|}
\hline 38 & DESENVOLVIMENT + \\
\hline 39 & BRASIL \\
\hline 40 & ENTRE \\
\hline 41 & SUSTENTÁVEL \\
\hline 42 & AMBIENTE \\
\hline 43 & GRANDE \\
\hline 44 & TAMBÉM \\
\hline 45 & PELO \\
\hline 46 & ATIVIDADES \\
\hline 47 & NATURAIS \\
\hline 48 & NATUREZA \\
\hline 49 & FOI \\
\hline 50 & NOS \\
\hline 51 & TEM \\
\hline 52 & ONDE \\
\hline 53 & NAS \\
\hline 54 & LOCAL \\
\hline 55 & ATIVIDADE \\
\hline 56 & BR \\
\hline 57 & SEU \\
\hline 58 & PARQUE \\
\hline 59 & SOBRE \\
\hline 60 & ÁREA \\
\hline 61 & ALÉM \\
\hline 62 & ESTÁ \\
\hline 63 & SEUS \\
\hline 64 & ATÉ \\
\hline 65 & ÁREAS \\
\hline 66 & PODE \\
\hline 67 & LOCAIS \\
\hline 68 & WWW \\
\hline 69 & AVENTURA \\
\hline 70 & SERRA \\
\hline 71 & CONSERVAÇÃO \\
\hline 72 & RECURSOS \\
\hline 73 & MUITO \\
\hline 74 & AINDA \\
\hline 75 & MAS \\
\hline 76 & NACIONAL \\
\hline 77 & MAIOR \\
\hline 78 & PESSOAS \\
\hline 79 & FORMA \\
\hline 80 & SUAS \\
\hline 81 & SEM \\
\hline 82 & ESPÉCIES \\
\hline 83 & AOS \\
\hline 84 & JÁ \\
\hline 85 & ÁGUA \\
\hline 86 & RIOS \\
\hline & \\
\hline 5
\end{tabular}

\begin{tabular}{|r|l|}
\hline 38 & SOBRE \\
\hline 39 & CONSERVAÇÃO \\
\hline 40 & NATUREZA \\
\hline 41 & WWF \\
\hline 42 & ENTRE \\
\hline 43 & FOI \\
\hline 44 & SUA \\
\hline 45 & PELA \\
\hline 46 & PELO \\
\hline 47 & PROJETO \\
\hline 48 & SUSTENTABILIDA+ \\
\hline 49 & TAMBÉM \\
\hline 50 & CERTIFICAÇÃO \\
\hline 51 & NACIONAL \\
\hline 52 & LOCAIS \\
\hline 53 & REGIÃO \\
\hline 54 & ÁREAS \\
\hline 55 & NOS \\
\hline 56 & PROGRAMA \\
\hline 57 & CULTURAL \\
\hline 58 & COMUNIDADES \\
\hline 59 & EDUCAÇÃO \\
\hline 60 & RECURSOS \\
\hline 61 & FORMA \\
\hline 62 & PARQUE \\
\hline 63 & TEM \\
\hline 64 & ATIVIDADES \\
\hline 65 & BR \\
\hline 66 & ATIVIDADE \\
\hline 67 & SOCIAL \\
\hline 68 & CABO \\
\hline 69 & FRIO \\
\hline 70 & ÁREA \\
\hline 71 & PANTANAL \\
\hline 72 & TRABALHO \\
\hline 73 & NATURAIS \\
\hline 74 & SEUS \\
\hline 75 & SETOR \\
\hline 76 & PLANEJAMENTO \\
\hline 77 & MUNDO \\
\hline 78 & PROJETOS \\
\hline 79 & ANOS \\
\hline 80 & USO \\
\hline 81 & SUAS \\
\hline 82 & POLÍTICAS \\
\hline 83 & ESTÁ \\
\hline 84 & AOS \\
\hline 85 & ORG \\
\hline 86 & INTERNACIONAL \\
\hline & \\
\hline
\end{tabular}

\begin{tabular}{|r|l|}
\hline 38 & AMBIENTAL \\
\hline 39 & PAULO \\
\hline 40 & AVENTURA \\
\hline 41 & VISITAÇÃO \\
\hline 42 & CADA \\
\hline 43 & PARQUE \\
\hline 44 & NOS \\
\hline 45 & UNIDADES \\
\hline 46 & SER \\
\hline 47 & ESTADUAL \\
\hline 48 & ÁREAS \\
\hline 49 & REGIÃO \\
\hline 50 & IMPACTOS \\
\hline 51 & MEIO \\
\hline 52 & NAS \\
\hline 53 & SOBRE \\
\hline 54 & PELA \\
\hline 55 & AMBIENTE \\
\hline 56 & SMA \\
\hline 57 & AÇÕES \\
\hline 58 & NATURAIS \\
\hline 59 & ENTRE \\
\hline 60 & AOS \\
\hline 61 & RECURSOS \\
\hline 62 & SUSTENTÁVEL \\
\hline 63 & SUA \\
\hline 64 & TAMBÉM \\
\hline 65 & GESTÃO \\
\hline 66 & LOCAIS \\
\hline 67 & PELO \\
\hline 68 & RESPONSABILIDA+ \\
\hline 69 & TURÍSTICO \\
\hline 70 & FOI \\
\hline 71 & COMUNIDADES \\
\hline 72 & ESTRUTURA \\
\hline 73 & REGIONAL \\
\hline 74 & BRASIL \\
\hline 75 & SETOR \\
\hline 76 & ÁREA \\
\hline 77 & NESTE \\
\hline 78 & VISITANTES \\
\hline 79 & JÁ \\
\hline 80 & ALÉM \\
\hline 81 & GRANDE \\
\hline 82 & MUNICÍPIOS \\
\hline 83 & MERCADO \\
\hline 84 & IMPLANTAÇÃO \\
\hline 85 & USO \\
\hline 86 & SERVIÇOS \\
\hline & \\
\hline
\end{tabular}




\begin{tabular}{|c|c|}
\hline 87 & ESTADO \\
\hline 88 & TODOS \\
\hline 89 & HTTP \\
\hline 90 & PARTE \\
\hline 91 & NATURAL \\
\hline 92 & DEVE \\
\hline 93 & CIDADE \\
\hline 94 & BEM \\
\hline 95 & OUTROS \\
\hline 96 & VISITANTES \\
\hline 97 & MESMO \\
\hline 98 & QUALIDADE \\
\hline 99 & HÁ \\
\hline 100 & CADA \\
\hline 101 & MUNDO \\
\hline 102 & KM \\
\hline 103 & ATRAVÉS \\
\hline 104 & MATA \\
\hline 105 & ÀS \\
\hline 106 & SENDO \\
\hline 107 & FAUNA \\
\hline 108 & PAís \\
\hline 109 & PODEM \\
\hline 110 & AMBIENTAIS \\
\hline 111 & TRILHAS \\
\hline 112 & ESTÃO \\
\hline 113 & VIDA \\
\hline 114 & PRODUTOS \\
\hline 115 & PROJETO \\
\hline 116 & ESTA \\
\hline 117 & PROGRAMA \\
\hline 118 & OUTRAS \\
\hline 119 & ESTE \\
\hline 120 & MERCADO \\
\hline 121 & ANOS \\
\hline 122 & SUSTENTABILIDA+ \\
\hline 123 & HOJE \\
\hline 124 & SEGURANÇA \\
\hline 125 & TEMPO \\
\hline 126 & ITACARÉ \\
\hline 127 & MUNICÍPIO \\
\hline 128 & MELHOR \\
\hline 129 & USO \\
\hline 130 & VOCÊ \\
\hline 131 & CERTIFICAÇÃO \\
\hline 132 & SOCIAL \\
\hline 133 & TRILHA \\
\hline 134 & PRÁTICA \\
\hline 135 & PELOS \\
\hline
\end{tabular}

\begin{tabular}{|r|l|}
\hline 87 & PROCESSO \\
\hline 88 & FIECOTUR \\
\hline 89 & ALÉM \\
\hline 90 & GESTÃO \\
\hline 91 & ECOLÓGICO \\
\hline 92 & HOMEM \\
\hline 93 & SOCIEDADE \\
\hline 94 & APOIO \\
\hline 95 & NAS \\
\hline 96 & PODE \\
\hline 97 & AMBIENTAIS \\
\hline 98 & QUALIDADE \\
\hline 99 & AINDA \\
\hline 100 & OUTROS \\
\hline 101 & FORAM \\
\hline 102 & HÁ \\
\hline 103 & COMUNIDADE \\
\hline 104 & LOCAL \\
\hline 105 & MUNICIPAL \\
\hline 106 & TEIA \\
\hline 107 & MAS \\
\hline 108 & TURISTAS \\
\hline 109 & MERCADO \\
\hline 110 & LAGOS \\
\hline 111 & VISITANTES \\
\hline 112 & SEU \\
\hline 113 & ATÉ \\
\hline 114 & BRASILEIRO \\
\hline 115 & CULTURA \\
\hline 116 & TODOS \\
\hline 117 & POLÍTICA \\
\hline 118 & ESTE \\
\hline 119 & NOVOS \\
\hline 120 & DIRETOR \\
\hline 121 & SOCIAIS \\
\hline 122 & NATURAL \\
\hline 123 & PRODUTOS \\
\hline 124 & BASE \\
\hline 125 & SENDO \\
\hline 126 & RESPONSÁVEL \\
\hline 127 & SISTEMA \\
\hline 128 & PARTE \\
\hline 129 & FEIRA \\
\hline 130 & ORGANIZAÇÃO \\
\hline 131 & MATA \\
\hline 132 & PAÍS \\
\hline 133 & AÇÕES \\
\hline 134 & ÁS \\
\hline 135 & DEVE \\
\hline & \\
\hline 10.9
\end{tabular}

\begin{tabular}{|r|l|}
\hline 87 & NACIONAL \\
\hline 88 & ÀS \\
\hline 89 & SECRETARIA \\
\hline 90 & RIBEIRA \\
\hline 91 & EQUIPAMENTOS \\
\hline 92 & ANO \\
\hline 93 & PLANEJAMENTO \\
\hline 94 & FORMA \\
\hline 95 & TEM \\
\hline 96 & PÚBLICA \\
\hline 97 & ATRAVÉS \\
\hline 98 & TEXTOS \\
\hline 99 & ATRATIVOS \\
\hline 100 & PROGRAMA \\
\hline 101 & TURISTAS \\
\hline 102 & SEU \\
\hline 103 & INFRA \\
\hline 104 & PESSOAS \\
\hline 105 & ORGANIZAÇÃO \\
\hline 106 & ONDE \\
\hline 107 & MAIOR \\
\hline 108 & ESTÃO \\
\hline 109 & VALE \\
\hline 110 & MATA \\
\hline 111 & ESTÁ \\
\hline 112 & ETC \\
\hline 113 & TURÍSTICA \\
\hline 114 & PROJETOS \\
\hline 115 & OUTROS \\
\hline 116 & HÁ \\
\hline 117 & SUAS \\
\hline 118 & ATLÂNTICA \\
\hline 119 & ENTIDADES \\
\hline 120 & APOIO \\
\hline 121 & FLORESTAL \\
\hline 122 & PODE \\
\hline 123 & TURÍSTICOS \\
\hline 124 & FORAM \\
\hline 125 & SEGMENTO \\
\hline 126 & OUTRAS \\
\hline 127 & SEUS \\
\hline 128 & I \\
\hline 129 & TODOS \\
\hline 130 & SET \\
\hline 131 & ESTADUAIS \\
\hline 132 & TURISTA \\
\hline 133 & CAPACITAÇÃO \\
\hline 135 & AINDA \\
\hline & \\
\hline $10 S O S$ \\
\hline 10.1
\end{tabular}




\begin{tabular}{|c|c|}
\hline 136 & TODO \\
\hline 137 & FORAM \\
\hline 138 & ESTRUTURA \\
\hline 139 & COMUNIDADE \\
\hline 140 & SEMPRE \\
\hline 141 & QUANDO \\
\hline 142 & DESDE \\
\hline 143 & EQUIPAMENTOS \\
\hline 144 & PROCESSO \\
\hline 145 & ASSIM \\
\hline 146 & BASE \\
\hline 147 & TRABALHO \\
\hline 148 & SUL \\
\hline 149 & SP \\
\hline 150 & ETC \\
\hline 151 & SEJA \\
\hline 152 & PRÁTICAS \\
\hline 153 & ÁGUAS \\
\hline 154 & FLORA \\
\hline 155 & CAVERNAS \\
\hline 156 & DURANTE \\
\hline 157 & CULTURAL \\
\hline 158 & TURISTAS \\
\hline 159 & CACHOEIRA \\
\hline 160 & SERVIÇOS \\
\hline 161 & TERRA \\
\hline 162 & PAULO \\
\hline 163 & POIS \\
\hline 164 & ANO \\
\hline 165 & DENTRO \\
\hline 166 & BRASILEIRO \\
\hline 167 & ANIMAIS \\
\hline 168 & CULTURA \\
\hline 169 & PANTANAL \\
\hline 170 & ROTEIROS \\
\hline 171 & PRINCIPAIS \\
\hline 172 & COMUNIDADES \\
\hline 173 & HOMEM \\
\hline 174 & VEGETAÇÃO \\
\hline 175 & TODAS \\
\hline 176 & APENAS \\
\hline 177 & ESSA \\
\hline 178 & EMPRESAS \\
\hline 179 & PRAIA \\
\hline 180 & IMPACTOS \\
\hline 181 & EDUCAÇÃO \\
\hline 182 & CULTURAIS \\
\hline 183 & PRESERVAÇÃO \\
\hline 184 & DIA \\
\hline
\end{tabular}

\begin{tabular}{|r|l|}
\hline 136 & CAMPOS \\
\hline 137 & ONDE \\
\hline 138 & TURÍSTICO \\
\hline 139 & MUITO \\
\hline 140 & MESMO \\
\hline 141 & ATLÂNTICA \\
\hline 142 & PARTICIPAÇÃO \\
\hline 143 & ATEIA \\
\hline 144 & WWW \\
\hline 145 & GRANDE \\
\hline 146 & PROGRAMAS \\
\hline 147 & INFORMAÇÕES \\
\hline 148 & PESSOAS \\
\hline 149 & DIA \\
\hline 150 & JÁ \\
\hline 151 & PAULO \\
\hline 152 & SERVIÇOS \\
\hline 153 & CULTURAIS \\
\hline 154 & PÚBLICO \\
\hline 155 & DIRETRIZES \\
\hline 156 & SEM \\
\hline 157 & SERÁ \\
\hline 158 & ESTA \\
\hline 159 & FUNDAÇÃO \\
\hline 160 & OUTRAS \\
\hline 161 & RIO \\
\hline 162 & DURANTE \\
\hline 163 & ESSA \\
\hline 164 & PATRIMÔNIO \\
\hline 165 & PESQUISA \\
\hline 166 & GRUPO \\
\hline 167 & EMPRESAS \\
\hline 168 & MINISTÉRIO \\
\hline 169 & PARCERIA \\
\hline 170 & QUESTÃO \\
\hline 171 & VIDA \\
\hline 172 & ESTADO \\
\hline 173 & CONCEITO \\
\hline 174 & MARKETING \\
\hline 175 & MAIOR \\
\hline 176 & ISSO \\
\hline 177 & BEM \\
\hline 178 & DOCUMENTO \\
\hline 179 & ESTÃO \\
\hline 180 & PÚBLICAS \\
\hline 181 & IMPLEMENTAÇÃO \\
\hline 182 & ECONÔMICA \\
\hline 183 & RESERVA \\
\hline 184 & VISITAÇÃO \\
\hline & \\
\hline
\end{tabular}

\begin{tabular}{|c|c|}
\hline 136 & LOCAL \\
\hline 137 & PRÁTICA \\
\hline 138 & PARTICIPAÇÃO \\
\hline 139 & SEGURANÇA \\
\hline 140 & SEM \\
\hline 141 & EMBRATUR \\
\hline 142 & PLANO \\
\hline 143 & ILHA \\
\hline 144 & RIO \\
\hline 145 & RELAÇÃO \\
\hline 146 & PROMOVER \\
\hline 147 & TRILHAS \\
\hline 148 & MANEJO \\
\hline 149 & NATURAL \\
\hline 150 & ILHABELA \\
\hline 151 & PELOS \\
\hline 152 & SENDO \\
\hline 153 & PARTE \\
\hline 154 & ESTUDOS \\
\hline 155 & SEMINÁRIO \\
\hline 156 & EDUCAÇÃO \\
\hline 157 & MERGULHO \\
\hline 158 & ESSE \\
\hline 159 & DEVE \\
\hline 160 & QUALIDADE \\
\hline 161 & SISTEMA \\
\hline 162 & AMBIENTAIS \\
\hline 163 & MAS \\
\hline 164 & OBRAS \\
\hline 165 & MESMO \\
\hline 166 & ESTRATÉGIA \\
\hline 167 & AMAZÔNIA \\
\hline 168 & PROTEÇÃO \\
\hline 169 & PROGRAMAS \\
\hline 170 & REGULAMENTAÇÃO \\
\hline 171 & SERÃO \\
\hline 172 & PRESENTE \\
\hline 173 & PATRIMÔNIO \\
\hline 174 & ATÉ \\
\hline 175 & ESTE \\
\hline 176 & ENTORNO \\
\hline 177 & TÉCNICAS \\
\hline 178 & SOCIEDADE \\
\hline 179 & ÓRGÃOS \\
\hline 180 & ETAPA \\
\hline 181 & INFORMAÇÕES \\
\hline 182 & PÚBLICO \\
\hline 183 & INSTITUTO \\
\hline 184 & PARTICIPANTES \\
\hline
\end{tabular}




\begin{tabular}{|l|l|}
\hline 185 & IMPORTANTE \\
\hline 186 & PELAS \\
\hline 187 & TER \\
\hline 188 & CASO \\
\hline 189 & ESSE \\
\hline 190 & MAR \\
\hline 191 & GRUPO \\
\hline 192 & ECOLÓGICO \\
\hline 193 & ACESSO \\
\hline 194 & OBJETIVO \\
\hline 195 & PRAIAS \\
\hline 196 & HTML \\
\hline 197 & ECOSSISTEMAS \\
\hline 198 & ALGUMAS \\
\hline 199 & PROTEÇÃO \\
\hline 200 & CERCA \\
\hline 201 & CACHOEIRAS \\
\hline 202 & PLANEJAMENTO \\
\hline 203 & ISSO \\
\hline 204 & POSSUI \\
\hline 205 & GUIAS \\
\hline 206 & FLORESTA \\
\hline 207 & TIPO \\
\hline 208 & GRANDES \\
\hline 209 & PARTIR \\
\hline 210 & METROS \\
\hline 211 & NÚMERO \\
\hline 212 & FAZER \\
\hline 213 & ATLÂNTICA \\
\hline 214 & ALAYA \\
\hline 215 & MELHORES \\
\hline 216 & SÓ \\
\hline 217 & VISITAC̃̃̃O \\
\hline 218 & ATRATIVOS \\
\hline 219 & ESTUDOS \\
\hline 220 & INFRA \\
\hline 221 & DOIS \\
\hline 222 & IMPACTO \\
\hline 223 & PLANO \\
\hline 224 & SOCIEDADE \\
\hline 225 & EXPERIÊNCIA \\
\hline 226 & PÓLO \\
\hline 227 & IMPORTÂNCIA \\
\hline 228 & VEZ \\
\hline 229 & CENTRO \\
\hline 230 & INTERNACIONAL \\
\hline 231 & TURÍSTICO \\
\hline 232 & CHAPADA \\
\hline 233 & VIAGEM \\
\hline & \\
\hline
\end{tabular}

\begin{tabular}{|l|l|}
185 & PARTICIPANTES \\
\hline 186 & IMPLANTAÇÃO \\
\hline 187 & INSTITUTO \\
\hline 188 & SEMINÁRIO \\
\hline 189 & ASSOCIAÇÃO \\
\hline 190 & PROTEÇÃO \\
\hline 191 & MUNDIAL \\
\hline 192 & ASSIM \\
\hline 193 & DESDE \\
\hline 194 & OBJETIVO \\
\hline 195 & ELABORAÇÃO \\
\hline 196 & ATRAVÉS \\
\hline 197 & PROTEGIDAS \\
\hline 198 & GOVERNO \\
\hline 199 & CONSELHO \\
\hline 200 & TÊM \\
\hline 201 & CRIAÇÃO \\
\hline 202 & TAIS \\
\hline 203 & PRODUTO \\
\hline 204 & RELAÇÃO \\
\hline 205 & CAPACITAÇÃO \\
\hline 206 & PRINCIPAIS \\
\hline 207 & ECONÔMICO \\
\hline 208 & PRESIDENTE \\
\hline 209 & ANO \\
\hline 210 & TEMA \\
\hline 211 & EXPERIÊNCIAS \\
\hline 212 & VEM \\
\hline 213 & ESTRADA \\
\hline 214 & PELOS \\
\hline 215 & TER \\
\hline 216 & RESULTADOS \\
\hline 217 & BENEFÍCIOS \\
\hline 218 & IMPORTÂNCIA \\
\hline 219 & NOVEMBRO \\
\hline 220 & PRÁTICA \\
\hline 221 & BIODIVERSIDADE \\
\hline 222 & MODELO \\
\hline 223 & PROPOSTA \\
\hline 224 & ESTRUTURA \\
\hline 225 & PROBLEMAS \\
\hline 226 & RESPEITO \\
\hline 227 & EVENTO \\
\hline 228 & SECRETARIA \\
\hline 229 & PARTIR \\
\hline 230 & PESCA \\
\hline 231 & THE \\
\hline 232 & CADA \\
\hline 233 & CONSUMO \\
\hline & \\
\hline
\end{tabular}

\begin{tabular}{|l|l|}
185 & ALGUNS \\
\hline 186 & CULTURAL \\
\hline 187 & ETAPAS \\
\hline 188 & UNIDADE \\
\hline 189 & DESDE \\
\hline 190 & PLANOS \\
\hline 191 & ASSIM \\
\hline 192 & FUNDAÇÃO \\
\hline 193 & PRODUTOS \\
\hline 194 & RESPONSÁVEL \\
\hline 195 & QUEM \\
\hline 196 & APRESENTAÇÃO \\
\hline 197 & TODO \\
\hline 198 & PROCESSO \\
\hline 199 & APENAS \\
\hline 200 & GOVERNO \\
\hline 201 & PÁRA \\
\hline 202 & TRABALHO \\
\hline 203 & CONDIÇÕES \\
\hline 204 & MUNICÍPIO \\
\hline 205 & PAÍS \\
\hline 206 & NATUREZA \\
\hline 207 & SUL \\
\hline 208 & POSSUI \\
\hline 209 & REPRESENTAM \\
\hline 210 & SERÁ \\
\hline 211 & RESUMO \\
\hline 212 & OBJETIVOS \\
\hline 213 & BEM \\
\hline 214 & NÚCLEO \\
\hline 215 & INVESTIMENTOS \\
\hline 216 & LITORAL \\
\hline 217 & CRIAÇÃO \\
\hline 218 & PONTOS \\
\hline 219 & BRASILEIRA \\
\hline 220 & MUNICIPAL \\
\hline 221 & CIVIL \\
\hline 222 & SERRA \\
\hline 223 & TÉCNICA \\
\hline 224 & CASO \\
\hline 225 & DURANTE \\
\hline 226 & POLÍTICA \\
\hline 227 & SEJA \\
\hline 228 & ESTA \\
\hline 229 & COMPLEMENTARES \\
\hline 230 & VEZ \\
\hline 231 & PREFEITURAS \\
\hline 232 & ESTRATÉGIAS \\
\hline & EMPRESAS \\
\hline
\end{tabular}




\begin{tabular}{|l|l|}
234 & ALTO \\
\hline 235 & ALGUNS \\
\hline 236 & TODA \\
\hline 237 & CONDIÇÕES \\
\hline 238 & PATRIMÔNIO \\
\hline 239 & MPE \\
\hline 240 & DIFERENTES \\
\hline 241 & QUEM \\
\hline 242 & TÉCNICAS \\
\hline 243 & LUGAR \\
\hline 244 & ROTEIRO \\
\hline 245 & ESTADUAL \\
\hline 246 & RESERVA \\
\hline 247 & PROJETOS \\
\hline 248 & TÊM \\
\hline 249 & POSSÍVEL \\
\hline 250 & DEVEM \\
\hline 251 & PERCURSO \\
\hline 252 & ILHA \\
\hline 253 & SERÁ \\
\hline 254 & BONITO \\
\hline 255 & MUITAS \\
\hline 256 & FAZ \\
\hline 257 & MUITOS \\
\hline 258 & NOSSA \\
\hline 259 & QUALQUER \\
\hline 260 & INSTITUTO \\
\hline 261 & CONHECER \\
\hline 262 & PRINCIPALMENTE \\
\hline 263 & NORTE \\
\hline 264 & DIAS \\
\hline 265 & RELAÇÃO \\
\hline 266 & GRUPOS \\
\hline 267 & INTERPRETAÇÃO \\
\hline 268 & ESPORTE \\
\hline 269 & CRIAÇÃO \\
\hline 270 & CIPÓ \\
\hline 271 & VIAGENS \\
\hline 272 & EQUIPE \\
\hline 273 & CAMPOS \\
\hline 274 & INFORMAÇÕES \\
\hline 275 & BUSCA \\
\hline 276 & SETOR \\
\hline 277 & TURÍSTICA \\
\hline 278 & MENOS \\
\hline 279 & POPULAÇÃO \\
\hline 280 & FORMAÇÃO \\
\hline 281 & EXEMPLO \\
\hline 282 & LIXO \\
\hline & \\
\hline
\end{tabular}

\begin{tabular}{|c|c|}
\hline 234 & ALGUNS \\
\hline 235 & TURÍSTICOS \\
\hline 236 & IDÉIA \\
\hline 237 & MELHOR \\
\hline 238 & PODEM \\
\hline 239 & CBTS \\
\hline 240 & ECOLÓGICA \\
\hline 241 & BRASILEIRA \\
\hline 242 & MONITORAMENTO \\
\hline 243 & POIS \\
\hline 244 & IMPACTOS \\
\hline 245 & OBJETIVOS \\
\hline 246 & FAZER \\
\hline 247 & UNIDADES \\
\hline 248 & ENTIDADES \\
\hline 249 & QUANDO \\
\hline 250 & TURÍSTICA \\
\hline 251 & PRESERVAÇÃO \\
\hline 252 & ALDEIA \\
\hline 253 & CONTROLE \\
\hline 254 & PAÍSES \\
\hline 255 & REALIZAÇÃO \\
\hline 256 & QUAL \\
\hline 257 & ARQUEOLOGIA \\
\hline 258 & TEMPO \\
\hline 259 & TODAS \\
\hline 260 & EMPREENDIMENTO+ \\
\hline 261 & ESTUDOS \\
\hline 262 & VAl \\
\hline 263 & AÇÃO \\
\hline 264 & PROFISSIONAIS \\
\hline 265 & FONTE \\
\hline 266 & TODO \\
\hline 267 & HOJE \\
\hline 268 & ISTO \\
\hline 269 & APENAS \\
\hline 270 & GERAL \\
\hline 271 & DESTINOS \\
\hline 272 & EXEMPLO \\
\hline 273 & GOVERNOS \\
\hline 274 & IMPACTO \\
\hline 275 & NÍVEL \\
\hline 276 & IBAMA \\
\hline 277 & ENTÃO \\
\hline 278 & CENTRO \\
\hline 279 & NORONHA \\
\hline 280 & sos \\
\hline 281 & QUESTÕES \\
\hline 282 & MIL \\
\hline
\end{tabular}

\begin{tabular}{|l|l|}
234 & CONJUNTO \\
\hline 235 & MODALIDADES \\
\hline 236 & IMPACTO \\
\hline 237 & CONTROLE \\
\hline 238 & MONITORAMENTO \\
\hline 239 & SOCIAIS \\
\hline 240 & POSIÇÃO \\
\hline 241 & PE \\
\hline 242 & CARDOSO \\
\hline 243 & PARTIR \\
\hline 244 & EDIÇÃO \\
\hline 245 & ESTADOS \\
\hline 246 & DIRETRIZES \\
\hline 247 & ALGUMAS \\
\hline 248 & POTENCIAL \\
\hline 249 & UTILIZAÇÃO \\
\hline 250 & INTERVALES \\
\hline 251 & SITE \\
\hline 252 & VERIFICAR \\
\hline 253 & MUNICIPAIS \\
\hline 254 & DOCUMENTO \\
\hline 255 & DENTRO \\
\hline 256 & PROGRAMAÇÃO \\
\hline 257 & OBJETIVO \\
\hline 258 & PODEM \\
\hline 259 & EMPRESARIAL \\
\hline 260 & CAVERNAS \\
\hline 261 & SP \\
\hline 262 & NÚMERO \\
\hline 263 & NACIONAIS \\
\hline 264 & REGIÕES \\
\hline 265 & FEDERAL \\
\hline 266 & TANTO \\
\hline 267 & ISSO \\
\hline 268 & POPULAC̃ÃO \\
\hline 269 & AVALIAÇÃO \\
\hline 270 & GERAL \\
\hline 271 & DADOS \\
\hline 272 & NíVEL \\
\hline 273 & VISITANTE \\
\hline 274 & AUTORES \\
\hline 275 & DESSA \\
\hline 276 & DESTA \\
\hline 277 & LIVRE \\
\hline 278 & TAIS \\
\hline 279 & DESTE \\
\hline 280 & ONGS \\
\hline & MARQUE \\
\hline 28 \\
\hline
\end{tabular}




\begin{tabular}{|c|c|}
\hline 283 & APOIO \\
\hline 284 & ECONÔMICA \\
\hline 285 & UNIDADES \\
\hline 286 & TURÍSTICOS \\
\hline 287 & PERÍODO \\
\hline 288 & QUESTÃO \\
\hline 289 & PORTO \\
\hline 290 & VÁRIOS \\
\hline 291 & HISTÓRIA \\
\hline 292 & PESCA \\
\hline 293 & DESTINO \\
\hline 294 & ESTRADA \\
\hline 295 & CLIMA \\
\hline 296 & PRINCIPAL \\
\hline 297 & CONTA \\
\hline 298 & PARTICIPAÇÃO \\
\hline 299 & DUAS \\
\hline 300 & GESTÃO \\
\hline 301 & AMBIENTES \\
\hline 302 & INDEX \\
\hline 303 & CONHECIMENTO \\
\hline 304 & CONTATO \\
\hline 305 & PASSEIOS \\
\hline 306 & CHEGAR \\
\hline 307 & PRIMEIRO \\
\hline 308 & VEM \\
\hline 309 & DIVERSAS \\
\hline 310 & SOCIAIS \\
\hline 311 & ESPORTES \\
\hline 312 & PONTOS \\
\hline 313 & CURSOS \\
\hline 314 & ID \\
\hline 315 & TURISTA \\
\hline 316 & ORGANIZAÇÃO \\
\hline 317 & RESPONSÁVEL \\
\hline 318 & GUIA \\
\hline 319 & VALE \\
\hline 320 & REALIZADO \\
\hline 321 & REGIÕES \\
\hline 322 & APÓS \\
\hline 323 & MANEJO \\
\hline 324 & LADO \\
\hline 325 & SÉCULO \\
\hline 326 & DEVIDO \\
\hline 327 & BRASILEIRA \\
\hline 328 & ELE \\
\hline 329 & OUTRO \\
\hline 330 & DESCIDA \\
\hline 331 & MERGULHO \\
\hline
\end{tabular}

\begin{tabular}{|c|c|}
\hline 283 & PROMOÇÃO \\
\hline 284 & GRUPOS \\
\hline 285 & ENVOLVIDOS \\
\hline 286 & AUMENTO \\
\hline 287 & TIPO \\
\hline 288 & NORTE \\
\hline 289 & IBAMA \\
\hline 290 & TODAS \\
\hline 291 & JACUPIRANGA \\
\hline 292 & PRINCIPALMENTE \\
\hline 293 & PETAR \\
\hline 294 & EXECUÇÃO \\
\hline 295 & RENDA \\
\hline 296 & EXEMPLO \\
\hline 297 & FORMAÇÃO \\
\hline 298 & VEM \\
\hline 299 & CURSOS \\
\hline 300 & ALTO \\
\hline 301 & MUITO \\
\hline 302 & ATENDIMENTO \\
\hline 303 & SEGUNDO \\
\hline 304 & PRINCIPAIS \\
\hline 305 & ASSOCIAÇÃO \\
\hline 306 & IMPORTÂNCIA \\
\hline 307 & CARACTERÍSTICA+ \\
\hline 308 & CRESCIMENTO \\
\hline 309 & SEREM \\
\hline 310 & MELHOR \\
\hline 311 & CERCA \\
\hline 312 & CAPACIDADE \\
\hline 313 & ADMINISTRAÇÃO \\
\hline 314 & CIDADE \\
\hline 315 & CONSELHO \\
\hline 316 & REPRESENTATIVA+ \\
\hline 317 & $\mathrm{R}$ \\
\hline 318 & REUNIÕES \\
\hline 319 & MELHORIA \\
\hline 320 & APRESENTA \\
\hline 321 & MILHÕES \\
\hline 322 & ESPÉCIES \\
\hline 323 & MUNDO \\
\hline 324 & Vôo \\
\hline 325 & $\mathrm{~N}$ \\
\hline 326 & ÁGUA \\
\hline 327 & RURAL \\
\hline 328 & NOVOS \\
\hline 329 & NEGATIVOS \\
\hline 330 & CARLOS \\
\hline 331 & FAUNA \\
\hline
\end{tabular}




\begin{tabular}{|l|l|}
332 & SEREM \\
\hline 333 & ÁRORES \\
\hline 334 & LONGO \\
\hline 335 & DESTINOS \\
\hline 336 & ATUALMENTE \\
\hline 337 & COSTA \\
\hline 338 & ASSOCIAÇÃO \\
\hline 339 & APA \\
\hline 340 & AÇÕES \\
\hline 341 & MAIORES \\
\hline 342 & DESSA \\
\hline 343 & LITORAL \\
\hline 344 & BIODIVERSIDADE \\
\hline 345 & NOSSOS \\
\hline 346 & ANTES \\
\hline 347 & SISTEMA \\
\hline 348 & ESSES \\
\hline 349 & PORÉM \\
\hline 350 & EXISTEM \\
\hline 351 & CAPITAL \\
\hline 352 & POUCO \\
\hline 353 & PARTICIPANTES \\
\hline 354 & CARACTERÍSTICA + \\
\hline 355 & APROXIMADAMENT + \\
\hline 356 & C \\
\hline 357 & TRÊS \\
\hline 358 & BROTAS \\
\hline 359 & ESTAR \\
\hline 360 & PROBLEMAS \\
\hline 361 & AVES \\
\hline 362 & CAMINHADA \\
\hline 363 & NESTE \\
\hline 364 & VÁRIAS \\
\hline 365 & PRIMEIRA \\
\hline 366 & MANEIRA \\
\hline 367 & MUNICÍPIOS \\
\hline 368 & TUDO \\
\hline 369 & ECONÔMICO \\
\hline 370 & RESPEITO \\
\hline 371 & TREINAMENTO \\
\hline 372 & CONJUNTO \\
\hline 373 & SEGUNDO \\
\hline 374 & EMPRESA \\
\hline 375 & NOSSO \\
\hline 376 & ECO \\
\hline 377 & POTENCIAL \\
\hline 378 & PAÍSES \\
\hline 379 & ÉPOCA \\
\hline 380 & ACORDO \\
\hline & \\
\hline
\end{tabular}

\begin{tabular}{|l|l|}
\hline 332 & ENVOLVIDAS \\
\hline 333 & CONSCIÊNCIA \\
\hline 334 & II \\
\hline 335 & INICIATIVA \\
\hline 336 & NACIONAIS \\
\hline 337 & PRÁTICAS \\
\hline 338 & SISTEMAS \\
\hline 339 & REGIONAL \\
\hline 340 & NEGÓCIOS \\
\hline 341 & ESPAÇO \\
\hline 342 & MUNICÍPIO \\
\hline 343 & PARTES \\
\hline 344 & PADRÕES \\
\hline 345 & SITE \\
\hline 346 & CASO \\
\hline 347 & CONSTRUÇÃO \\
\hline 348 & INSTITUIÇÕES \\
\hline 349 & ESTAR \\
\hline 350 & FATO \\
\hline 351 & INFRA \\
\hline 352 & AGENDA \\
\hline 353 & FORMACCÃO \\
\hline 354 & IMPORTANTE \\
\hline 355 & DESTINO \\
\hline 356 & PRIVADO \\
\hline 357 & CIVIL \\
\hline 358 & ESTADUAL \\
\hline 359 & LAZER \\
\hline 360 & LONGO \\
\hline 361 & REALIDADE \\
\hline 362 & ESPÉCIES \\
\hline 363 & INVESTIMENTOS \\
\hline 364 & RESPONSABILIDA+ \\
\hline 365 & SETORES \\
\hline 366 & MARINHO \\
\hline 367 & REALIZADO \\
\hline 368 & INTERESSE \\
\hline 369 & PARCEIROS \\
\hline 370 & ALTO \\
\hline 371 & BUSCA \\
\hline 372 & HUMANA \\
\hline 373 & P \\
\hline 374 & CONHECER \\
\hline 375 & RJ \\
\hline 376 & CONHECIMENTO \\
\hline 377 & INDÚSTRIA \\
\hline 378 & CERCA \\
\hline 379 & EXISTENTES \\
\hline 380 & INTEGRADO \\
\hline & \\
\hline
\end{tabular}

\begin{tabular}{|l|l|}
332 & EMPRESÁRIOS \\
\hline 333 & EVENTOS \\
\hline 334 & TABELA \\
\hline 335 & GERAÇÃO \\
\hline 336 & ELABORAÇÃO \\
\hline 337 & GRUPO \\
\hline 338 & UCS \\
\hline 339 & RAFTING \\
\hline 340 & LONGO \\
\hline 341 & BRASILEIRO \\
\hline 342 & B \\
\hline 343 & RIOS \\
\hline 344 & COMUNIDADE \\
\hline 345 & RESPONSÁVEIS \\
\hline 346 & ECONÔMICA \\
\hline 347 & ESSA \\
\hline 348 & TURÍSTICAS \\
\hline 349 & INSTITUIÇÕES \\
\hline 350 & ACOMPANHAMENTO \\
\hline 351 & SUSTENTABILIDA+ \\
\hline 352 & IMPORTANTE \\
\hline 353 & BOTELHO \\
\hline 354 & PÚBLICOS \\
\hline 355 & FASE \\
\hline 356 & PRÁTICAS \\
\hline 357 & EXISTENTES \\
\hline 358 & MIL \\
\hline 359 & ATUALMENTE \\
\hline 360 & ESPORTE \\
\hline 361 & RALLY \\
\hline 362 & PAULISTA \\
\hline 363 & CONFORME \\
\hline 364 & QUANDO \\
\hline 365 & BASTANTE \\
\hline 366 & QUALQUER \\
\hline 367 & ESTABELECIMENT+ \\
\hline 368 & PRODUTO \\
\hline 369 & PÚBLICAS \\
\hline 370 & AR \\
\hline 371 & P \\
\hline 372 & FLORESTAS \\
\hline 373 & LAZER \\
\hline 374 & INTERIOR \\
\hline 375 & MINISTÉRIO \\
\hline 376 & SENTIDO \\
\hline 377 & ASSISTÊNCIA \\
\hline 378 & GARANTIR \\
\hline 379 & DISSO \\
\hline 380 & JUNTO \\
\hline & \\
\hline
\end{tabular}




\begin{tabular}{|l|l|}
\hline 381 & PLANETA \\
\hline 382 & CRESCIMENTO \\
\hline 383 & EVENTOS \\
\hline 384 & DIVERSIDADE \\
\hline 385 & TANTO \\
\hline 386 & AMAZÔNIA \\
\hline 387 & CASA \\
\hline 388 & ECOTURÍSTICO \\
\hline 389 & POUSADAS \\
\hline 390 & NÍVEL \\
\hline 391 & PROMOVER \\
\hline 392 & QUAL \\
\hline 393 & QUANTO \\
\hline 394 & POLITICA \\
\hline 395 & NOVA \\
\hline 396 & MATO \\
\hline 397 & NUMA \\
\hline 398 & FONTE \\
\hline 399 & FEITO \\
\hline 400 & INTERESSE \\
\hline 401 & OFERECE \\
\hline 402 & HOTÉIS \\
\hline 403 & PONTO \\
\hline 404 & MUNDIAL \\
\hline 405 & SOB \\
\hline 406 & VISTA \\
\hline 407 & NECESSÁRIO \\
\hline 408 & RENDA \\
\hline 409 & OUTRA \\
\hline 410 & IMPLANTAÇÃO \\
\hline 411 & SERÃO \\
\hline 412 & PÚBLICO \\
\hline 413 & APRESENTA \\
\hline 414 & MODELO \\
\hline 415 & IMPORTANTES \\
\hline 416 & FINAL \\
\hline 417 & BOM \\
\hline 418 & PRINCÍPIOS \\
\hline 419 & DESTE \\
\hline 420 & PROGRAMAS \\
\hline 421 & BOA \\
\hline 422 & ESTUDO \\
\hline 423 & TÉCNICA \\
\hline 424 & FIM \\
\hline 425 & VISITANTE \\
\hline 426 & PRIMEIROS \\
\hline 427 & INÍCIO \\
\hline 428 & GERAIS \\
\hline 429 & DESENVOLVER \\
\hline & \\
\hline
\end{tabular}

\begin{tabular}{|l|l|}
381 & ESTUDO \\
\hline 382 & JUNTO \\
\hline 383 & RENDA \\
\hline 384 & NORMAS \\
\hline 385 & QUAIS \\
\hline 386 & CIDADE \\
\hline 387 & REPRESENTANTES \\
\hline 388 & GOVERNAMENTAIS \\
\hline 389 & ESTRATÉGIAS \\
\hline 390 & ABRIL \\
\hline 391 & PELAS \\
\hline 392 & CONGRESSO \\
\hline 393 & NECESSIDADE \\
\hline 394 & REALIZADA \\
\hline 395 & ALGUMAS \\
\hline 396 & SENTIDO \\
\hline 397 & PREFEITURA \\
\hline 398 & SÉRGIO \\
\hline 399 & FALTA \\
\hline 400 & RELAÇÕES \\
\hline 401 & COORDENADOR \\
\hline 402 & AVALIAÇÃO \\
\hline 403 & GRUPOS \\
\hline 404 & ONGS \\
\hline 405 & MANEIRA \\
\hline 406 & DIVERSOS \\
\hline 407 & MUITAS \\
\hline 408 & DESTA \\
\hline 409 & RECREATIVO \\
\hline 410 & DESTE \\
\hline 411 & REGIÕES \\
\hline 412 & EXPERIÊNCIA \\
\hline 413 & ÚLTIMOS \\
\hline 414 & DISSO \\
\hline 415 & JOÃO \\
\hline 416 & OUTUBRO \\
\hline 417 & INÍCIO \\
\hline 418 & DIVULGAÇÃO \\
\hline 419 & PROF \\
\hline 420 & NUMA \\
\hline 421 & PODERIA \\
\hline 422 & PROMOÇÃO \\
\hline 423 & SUSTENTÁVEIS \\
\hline 424 & PRÓPRIA \\
\hline 425 & CONTEXTO \\
\hline 426 & POUCO \\
\hline 427 & NECESSIDADES \\
\hline 428 & MANEJO \\
\hline & NOVA \\
\hline
\end{tabular}

\begin{tabular}{|r|l|}
381 & VÁRIOS \\
\hline 382 & DESSE \\
\hline 383 & MODALIDADE \\
\hline 384 & ACORDO \\
\hline 385 & TODA \\
\hline 386 & EMPREENDIMENTO+ \\
\hline 387 & ECOTURÍSTICOS \\
\hline 388 & PELAS \\
\hline 389 & RESULTADOS \\
\hline 390 & ESTUDO \\
\hline 391 & REGIONAIS \\
\hline 392 & ESPAÇO \\
\hline 393 & CURSO \\
\hline 394 & CONHECIMENTO \\
\hline 395 & CULTURAIS \\
\hline 396 & VISANDO \\
\hline 397 & PREVÊ \\
\hline 398 & PERÍODO \\
\hline 399 & COMPONENTES \\
\hline 400 & MONITORES \\
\hline 401 & QUESTÃO \\
\hline 402 & POSSÍVEL \\
\hline 403 & GUIAS \\
\hline 404 & REPRESENTANTES \\
\hline 405 & QUEDISMO \\
\hline 406 & BASE \\
\hline 407 & DEMAIS \\
\hline 408 & IEB \\
\hline 409 & SOB \\
\hline 410 & FICHAS \\
\hline 411 & PRIMEIRO \\
\hline 412 & CONSELHOS \\
\hline 413 & TRÊS \\
\hline 414 & POPULAÇÕES \\
\hline 415 & VIDA \\
\hline 416 & REALIZAÇÃO \\
\hline 417 & NEGÓCIOS \\
\hline 418 & INTERESSE \\
\hline 419 & INICIATIVA \\
\hline 420 & DIVERSAS \\
\hline 421 & PARCERIAS \\
\hline 422 & AMBIENTES \\
\hline 423 & OUTRO \\
\hline 424 & ESTAS \\
\hline 425 & ATORES \\
\hline 426 & INCENTIVAR \\
\hline 427 & PESCA \\
\hline 428 & ECONÔMICO \\
\hline 429 & ECOSSISTEMAS \\
\hline & \\
\hline
\end{tabular}




\begin{tabular}{|c|c|}
\hline 430 & MÍNIMO \\
\hline 431 & ESCALADA \\
\hline 432 & CAPACIDADE \\
\hline 433 & PROFISSIONAIS \\
\hline 434 & DESTA \\
\hline 435 & ECOLÓGICA \\
\hline 436 & PAPEL \\
\hline 437 & PEIXES \\
\hline 438 & SENTIDO \\
\hline 439 & FLORESTAS \\
\hline 440 & MÉDIA \\
\hline 441 & CONTROLE \\
\hline 442 & PARQUES \\
\hline 443 & GERAL \\
\hline 444 & LUGARES \\
\hline 445 & NUM \\
\hline 446 & AR \\
\hline 447 & OBJETIVOS \\
\hline 448 & INTERNACIONAIS \\
\hline 449 & $\mathrm{R}$ \\
\hline 450 & PRODUTO \\
\hline 451 & DIVERSOS \\
\hline 452 & INDÚSTRIA \\
\hline 453 & PROPOSTA \\
\hline 454 & BASTANTE \\
\hline 455 & CAMPO \\
\hline 456 & BAHIA \\
\hline 457 & ALTURA \\
\hline 458 & CONSCIÊNCIA \\
\hline 459 & PRESENÇA \\
\hline 460 & ECOLÓGICOS \\
\hline 461 & FUNDAMENTAL \\
\hline 462 & NOVOS \\
\hline 463 & RAFTING \\
\hline 464 & TREKKING \\
\hline 465 & NACIONAIS \\
\hline 466 & TOTAL \\
\hline 467 & TENDO \\
\hline 468 & ESSAS \\
\hline 469 & AÇÃO \\
\hline 470 & JANEIRO \\
\hline 471 & ELA \\
\hline 472 & MATAS \\
\hline 473 & ORG \\
\hline 474 & CONSELHO \\
\hline 475 & CONSTRUÇÃO \\
\hline 476 & ENTÃO \\
\hline 477 & GOVERNO \\
\hline 478 & VAl \\
\hline
\end{tabular}

\begin{tabular}{|c|c|}
\hline 430 & ECOGÊNESE \\
\hline 431 & ENVOLVIMENTO \\
\hline 432 & EXPOSIÇÃO \\
\hline 433 & DESSE \\
\hline 434 & INTERPRETAÇÃO \\
\hline 435 & PARCERIAS \\
\hline 436 & PÓLOS \\
\hline 437 & DIVERSAS \\
\hline 438 & FEITO \\
\hline 439 & VISANDO \\
\hline 440 & ACESSO \\
\hline 441 & TÉCNICA \\
\hline 442 & PAPEL \\
\hline 443 & MODELOS \\
\hline 444 & PARTICIPANTE \\
\hline 445 & VÁRIOS \\
\hline 446 & PCTS \\
\hline 447 & ASPAC \\
\hline 448 & SIDO \\
\hline 449 & WORKSHOP \\
\hline 450 & PLANETA \\
\hline 451 & MUITOS \\
\hline 452 & MS \\
\hline 453 & ANTES \\
\hline 454 & ESPECIALISTAS \\
\hline 455 & SIG \\
\hline 456 & ATRATIVOS \\
\hline 457 & ESTADOS \\
\hline 458 & METODOLOGIA \\
\hline 459 & TERRA \\
\hline 460 & DIFERENTES \\
\hline 461 & TURÍSTICAS \\
\hline 462 & HISTÓRIA \\
\hline 463 & CERRADO \\
\hline 464 & SERÃO \\
\hline 465 & TREINAMENTO \\
\hline 466 & FIM \\
\hline 467 & NUM \\
\hline 468 & GERALDO \\
\hline 469 & SEGUNDO \\
\hline 470 & TUDO \\
\hline 471 & SEJAM \\
\hline 472 & TEMOS \\
\hline 473 & LADO \\
\hline 474 & PARQUES \\
\hline 475 & ÍNDIOS \\
\hline 476 & PRIVADA \\
\hline 477 & VALE \\
\hline 478 & COMUNITÁRIO \\
\hline
\end{tabular}

\begin{tabular}{|c|c|}
\hline 430 & EXPERIÊNCIA \\
\hline 431 & DISPONÍVEIS \\
\hline 432 & PROPOSTAS \\
\hline 433 & RELACIONADAS \\
\hline 434 & SEMINÁRIOS \\
\hline 435 & INSTITUCIONAL \\
\hline 436 & SENSIBILIZAÇÃO \\
\hline 437 & PRESENÇA \\
\hline 438 & HUMANOS \\
\hline 439 & TREINAMENTO \\
\hline 440 & DEVIDO \\
\hline 441 & CONDUTA \\
\hline 442 & C \\
\hline 443 & MANUTENÇÃO \\
\hline 444 & DEMANDA \\
\hline 445 & NESSE \\
\hline 446 & CRIAR \\
\hline 447 & INFLUÊNCIA \\
\hline 448 & INTERPRETAÇÃO \\
\hline 449 & INCLUINDO \\
\hline 450 & VISTA \\
\hline 451 & CULTURA \\
\hline 452 & PRINCÍPIOS \\
\hline 453 & DIVERSIDADE \\
\hline 454 & DISCUSSÃO \\
\hline 455 & RURAIS \\
\hline 456 & UNIVERSIDADES \\
\hline 457 & ECOLÓGICO \\
\hline 458 & FLORESTA \\
\hline 459 & DUAS \\
\hline 460 & INTEGRAÇÃO \\
\hline 461 & ESTRUTURAS \\
\hline 462 & POSITIVOS \\
\hline 463 & PONTO \\
\hline 464 & EXISTEM \\
\hline 465 & ECOBRASIL \\
\hline 466 & PROCEDIMENTOS \\
\hline 467 & ÂMBITO \\
\hline 468 & PRIVADA \\
\hline 469 & POSSUEM \\
\hline 470 & TERMOS \\
\hline 471 & NECESSIDADE \\
\hline 472 & DEPARTAMENTO \\
\hline 473 & REALIZAR \\
\hline 474 & CENTRO \\
\hline 475 & CAVALGADA \\
\hline 476 & INFORMAÇÃO \\
\hline 477 & DAR \\
\hline 478 & COMPONENTE \\
\hline
\end{tabular}




\begin{tabular}{|l|l|}
479 & SEGURO \\
\hline 480 & NÚCLEO \\
\hline 481 & FRANCISCO \\
\hline 482 & PARAÍSO \\
\hline 483 & DISSO \\
\hline 484 & SIMPLES \\
\hline 485 & LAZER \\
\hline 486 & PESQUISA \\
\hline 487 & MORADORES \\
\hline 488 & ELES \\
\hline 489 & ERA \\
\hline 490 & QUAIS \\
\hline 491 & POPULAÇÕES \\
\hline 492 & RESPONSABILIDA + \\
\hline 493 & ORIGEM \\
\hline 494 & PAISAGEM \\
\hline 495 & PRODUÇÃO \\
\hline 496 & ESPAÇO \\
\hline 497 & CIDADES \\
\hline 498 & GROSSO \\
\hline 499 & EXISTE \\
\hline 500 & PEIXE \\
\hline & \\
\hline
\end{tabular}

\begin{tabular}{|l|l|}
479 & JANEIRO \\
\hline 480 & CARACTERÍSTICA+ \\
\hline 481 & NOVO \\
\hline 482 & NOTA \\
\hline 483 & FORMAS \\
\hline 484 & GROSSO \\
\hline 485 & GUAPORÉ \\
\hline 486 & RONDÔNIA \\
\hline 487 & GARANTIR \\
\hline 488 & FINAL \\
\hline 489 & RELATÓRIO \\
\hline 490 & PRINCÍPIOS \\
\hline 491 & OPORTUNIDADE \\
\hline 492 & TOTAL \\
\hline 493 & MEIOS \\
\hline 494 & MATO \\
\hline 495 & SEGMENTO \\
\hline 496 & PROPOSTAS \\
\hline 497 & COMUNICAÇÃO \\
\hline 498 & CONCEITOS \\
\hline 499 & DESCRIÇÃO \\
\hline 500 & ATUALMENTE \\
\hline & \\
\hline
\end{tabular}

\begin{tabular}{|l|l|}
\hline 479 & SETORES \\
\hline 480 & TENDO \\
\hline 481 & DEFINIÇÃO \\
\hline 482 & TÊM \\
\hline 483 & QUANTO \\
\hline 484 & PRESERVAÇÃO \\
\hline 485 & ESTRUTURAÇÃO \\
\hline 486 & PESQUISAS \\
\hline 487 & ARTIGO \\
\hline 488 & AÇÃO \\
\hline 489 & GRANDES \\
\hline 490 & PROFISSIONAIS \\
\hline 491 & EMPREENDEDORES \\
\hline 492 & DESTINOS \\
\hline 493 & DEVERÃO \\
\hline 494 & CAMPOS \\
\hline 495 & CANANÉIA \\
\hline 496 & NORMAS \\
\hline 497 & PREVISTAS \\
\hline 498 & PROTEGIDAS \\
\hline 499 & BIODIVERSIDADE \\
\hline 500 & ESPECÍFICOS \\
\hline & \\
\hline
\end{tabular}




\section{ANEXO C - KEYWORDS: RESULTADO DO CRUZAMENTO DAS LISTAS DOS SUBCORPORA DE ESTUDO EM INGLÊS COM O RESPECTIVO CORPUS DE REFERÊNCIA}

Optamos por apresentar apenas a relação das palavras.

\begin{tabular}{|c|c|c|c|c|c|}
\hline \multicolumn{3}{|c|}{ Agências de turismo } & \multicolumn{2}{|c|}{ Entidades ambientalistas } & $\begin{array}{c}\text { Órgãos } \\
\text { governamentais }\end{array}$ \\
\hline $\mathbf{N}$ & WORD & $\mathbf{N}$ & WORD & $\mathbf{N}$ & WORD \\
\hline 1 & ZEALAND & 1 & TOURISM & 1 & TOURISM \\
\hline 2 & $\mathrm{NZ}$ & 2 & ECOTOURISM & 2 & SUBMITTER \\
\hline 3 & wwW & 3 & ZEALAND & 3 & NATIVE \\
\hline 4 & HTTP & 4 & CONSERVATION & 4 & ZEALAND \\
\hline 5 & ECOTOURISM & 5 & SUSTAINABLE & 5 & FOREST \\
\hline 6 & NEW & 6 & VISITOR & 6 & SUSTAINABLE \\
\hline 7 & TOURS & 7 & SPECIES & 7 & SUBMITTERS \\
\hline 8 & TOURISM & 8 & NZ & 8 & INDIGENOUS \\
\hline 9 & ECO & 9 & WWW & 9 & BIODIVERSITY \\
\hline 10 & ECOTOURS & 10 & VISITORS & 10 & FORESTS \\
\hline 11 & KAIKOURA & 11 & ENVIRONMENTAL & 11 & CONSERVATION \\
\hline 12 & ISLAND & 12 & NMPAS & 12 & ECOTOURISM \\
\hline 13 & DOLPHINS & 13 & HTTP & 13 & PLANTS \\
\hline 14 & ZEALAND'S & 14 & KIWI & 14 & TIMBER \\
\hline 15 & HTM & 15 & ORG & 15 & MAORI \\
\hline 16 & TRACK & 16 & SUSTAINABILITY & 16 & PRODUCTS \\
\hline 17 & NATURAL & 17 & NMPA & 17 & MANAGEMENT \\
\hline 18 & OUR & 18 & MANIAPOTO & 18 & LAND \\
\hline 19 & NATIVE & 19 & PACIFIC & 19 & NEW \\
\hline 20 & CONSERVATION & 20 & OVERFISHED & 20 & FORESTRY \\
\hline 21 & KAYAKING & 21 & TOURS & 21 & RESEARCH \\
\hline 22 & HIKING & 22 & SPTO & 22 & $s$ \\
\hline 23 & $\mathrm{CO}$ & 23 & BIODIVERSITY & 23 & NATURAL \\
\hline 24 & PARK & 24 & $S$ & 24 & ECOSYSTEMS \\
\hline 25 & TOUR & 25 & TOURISTS & 25 & www \\
\hline 26 & WILDLIFE & 26 & IMPACTS & 26 & LANDOWNERS \\
\hline 27 & PUNAKAIKI & 27 & MARINE & 27 & CERTIFICATION \\
\hline 28 & BIKING & 28 & NGATI & 28 & TRADE \\
\hline 29 & WALKS & 29 & TOURIST & 29 & MANIAPOTO \\
\hline 30 & MOUNTAIN & 30 & WELLINGTON & 30 & ENVIRONMENT \\
\hline 31 & ENVIRONMENT & 31 & WILDLIFE & 31 & HTTP \\
\hline 32 & GUIDED & 32 & SANCTUARY & 32 & SPECIES \\
\hline 33 & RAFTING & 33 & MANAGEMENT & 33 & $\mathrm{NZ}$ \\
\hline 34 & UNIQUE & 34 & ISLAND & 34 & PARKS \\
\hline 35 & PHP & 35 & HABITAT & 35 & SUSTAINABILITY \\
\hline 36 & ADVENTURE & 36 & HORTICULTURE & 36 & GOVT \\
\hline 37 & MAORI & 37 & WEBSITE & 37 & NGATI \\
\hline 38 & RIVER & 38 & PARKS & 38 & AREAS \\
\hline
\end{tabular}




\begin{tabular}{|r|l|}
\hline 39 & NATURE \\
\hline 40 & BIRD \\
\hline 41 & WALKING \\
\hline 42 & MT \\
\hline 43 & TRIPS \\
\hline 44 & BIRDING \\
\hline 45 & TASMAN \\
\hline 46 & FORESTS \\
\hline 47 & COAST \\
\hline 48 & KIWI \\
\hline 49 & FLORA \\
\hline 50 & PARKS \\
\hline 51 & LODGE \\
\hline 52 & BUNGY \\
\hline 53 & BUSH \\
\hline 54 & SCENERY \\
\hline 55 & WILDERNESS \\
\hline 56 & WAIMANGU \\
\hline 57 & NATUREQUEST \\
\hline 58 & RAGLAN \\
\hline 59 & SCENIC \\
\hline 60 & AWAROA \\
\hline 61 & COASTLINE \\
\hline 62 & KAURI \\
\hline 63 & EXPERIENCE \\
\hline 64 & ALPINE \\
\hline 65 & WALK \\
\hline 66 & FIORDLAND \\
\hline 67 & COASTAL \\
\hline 68 & HERITAGE \\
\hline 69 & TATAPOURI \\
\hline 70 & KAHURANGI \\
\hline 71 & AND \\
\hline 72 & NATIONAL \\
\hline 73 & MARINE \\
\hline 74 & BIRDWATCHING \\
\hline 75 & BIRDS \\
\hline 76 & FOREST \\
\hline 77 & WHALE \\
\hline 78 & LAKES \\
\hline 79 & ARE \\
\hline 80 & WHITEWATER \\
\hline 81 & WAPITI \\
\hline 82 & SPECTACULAR \\
\hline 83 & VISITORS \\
\hline 84 & TRIP \\
\hline 85 & S \\
\hline 86 & WE \\
\hline 87 & QUEENSTOWN \\
\hline & \\
\hline
\end{tabular}

\begin{tabular}{|r|l|}
\hline 39 & COAST \\
\hline 40 & NATIVE \\
\hline 41 & KAIKOURA \\
\hline 42 & NEW \\
\hline 43 & STOCKS \\
\hline 44 & RESOURCE \\
\hline 45 & PROTECTED \\
\hline 46 & ATTRACTIONS \\
\hline 47 & DEVELOPMENT \\
\hline 48 & LOCAL \\
\hline 49 & ENVIRONMENT \\
\hline 50 & FOREST \\
\hline 51 & PARK \\
\hline 52 & INDUSTRY \\
\hline 53 & ISSUES \\
\hline 54 & EXPERIENCES \\
\hline 55 & AKAROA \\
\hline 56 & VALUES \\
\hline 57 & MIGRATORY \\
\hline 58 & OTAGO \\
\hline 59 & QEII \\
\hline 60 & RESPONDENTS \\
\hline 61 & AREAS \\
\hline 62 & SITE \\
\hline 63 & ECOSYSTEMS \\
\hline 64 & COMMUNITIES \\
\hline 65 & OVERFISHING \\
\hline 66 & GROUPER \\
\hline 67 & BENEFITS \\
\hline 68 & NATURAL \\
\hline 69 & KOMODO \\
\hline 70 & SPAWNING \\
\hline 71 & SNAPPER \\
\hline 72 & ITML \\
\hline 73 & STRATEGIES \\
\hline 74 & CHRISTCHURCH \\
\hline 75 & ORAMS \\
\hline 76 & IMPACT \\
\hline 77 & TE \\
\hline 78 & BUSINESSES \\
\hline 79 & RECREATION \\
\hline 80 & TNC \\
\hline 81 & FISHERY \\
\hline 82 & FORESTS \\
\hline 83 & BENEFI \\
\hline 84 & ECO \\
\hline 85 & DATA \\
\hline 86 & TRAVEL \\
\hline 87 & STOCK \\
\hline & \\
\hline
\end{tabular}

\begin{tabular}{|r|l|}
\hline 39 & PLANTATION \\
\hline 40 & AQUACULTURE \\
\hline 41 & KAIKOURA \\
\hline 42 & VISITORS \\
\hline 43 & WRC \\
\hline 44 & INTERNATIONAL \\
\hline 45 & ENVIRONMENTAL \\
\hline 46 & TROPICAL \\
\hline 47 & VEGETATION \\
\hline 48 & AND \\
\hline 49 & STATED \\
\hline 50 & WAITAKI \\
\hline 51 & RMA \\
\hline 52 & DEVELOPING \\
\hline 53 & WETLANDS \\
\hline 54 & EXOTIC \\
\hline 55 & SUSTAINABLY \\
\hline 56 & PRIVATE \\
\hline 57 & PLANTING \\
\hline 58 & USE \\
\hline 59 & ROLE \\
\hline 60 & COUNTRIES \\
\hline 61 & RIPARIAN \\
\hline 62 & ECOLOGICAL \\
\hline 63 & ECOSYSTEM \\
\hline 64 & COMMERCIAL \\
\hline 65 & HARVESTING \\
\hline 66 & SECTOR \\
\hline 67 & LANDSCAPE \\
\hline 68 & BENEFITS \\
\hline 69 & FUNDING \\
\hline 70 & WHENUA \\
\hline 71 & OPPORTUNITIES \\
\hline 72 & ECONOMIC \\
\hline 73 & HERITAGE \\
\hline 74 & DEVELOPMENT \\
\hline 75 & TRC \\
\hline 76 & LANDS \\
\hline 77 & KNOWLEDGE \\
\hline 78 & VISITOR \\
\hline 79 & LANDSCAPES \\
\hline 80 & RESOURCE \\
\hline 81 & POTENTIAL \\
\hline 82 & DOC \\
\hline 83 & MARINE \\
\hline 84 & CONCESSIONAIRE + \\
\hline 85 & ZEALAND'S \\
\hline 86 & PLANTATIONS \\
\hline 87 & LANDOWNER \\
\hline & \\
\hline 5
\end{tabular}




\begin{tabular}{rr|l|}
\hline 88 & HAAST \\
\hline 89 & OPERATORS \\
\hline 90 & PORORARI \\
\hline 91 & ECOTOUR \\
\hline 92 & FAUNA \\
\hline 93 & SEA \\
\hline 94 & PENGUINS \\
\hline 95 & CREEK \\
\hline 96 & PHILOS \\
\hline 97 & TRACKS \\
\hline 98 & VALLEY \\
\hline 99 & AREA \\
\hline 100 & TUSSOCK \\
\hline 101 & WESTLAND \\
\hline 102 & LAKE \\
\hline 103 & HEAPHY \\
\hline 104 & NZNATURE \\
\hline 105 & BEACHES \\
\hline 106 & SOUTH \\
\hline 107 & SUSTAINABLE \\
\hline 108 & GUIDES \\
\hline 109 & SEALS \\
\hline 110 & GLACIERS \\
\hline 111 & CATLINS \\
\hline 112 & MARLBOROUGH \\
\hline 113 & WATCHING \\
\hline 114 & RAINFOREST \\
\hline 115 & TONGARIRO \\
\hline 116 & ENDANGERED \\
\hline 117 & BEECH \\
\hline 118 & LOTR \\
\hline 119 & NZHOLIDAYS \\
\hline 120 & EDORAS \\
\hline 121 & SUBALPINE \\
\hline 122 & TOURIST \\
\hline 123 & MOUNT \\
\hline 124 & RUAPEHU \\
\hline 125 & TRAMPING \\
\hline 126 & RUGGED \\
\hline 127 & ACTIVITIES \\
\hline 128 & HIKES \\
\hline 129 & CAVES \\
\hline 130 & BAY \\
\hline 131 & AMAZING \\
\hline 132 & MILFORD \\
\hline 133 & ITINERARIES \\
\hline 134 & TREKS \\
\hline 135 & MOA \\
\hline 136 & EXPLORE \\
\hline & \\
\hline 10.0
\end{tabular}

\begin{tabular}{|r|l|}
\hline 88 & OPERATIONS \\
\hline 89 & ARE \\
\hline 90 & HARVEST \\
\hline 91 & GARDENS \\
\hline 92 & REGIONAL \\
\hline 93 & COASTAL \\
\hline 94 & GOMFMC \\
\hline 95 & OKARITO \\
\hline 96 & ACTIVITIES \\
\hline 97 & OPERATORS \\
\hline 98 & FISHERIES \\
\hline 99 & KARORI \\
\hline 100 & MAORI \\
\hline 101 & FERRARO \\
\hline 102 & SCORE \\
\hline 103 & ECONOMIC \\
\hline 104 & HABITATS \\
\hline 105 & ROHE \\
\hline 106 & AND \\
\hline 107 & PDF \\
\hline 108 & WHALE \\
\hline 109 & RAEKAIHAU \\
\hline 110 & RECREATIONAL \\
\hline 111 & NOAA \\
\hline 112 & LOGGING \\
\hline 113 & CRUISE \\
\hline 114 & BIRD \\
\hline 115 & ATLANTIC \\
\hline 116 & FISHING \\
\hline 117 & KNP \\
\hline 118 & NATIONAL \\
\hline 119 & ECOLOGICAL \\
\hline 120 & REVENUE \\
\hline 121 & PELAGIC \\
\hline 122 & PROTECTION \\
\hline 123 & BIRDS \\
\hline 124 & GALÁPAGOS \\
\hline 125 & VOLUNTEERS \\
\hline 126 & ISLANDS \\
\hline 127 & PKA \\
\hline 128 & HORTICULTURAL \\
\hline 129 & LIVELIHOODS \\
\hline 130 & RESEARCH \\
\hline 131 & SOUTH \\
\hline 132 & QWA \\
\hline 133 & CATLINS \\
\hline 134 & CONSIDERED \\
\hline 135 & ZEALAND'S \\
\hline 136 & RESERVE \\
\hline & \\
\hline 10.1
\end{tabular}

\begin{tabular}{|r|l|}
\hline 88 & ITTO \\
\hline 89 & VALUES \\
\hline 90 & SEABIRD \\
\hline 91 & SUBMISSIONS \\
\hline 92 & STRATEGY \\
\hline 93 & ZEALANDERS \\
\hline 94 & PROTECTION \\
\hline 95 & INDUSTRY \\
\hline 96 & RECREATION \\
\hline 97 & VALUE \\
\hline 98 & MAF \\
\hline 99 & RESOURCES \\
\hline 100 & WETLAND \\
\hline 101 & ROHE \\
\hline 102 & DISCUSSION \\
\hline 103 & WAIKATO \\
\hline 104 & KAURI \\
\hline 105 & NON \\
\hline 106 & ORI \\
\hline 107 & WOOD \\
\hline 108 & PROTECT \\
\hline 109 & COMMENTED \\
\hline 110 & ECOLOGICALLY \\
\hline 111 & OUR \\
\hline 112 & IMPACTS \\
\hline 113 & WEBSITE \\
\hline 114 & ASPX \\
\hline 115 & OPERATORS \\
\hline 116 & RESILIENCE \\
\hline 117 & COUNCIL \\
\hline 118 & TARIFF \\
\hline 119 & TAHU \\
\hline 120 & NPS \\
\hline 121 & REGIONAL \\
\hline 122 & PROMOTE \\
\hline 123 & TAIAPURE \\
\hline 124 & DOCUMENTID \\
\hline 125 & LANDCARE \\
\hline 126 & EXPRESSED \\
\hline 127 & ACTIVITIES \\
\hline 128 & USES \\
\hline 129 & PRODUCTIVE \\
\hline 130 & MANAGED \\
\hline 131 & PAPER \\
\hline 132 & TE \\
\hline 133 & CLEARWATER \\
\hline 134 & TANGATA \\
\hline 135 & IWI \\
\hline 136 & PCE \\
\hline & \\
\hline 10.9
\end{tabular}




\begin{tabular}{|l|l|}
\hline 137 & RIMU \\
\hline 138 & OAMARU \\
\hline 139 & CHRISTCHURCH \\
\hline 140 & BOATING \\
\hline 141 & DAY \\
\hline 142 & ACCOMMODATION \\
\hline 143 & STUNNING \\
\hline 144 & WHALES \\
\hline 145 & SOUTHERN \\
\hline 146 & BALCLUTHA \\
\hline 147 & ENVIRONMENTAL \\
\hline 148 & FOX \\
\hline 149 & QUEST \\
\hline 150 & ENJOY \\
\hline 151 & AUCKLAND \\
\hline 152 & ABEL \\
\hline 153 & FIORDS \\
\hline 154 & SEABIRD \\
\hline 155 & VOLCANIC \\
\hline 156 & FISHING \\
\hline 157 & HTML \\
\hline 158 & UREWERA \\
\hline 159 & TETEPARE \\
\hline 160 & PELAGICS \\
\hline 161 & WAIKAREMOANA \\
\hline 162 & TE \\
\hline 163 & ULVA \\
\hline 164 & OJ \\
\hline 165 & PACIFIC \\
\hline 166 & JUMPING \\
\hline 167 & RIVERS \\
\hline 168 & OTAGO \\
\hline 169 & TOTARA \\
\hline 170 & TOBI \\
\hline 171 & BLOWHOLES \\
\hline 172 & ROTOMAHANA \\
\hline 173 & SPECIES \\
\hline 174 & MOUNTAINS \\
\hline 175 & ECOLOGY \\
\hline 176 & TRAILS \\
\hline 177 & ALBATROSS \\
\hline 178 & TREKKING \\
\hline 179 & BEAUTIFUL \\
\hline 180 & ENCOUNTER \\
\hline 181 & GLACIER \\
\hline 182 & CRUISE \\
\hline 183 & NORTH \\
\hline 184 & OVERHANG \\
\hline 185 & SANCTUARY \\
\hline & \\
\hline 19
\end{tabular}

\begin{tabular}{|r|l|}
\hline 137 & FI \\
\hline 138 & THESE \\
\hline 139 & DOLPHIN \\
\hline 140 & ROCKFISH \\
\hline 141 & VANUATU \\
\hline 142 & KAKA \\
\hline 143 & ROCKFISHES \\
\hline 144 & SHERMEN \\
\hline 145 & RANGITATA \\
\hline 146 & CENTRE \\
\hline 147 & ZEALANDERS \\
\hline 148 & SITES \\
\hline 149 & CODE \\
\hline 150 & HUTS \\
\hline 151 & SURVEY \\
\hline 152 & INTERNATIONAL \\
\hline 153 & WHALES \\
\hline 154 & MPAS \\
\hline 155 & COUNTRIES \\
\hline 156 & TIBET \\
\hline 157 & IWI \\
\hline 158 & RIMU \\
\hline 159 & INTERVIEWEES \\
\hline 160 & REGION \\
\hline 161 & KAPITI \\
\hline 162 & AREA \\
\hline 163 & INDIGENOUS \\
\hline 164 & LINKAGES \\
\hline 165 & WILDERNESS \\
\hline 166 & PLACES \\
\hline 167 & VIEWING \\
\hline 168 & HERITAGE \\
\hline 169 & NATURE \\
\hline 170 & HTM \\
\hline 171 & EE \\
\hline 172 & RESPONSES \\
\hline 173 & GLOBAL \\
\hline 174 & ET \\
\hline 175 & ALBATROSS \\
\hline 176 & WINSER \\
\hline 177 & NIUE \\
\hline 178 & RESOURCES \\
\hline 179 & COLONY \\
\hline 180 & COMMUNITY \\
\hline 181 & HISTORIC \\
\hline 182 & VISIT \\
\hline 183 & INTERPRETATION \\
\hline 184 & ECOSYSTEM \\
\hline 185 & FUNDING \\
\hline & \\
\hline 19
\end{tabular}

\begin{tabular}{|r|l|}
137 & SEQUESTRATION \\
\hline 138 & PRACTICES \\
\hline 139 & INCENTIVES \\
\hline 140 & FOR \\
\hline 141 & MUSSEL \\
\hline 142 & COMMISSIONER \\
\hline 143 & ROTORUA \\
\hline 144 & OTAGO \\
\hline 145 & CULTURAL \\
\hline 146 & OF \\
\hline 147 & QEII \\
\hline 148 & FAUNA \\
\hline 149 & SFM \\
\hline 150 & RAHUI \\
\hline 151 & QUALMARK \\
\hline 152 & NZTE \\
\hline 153 & IMPACT \\
\hline 154 & TREES \\
\hline 155 & WHALE \\
\hline 156 & QUALITY \\
\hline 157 & EXTRACTIVE \\
\hline 158 & ACHIEVING \\
\hline 159 & RADIATA \\
\hline 160 & FUTURE \\
\hline 161 & NGAI \\
\hline 162 & MINISTRY \\
\hline 163 & FARMERS \\
\hline 164 & STAKEHOLDERS \\
\hline 165 & UNFF \\
\hline 166 & VIEWDOCUMENT \\
\hline 167 & WHALEWATCH \\
\hline 168 & WILDLIFE \\
\hline 169 & ENSURE \\
\hline 170 & FOCUS \\
\hline 171 & MARKETS \\
\hline 172 & FLORA \\
\hline 173 & PLANT \\
\hline 174 & INFORMATION \\
\hline 175 & LOCAL \\
\hline 176 & FISHERIES \\
\hline 177 & OUTCOMES \\
\hline 178 & IMPORTANT \\
\hline 179 & PROMOTING \\
\hline 180 & CURRENT \\
\hline 181 & KAITIAKI \\
\hline 182 & BACKCOUNTRY \\
\hline 183 & TEMPERATE \\
\hline 184 & ACT \\
\hline 185 & BARRIERS \\
\hline & \\
\hline 10.9
\end{tabular}




\begin{tabular}{|c|c|c|c|c|c|}
\hline 186 & WAIRERE & 186 & EXPERIENCE & 186 & PLANTINGS \\
\hline 187 & HAURAKI & 187 & POTENTIAL & 187 & IFF \\
\hline 188 & WORLD & 188 & INSIGHTS & 188 & PEST \\
\hline 189 & DOLPHIN & 189 & TIMBERLANDS & 189 & ONGOING \\
\hline 190 & SOUNDS & 190 & BIRDING & 190 & ECOLOGY \\
\hline 191 & BALLROOM & 191 & REEF & 191 & DISTRICT \\
\hline 192 & LOCATIONS & 192 & $A L$ & 192 & PROVIDE \\
\hline 193 & LANDSCAPES & 193 & KAURI & 193 & LCA \\
\hline 194 & VARIETY & 194 & BENEFIT & 194 & PRINCIPLES \\
\hline 195 & ITINERARY & 195 & MARLBOROUGH & 195 & SILVICULTURE \\
\hline 196 & SWIMMING & 196 & PHKA & 196 & HAURAKI \\
\hline 197 & OPPORTUNITIES & 197 & GREENGLOBE & 197 & NZMSC \\
\hline 198 & COUNTRY & 198 & WHENUA & 198 & ADVOCACY \\
\hline 199 & PROGRAMMES & 199 & CAWTHRON & 199 & THESE \\
\hline 200 & IMPACTS & 200 & CROAKER & 200 & FISHERS \\
\hline 201 & PLANTS & 201 & POTAE & 201 & DEPARTMENT \\
\hline 202 & CAVE & 202 & AROHA & 202 & IPF \\
\hline 203 & DIVERSE & 203 & TIANZ & 203 & MARKET \\
\hline 204 & HIKE & 204 & WTTC & 204 & GLOBAL \\
\hline 205 & ZEALANDERS & 205 & TRACKERS & 205 & VISIONS \\
\hline 206 & PETRELS & 206 & TUI & 206 & MARKETING \\
\hline 207 & BEACH & 207 & LOCATED & 207 & DISCUSSED \\
\hline 208 & LEGENDS & 208 & INFORMATION & 208 & MANAGING \\
\hline 209 & CAVERN & 209 & GULF & 209 & BEEHIVE \\
\hline 210 & SWIM & 210 & FLORA & 210 & ACHIEVE \\
\hline 211 & EMAIL & 211 & RESERVES & 211 & GROWTH \\
\hline 212 & COOK & 212 & EXPENDITURE & 212 & SEABIRDS \\
\hline 213 & DESTINATION & 213 & QTS & 213 & SERVICES \\
\hline 214 & HOKIANGA & 214 & ESTIMATES & 214 & POLICIES \\
\hline 215 & BOAT & 215 & LOCATION & 215 & ECO \\
\hline 216 & ALPS & 216 & OVERCUT & 216 & DEVELOPED \\
\hline 217 & PARTICIPANTS & 217 & SADDLEBACKS & 217 & TARIFFS \\
\hline 218 & NELSON & 218 & BALMFORD & 218 & COMPETITIVENES+ \\
\hline 219 & PRISTINE & 219 & TUATARA & 219 & INCREASING \\
\hline 220 & COM & 220 & TAKAHE & 220 & CURRENTLY \\
\hline 221 & ASHBURTON & 221 & INDIRECT & 221 & SIGNIFICANT \\
\hline 222 & WANGANUI & 222 & BUSINESS & 222 & ROUNDWOOD \\
\hline 223 & OCEAN & 223 & PROVIDE & 223 & PRESERVATION \\
\hline 224 & LODGES & 224 & TOUR & 224 & GUIDELINES \\
\hline 225 & VISITOR & 225 & EXTRACTIVE & 225 & FEDERATED \\
\hline 226 & PAPATOWAI & 226 & BAY & 226 & ENHANCEMENT \\
\hline 227 & WEBSITE & 227 & USE & 227 & BUSINESSES \\
\hline 228 & PAPAROA & 228 & ASP & 228 & HUTS \\
\hline 229 & WRYBILL & 229 & OPPORTUNITIES & 229 & COASTAL \\
\hline 230 & GALAXSEA & 230 & BRECHIN & 230 & ACCESS \\
\hline 231 & OKARITO & 231 & PYLE & 231 & NATURE \\
\hline 232 & ECOSAIL & 232 & RURAL & 232 & WDB \\
\hline 233 & ECOWALKS & 233 & DIRECT & 233 & MATAITAI \\
\hline 234 & ECOTOURDIRECTO+ & 234 & FACILITIES & 234 & GROWOTAGO \\
\hline
\end{tabular}




\begin{tabular}{|l|l|}
\hline 235 & WARREN \\
\hline 236 & HIGHLIGHTS \\
\hline 237 & MANY \\
\hline 238 & LARGEST \\
\hline 239 & SWIMMERS \\
\hline 240 & TAUPO \\
\hline 241 & WATER \\
\hline 242 & RINGS \\
\hline 243 & AREAS \\
\hline 244 & PANCAKE \\
\hline 245 & ENDEMIC \\
\hline 246 & PERSONALISED \\
\hline 247 & BOULDERS \\
\hline 248 & TAKAHE \\
\hline 249 & AORAKI \\
\hline 250 & ECOLOGICAL \\
\hline 251 & SOMERS \\
\hline 252 & WATERFALLS \\
\hline 253 & ISLANDS \\
\hline 254 & PETREL \\
\hline 255 & RAINFORESTS \\
\hline 256 & LIMESTONE \\
\hline 257 & HUTS \\
\hline 258 & CULTURAL \\
\hline 259 & TOURISTS \\
\hline 260 & PLENTY \\
\hline 261 & HOURS \\
\hline 262 & CLICK \\
\hline 263 & OFFER \\
\hline 264 & SUSTAINABILITY \\
\hline 265 & ATTRACTIONS \\
\hline 266 & STEWART \\
\hline 267 & WILD \\
\hline 268 & KAKAPO \\
\hline 269 & PICNIC \\
\hline 270 & UNSPOILED \\
\hline 271 & RARE \\
\hline 272 & INCLUDING \\
\hline 273 & INLAND \\
\hline 274 & DUNEDIN \\
\hline 275 & GREAT \\
\hline 276 & REVEGETATION \\
\hline 277 & WALKWAY \\
\hline 278 & GREBE \\
\hline 279 & HISTORY \\
\hline 280 & AVAILABLE \\
\hline 281 & OUTDOORS \\
\hline 282 & SEABIRDS \\
\hline 283 & HISTORIC \\
\hline & \\
\hline
\end{tabular}

\begin{tabular}{|l|l|}
235 & CONSERVATIONIS+ \\
\hline 236 & EMAIL \\
\hline 237 & MAASAI \\
\hline 238 & BULLER \\
\hline 239 & TRAVELLERS \\
\hline 240 & AGGREGATIONS \\
\hline 241 & BENCHMARKING \\
\hline 242 & STAKEHOLDERS \\
\hline 243 & SPEND \\
\hline 244 & SCENIC \\
\hline 245 & PLOSBIOLOGY \\
\hline 246 & OTARI \\
\hline 247 & PIMBERT \\
\hline 248 & MIRAB \\
\hline 249 & KOKAKO \\
\hline 250 & PBIO \\
\hline 251 & NANCIAL \\
\hline 252 & NZTRI \\
\hline 253 & DIVCOM \\
\hline 254 & GHIMIRE \\
\hline 255 & ECOTOURIST \\
\hline 256 & SPREP \\
\hline 257 & SAFMC \\
\hline 258 & FERNBIRDS \\
\hline 259 & ECOTOURISMVISI+ \\
\hline 260 & SCHEYVENS \\
\hline 261 & FINFISH \\
\hline 262 & QNP \\
\hline 263 & SEBASTES \\
\hline 264 & SHOREBIRD \\
\hline 265 & SPILLOVER \\
\hline 266 & MOU \\
\hline 267 & BRANDON \\
\hline 268 & TUVALU \\
\hline 269 & MT \\
\hline 270 & CULTURAL \\
\hline 271 & RMA \\
\hline 272 & COM \\
\hline 273 & BREEDING \\
\hline 274 & DOWNLOAD \\
\hline 275 & SYMPATRIC \\
\hline 276 & TRIGGERFISH \\
\hline 277 & COUNTRY \\
\hline 278 & STD \\
\hline 279 & ROTORUA \\
\hline 280 & UNSUSTAINABLE \\
\hline 281 & ATTITUDES \\
\hline 282 & SEDENTARY \\
\hline 283 & DESTINATIONS \\
\hline & \\
\hline
\end{tabular}

\begin{tabular}{|l|l|}
235 & POTAE \\
\hline 236 & TRCNZ \\
\hline 237 & MFE \\
\hline 238 & PODOCARP \\
\hline 239 & EDUCATION \\
\hline 240 & ARE \\
\hline 241 & ISSUES \\
\hline 242 & ORGANISATIONS \\
\hline 243 & CARBON \\
\hline 244 & CONCESSIONAIRE \\
\hline 245 & VISION \\
\hline 246 & LABELLING \\
\hline 247 & SILVICULTURAL \\
\hline 248 & COMMUNITY \\
\hline 249 & PROCESSED \\
\hline 250 & LACK \\
\hline 251 & EFFORTS \\
\hline 252 & NORTHLAND \\
\hline 253 & WAI \\
\hline 254 & GOVERNMENT \\
\hline 255 & HECTARES \\
\hline 256 & AGENCIES \\
\hline 257 & SHELTERBELTS \\
\hline 258 & ENHANCE \\
\hline 259 & SCENARIOS \\
\hline 260 & PDF \\
\hline 261 & DERIVED \\
\hline 262 & DETRIMENTAL \\
\hline 263 & DEGRADATION \\
\hline 264 & FARMS \\
\hline 265 & BUSH \\
\hline 266 & ACCOMMODATION \\
\hline 267 & RELATIONSHIPS \\
\hline 268 & VIEW \\
\hline 269 & PROVIDING \\
\hline 270 & PARTICULARLY \\
\hline 271 & CERTIFIED \\
\hline 272 & UNIQUE \\
\hline 273 & UNSUSTAINABLY \\
\hline 274 & GLOBE \\
\hline 275 & RURAL \\
\hline 276 & APPROACHES \\
\hline 277 & INCLUDING \\
\hline 278 & ESTABLISHMENT \\
\hline 279 & PACIFIC \\
\hline 280 & PROTECTED \\
\hline 281 & NGAHERE \\
\hline & NZTTB \\
\hline
\end{tabular}




\begin{tabular}{|l|l|}
\hline 284 & PRODUCTS \\
\hline 285 & DURATION \\
\hline 286 & ALONG \\
\hline 287 & BULLOCK \\
\hline 288 & VISIT \\
\hline 289 & GORGE \\
\hline 290 & ROCKS \\
\hline 291 & HUTT \\
\hline 292 & PURETRAILS \\
\hline 293 & TAKUTAI \\
\hline 294 & WETA \\
\hline 295 & WAITAKI \\
\hline 296 & TAURANGA \\
\hline 297 & PATHWALKER \\
\hline 298 & WOOLSHED \\
\hline 299 & MOERAKI \\
\hline 300 & KWT \\
\hline 301 & NATURETOURS \\
\hline 302 & GLENFERN \\
\hline 303 & FLIGHTLESS \\
\hline 304 & FRAGILE \\
\hline 305 & JET \\
\hline 306 & LL \\
\hline 307 & NZ'S \\
\hline 308 & PACK \\
\hline 309 & RIFLEMAN \\
\hline 310 & FORMATIONS \\
\hline 311 & METHVEN \\
\hline 312 & COASTLINES \\
\hline 313 & OFFERS \\
\hline 314 & WETLAND \\
\hline 315 & HABITATS \\
\hline 316 & UNDERWATER \\
\hline 317 & PLACES \\
\hline 318 & DIVING \\
\hline 319 & GLOW \\
\hline 320 & MEALS \\
\hline 321 & YOU \\
\hline 322 & VEGETATION \\
\hline 323 & TROUT \\
\hline 324 & BEAUTY \\
\hline 325 & NEWZEALAND \\
\hline 326 & KAHIKATEA \\
\hline 327 & ROADING \\
\hline 328 & MARAE \\
\hline 329 & RECREATIONAL \\
\hline 330 & HECTOR'S \\
\hline 331 & OPTIONS \\
\hline 332 & INFORMATION \\
\hline & \\
\hline
\end{tabular}

\begin{tabular}{|l|l|}
\hline 284 & DEPARTMENT \\
\hline 285 & WESTLAND \\
\hline 286 & POSSUMS \\
\hline 287 & WAITOMO \\
\hline 288 & ECOLOGIC \\
\hline 289 & TAPU \\
\hline 290 & HOKITIKA \\
\hline 291 & BELLBIRDS \\
\hline 292 & INTERVIEWS \\
\hline 293 & KIRIBATI \\
\hline 294 & POSSUM \\
\hline 295 & WHALING \\
\hline 296 & LANDS \\
\hline 297 & YIELD \\
\hline 298 & NMFS \\
\hline 299 & TS \\
\hline 300 & FIJI \\
\hline 301 & PENGUIN \\
\hline 302 & IS \\
\hline 303 & ADJACENT \\
\hline 304 & LIVELIHOOD \\
\hline 305 & TOOL \\
\hline 306 & GUIDED \\
\hline 307 & SHIPP \\
\hline 308 & PLOS \\
\hline 309 & WEB \\
\hline 310 & VIABILITY \\
\hline 311 & LOWLAND \\
\hline 312 & DOLPHINS \\
\hline 313 & DOC \\
\hline 314 & INVERCARGILL \\
\hline 315 & HIGHWAY \\
\hline 316 & PHONE \\
\hline 317 & O \\
\hline 318 & PAYMENTS \\
\hline 319 & ACCESS \\
\hline 320 & WADING \\
\hline 321 & PEOPLES \\
\hline 322 & LAND \\
\hline 323 & PROTECTING \\
\hline 324 & STUDY \\
\hline 325 & INFRASTRUCTURE \\
\hline 326 & FAUNA \\
\hline 327 & MACKEREL \\
\hline 328 & RESPONSIBLE \\
\hline 329 & CONTRIBUTES \\
\hline 330 & RESEARCHERS \\
\hline 331 & INITIATIVES \\
\hline 332 & MEAN \\
\hline & \\
\hline
\end{tabular}

\begin{tabular}{|l|l|}
284 & FRST \\
\hline 285 & FARMSTAYS \\
\hline 286 & SILNA \\
\hline 287 & HTML \\
\hline 288 & HTM \\
\hline 289 & SUBMISSION \\
\hline 290 & ENCOURAGEMENT \\
\hline 291 & PROJECTS \\
\hline 292 & PINUS \\
\hline 293 & KIWI \\
\hline 294 & PROGRESS \\
\hline 295 & TREE \\
\hline 296 & QUOTES \\
\hline 297 & REMOVAL \\
\hline 298 & CONSERVE \\
\hline 299 & SOUTHLAND \\
\hline 300 & REGULATORY \\
\hline 301 & BILLION \\
\hline 302 & NGA \\
\hline 303 & HARVEST \\
\hline 304 & INITIATIVES \\
\hline 305 & RANGE \\
\hline 306 & EXISTING \\
\hline 307 & NEED \\
\hline 308 & SUGGESTED \\
\hline 309 & ATTRACTIONS \\
\hline 310 & GOALS \\
\hline 311 & SECTION \\
\hline 312 & AUCKLAND \\
\hline 313 & TAPU \\
\hline 314 & ECOTOURISTS \\
\hline 315 & OAMARU \\
\hline 316 & SAWNWOOD \\
\hline 317 & ASP \\
\hline 318 & CONCESSION \\
\hline 319 & NATIVES \\
\hline 320 & ALSO \\
\hline 321 & TRACKS \\
\hline 322 & CAMPSITES \\
\hline 323 & WELLINGTON \\
\hline 324 & RUBBISH \\
\hline 325 & PRODUCTION \\
\hline 326 & LEGISLATION \\
\hline 327 & THAT \\
\hline 328 & TERM \\
\hline 329 & SITES \\
\hline 330 & ACTIVELY \\
\hline 331 & SHELTER \\
\hline 332 & HABITAT \\
\hline & \\
\hline
\end{tabular}




\begin{tabular}{|l|l|}
\hline 333 & ADVENTURES \\
\hline 334 & SHAGS \\
\hline 335 & BARRIER \\
\hline 336 & CAN \\
\hline 337 & RESERVE \\
\hline 338 & TRAVELLERS \\
\hline 339 & ANAU \\
\hline 340 & YOUR \\
\hline 341 & GUIDE \\
\hline 342 & LOCAL \\
\hline 343 & PENINSULA \\
\hline 344 & FORESTED \\
\hline 345 & CLIENTS \\
\hline 346 & RATA \\
\hline 347 & SNOWBOARDING \\
\hline 348 & STAY \\
\hline 349 & BRAIDED \\
\hline 350 & HABITAT \\
\hline 351 & PENGUIN \\
\hline 352 & ELK \\
\hline 353 & WORMS \\
\hline 354 & LUSH \\
\hline 355 & POD \\
\hline 356 & DUSKY \\
\hline 357 & OFFSHORE \\
\hline 358 & TREES \\
\hline 359 & COLETTE \\
\hline 360 & FANTASTIC \\
\hline 361 & ROUTEBURN \\
\hline 362 & SANDFLIES \\
\hline 363 & ENVIRONMENTS \\
\hline 364 & INTERNATIONALL+ \\
\hline 365 & FERNS \\
\hline 366 & SKIING \\
\hline 367 & CANYON \\
\hline 368 & LAND \\
\hline 369 & BIKE \\
\hline 370 & BOTTLENOSE \\
\hline 371 & RESERVES \\
\hline 372 & REGION \\
\hline 373 & CREATURES \\
\hline 374 & EWERS \\
\hline 375 & MARYANN \\
\hline 376 & CANTERBURY \\
\hline 377 & ESTUARY \\
\hline 378 & LANDSCAPE \\
\hline 379 & VACCINATIONS \\
\hline 380 & DRIVE \\
\hline 381 & WONDERS \\
\hline & \\
\hline
\end{tabular}

\begin{tabular}{|l|l|}
\hline 333 & ENDANGERED \\
\hline 334 & CONDUCTED \\
\hline 335 & RELATED \\
\hline 336 & SECTOR \\
\hline 337 & COMMERCIAL \\
\hline 338 & ORGANISATIONS \\
\hline 339 & AOTEAROA \\
\hline 340 & WALKWAYS \\
\hline 341 & SCHWARTZ \\
\hline 342 & DEPARTURE \\
\hline 343 & JOLLIFFE \\
\hline 344 & KARST \\
\hline 345 & INCLUDING \\
\hline 346 & ONGOING \\
\hline 347 & PROFILE \\
\hline 348 & BEECH \\
\hline 349 & G \\
\hline 350 & SPOONBILL \\
\hline 351 & DIVERSITY \\
\hline 352 & WRYBILL \\
\hline 353 & QUALMARK \\
\hline 354 & SKÅL \\
\hline 355 & STITCHBIRD \\
\hline 356 & PODOCARP \\
\hline 357 & RESPONSIBLETOU + \\
\hline 358 & WAAHI \\
\hline 359 & TPG \\
\hline 360 & VATTHE \\
\hline 361 & TAPUTERANGA \\
\hline 362 & TOWHICH \\
\hline 363 & TIRITIRI \\
\hline 364 & WHATSNEW \\
\hline 365 & DWM \\
\hline 366 & MATANGI \\
\hline 367 & EPINEPHELUS \\
\hline 368 & BRUCENATIONALW + \\
\hline 369 & DJOHANI \\
\hline 370 & CRUISESHIP \\
\hline 371 & BILSKY \\
\hline 372 & KERERU \\
\hline 373 & KOUTOU \\
\hline 374 & HAMMITT \\
\hline 375 & NZTIA \\
\hline 376 & LINGCOD \\
\hline 377 & FORESTANDBIRD \\
\hline 378 & FLATFISHES \\
\hline 379 & HAURAKI \\
\hline 380 & NZTB \\
\hline 381 & WILSHUSEN \\
\hline & \\
\hline
\end{tabular}




\begin{tabular}{|l|l|}
\hline 382 & FUR \\
\hline 383 & ACCOMMODATIONS \\
\hline 384 & CRESTED \\
\hline 385 & GEOTHERMAL \\
\hline 386 & TRANSPORT \\
\hline 387 & KIA \\
\hline 388 & MYTHS \\
\hline 389 & MAIN \\
\hline 390 & GISBORNE \\
\hline 391 & ROTORUA \\
\hline 392 & PICTON \\
\hline 393 & TAKE \\
\hline 394 & KEA \\
\hline 395 & NIKAU \\
\hline 396 & GEMINI \\
\hline 397 & OVERNIGHT \\
\hline 398 & EDUCATIONAL \\
\hline 399 & WEB \\
\hline 400 & SPECIAL \\
\hline 401 & PELAGIC \\
\hline 402 & ARTHURS \\
\hline 403 & NORTHLAND \\
\hline 404 & DESTINATIONS \\
\hline 405 & ENHANCE \\
\hline 406 & IS \\
\hline 407 & ORA \\
\hline 408 & DAYS \\
\hline 409 & WORLD'S \\
\hline 410 & OPPORTUNITY \\
\hline 411 & COMFORTABLE \\
\hline 412 & LOCATED \\
\hline 413 & RELAXING \\
\hline 414 & EXPEDITIONS \\
\hline 415 & OPERATOR \\
\hline 416 & AWESOME \\
\hline 417 & TRAVEL \\
\hline 418 & OUTDOOR \\
\hline 419 & RAINFALL \\
\hline 420 & EXCELLENT \\
\hline 421 & RESOURCE \\
\hline 422 & RANGE \\
\hline 423 & SPERM \\
\hline 424 & ASP \\
\hline 425 & DOC \\
\hline 426 & ANIMALS \\
\hline 427 & FAMOUS \\
\hline 428 & PREDATORS \\
\hline 429 & PROVIDES \\
\hline 430 & OCEANS \\
\hline & \\
\hline
\end{tabular}

\begin{tabular}{|l|l|}
382 & NZERS \\
\hline 383 & BAYLINE \\
\hline 384 & TAUPO \\
\hline 385 & PRO \\
\hline 386 & HECTARE \\
\hline 387 & E \\
\hline 388 & PROVIDING \\
\hline 389 & GROUPERS \\
\hline 390 & GISBORNE \\
\hline 391 & TOIT \\
\hline 392 & AUCKLAND \\
\hline 393 & INTERNET \\
\hline 394 & BASED \\
\hline 395 & PROTECT \\
\hline 396 & ARBORETUM \\
\hline 397 & SURVEYS \\
\hline 398 & RESTRICTIONS \\
\hline 399 & SEX \\
\hline 400 & KEARSLEY \\
\hline 401 & GANNETS \\
\hline 402 & CODES \\
\hline 403 & COSTS \\
\hline 404 & BEHAVIOURS \\
\hline 405 & PERS \\
\hline 406 & POLYNESIA \\
\hline 407 & PATTERNS \\
\hline 408 & OCEAN \\
\hline 409 & OUTDOOR \\
\hline 410 & ECOTOURISTS \\
\hline 411 & KAITIAKI \\
\hline 412 & TANGATA \\
\hline 413 & GROUNDFISH \\
\hline 414 & BACKCOUNTRY \\
\hline 415 & OAMARU \\
\hline 416 & MAHIA \\
\hline 417 & HANMER \\
\hline 418 & WALKS \\
\hline 419 & FOCUS \\
\hline 420 & PORGY \\
\hline 421 & EXPERIENCING \\
\hline 422 & WETLAND \\
\hline 423 & CONTACT \\
\hline 424 & GEF \\
\hline 425 & VOLUNTEER \\
\hline 426 & PRESSURES \\
\hline 427 & SIGNPOSTED \\
\hline 428 & RANGE \\
\hline 429 & ALASKA \\
\hline 430 & ATTRACTION \\
\hline & \\
\hline
\end{tabular}




\begin{tabular}{|l|l|}
\hline 431 & CONTACT \\
\hline 432 & SANCTUARIES \\
\hline 433 & LEARN \\
\hline 434 & ALBATROSSES \\
\hline 435 & HERON \\
\hline 436 & CYCLING \\
\hline 437 & LANDMASS \\
\hline 438 & FRIENDLY \\
\hline 439 & WEST \\
\hline 440 & ISLAND'S \\
\hline 441 & WINERY \\
\hline 442 & STREAMS \\
\hline 443 & UNDISTURBED \\
\hline 444 & WATCH \\
\hline 445 & BLUFFS \\
\hline 446 & INFORMATIVE \\
\hline 447 & WATERWAYS \\
\hline 448 & NETWORK \\
\hline 449 & HIMALAYAN \\
\hline 450 & MAMMALS \\
\hline 451 & DEER \\
\hline 452 & LOWLAND \\
\hline 453 & TRANQUIL \\
\hline 454 & BIRDLIFE \\
\hline 455 & FLUTING \\
\hline 456 & WATERS \\
\hline 457 & VIEWS \\
\hline 458 & TRAIL \\
\hline 459 & TRILOGY \\
\hline 460 & PARADISE \\
\hline 461 & CAGE \\
\hline 462 & CHARTERS \\
\hline 463 & HOOKER'S \\
\hline 464 & KNOWLEDGEABLE \\
\hline 465 & COMMUNITIES \\
\hline 466 & ROAD \\
\hline 467 & SITE \\
\hline 468 & ATTRACTION \\
\hline 469 & MOVIES \\
\hline 470 & COLONY \\
\hline 471 & STALACTITES \\
\hline 472 & TREK \\
\hline 473 & INCLUDE \\
\hline 474 & NESTING \\
\hline 475 & BEST \\
\hline 476 & KILOMETRES \\
\hline 477 & PHOTOGRAPHY \\
\hline 478 & KAYAKS \\
\hline 479 & RENOWNED \\
\hline & \\
\hline
\end{tabular}

\begin{tabular}{|l|l|}
\hline 431 & PROMOTE \\
\hline 432 & TIA \\
\hline 433 & SHAGS \\
\hline 434 & TAKAKA \\
\hline 435 & TENA \\
\hline 436 & PATA \\
\hline 437 & ANAU \\
\hline 438 & FAX \\
\hline 439 & MOST \\
\hline 440 & STATIONS \\
\hline 441 & AUSTRALASIAN \\
\hline 442 & RIVERS \\
\hline 443 & GOODWIN \\
\hline 444 & EFFECTIVE \\
\hline 445 & SOCIOECONOMIC \\
\hline 446 & ALPS \\
\hline 447 & GLOBE \\
\hline 448 & PROJECT \\
\hline 449 & DUNEDIN \\
\hline 450 & EMPOWERMENT \\
\hline 451 & TERM \\
\hline 452 & DOWNLOADS \\
\hline 453 & BENCHMARKED \\
\hline 454 & BOTANIC \\
\hline 455 & COASTERS \\
\hline 456 & ALSO \\
\hline 457 & OCCURRING \\
\hline 458 & TRIPS \\
\hline 459 & STATING \\
\hline 460 & SWAMP \\
\hline 461 & GARDEN \\
\hline 462 & WALKING \\
\hline 463 & MAINLAND \\
\hline 464 & EXPLOITED \\
\hline 465 & BUSH \\
\hline 466 & IMPLEMENTED \\
\hline 467 & ESTIMATE \\
\hline 468 & WATERS \\
\hline 469 & GANNET \\
\hline 470 & MANAGED \\
\hline 471 & ORGANISATION \\
\hline 472 & NORTH \\
\hline 473 & BEHAVIOUR \\
\hline 474 & SANCTUARIES \\
\hline 475 & LOCALS \\
\hline 476 & STANDARDS \\
\hline 477 & LAGOON \\
\hline 478 & WANGANUI \\
\hline 479 & QUALITY \\
\hline & \\
\hline
\end{tabular}

\begin{tabular}{|l|l|}
\hline 431 & PASTURE \\
\hline 432 & INTERACTIVE \\
\hline 433 & QUESTIONED \\
\hline 434 & RECOGNISES \\
\hline 435 & OPPORTUNITY \\
\hline 436 & SOURCED \\
\hline 437 & PROTECTING \\
\hline 438 & T \\
\hline 439 & WILDERNESS \\
\hline 440 & MAMMAL \\
\hline 441 & ADVENTURE \\
\hline 442 & ISLANDS \\
\hline 443 & RIVERS \\
\hline 444 & PAKEHA \\
\hline 445 & RESPECT \\
\hline 446 & FARMING \\
\hline 447 & ADVISORY \\
\hline 448 & CRITICAL \\
\hline 449 & RULES \\
\hline 450 & AOTEAROA \\
\hline 451 & ORGANIZATION \\
\hline 452 & RECOGNISED \\
\hline 453 & WHITESTONE \\
\hline 454 & REMNANT \\
\hline 455 & SANCTUARY \\
\hline 456 & MONETARY \\
\hline 457 & KARST \\
\hline 458 & CATCHMENTS \\
\hline 459 & NE \\
\hline 460 & RELATION \\
\hline 461 & IMPORTANCE \\
\hline 462 & ESCALATION \\
\hline 463 & FRAMEWORK \\
\hline 464 & MOTELS \\
\hline 465 & PROVIDED \\
\hline 466 & DIVERSITY \\
\hline 467 & CONSERVATIONIS + \\
\hline 468 & CONTEXT \\
\hline 469 & CUSTOMARY \\
\hline 470 & ENVIRONMENTS \\
\hline 471 & HIGHLIGHT \\
\hline 472 & TOURISTS \\
\hline 473 & STOAT \\
\hline 474 & BACKPACKERS \\
\hline 475 & INTEGRATED \\
\hline 476 & POINTED \\
\hline 477 & MONOCULTURAL \\
\hline 478 & LIBERALIIATION \\
\hline 479 & SUBSTITUTES \\
\hline & \\
\hline
\end{tabular}




\begin{tabular}{|l|l|}
\hline 480 & CAMPING \\
\hline 481 & VOLCANO \\
\hline 482 & DUCK \\
\hline 483 & ROCK \\
\hline 484 & SO \\
\hline 485 & TO \\
\hline 486 & THEM \\
\hline 487 & WHO \\
\hline 488 & THEN \\
\hline 489 & THE \\
\hline 490 & IF \\
\hline 491 & BEEN \\
\hline 492 & BE \\
\hline 493 & THEY \\
\hline 494 & NO \\
\hline 495 & DID \\
\hline 496 & WHICH \\
\hline 497 & WHEN \\
\hline 498 & MY \\
\hline 499 & COULD \\
\hline 500 & SAID \\
\hline & \\
\hline
\end{tabular}

\begin{tabular}{|l|l|}
\hline 480 & JUVENILES \\
\hline 481 & ECONOMIES \\
\hline 482 & SPECIFIC \\
\hline 483 & POPULATIONS \\
\hline 484 & NEEDS \\
\hline 485 & AWARENESS \\
\hline 486 & CLEARANCE \\
\hline 487 & AC \\
\hline 488 & APPROXIMATELY \\
\hline 489 & RECENT \\
\hline 490 & PENINSULA \\
\hline 491 & TASMAN \\
\hline 492 & BRUCE \\
\hline 493 & WETLANDS \\
\hline 494 & TRADITIONAL \\
\hline 495 & SEASONAL \\
\hline 496 & NPS \\
\hline 497 & WHITEBAIT \\
\hline 498 & CBD \\
\hline 499 & ALTERNATIVES \\
\hline 500 & METHODOLOGY \\
\hline & \\
\hline
\end{tabular}

\begin{tabular}{|l|l|}
\hline 480 & FOCUSED \\
\hline 481 & SKILLS \\
\hline 482 & AESTHETIC \\
\hline 483 & TREKS \\
\hline 484 & IDENTIFYING \\
\hline 485 & MALAYSIA \\
\hline 486 & PROVIDES \\
\hline 487 & MUTUALLY \\
\hline 488 & BASED \\
\hline 489 & GRASSLANDS \\
\hline 490 & INCENTIVE \\
\hline 491 & PROMOTION \\
\hline 492 & ENVIRONMENTALL+ \\
\hline 493 & VANUATU \\
\hline 494 & DOCUMENT \\
\hline 495 & INFRASTRUCTURE \\
\hline 496 & CONSERVING \\
\hline 497 & MCSWEENEY \\
\hline 498 & AMENDMENT \\
\hline 499 & GIARDIA \\
\hline 500 & POSITIVE \\
\hline & \\
\hline
\end{tabular}




\section{ANEXO D - RELAÇÃO DAS KEYWORDS EM PORTUGUÊS JÁ LIMPAS}

As cores correspondem às listas nas quais as palavras aparecem.

Palavras que aparecem nos três corpora - amarelo

Palavras que aparecem nos corpora de agências e ambientalistas - azul

Palavras que aparecem nos corpora de agências e governo - verde

Palavras que aparecem nos corpora de ambientalistas e governo - rosa

\begin{tabular}{|l|}
\hline AG $\mathbf{X}$ Ref \\
\hline ACESSO \\
\hline ÁGUA \\
\hline ÁGUAS \\
\hline AMBIENTAIS \\
\hline AMBIENTAL \\
\hline AMBIENTE \\
\hline AMBIENTES \\
\hline ANIMAIS \\
\hline ÁREA \\
\hline ÁREAS \\
\hline ÁRVORES \\
\hline ARVORISMO \\
\hline ASSOCIAÇÃO \\
\hline ATIVIDADE \\
\hline ATIVIDADES \\
\hline ATRATIVOS \\
\hline AVENTURA \\
\hline AVES \\
\hline BIODIVERSIDADE \\
\hline BÓIA \\
\hline CACHOEIRA \\
\hline CACHOEIRAS \\
\hline CAMINHADA \\
\hline CAMINHADAS \\
\hline CANOAGEM \\
\hline CANYONING \\
\hline CAVERNA \\
\hline CAVERNAS \\
\hline COMUNIDADE \\
\hline COMUNIDADES \\
\hline CONSERVAÇÃO \\
\hline CORDA \\
\hline CORREDEIRAS \\
\hline CULTURA \\
\hline CULTURAIS \\
\hline CULTURAL \\
\hline
\end{tabular}

\begin{tabular}{|l|}
\hline AMB X REF \\
\hline AÇÃO \\
\hline AMBIENTAIS \\
\hline AMBIENTAL \\
\hline AMBIENTE \\
\hline ÁREA \\
\hline ÁREAS \\
\hline ATIVIDADE \\
\hline ATIVIDADES \\
\hline ATLÂNTICA \\
\hline ATRATIVOS \\
\hline BENEFÍCIOS \\
\hline BIODIVERSIDADE \\
\hline CAPACITAÇÃO \\
\hline CERTIFICAÇÃO \\
\hline COMUNIDADE \\
\hline COMUNIDADES \\
\hline COMUNITÁRIA \\
\hline COMUNITÁRIO \\
\hline CONSCIÊNCIA \\
\hline CONSERVAÇÃO \\
\hline CULTURA \\
\hline CULTURAIS \\
\hline CULTURAL \\
\hline DESENVOLVIMENTO \\
\hline DESTINO \\
\hline DESTINOS \\
\hline ECOGÊNESE \\
\hline ECOLÓGICA \\
\hline ECOLÓGICO \\
\hline ECONÔMICA \\
\hline ECONÔMICO \\
\hline ECOTURISMO \\
\hline ECOTURÍSTICO \\
\hline EDUCAÇÃO \\
\hline EMPREENDIMENTO \\
\hline ENTIDADES \\
\hline
\end{tabular}

\begin{tabular}{|l|} 
GOV $\mathbf{X}$ REF \\
\hline ACOMPANHAMENTO \\
\hline ADMINISTRAÇÃO \\
\hline ÁGUA \\
\hline AMBIENTAIS \\
\hline AMBIENTAL \\
\hline AMBIENTE \\
\hline AMBIENTES \\
\hline ÁREA \\
\hline ÁREAS \\
\hline ATIVIDADE \\
\hline ATIVIDADES \\
\hline ATLÂNTICA \\
\hline ATRATIVOS \\
\hline AVENTURA \\
\hline BIODIVERSIDADE \\
\hline CAPACITAÇÃO \\
\hline CAVALGADA \\
\hline CAVERNAS \\
\hline COMPLEMENTARES \\
\hline COMUNIDADE \\
\hline COMUNIDADES \\
\hline CONSERVAÇÃO \\
\hline CONTROLE \\
\hline CRESCIMENTO \\
\hline CULTURA \\
\hline CULTURAIS \\
\hline CULTURAL \\
\hline DESENVOLVIMENT+ \\
\hline DESTINOS \\
\hline DIVERSIDADE \\
\hline ECOLÓGICO \\
\hline ECONÔMICA \\
\hline ECONÔMICO \\
\hline ECOSSISTEMAS \\
\hline ECOTURISMO \\
\hline ECOTURÍSTICOS \\
\hline
\end{tabular}




\begin{tabular}{|c|}
\hline DESCIDA \\
\hline DESENVOLVIMENT+ \\
\hline DESTINO \\
\hline DIVERSIDADE \\
\hline ECO \\
\hline ECOESPORTES \\
\hline ECOLÓGICO \\
\hline ECOSSISTEMAS \\
\hline ECOTURISMO \\
\hline ECOTURÍSTICO \\
\hline ECOTURÍSTICOS \\
\hline EDUCAÇÃO \\
\hline EQUIPAMENTOS \\
\hline ESCALADA \\
\hline ESPÉCIES \\
\hline ESPORTE \\
\hline ESPORTES \\
\hline ESPORTIVA \\
\hline ESTRUTURA \\
\hline ESTUDO \\
\hline ESTUDOS \\
\hline EXPEDIÇÕES \\
\hline EXPERIÊNCIA \\
\hline EXPLORAÇÃO \\
\hline FAUNA \\
\hline FLORA \\
\hline FLORESTA \\
\hline FLORESTAS \\
\hline GUIA \\
\hline GUIAS \\
\hline HISTÓRIA \\
\hline IMPACTO \\
\hline IMPACTOS \\
\hline IMPLANTAÇÃO \\
\hline INFRA \\
\hline INTERPRETAÇÃO \\
\hline LAZER \\
\hline LIXO \\
\hline LOCAIS \\
\hline LOCAL \\
\hline LUGAR \\
\hline MANEJO \\
\hline MATA \\
\hline MATAS \\
\hline MEIO \\
\hline MERGULHO \\
\hline NATURAIS \\
\hline NATURAL \\
\hline NATUREZA \\
\hline NÚCLEO \\
\hline OBSERVAÇÃO \\
\hline PAISAGEM \\
\hline PAISAGENS \\
\hline PARQUE \\
\hline PASSEIO \\
\hline
\end{tabular}

\begin{tabular}{|c|}
\hline ESPÉCIES \\
\hline ESTRATÉGIAS \\
\hline ESTRUTURA \\
\hline ESTUDO \\
\hline ESTUDOS \\
\hline GESTÃO \\
\hline IMPACTO \\
\hline IMPACTOS \\
\hline IMPLANTAÇÃO \\
\hline IMPLEMENTAÇÃO \\
\hline INFORMAÇÕES \\
\hline INFRA \\
\hline INTERPRETAÇÃO \\
\hline INVESTIMENTOS \\
\hline LAZER \\
\hline LOCAIS \\
\hline LOCAL \\
\hline MANEJO \\
\hline MARKETING \\
\hline MATA \\
\hline MEIO \\
\hline MEIOS \\
\hline MONITORAMENTO \\
\hline NATURAIS \\
\hline NATURAL \\
\hline NATUREZA \\
\hline ORGANIZAÇÃO \\
\hline ORGANIZAÇÕES \\
\hline PARQUE \\
\hline PARQUES \\
\hline PARTICIPAÇÃO \\
\hline PARTICIPANTES \\
\hline PATRIMÔNIO \\
\hline PESCA \\
\hline PESSOAS \\
\hline PLANEJAMENTO \\
\hline POLÍTICA \\
\hline POLÍTICAS \\
\hline PÓLOS \\
\hline POPULAÇÃO \\
\hline POPULAÇÕES \\
\hline POTENCIAL \\
\hline PRÁTICA \\
\hline PRÁTICAS \\
\hline PRESERVAÇÃO \\
\hline PRINCÍPIOS \\
\hline PROBLEMAS \\
\hline PROCESSO \\
\hline PRODUTOS \\
\hline PROGRAMA \\
\hline PROGRAMAS \\
\hline PROJETO \\
\hline PROJETOS \\
\hline PROMOÇÃO \\
\hline PROMOVER \\
\hline
\end{tabular}

\begin{tabular}{|l|}
\hline EDUCAÇÃO \\
\hline ENTIDADES \\
\hline ENTORNO \\
\hline EQUIPAMENTOS \\
\hline ESPÉCIES \\
\hline ESPORTE \\
\hline ESTRATÉGIA \\
\hline ESTRATÉGIAS \\
\hline ESTRUTURA \\
\hline ESTRUTURAS \\
\hline ESTUDO \\
\hline ESTUDOS \\
\hline FAUNA \\
\hline FLORESTA \\
\hline FLORESTAL \\
\hline FLORESTAS \\
\hline GARANTIR \\
\hline GESTÃO \\
\hline GUIAS \\
\hline IMPACTO \\
\hline IMPACTOS \\
\hline IMPLANTAÇÃO \\
\hline INCENTIVAR \\
\hline INFRA \\
\hline INSTITUIÇÕES \\
\hline INVESTIMENTOS \\
\hline LAZER \\
\hline LOCAIS \\
\hline LOCAL \\
\hline MANEJO \\
\hline MATA \\
\hline MEIO \\
\hline MERGULHO \\
\hline MODALIDADE \\
\hline MODALIDADES \\
\hline MONITORAMENTO \\
\hline MONITORES \\
\hline NATURAIS \\
\hline NATURAL \\
\hline NATUREZA \\
\hline ORGANIZAÇÃO \\
\hline PARQUE \\
\hline PARQUES \\
\hline PARTICIPAÇÃO \\
\hline PATRIMÔNIO \\
\hline PESCA \\
\hline PRSSOAIICASACACOAÕOES \\
\hline PROCEDIMENTOS \\
\hline
\end{tabular}




\begin{tabular}{|c|c|c|}
\hline PASSEIOS & PROTEÇÃO & PROGRAMA (S) \\
\hline PATRIMÔNIO & PROTEGIDAS & PROJETO \\
\hline PEIXE & RECREATIVO & PROJETOS \\
\hline PERCURSO & RECURSOS & PROMOÇÃO \\
\hline PESCA & REGIÃO & PROMOVER \\
\hline PESSOAS & REGIÕES & PROTEÇÃO \\
\hline PLANEJAMENTO & RENDA & PROTEGIDAS \\
\hline PÓLO & RESERVA & QUEDISMO \\
\hline POPULAÇÃO & RESERVAS & RAFTING \\
\hline POTENCIAL & RESPEITO & RALLY \\
\hline PRÁTICA & RESPONSABILIDA+ & RECURSOS \\
\hline PRESERVAÇÃO & RESPONSÁVEL & REGIÃO \\
\hline PRODUTOS & SOCIAIS & RENDA \\
\hline PROGRAMA & $\overline{\text { SOCIAL }}$ & REPRESENTATIVA+ \\
\hline PROJETO & SOCIEDADE & RESPONSABILIDA+ \\
\hline PROTEÇÃO & SUSTENTABILIDA+ & RESPONSÁVEIS \\
\hline RAFTING & SUSTENTÁVEIS & RESPONSÁVEL \\
\hline RAPEL & SUSTENTÁVEL & RURAL \\
\hline RECURSOS & TRABALHO & SEGURANÇA \\
\hline REGIÃO & TRILHAS & SENSIBILIZAÇÃO \\
\hline REGIÕES & TURISMO & SOCIAIS \\
\hline RESERVA & TURISTAS & SOCIEDADE \\
\hline RESERVAS & TURÍSTICA & SUSTENTABILIDA+ \\
\hline ROTEIRO & TURÍSTICAS & SUSTENTÁVEL \\
\hline ROTEIROS & TURÍSTICO & TRABALHO \\
\hline SEGURANÇA & TURÍSTICOS & TREINAMENTO \\
\hline SUSTENTÁVEL & UNIDADES & TRILHAS \\
\hline TÉCNICA & USO & TURISMO \\
\hline TRABALHO & VIAGENS & TURISTA (S) \\
\hline TREINAMENTO & $\overline{V I D A}$ & TURÍSTICA \\
\hline TREKKING & VISITAÇÃO & TURÍSTICAS \\
\hline TRILHA & VISITANTES & TURÍSTICO (S) \\
\hline TRILHAS & & UNIDADE (S) \\
\hline TURISMO & & USO \\
\hline TURISTAS & & VIDA \\
\hline TURÍSTICO & & VISITAÇÃO \\
\hline UNIDADES & & VISITANTE (S) \\
\hline USO & & \\
\hline VEGETAÇÃO & & \\
\hline VIAGEM & & \\
\hline VIAGENS & & \\
\hline VISITAÇÃO & & \\
\hline VISITANTE & & \\
\hline VISITANTES & & \\
\hline
\end{tabular}




\section{ANEXO E - RELAÇÃO DAS KEYWORDS EM INGLÊS JÁ LIMPAS}

As cores correspondem às listas nas quais as palavras aparecem.

Palavras que aparecem nos três corpora - amarelo

Palavras que aparecem nos corpora de agências e ambientalistas - azul

Palavras que aparecem nos corpora de agências e governo - verde

Palavras que aparecem nos corpora de ambientalistas e governo - rosa

\begin{tabular}{|l|}
\hline Ag $\mathbf{x}$ Ref inglês \\
\hline ACCOMMODATION \\
\hline ACCOMMODATIONS \\
\hline ACTIVITIES \\
\hline ADVENTURE \\
\hline ADVENTURES \\
\hline ANIMALS \\
\hline AREA \\
\hline AREAS \\
\hline ATTRACTION \\
\hline ATTRACTIONS \\
\hline BARRIER \\
\hline BIKE \\
\hline BIKING \\
\hline BIRD \\
\hline BIRDING \\
\hline BIRDLIFE \\
\hline BIRDS \\
\hline BIRDWATCHING \\
\hline BUNGY \\
\hline CAGE \\
\hline CAMPING \\
\hline CAVE \\
\hline CAVERN \\
\hline CAVES \\
\hline CLIENTS \\
\hline COAST \\
\hline COASTAL \\
\hline COASTLINE \\
\hline COASTLINES \\
\hline COMMUNITIES \\
\hline CONSERVATION \\
\hline CRUISE \\
\hline CULTURAL \\
\hline CYCLING \\
\hline DESTINATION \\
\hline DESTINATIONS \\
\hline
\end{tabular}

\begin{tabular}{|l|}
\hline Amb $\mathbf{x}$ Ref inglês \\
\hline ACCESS \\
\hline ACTIVITIES \\
\hline ALTERNATIVES \\
\hline AREA \\
\hline AREAS \\
\hline ATTITUDES \\
\hline ATTRACTION \\
\hline ATTRACTIONS \\
\hline AWARENESS \\
\hline BEHAVIOUR \\
\hline BEHAVIOURS \\
\hline BELLBIRDS \\
\hline BENEFIT \\
\hline BENEFITS \\
\hline BIODIVERSITY \\
\hline BIRD \\
\hline BIRDING \\
\hline BIRDS \\
\hline BUSINESS \\
\hline BUSINESSES \\
\hline COAST \\
\hline COASTAL \\
\hline COASTERS \\
\hline COMMERCIAL \\
\hline COMMUNITIES \\
\hline COMMUNITY \\
\hline CONSERVATION \\
\hline CONSERVATIONIS+ \\
\hline CRUISE \\
\hline CRUISESHIP \\
\hline CULTURAL \\
\hline DESTINATIONS \\
\hline DEVELOPMENT \\
\hline DIVERSITY \\
\hline DOLPHIN \\
\hline DOLPHINS \\
\hline
\end{tabular}

\begin{tabular}{|l|}
\hline GoV $\mathbf{x}$ Ref inglês \\
\hline ACCESS \\
\hline ACCOMMODATION \\
\hline ACHIEVE \\
\hline ACTIVITIES \\
\hline ADVENTURE \\
\hline AGENCIES \\
\hline AQUACULTURE \\
\hline AREA \\
\hline AREAS \\
\hline ATTRACTIONS \\
\hline BACKPACKER \\
\hline BACKPACKERS \\
\hline BENEFITS \\
\hline BIODIVERSITY \\
\hline BUSINESSES \\
\hline CAMPSITES \\
\hline CERTIFICATION \\
\hline CERTIFIED \\
\hline COASTAL \\
\hline COMMERCIAL \\
\hline COMMITMENT \\
\hline COMMUNITIES \\
\hline COMMUNITY \\
\hline CONSERVATION \\
\hline CONSERVATIONIS+ \\
\hline CONCERN \\
\hline CONSERVE \\
\hline CONSERVING \\
\hline CULTURAL \\
\hline DEFORESTATION \\
\hline DEGRADATION \\
\hline DEVELOP \\
\hline DEVELOPED \\
\hline DEVELOPING \\
\hline DEVELOPMENT \\
\hline DIVERSITY \\
\hline
\end{tabular}




\begin{tabular}{|l|}
\hline DIVERSE \\
\hline DIVING \\
\hline DOLPHIN \\
\hline DOLPHINS \\
\hline DUCK \\
\hline ECO \\
\hline ECOLOGICAL \\
\hline ECOLOGY \\
\hline ECOSAIL \\
\hline ECOTOUR \\
\hline ECOTOURISM \\
\hline ECOTOURS \\
\hline ECOWALKS \\
\hline EDUCATIONAL \\
\hline ENDANGERED \\
\hline ENHANCE \\
\hline ENVIRONMENT \\
\hline ENVIRONMENTAL \\
\hline ENVIRONMENTS \\
\hline EXPERIENCE \\
\hline EXPEDITIONS \\
\hline EXPLORE \\
\hline FAUNA \\
\hline FISHING \\
\hline FLORA \\
\hline FOREST \\
\hline FORESTED \\
\hline FORESTS \\
\hline FRAGILE \\
\hline GUIDE \\
\hline GUIDED \\
\hline GUIDES \\
\hline HABITAT \\
\hline HABITATS \\
\hline HERITAGE \\
\hline HIKE \\
\hline HIKES \\
\hline HIKING \\
\hline HISTORIC \\
\hline IMPACTS \\
\hline INFORMATION \\
\hline ITINERARIES \\
\hline ITINERARY \\
\hline JUMPING \\
\hline LAND \\
\hline LANDSCAPE \\
\hline LANDSCAPES \\
\hline LOCAL \\
\hline LOCATED \\
\hline NATATIONS \\
\hline
\end{tabular}

\begin{tabular}{|l|}
\hline ECO \\
\hline ECOLOGICAL \\
\hline ECOLOGIC \\
\hline ECOTOURISM \\
\hline ECOSYSTEM \\
\hline ECOSYSTEMS \\
\hline ECOTOURIST \\
\hline ECOTOURISTS \\
\hline ECONOMIC \\
\hline ECONOMIES \\
\hline ENDANGERED \\
\hline ENVIRONMENT \\
\hline ENVIRONMENTAL \\
\hline EXPERIENCE \\
\hline EXPERIENCES \\
\hline EXPERIENCING \\
\hline EXPLOITED \\
\hline EXTRACTIVE \\
\hline FACILITIES \\
\hline FAUNA \\
\hline FISHERIES \\
\hline FISHERY \\
\hline FISHING \\
\hline FLORA \\
\hline FOREST \\
\hline FORESTANDBIRD \\
\hline FORESTS \\
\hline GUIDED \\
\hline HABITAT \\
\hline HABITATS \\
\hline HARVEST \\
\hline HERITAGE \\
\hline HISTORIC \\
\hline IMPACT \\
\hline IMPACTS \\
\hline IMPLEMENTED \\
\hline INDIGENOUS \\
\hline INFORMATION \\
\hline INDUSTRY \\
\hline INFRASTRUCTURE \\
\hline INTERPRETATION \\
\hline LAND \\
\hline LANDS \\
\hline LOCAL \\
\hline LOCALS \\
\hline LOCATED \\
\hline LOCATION \\
\hline MARINE \\
\hline NATIVE \\
\hline NATURAL \\
\hline NATURE \\
\hline OPERATIONS \\
\hline OPPORTUNITIES \\
\hline OUTDOOR \\
\hline
\end{tabular}

\begin{tabular}{|l|}
\hline ECO \\
\hline ECOLOGICAL \\
\hline ECOLOGY \\
\hline ECOLOGICALLY \\
\hline ECOTOURISM \\
\hline ECOSYSTEM \\
\hline ECOSYSTEMS \\
\hline ECOTOURISTS \\
\hline ECONOMIC \\
\hline EDUCATION \\
\hline EFFORTS \\
\hline ENHANCE \\
\hline ENHANCEMENT \\
\hline ENHANCING \\
\hline ENVIRONMENT \\
\hline ENVIRONMENTAL \\
\hline ENVIRONMENTALL+ \\
\hline ENVIRONMENTS \\
\hline EXPERIENCE \\
\hline EXOTIC \\
\hline EXTRACTIVE \\
\hline FACILITIES \\
\hline FAUNA \\
\hline FARM \\
\hline FISHERIES \\
\hline FISHERS \\
\hline FISHING \\
\hline FLORA \\
\hline FOREST \\
\hline FORESTRY \\
\hline FORESTS \\
\hline GROWING \\
\hline HABITAT \\
\hline HARVEST \\
\hline HARVESTING \\
\hline HERITAGE \\
\hline HISTORIC \\
\hline IMPACT \\
\hline IMPACTS \\
\hline INCENTIVE \\
\hline INCENTIVES \\
\hline INDIGENOUS \\
\hline INFORMATION \\
\hline INDUSTRY \\
\hline INFRASTRUCTURE \\
\hline LANDS \\
\hline LAND \\
\hline MANDSCAPCARES \\
\hline
\end{tabular}




\begin{tabular}{|l|}
\hline OPERATOR \\
\hline OPERATORS \\
\hline OPPORTUNITIES \\
\hline OPPORTUNITY \\
\hline OUTDOOR \\
\hline OUTDOORS \\
\hline PARK \\
\hline PARKS \\
\hline PENGUIN \\
\hline PENGUINS \\
\hline PLACES \\
\hline RAFTING \\
\hline RAINFOREST(S) \\
\hline RECREATIONAL \\
\hline REGION \\
\hline RESERVE \\
\hline RESERVES \\
\hline RESOURCE \\
\hline SANCTUARIES \\
\hline SANCTUARY \\
\hline SEABIRD \\
\hline SEABIRDS \\
\hline SNOWBOARDING \\
\hline SPECIES \\
\hline SUSTAINABILITY \\
\hline SUSTAINABLE \\
\hline TOUR \\
\hline TOURS \\
\hline TOURISM \\
\hline TOURIST \\
\hline TOURISTS \\
\hline TRACK \\
\hline TRACKS \\
\hline TRAIL \\
\hline TRAILS \\
\hline TRAVEL \\
\hline TRAVELLERS \\
\hline TRIP \\
\hline TRIPS \\
\hline TREKKING \\
\hline TREK \\
\hline TREKS \\
\hline UNDISTURBED \\
\hline UNIQUE \\
\hline UNSPOILED \\
\hline VARIETY \\
\hline VISIT \\
\hline VISITOR \\
\hline VISITORS \\
\hline WALK \\
\hline WALKING \\
\hline WALKS \\
\hline WALKWAY \\
\hline WATCH \\
\hline WATCHING \\
\hline
\end{tabular}

\begin{tabular}{|l|}
\hline OVERFISHED \\
\hline OVERFISHING \\
\hline PARK \\
\hline PARKS \\
\hline PENGUIN \\
\hline PEOPLES \\
\hline PLACES \\
\hline POTENTIAL \\
\hline PROJECT \\
\hline PROMOTE \\
\hline PROTECT \\
\hline PROTECTED \\
\hline PROTECTING \\
\hline PROTECTION \\
\hline RECREATION \\
\hline RECREATIONAL \\
\hline REGION \\
\hline RESERVE \\
\hline RESERVES \\
\hline RESEARCH \\
\hline RESOURCE \\
\hline RESOURCES \\
\hline RESTRICTIONS \\
\hline RESPONSIBLE \\
\hline RESPONSIBLETOU+ \\
\hline SANCTUARIES \\
\hline SANCTUARY \\
\hline SEX \\
\hline SPECIES \\
\hline SOCIOECONOMIC \\
\hline SUSTAINABILITY \\
\hline SUSTAINABLE \\
\hline STRATEGIES \\
\hline TOUR \\
\hline TOURS \\
\hline TOURISM \\
\hline TOURIST \\
\hline TOURISTS \\
\hline TRACKERS \\
\hline TRAVEL \\
\hline TRAVELLERS \\
\hline TRIPS \\
\hline UNSUSTAINABLE \\
\hline USE \\
\hline VISIT \\
\hline VISITOR \\
\hline VISITORS \\
\hline WALKING \\
\hline WALKS \\
\hline WALKWAYS \\
\hline WHALE \\
\hline WHALES \\
\hline WHALING \\
\hline WILDERNESS \\
\hline WILDLIFE \\
\hline
\end{tabular}

\begin{tabular}{|l|}
\hline NATIVE \\
\hline NATIVES \\
\hline NATURAL \\
\hline NATURE \\
\hline OPERATORS \\
\hline OPPORTUNITIES \\
\hline OPPORTUNITY \\
\hline OUTDOOR \\
\hline PARKS \\
\hline PLACES \\
\hline POLICIES \\
\hline POTENTIAL \\
\hline PRACTICES \\
\hline PRESERVATION \\
\hline PROJECT \\
\hline PROJECTS \\
\hline PROMOTE \\
\hline PROMOTING \\
\hline PROMOTION \\
\hline PROTECT \\
\hline PROTECTED \\
\hline PROTECTING \\
\hline PROTECTION \\
\hline RECREATION \\
\hline RECREATIONAL \\
\hline REGENERATING \\
\hline RESERVES \\
\hline RESEARCH \\
\hline RESOURCE \\
\hline RESOURCES \\
\hline RULES \\
\hline SANCTUARIES \\
\hline SANCTUARY \\
\hline SEABIRD \\
\hline SEABIRDS \\
\hline SPECIES \\
\hline SUSTAINABILITY \\
\hline SUSTAINABLE \\
\hline SUSTAINABLY \\
\hline STRATEGY \\
\hline TOURS \\
\hline TOURISM \\
\hline TOURISTS \\
\hline TRACKS \\
\hline UNSUSTAINABLY \\
\hline UNIQUE \\
\hline USE \\
\hline USES \\
\hline VISITOR \\
\hline VISITORS \\
\hline WALKS \\
\hline WALKWAYS \\
\hline WHALE \\
\hline WHALERS \\
\hline WHALES \\
\hline
\end{tabular}


WHALE

WHALES

WILD

WILDERNESS

WILDLIFE
WHALEWATCH

WHALING

WILDERNESS

WILDLIFE 


\section{ANEXO F - LISTA DE PALAVRAS QUE OCORREM NOS CORPORA EM PORTUGUÊS E EM INGLÊS}

Essas palavras correspondem aos Anexos D e E.

\begin{tabular}{|c|c|c|c|}
\hline \multicolumn{2}{|r|}{ AG } & AMB & GOV \\
\hline 1 & & ACCESS & ACCESS \\
\hline 2 & ACCOMMODATION(s) & & ACCOMMODATION \\
\hline 3 & ACTIVITIES & ACTIVITIES & ACTIVITIES \\
\hline 4 & ADVENTURE(s) & & ADVENTURE \\
\hline 5 & & & AGENCIES \\
\hline 6 & & ALTERNATIVES & \\
\hline 7 & ANIMALS & & \\
\hline 8 & AREA (s) & AREA (s) & AREA (s) \\
\hline 9 & ATTRACTION(S) & ATTRACTION(S) & ATTRACTION(S) \\
\hline 10 & & ATTITUDES & \\
\hline 11 & & AWARENESS & \\
\hline 12 & & & BACKPACKER(S) \\
\hline 13 & & BEHAVIOUR(S) & \\
\hline 14 & BIKE /BIKING & & \\
\hline 15 & & BENEFIT(S) & BENEFIT(S) \\
\hline 16 & BIRD(S) / BIRDING & BIRD(S) / BIRDING & \\
\hline 17 & & BIODIVERSITY & BIODIVERSITY \\
\hline 18 & $\begin{array}{l}\text { BIRDLIFE / } \\
\text { BIRDWATCHING }\end{array}$ & & \\
\hline 19 & & BUSINESS & BUSINESSES \\
\hline 20 & BUNGY & & \\
\hline 21 & CAMPING & & CAMPSITES \\
\hline 22 & CAVE(S) / CAVERN & & \\
\hline 23 & & & CERTIFICATION/CERTIFIED \\
\hline 24 & CLIENTS & & \\
\hline 25 & & & COMMITMENT \\
\hline
\end{tabular}

\begin{tabular}{|c|c|c|}
\hline AG & AMB & GOV \\
\hline AÇÃO / AÇÕES & AÇÃO / AÇÕES & AÇÃO / AÇÕES \\
\hline \multirow[t]{2}{*}{ ACESSO } & ACESSO & \\
\hline & & ADMINISTRAÇÃO \\
\hline \multirow[t]{2}{*}{ ÁGUA / ÁGUAS } & & ÁGUA \\
\hline & AGÊNCIAS & \\
\hline AMBIENTAIS & AMBIENTAIS & AMBIENTAIS \\
\hline AMBIENTAL & AMBIENTAL & AMBIENTAL \\
\hline AMBIENTE (S) & AMBIENTE & AMBIENTE (S) \\
\hline \multicolumn{3}{|l|}{ ANIMAIS } \\
\hline APOIO & APOIO & APOIO \\
\hline ÁREA (S) & ÁREA (S) & ÁREA (S) \\
\hline ASSOCIAÇÃO & ASSOCIAÇÃO & ASSOCIAÇÃO \\
\hline ATIVIDADE (S) & ATIVIDADE (S) & ATIVIDADE (S) \\
\hline \multicolumn{3}{|l|}{ ÁRVORES } \\
\hline \multirow[t]{2}{*}{ ATRATIVOS } & ATRATIVOS & ATRATIVOS \\
\hline & AVALIAÇÃO & AVALIAÇÃO \\
\hline AVENTURA & & AVENTURA \\
\hline \multicolumn{3}{|l|}{ AVES } \\
\hline & BENEFÍCIOS & \\
\hline \multirow[t]{2}{*}{\begin{tabular}{|l} 
BIODIVERSIDADE \\
\end{tabular}} & BIODIVERSIDADE & BIODIVERSIDADE \\
\hline & CAPACITAÇÃO & CAPACITAÇÃO \\
\hline CAPACIDADE & & CAPACIDADE \\
\hline CARACTERÍSTICA(S) & CARACTERÍSTICA(S) & CARACTERÍSTICA(S) \\
\hline CERTIFICAÇÃO & CERTIFICAÇÃO & \\
\hline CACHOEIRA (S) & & \\
\hline
\end{tabular}




\begin{tabular}{|c|c|c|c|}
\hline 26 & COMMUNITY(IES) & COMMUNITY(IES) & COMMUNITY(IES) \\
\hline 27 & & & CONCERN \\
\hline 28 & CONSERVATION & CONSERVATION & CONSERVATION \\
\hline 29 & & CONSERVATIONIS+ & CONSERVATIONIS+ \\
\hline 30 & & & CONSERVE \\
\hline 31 & CULTURAL & CULTURAL & CULTURAL \\
\hline 32 & CYCLING & & \\
\hline 33 & & & DEFORESTATION \\
\hline 34 & & & DEGRADATION \\
\hline 35 & DESTINATION(S) & DESTINATION(S) & \\
\hline 36 & DIVERSE & & \\
\hline 37 & & & DETRIMENTAL \\
\hline 38 & & & DEVELOP $(\sim)$ \\
\hline 39 & & DEVELOPMENT & DEVELOPMENT \\
\hline 40 & & DIVERSITY & DIVERSITY \\
\hline 41 & DIVING & & \\
\hline 42 & DOLPHIN(S) & DOLPHIN(S) & \\
\hline 43 & ECO & ECO & ECO \\
\hline 44 & ECOLOGICAL & ECOLOGICAL & ECOLOGICAL \\
\hline 45 & ECOLOGY & & ECOLOGY \\
\hline 46 & & & ECOLOGICALLY \\
\hline 47 & & ECOLOGIC & \\
\hline 48 & ECOSAIL & & \\
\hline 49 & ECOTOUR & & \\
\hline 50 & & \begin{tabular}{|l|} 
ECONOMIC/ \\
ECONOMIES
\end{tabular} & ECONOMIC \\
\hline 51 & & ECOSYSTEM(S) & ECOSYSTEM(S) \\
\hline 52 & ECOTOURISM & ECOTOURISM & ECOTOURISM \\
\hline 53 & & ECOTOURIST(S) & ECOTOURIST(S) \\
\hline 54 & ECOTOURS & & \\
\hline 55 & EDUCATIONAL & & EDUCATION \\
\hline 56 & ECOWALKS & & \\
\hline 57 & & & EFFECTS \\
\hline 58 & ENDANGERED & ENDANGERED & \\
\hline 59 & ENVIRONMENT(S) & ENVIRONMENT(S) & ENVIRONMENT(S) \\
\hline
\end{tabular}

\begin{tabular}{|l|l|l|}
\hline CAMINHADA & & \\
\hline COMUNIDADE (S) & COMUNIDADE(S)/COMUNITÁRIA(O) & COMUNIDADE (S) \\
\hline & & CAVALGADA \\
\hline CAVERNAS & & CAVERNAS \\
\hline CONHECER & CONHECER & \\
\hline CONHECIMENTO & CONHECIMENTO & CONHECIMENTO \\
\hline CONSCIÊNCIA & CONSCIÊNCIA & \\
\hline CONSELHO & CONSELHO & CONSELHO \\
\hline CONSERVAÇÃO & CONSERVAÇÃO & CONSERVAÇÃO \\
\hline CONSTRUÇÃO & CONSTRUÇÃO & \\
\hline & & CONDUTA \\
\hline & CONSUMO & \\
\hline CONTROLE & CONTROLE & CONTROLE \\
\hline & CONTRIBUIR & \\
\hline CRESCIMENTO & CRESCIMENTO & CRESCIMENTO \\
\hline $\begin{array}{l}\text { CULTURA / CULTURAL } \\
\text { (AIS) }\end{array}$ & CULTURA / CULTURAL (AIS) & $\begin{array}{l}\text { CULTURA / CULTURAL } \\
\text { (AIS) }\end{array}$ \\
\hline DESENVOLVER & DESENVOLVER & \\
\hline DESENVOLVIMENT+ & DESENVOLVIMENT+ & DESENVOLVIMENT+ \\
\hline DESTINO (S) & DESTINO (S) & DESTINO (S) \\
\hline & & DEMANDA \\
\hline & DIRETRIZES & DIRETRIZES \\
\hline DIFERENTES & DIFERENTES & \\
\hline DIVERSIDADE & & DIVERSIDADE \\
\hline & ECOGÊNESE & \\
\hline ECOLÓGICA (O)(S) & ECOLÓGICA (O)(S) & ECOLÓGICA (O)(S) \\
\hline ECONÔMICA (O) & ECONÔMICA (O) & ECONÔMICA (O) \\
\hline ECO & & ECOTURISMO \\
\hline ECOTURISMO & ECOTURISMO & ECOTURISTICO (S) \\
\hline ECOTURÍSTICO (S) & ECOTURISTICO (S) & EDUCAÇÃO \\
\hline ECOSSISTEMAS & & EMPREENDIMENTO+ \\
\hline EDUCAÇÃO & EDUCAÇÃO & EMPRESA (S) \\
\hline & EMPREENDIMENTO+ & \\
\hline EMPRESA (S) & & \\
\hline & EMPRESA (S) & \\
\hline & & \\
\hline & & \\
\hline
\end{tabular}




\begin{tabular}{|c|c|c|c|}
\hline 60 & ENVIRONMENTAL & ENVIRONMENTAL & ENVIRONMENTAL \\
\hline 61 & EXPEDITIONS & & \\
\hline 62 & EXPERIENCE(S) & EXPERIENCE(S) & EXPERIENCE(S) \\
\hline 63 & EXPLORE & & \\
\hline 64 & & & EFFORTS \\
\hline 65 & & & ENHANCE/ ENHANCEMENT \\
\hline 66 & & & EXOTIC \\
\hline 67 & & EXPERIENCING & \\
\hline 68 & & EXPLOITED & \\
\hline 69 & & EXTRACTIVE & EXTRACTIVE \\
\hline 70 & & FACILITIES & FACILITIES \\
\hline 71 & FAUNA & FAUNA & FAUNA \\
\hline 72 & FISHING & FISHING/FISHERY(IES) & FISHING/FISHERY(IES) \\
\hline 73 & FLORA & FLORA & FLORA \\
\hline 74 & FOREST(S) & FOREST(S) & FOREST(S) \\
\hline 75 & & & FISHERS \\
\hline 76 & & & FORESTRY \\
\hline 77 & FRAGILE & & \\
\hline 78 & GUIDE(s)(d) & & \\
\hline 79 & & & GOALS \\
\hline 80 & & & GROWING/GROWN \\
\hline 81 & $\operatorname{HABITAT}(\mathrm{S})$ & HABITAT(S) & $\operatorname{HABITAT}(\mathrm{S})$ \\
\hline 82 & HERITAGE & HERITAGE & HERITAGE \\
\hline 83 & HIKE(S) (ING) & & \\
\hline 84 & IMPACT(S) & IMPACT(S) & IMPACT(S) \\
\hline 85 & & & INCENTIVE(S) \\
\hline 86 & INFORMATION & INFORMATION & INFORMATION \\
\hline 87 & & INDUSTRY & INDUSTRY \\
\hline 88 & & INDIGENOUS & INDIGENOUS \\
\hline 89 & ITINERARY(IES) & & \\
\hline 90 & & IMPLEMENTED & \\
\hline 91 & & INFRASTRUCTURE & INFRASTRUCTURE \\
\hline 92 & & INITIATIVES & INITIATIVES \\
\hline 93 & & INTERPRETATION & \\
\hline 94 & JUMPING & & \\
\hline
\end{tabular}

\begin{tabular}{|l|l|l|}
\multicolumn{1}{|l}{} & ENTIDADES & ENTIDADES \\
\hline ESPÉCIES & ESPÉCIES & ESPÉCIES \\
\hline & & ENTORNO \\
\hline EQUIPAMENTOS & & EQUIPAMENTOS \\
\hline ESCALADA & & \\
\hline & & \\
\hline & ESTRATÉGIA (S) & ESTRATÉGIA (S) \\
\hline ESTRUTURA & ESTRUTURA & ESTRUTURA (S) \\
\hline ESPORTE (S) & & ESPORTE \\
\hline & ESTUDO (S) & \\
\hline EVENTOS & EVENTO & EVENTOS \\
\hline EXPERIÊNCIA & EXPERIÊNCIA & EXPERIÊNCIA \\
\hline & EXPOSIÇÃO & \\
\hline FAUNA & & FAUNA \\
\hline FLORA & & \\
\hline FLORESTA (S) (L) & & FLORESTA (S) (L) \\
\hline & GARANTIR & GARANTIR \\
\hline GESTÃO & GESTÃO & GESTÃO \\
\hline GUIA (S) & & GUIAS \\
\hline & HISTÓRICO & \\
\hline IMPACTO (S) & IMPACTO (S) & IMPACTO (S) \\
\hline IMPLANTAÇÃO & IMPLANTAÇÃO & IMPLANTAÇÃO \\
\hline & IMPLEMENTAÇÃO & \\
\hline INDÚSTRIA & INDÚSTRIA & INFORMAÇÕES \\
\hline INFORMAÇÕES & INFORMAÇÕES & INFRA \\
\hline INFRA & INFRA & INCENTIVAR \\
\hline & & INICIATIVA (S) \\
\hline & INICIATIVA (S) & INSTITUIÇÕES \\
\hline INTERPRETAÇÃO & INSTITUIÇÕES & INTERPRETAÇÃO \\
\hline & INTERPRETAÇÃO & INVESTIMENTOS \\
\hline INTERESSE & & INTERESSE \\
\hline LAZER & INVESTIMENTOS & LAZER \\
\hline & LAZER & \\
\hline & & \\
\hline & & \\
\hline & & \\
\hline & & \\
\hline & & \\
\hline & & \\
\hline & & \\
\hline & & \\
\hline
\end{tabular}




\begin{tabular}{|c|c|c|c|}
\hline 95 & KAYAKING & & \\
\hline 96 & & & KNOWLEDGE \\
\hline 97 & LANDSCAPE(S) & & LANDSCAPE(S) \\
\hline 98 & LOCAL & LOCAL & LOCAL \\
\hline 99 & LOCATION(S) & LOCATION & \\
\hline 100 & MAMMALS & & MAMMAL \\
\hline 101 & & MANAGED & MANAGED ING \\
\hline 102 & & MANAGEMENT & MANAGEMENT \\
\hline 103 & & & MONITORING \\
\hline 104 & NATIVE & NATIVE & NATIVE \\
\hline 105 & NATURAL & NATURAL & NATURAL \\
\hline 106 & NATURE & NATURE & NATURE \\
\hline 107 & & OPERATIONS & \\
\hline 108 & OPERATOR(S) & OPERATOR(S) & OPERATOR(S) \\
\hline 109 & OPPORTUNITY(IES) & OPPORTUNITY(IES) & OPPORTUNITY(IES) \\
\hline 110 & OUTDOOR(S) & OUTDOOR(S) & OUTDOOR(S) \\
\hline 111 & & ORGANISATION(S) & ORGANISATION(S) \\
\hline 112 & & OVERFISHED/ING & \\
\hline 113 & PARK(S) & PARK(S) & PARK(S) \\
\hline 114 & PENGUIN(S) & PENGUIN(S) & \\
\hline 115 & PLACES & PLACES & PLACES \\
\hline 116 & PREDATORS & & \\
\hline 117 & & POPULATIONS & \\
\hline 118 & PRODUCTS & & PRODUCTS \\
\hline 119 & PROGRAMMES & & PROGRAMME \\
\hline 120 & & & POLICIES \\
\hline 121 & & POTENTIAL & POTENTIAL \\
\hline 122 & & PROJECT & PROJECT \\
\hline 123 & & PROMOTE & PROMOTE \\
\hline 124 & & PROTECT(ed)(ing) & PROTECT(ed)(ing) \\
\hline 125 & & PROTECTION & PROTECTION \\
\hline 126 & & & PRACTICES \\
\hline 127 & & & PRESERVATION \\
\hline 128 & & & PRINCIPLES \\
\hline 129 & & PROMOTION & \\
\hline
\end{tabular}

\begin{tabular}{|l|l|l|} 
LOCAL (AIS) & LOCAL (AIS) & LOCAL (AIS) \\
\hline LIXO & & \\
\hline LUGAR (ES) & & \\
\hline MANEJO & MANEJO & MANEJO \\
\hline & MARKETING & \\
\hline MATA (S) (O) & MATA & MATA \\
\hline MEIO & MEIO & MEIO \\
\hline MERCADO & MERCADO & MERCADO \\
\hline MERGULHO & & MERGULHO \\
\hline & & MODALIDADE (S) \\
\hline & MONITORAMENTO & MONITORAMENTO \\
\hline & & MONITORES \\
\hline MODELO & MODELOS & \\
\hline MORADORES & & \\
\hline NATURAIS & NATURAIS & NATURAIS \\
\hline NATURAL & NATURAL & NATURAL \\
\hline NATUREZA & NATUREZA & NATUREZA \\
\hline NECESSIDADE (S) & NECESSIDADE (S) & NECESSIDADE (S) \\
\hline & NEGÓCIOS & NEGÓCIOS \\
\hline OBJETIVO (S) & OBJETIVO (S) & OBJETIVO (S) \\
\hline ORGANIZAÇÃO & ORGANIZAÇÃO & ORGANIZAÇÃO \\
\hline PARQUE (S) & PARQUE (S) & PARQUE (S) \\
\hline PAISAGEM & & PARCERIAS \\
\hline PARAÍSO & & \\
\hline PARTICIPAÇÃO & PARTICIPAÇÃO & PARTICIPAÇÃO \\
\hline PARTICIPANTE (S) & PARTICIPANTE (S) & PARTICIPANTE (S) \\
\hline PATRIMÔNIO & PATRIMÔNIO & PATRIMÔNIO \\
\hline PASSEIOS & & PESCA \\
\hline PEIXE (S) & PESCA & PESQUISAS \\
\hline PESCA & PESQUISA & PESSOAS \\
\hline & PESSOAS & PLANEJAMENTO \\
\hline PESSOAS & PLANEJAMENTO & POLITICA (S) \\
\hline PLANEJAMENTO & PLANO (S) & \\
\hline PLANO (S) & POLÍTICA (S) & \\
\hline POLITICA & & \\
\hline & & \\
\hline & & \\
\hline & & \\
\hline & & \\
\hline & & \\
\hline
\end{tabular}




\begin{tabular}{|c|c|c|c|}
\hline 130 & RAFTING & & \\
\hline 131 & RAINFOREST(S) & & \\
\hline 132 & RECREATIONAL & RECREATIONAL & RECREATIONAL \\
\hline 133 & REGION & REGION & \\
\hline 134 & RESERVE(S) & RESERVE(S) & \\
\hline 135 & RESOURCE(S) & RESOURCE(S) & RESOURCE(S) \\
\hline 136 & & RECREATION & RECREATION \\
\hline 137 & & REGIONAL & REGIONAL \\
\hline 138 & & RESEARCH(ERS) & RESEARCH(ERS) \\
\hline 139 & & RESPONSIBLE & \\
\hline 140 & & RESTRICTIONS & \\
\hline 141 & & & REGULATION \\
\hline 142 & & & RESPECT \\
\hline 143 & SANCTUARY(IES) & SANCTUARY(IES) & SANCTUARY(IES) \\
\hline 144 & SKIING & & \\
\hline 145 & SNOWBOARDING & & \\
\hline 146 & SPECIES & SPECIES & SPECIES \\
\hline 147 & SUSTAINABILITY & SUSTAINABILITY & SUSTAINABILITY \\
\hline 148 & SUSTAINABLE & SUSTAINABLE & SUSTAINABLE \\
\hline 149 & & & SERVICES \\
\hline 150 & & STRATEGIES & STRATEGY \\
\hline 151 & & STUDY & \\
\hline 152 & & & SUPPORTIVE \\
\hline 153 & & & SUSTAINABILITY \\
\hline 154 & TOUR(S) & TOUR & TOURS \\
\hline 155 & TOURISM & TOURISM & TOURISM \\
\hline 156 & TOURIST & TOURIST & TOURISTS \\
\hline 157 & TRAIL(S) & & \\
\hline 158 & TRACK(S) & TRACKERS & TRACKS \\
\hline 159 & TREK(S)(ING) & & TREKS \\
\hline 160 & TRAVEL & TRAVEL & \\
\hline 161 & TRAVELLERS & TRAVELLERS & \\
\hline 162 & TRIPS & TRIPS & \\
\hline 163 & UNIQUE & & UNIQUE \\
\hline 164 & UNDISTURBED & & \\
\hline
\end{tabular}

\begin{tabular}{|c|c|c|}
\hline & & POPULAÇÃO (ões) \\
\hline PÓLO & PÓLOS & \\
\hline \multirow[t]{2}{*}{ POTENCIAL } & POTENCIAL & POTENCIAL \\
\hline & PRÁTICA (S) & \\
\hline PRESERVAÇÃO & PRESERVAÇÃO & PRESERVAÇÃO \\
\hline PRINCÍPIOS & PRINCÍPIOS & PRINCÍPIOS \\
\hline PROBLEMAS & PROBLEMAS & \\
\hline PROCESSO & PROCESSO & PROCESSO \\
\hline \multirow[t]{2}{*}{ PRODUTO (S) } & PRODUTO (S) & PRODUTO (S) \\
\hline & & PROCEDIMENTOS \\
\hline PROFISSIONAIS & PROFISSIONAIS & PROFISSIONAIS \\
\hline PROGRAMA (s) & PROGRAMA (s) & PROGRAMA (s) \\
\hline \multirow[t]{3}{*}{ PROJETO (s) } & PROJETO (s) & PROJETO (s) \\
\hline & & PROGRAMAÇÃO \\
\hline & PROMOÇÃO & PROMOÇÃO \\
\hline PROMOVER & PROMOVER & PROMOVER \\
\hline PROPOSTA (S) & PROPOSTA (S) & PROPOSTA (S) \\
\hline \multirow[t]{3}{*}{ PROTEÇÃO } & PROTEÇÃO & PROTEÇÃO \\
\hline & PROTEGIDAS & PROTEGIDAS \\
\hline & & PARA-QUEDISMO \\
\hline QUALIDADE & QUALIDADE & QUALIDADE \\
\hline QUESTÃO (ÕES) & QUESTÃO & QUESTÃO \\
\hline \multirow[t]{3}{*}{ RAFTING } & & RAFTING \\
\hline & & RALLY \\
\hline & REALIZAÇÃO & REALIZAÇÃO \\
\hline RECURSOS & RECURSOS & RECURSOS \\
\hline \multirow[t]{3}{*}{ REGIÃO (ÕES) } & REGIÃO (ÕES) & REGIÃO (ÕES) \\
\hline & RECREATIVO & \\
\hline & & REGULAMENTAÇÃO \\
\hline RELAÇÃO & RELAÇÃO & RELAÇÃO \\
\hline RENDA & RENDA & \begin{tabular}{|l|} 
RENDA \\
\end{tabular} \\
\hline \multirow[t]{2}{*}{ RESERVA (S) } & RESERVA (S) & \\
\hline & REPRESENTANTES & REPRESENTANTES \\
\hline RESPONSABILIDADE & RESPONSABILIDADE & RESPONSABILIDADE \\
\hline RESPEITO & RESPEITO & \\
\hline
\end{tabular}




\begin{tabular}{|l|l|l|l|}
165 & USE & USE & USE \\
\hline 166 & & UNSUSTAINABLE & UNSUSTAINABLY \\
\hline 167 & UNSPOILED & VISITOR & \\
\hline 168 & VISITOR & VISIT & VISITOR \\
\hline 169 & VISIT & VOLUNTEERS & \\
\hline 170 & & & \\
\hline 171 & VARIETY & WALK(S) (ING) & WALK(S) (ING) \\
\hline 172 & WALK(S) (ING) & WALKWAYS & WALKWAYS \\
\hline 173 & WALKWAY & & \\
\hline 174 & WATCH/ING & & \\
\hline 175 & WATERFALLS & WATERS & \\
\hline 176 & WATER(S) & & WATERWAYS \\
\hline 177 & WATERWAYS & WHALE & WHALE \\
\hline 178 & WHALE & & WHALERS \\
\hline 179 & & WHALING & WHALING \\
\hline 180 & & & WHALEWATCH \\
\hline 181 & & & \\
\hline 182 & WILD & WILDERNESS & WILDERNESS \\
\hline 183 & WILDERNESS & WILDLIFE & WILDLIFE \\
\hline 184 & WILDLIFE & & \\
\hline
\end{tabular}

\begin{tabular}{|l|l|l|} 
RESPONSÁVEL (IS) & RESPONSÁVEL (IS) & RESPONSÁVEL (IS) \\
\hline ROTEIRO (S) & & \\
\hline SEGURANÇA & & SEGURANÇA \\
\hline & SEGMENTO & SEGMENTO \\
\hline SERVIÇOS & SERVIÇOS & SERVIÇOS \\
\hline & & SENSIBILIZAÇÃO \\
\hline SETOR (ES) & SETOR (ES) & SETOR (ES) \\
\hline SISTEMA (S) & SISTEMA (S) & SISTEMA (S) \\
\hline SOCIAL (AIS) & SOCIAL (AIS) & SOCIAL (AIS) \\
\hline SOCIEDADE & SOCIEDADE & SOCIEDADE \\
\hline SUSTENTABILIDA+ & SUSTENTABILIDA+ & SUSTENTABILIDA+ \\
\hline SUSTENTÁVEL (IS) & SUSTENTÁVEL (IS) & SUSTENTÁVEL (IS) \\
\hline TRABALHO & TRABALHO & TRABALHO \\
\hline TREINAMENTO & TREINAMENTO & TREINAMENTO \\
\hline TRILHA (S) & TRILHA (S) & TRILHA (S) \\
\hline TREKKING & & \\
\hline TURISMO & TURISMO & TURISMO \\
\hline TURISTA (S) & TURISTA (S) & TURISTA (S) \\
\hline TURÍSTICA(O) (S) & TURÍSTICA(O) (S) & TURÍSTICA(O) (S) \\
\hline UNIDADES & UNIDADES & UNIDADES \\
\hline USO & USO & USO/UTILIZAÇÃO \\
\hline VIAGEM (NS) & VIAGEM (NS) & \\
\hline VIDA & VIDA & \\
\hline VISITACCÃO & VISITAÇÃO & VISITAÇÃO \\
\hline VISITANTE(S) & VISITANTE(S) & VISITANTE(S) \\
\hline
\end{tabular}




\section{ANEXO G - PALAVRAS-CHAVE: CRUZAMENTO ENTRE AS LISTAS DE PALAVRAS-CHAVE EM PORTUGUÊS}

\section{p_ag x amb (português / agências x ambientalistas)}

\begin{tabular}{|c|c|c|c|c|c|c|}
\hline $\mathbf{N}$ & WORD & FREQ. & WLP_AG2.LST \% & FREQ. & WLP_AMB.LST \% & KEYNESS \\
\hline 1 & ITACARÉ & 108 & 0,13 & 0 & 126,5 & 0 \\
\hline 2 & RIO & 234 & 0,29 & 41 & 0,06 & 109,3 \\
\hline 3 & $\mathrm{KM}$ & 110 & 0,14 & 3 & 106,1 & 0 \\
\hline 4 & AVENTURA & 139 & 0,17 & 11 & 0,02 & 102,1 \\
\hline 5 & ALAYA & 87 & 0,11 & 0 & 101,9 & 0 \\
\hline 6 & CAVERNAS & 84 & 0,1 & 0 & 98,4 & 0 \\
\hline 7 & RIOS & 115 & 0,14 & 7 & 0,01 & 92,5 \\
\hline 8 & HTML & 92 & 0,11 & 4 & 81 & 0 \\
\hline 9 & SERRA & 113 & 0,14 & 10 & 0,02 & 79,3 \\
\hline 10 & VOCÊ & 67 & 0,08 & 0 & 78,5 & 0 \\
\hline 11 & INDEX & 63 & 0,08 & 0 & 73,8 & 0 \\
\hline 12 & GRANDE & 198 & 0,24 & 47 & 0,07 & 68,9 \\
\hline 13 & MAIS & 417 & 0,51 & 173 & 0,27 & 56,2 \\
\hline 14 & É & 760 & 0,93 & 384 & 0,59 & 55,4 \\
\hline 15 & ESPORTE & 59 & 0,07 & 2 & 54,8 & 0 \\
\hline 16 & SEGURANÇA & 67 & 0,08 & 4 & 54,2 & 0 \\
\hline 17 & ÁGUA & 93 & 0,11 & 13 & 0,02 & 51,2 \\
\hline 18 & METROS & 59 & 0,07 & 3 & 50 & 0 \\
\hline 19 & SÃO & 448 & 0,55 & 203 & 0,31 & 47,3 \\
\hline 20 & COMPOSER & 40 & 0,05 & 0 & 46,9 & 0 \\
\hline 21 & CONTEUDO & 40 & 0,05 & 0 & 46,9 & 0 \\
\hline 22 & AMBIENTEBRASIL & 40 & 0,05 & 0 & 46,9 & 0 \\
\hline 23 & HTTP & 118 & 0,14 & 25 & 0,04 & 46,4 \\
\hline 24 & CACHOEIRA & 51 & 0,06 & 2 & 46 & 0 \\
\hline 25 & BROTAS & 46 & 0,06 & 1 & 45,8 & $\underline{0}$ \\
\hline 26 & ÁGUAS & 55 & 0,07 & 3 & 45,7 & 0 \\
\hline 27 & DESCIDA & 39 & 0,05 & 0 & 45,7 & 0 \\
\hline 28 & ARVORISMO & 38 & 0,05 & 0 & 44,5 & 0 \\
\hline 29 & PERCURSO & 49 & 0,06 & 2 & 43,8 & 0 \\
\hline 30 & PRAIA & 87 & 0,11 & 14 & 0,02 & 43,4 \\
\hline 31 & MAR & 63 & 0,08 & 6 & 42,8 & 0 \\
\hline 32 & CAVERNA & 36 & 0,04 & 0 & 42,2 & 0 \\
\hline 33 & BONITO & 59 & 0,07 & 5 & 42,2 & 0 \\
\hline 34 & FAUNA & 88 & 0,11 & 15 & 0,02 & 42 \\
\hline 35 & CLIMA & 42 & 0,05 & 1 & 41,3 & $\underline{0}$ \\
\hline 36 & TRILHA & 79 & 0,1 & 12 & 0,02 & 41,1 \\
\hline 37 & EQUIPAMENTOS & 75 & 0,09 & 11 & 0,02 & 40 \\
\hline 38 & ANUNCIOS & 34 & 0,04 & 0 & 39,8 & 0 \\
\hline 39 & WWW & 155 & 0,19 & 47 & 0,07 & 38,9 \\
\hline 40 & VEGETAÇÃO & 48 & 0,06 & 3 & 38,3 & 0 \\
\hline 41 & MPE & 50 & 0,06 & 4 & 36,6 & 0 \\
\hline
\end{tabular}




\begin{tabular}{|c|c|c|c|c|c|c|}
\hline 42 & RAFTING & 31 & 0,04 & 0 & 36,3 & 0 \\
\hline 43 & JACARÉ & 31 & 0,04 & 0 & 36,3 & 0 \\
\hline 44 & CACHOEIRAS & 48 & 0,06 & 4 & 34,5 & 0 \\
\hline 45 & CHEGAR & 44 & 0,05 & 3 & 34,1 & 0 \\
\hline 46 & CORREDEIRAS & 28 & 0,03 & 0 & 32,8 & 0 \\
\hline 47 & MÉDIA & 34 & 0,04 & 1 & 32,4 & 0 \\
\hline 48 & COM & 1.047 & 1,29 & 630 & 0,97 & 31,8 \\
\hline 49 & PRAIAS & 57 & 0,07 & 8 & 0,01 & 31,3 \\
\hline 50 & MARCA & 33 & 0,04 & 1 & 31,3 & 0 \\
\hline 51 & BAHIA & 37 & 0,05 & 2 & 30,8 & 0 \\
\hline 52 & CAPITAL & 44 & 0,05 & 4 & 30,5 & 0 \\
\hline 53 & CORDA & 26 & 0,03 & 0 & 30,5 & 0 \\
\hline 54 & TREKKING & 26 & 0,03 & 0 & 30,5 & 0 \\
\hline 55 & RAPEL & 26 & 0,03 & 0 & 30,5 & 0 \\
\hline 56 & ILHÉUS & 26 & 0,03 & 0 & 30,5 & 0 \\
\hline 57 & ESCALADA & 32 & 0,04 & 1 & 30,1 & 0 \\
\hline 58 & BÓIA & 25 & 0,03 & 0 & 29,3 & 0 \\
\hline 59 & DENSA & 25 & 0,03 & 0 & 29,3 & 0 \\
\hline 60 & ONDE & 142 & 0,17 & 50 & 0,08 & 27,5 \\
\hline 61 & CIDADE & 86 & 0,11 & 22 & 0,03 & 27,3 \\
\hline 62 & PETAR & 23 & 0,03 & 0 & 26,9 & 0 \\
\hline 63 & CACAU & 23 & 0,03 & 0 & 26,9 & 0 \\
\hline 64 & FICA & 29 & 0,04 & 1 & 26,8 & 0 \\
\hline 65 & SOLOS & 22 & 0,03 & 0 & 25,8 & 0 \\
\hline 66 & MORRETES & 22 & 0,03 & 0 & 25,8 & 0 \\
\hline 67 & RELEVO & 22 & 0,03 & 0 & 25,8 & 0 \\
\hline 68 & ALTURA & 28 & 0,03 & 1 & 25,7 & 0 \\
\hline 69 & ECOESPORTES & 21 & 0,03 & 0 & 24,6 & $1 \mathrm{E}-06$ \\
\hline 70 & TRAVESSIA & 21 & 0,03 & 0 & 24,6 & $1 \mathrm{E}-06$ \\
\hline 71 & CANYONING & 21 & 0,03 & 0 & 24,6 & $1 \mathrm{E}-06$ \\
\hline 72 & OUTDOOR & 21 & 0,03 & 0 & 24,6 & $1 \mathrm{E}-06$ \\
\hline 73 & CROSS & 21 & 0,03 & 0 & 24,6 & $1 \mathrm{E}-06$ \\
\hline 74 & PROVA & 21 & 0,03 & 0 & 24,6 & $1 \mathrm{E}-06$ \\
\hline 75 & $\mathrm{CIA}$ & 21 & 0,03 & 0 & 24,6 & $1 \mathrm{E}-06$ \\
\hline 76 & ESPORTES & 41 & 0,05 & 5 & 24,5 & $1 \mathrm{E}-06$ \\
\hline 77 & EXPOSIÇÃO & 1 & 19 & 0,03 & 24,2 & $1 \mathrm{E}-06$ \\
\hline 78 & MARINHO & 2 & 22 & 0,03 & 24,4 & $1 \mathrm{E}-06$ \\
\hline 79 & $\mathrm{P}$ & 2 & 22 & 0,03 & 24,4 & $1 \mathrm{E}-06$ \\
\hline 80 & INTEGRADO & 2 & 22 & 0,03 & 24,4 & $1 \mathrm{E}-06$ \\
\hline 81 & FOMENTO & 0 & 15 & 0,02 & 24,4 & $1 \mathrm{E}-06$ \\
\hline 82 & INICIATIVAS & 4 & 27 & 0,04 & 24,8 & $1 \mathrm{E}-06$ \\
\hline 83 & PROPOSTA & 7 & 33 & 0,05 & 24,8 & $1 \mathrm{E}-06$ \\
\hline 84 & SOCIAIS & 20 & 0,02 & 55 & 0,08 & 26 \\
\hline 85 & IDÉIA & 6 & 32 & 0,05 & 26 & 0 \\
\hline 86 & MONTEIRO & 0 & 16 & 0,02 & 26 & 0 \\
\hline 87 & NOVEMBRO & 7 & 34 & 0,05 & 26,1 & 0 \\
\hline 88 & TEMA & 7 & 34 & 0,05 & 26,1 & 0 \\
\hline 89 & DOCUMENTO & 9 & 0,01 & 38 & 0,06 & 26,5 \\
\hline 90 & CONGRESSO & 1 & 21 & 0,03 & 27,2 & 0 \\
\hline 91 & RECREATIVO & 1 & 21 & 0,03 & 27,2 & 0 \\
\hline 92 & PRESIDENTE & 7 & 35 & 0,05 & 27,3 & 0 \\
\hline
\end{tabular}




\begin{tabular}{|c|c|c|c|c|c|c|}
\hline 93 & PCTS & 0 & 17 & 0,03 & 27,7 & 0 \\
\hline 94 & ASPAC & 0 & 17 & 0,03 & 27,7 & 0 \\
\hline 95 & SIG & 0 & 18 & 0,03 & 29,3 & 0 \\
\hline 96 & GERALDO & 0 & 18 & 0,03 & 29,3 & 0 \\
\hline 97 & ECOGÊNESE & 0 & 18 & 0,03 & 29,3 & 0 \\
\hline 98 & PEDRO & 2 & 26 & 0,04 & 30,3 & 0 \\
\hline 99 & CONSELHO & 6 & 36 & 0,06 & 31,2 & 0 \\
\hline 100 & ORGANIZAÇÃO & 14 & 0,02 & 51 & 0,08 & 31,7 \\
\hline 101 & PROF & 0 & 20 & 0,03 & 32,6 & 0 \\
\hline 102 & GOVERNOS & 2 & 28 & 0,04 & 33,2 & 0 \\
\hline 103 & PUBLICAÇÃO & 1 & 25 & 0,04 & 33,4 & 0 \\
\hline 104 & PROJETO & 62 & 0,08 & 119 & 0,18 & 33,7 \\
\hline 105 & FUNDAÇÃO & 8 & 42 & 0,06 & 33,8 & 0 \\
\hline 106 & COMUNITÁRIA & 1 & 26 & 0,04 & 34,9 & 0 \\
\hline 107 & CONCEITO & 6 & 39 & 0,06 & 35,2 & 0 \\
\hline 108 & PROCESSO & 24 & 0,03 & 70 & 0,11 & 35,3 \\
\hline 109 & ARQUEOLOGIA & 2 & 30 & 0,05 & 36,2 & 0 \\
\hline 110 & BRASIL & 161 & 0,2 & 236 & 0,36 & 36,6 \\
\hline 111 & AGENDA & 0 & 23 & 0,04 & 37,4 & 0 \\
\hline 112 & QUESTÃO & 5 & 39 & 0,06 & 38,2 & 0 \\
\hline 113 & HOMEM & 19 & 0,02 & 65 & 0,1 & 38,2 \\
\hline 114 & POLÍTICA & 13 & 0,02 & 55 & 0,08 & 38,4 \\
\hline 115 & CONSUMO & 2 & 32 & 0,05 & 39,2 & 0 \\
\hline 116 & DIRETRIZES & 6 & 42 & 0,06 & 39,2 & 0 \\
\hline 117 & ORG & 21 & 0,03 & 70 & 0,11 & 40,2 \\
\hline 118 & CBTS & 1 & 30 & 0,05 & 41,2 & 0 \\
\hline 119 & ALDEIA & 1 & 30 & 0,05 & 41,2 & 0 \\
\hline 120 & GESTÃO & 18 & 0,02 & 66 & 0,1 & 41,2 \\
\hline 121 & AMBIENTE & 107 & 0,13 & 183 & 0,28 & 41,3 \\
\hline 122 & MARKETING & 4 & 39 & 0,06 & 41,6 & 0 \\
\hline 123 & SETOR & 24 & 0,03 & 77 & 0,12 & 42,7 \\
\hline 124 & ENTIDADES & 1 & 31 & 0,05 & 42,7 & 0 \\
\hline 125 & SOCIEDADE & 16 & 0,02 & 64 & 0,1 & 42,9 \\
\hline 126 & PROGRAMA & 42 & 0,05 & 104 & 0,16 & 43,3 \\
\hline 127 & THE & 1 & 32 & 0,05 & 44,3 & 0 \\
\hline 128 & MANUAL & 0 & 28 & 0,04 & 45,6 & 0 \\
\hline 129 & sos & 0 & 28 & 0,04 & 45,6 & 0 \\
\hline 130 & MUNICIPAL & 13 & 0,02 & 61 & 0,09 & 45,7 \\
\hline 131 & PÚBLICAS & 2 & 38 & 0,06 & 48,3 & 0 \\
\hline 132 & ECOTURISMO & 325 & 0,4 & 431 & 0,66 & 49,2 \\
\hline 133 & MEIO & 120 & 0,15 & 215 & 0,33 & 53,5 \\
\hline 134 & DIRETOR & 7 & 55 & 0,08 & 54 & 0 \\
\hline 135 & SOBRE & 75 & 0,09 & 161 & 0,25 & 54,9 \\
\hline 136 & PROJETOS & 17 & 0,02 & 76 & 0,12 & 55,2 \\
\hline 137 & CULTURAL & 33 & 0,04 & 104 & 0,16 & 56,7 \\
\hline 138 & SOCIAL & 19 & 0,02 & 82 & 0,13 & 58,1 \\
\hline 139 & SEMINÁRIO & 0 & 37 & 0,06 & 60,2 & 0 \\
\hline 140 & COMUNIDADES & 28 & 0,03 & 100 & 0,15 & 61,1 \\
\hline 141 & EDUCAÇÃO & 24 & 0,03 & 99 & 0,15 & 67,9 \\
\hline 142 & FEIRA & 2 & 51 & 0,08 & 68,3 & 0 \\
\hline 143 & AMBIENTAL & 118 & 0,14 & 236 & 0,36 & 71,8 \\
\hline
\end{tabular}




\begin{tabular}{|r|l|r|r|r|r|r|}
\hline 144 & CABO & 12 & 0,01 & 82 & 0,13 & 75,8 \\
\hline 145 & ATEIA & 0 & 47 & 0,07 & 76,5 & 0 \\
\hline 146 & FRIO & 7 & 81 & 0,12 & 91,2 & 0 \\
\hline 147 & TEIA & 6 & 0,09 & 97,7 & 0 \\
\hline 148 & SUSTENTABILIDA+ & 17 & 0,02 & 111 & 0,17 & 100,4 \\
\hline 149 & FIECOTUR & 0 & 0,1 & 109,1 & 0 \\
\hline 150 & POLÍTICAS & 1 & 73 & 0,11 & 109,4 & 0 \\
\hline 151 & CERTIFICAÇÃO & 10 & 0,01 & 109 & 0,17 & 120,5 \\
\hline 152 & DESENVOLVIMENT+ & 94 & 0,12 & 290 & 0,45 & 155 \\
\hline 153 & SUSTENTÁVEL & 43 & 0,05 & 221 & 0,34 & 175,7 \\
\hline 154 & WWF & 127 & 0,2 & 206,8 & 0 \\
\hline 155 & TURISMO & 0 & 0,25 & 558 & 0,86 & 267,4 \\
\hline
\end{tabular}

p_ag x gov (português / agências x governo)

\begin{tabular}{|c|c|c|c|c|c|c|}
\hline $\mathbf{N}$ & WORD & FREQ. & $\begin{array}{l}\text { WLP_AG2.LST } \\
\%\end{array}$ & FREQ. & $\begin{array}{l}\text { WLP_GOV.LST } \\
\%\end{array}$ & KEYNESS \\
\hline 1 & WWW & 155 & 0,19 & 1 & 183,7 & 0 \\
\hline 2 & BR & 169 & 0,21 & 8 & 0,01 & 158,8 \\
\hline 3 & ITACARÉ & 108 & 0,13 & 0 & 135,3 & 0 \\
\hline 4 & HTTP & 118 & 0,14 & 2 & 130,6 & 0 \\
\hline 5 & HTML & 92 & 0,11 & 0 & 115,3 & 0 \\
\hline 6 & ALAYA & 87 & 0,11 & 0 & 109 & 0 \\
\hline 7 & RIO & 234 & 0,29 & 54 & 0,08 & 97,9 \\
\hline 8 & INDEX & 63 & 0,08 & 0 & 78,9 & 0 \\
\hline 9 & VOCÊ & 67 & 0,08 & 1 & 75 & 0 \\
\hline 10 & KM & 110 & 0,14 & 13 & 0,02 & 74,7 \\
\hline 11 & PANTANAL & 91 & 0,11 & 7 & 74,3 & 0 \\
\hline 12 & PRAIA & 87 & 0,11 & 6 & 73,7 & 0 \\
\hline 13 & É & 760 & 0,93 & 397 & 0,56 & 71,5 \\
\hline 14 & MAIS & 417 & 0,51 & 178 & 0,25 & 68,7 \\
\hline 15 & MPE & 50 & 0,06 & 0 & 62,6 & 0 \\
\hline 16 & COM & 1.047 & 1,29 & 615 & 0,87 & 62,3 \\
\hline 17 & ID & 49 & 0,06 & 0 & 61,4 & 0 \\
\hline 18 & CONTEUDO & 40 & 0,05 & 0 & 50,1 & $\underline{0}$ \\
\hline 19 & COMPOSER & 40 & 0,05 & 0 & 50,1 & 0 \\
\hline 20 & AMBIENTEBRASIL & 40 & 0,05 & 0 & 50,1 & 0 \\
\hline 21 & TRILHA & 79 & 0,1 & 11 & 0,02 & 48,9 \\
\hline 22 & PEIXE & 39 & 0,05 & 0 & 48,8 & 0 \\
\hline 23 & RIOS & 115 & 0,14 & 27 & 0,04 & 47,2 \\
\hline 24 & PÓLO & 68 & 0,08 & 9 & 0,01 & 43,4 \\
\hline 25 & ANUNCIOS & 34 & 0,04 & 0 & 42,6 & 0 \\
\hline 26 & JACARÉ & 31 & 0,04 & 0 & 38,8 & 0 \\
\hline 27 & ARVORISMO & 38 & 0,05 & 2 & 34,8 & 0 \\
\hline 28 & HISTÓRIA & 38 & 0,05 & 2 & 34,8 & 0 \\
\hline 29 & BONITO & 59 & 0,07 & 9 & 0,01 & 34,5 \\
\hline 30 & ECO & 41 & 0,05 & 3 & 34 & 0 \\
\hline 31 & GRANDE & 198 & 0,24 & 83 & 0,12 & 33,9 \\
\hline
\end{tabular}




\begin{tabular}{|c|c|c|c|c|c|c|}
\hline 32 & NOSSOS & 33 & 0,04 & 1 & 33,8 & 0 \\
\hline 33 & BAHIA & 37 & 0,05 & 2 & 33,6 & 0 \\
\hline 34 & PRAIAS & 57 & 0,07 & 9 & 0,01 & 32,6 \\
\hline 35 & MARGENS & 26 & 0,03 & 0 & 32,6 & 0 \\
\hline 36 & ASP & 25 & 0,03 & 0 & 31,3 & 0 \\
\hline 37 & PAGINA & 24 & 0,03 & 0 & 30,1 & 0 \\
\hline 38 & UNA & 24 & 0,03 & 0 & 30,1 & 0 \\
\hline 39 & LUGAR & 43 & 0,05 & 5 & 29,4 & 0 \\
\hline 40 & SERRA & 113 & 0,14 & 38 & 0,05 & 29,3 \\
\hline 41 & APA & 56 & 0,07 & 10 & 0,01 & 29,3 \\
\hline 42 & CACHOEIRA & 51 & 0,06 & 8 & 0,01 & 29,3 \\
\hline 43 & UM & 626 & 0,77 & 386 & 0,54 & 29,2 \\
\hline 44 & NOSSA & 33 & 0,04 & 2 & 29,1 & 0 \\
\hline 45 & UMA & 628 & 0,77 & 388 & 0,55 & 29 \\
\hline 46 & CLIMA & 42 & 0,05 & 5 & 28,4 & 0 \\
\hline 47 & NATUREZA & 115 & 0,14 & 40 & 0,06 & 28,2 \\
\hline 48 & CHEGAR & 44 & 0,05 & 6 & 27,6 & 0 \\
\hline 49 & MORRETES & 22 & 0,03 & 0 & 27,6 & 0 \\
\hline 50 & MIRANDA & 22 & 0,03 & 0 & 27,6 & 0 \\
\hline 51 & PERCURSO & 49 & 0,06 & 8 & 0,01 & 27,4 \\
\hline 52 & ÁGUA & 93 & 0,11 & 29 & 0,04 & 27 \\
\hline 53 & BROTAS & 46 & 0,06 & 7 & 27 & 0 \\
\hline 54 & ROTEIROS & 58 & 0,07 & 12 & 0,02 & 26,9 \\
\hline 55 & AQUIDAUANA & 21 & 0,03 & 0 & 26,3 & 0 \\
\hline 56 & ECOESPORTES & 21 & 0,03 & 0 & 26,3 & 0 \\
\hline 57 & ATÉ & 124 & 0,15 & 47 & 0,07 & 26,1 \\
\hline 58 & HOJE & 61 & 0,07 & 14 & 0,02 & 25,6 \\
\hline 59 & ILHÉUS & 26 & 0,03 & 1 & 25,5 & 0 \\
\hline 60 & 0 & 1.982 & 2,43 & 1.455 & 2,05 & 25,1 \\
\hline 61 & FAUNA & 88 & 0,11 & 28 & 0,04 & 24,8 \\
\hline 62 & PROMOVER & 18 & 0,02 & 54 & 0,08 & 24,2 \\
\hline 63 & COORDENADORIA & 0 & 16 & 0,02 & 24,5 & 0,000001 \\
\hline 64 & ONGS & 6 & 33 & 0,05 & 24,5 & 0,000001 \\
\hline 65 & EMBRATUR & 19 & 0,02 & 56 & 0,08 & 24,6 \\
\hline 66 & SERVIÇOS & 36 & 0,04 & 81 & 0,11 & 24,6 \\
\hline 67 & INVESTIMENTOS & 9 & 0,01 & 39 & 0,06 & 24,6 \\
\hline 68 & MUNICÍPIOS & 37 & 0,05 & 83 & 0,12 & 25,1 \\
\hline 69 & DO & 1.671 & 2,05 & 1.726 & 2,43 & 25,4 \\
\hline 70 & SERÃO & 13 & 0,02 & 47 & 0,07 & 25,5 \\
\hline 71 & POSIÇÃO & 7 & 36 & 0,05 & 25,6 & 0 \\
\hline 72 & AVALIAÇÃO & 6 & 34 & 0,05 & 25,7 & 0 \\
\hline 73 & PLANOS & 10 & 0,01 & 42 & 0,06 & 25,9 \\
\hline 74 & ENVOLVIDOS & 5 & 32 & 0,05 & 25,9 & 0 \\
\hline 75 & $\mathrm{P}$ & 2 & 25 & 0,04 & 26,5 & 0 \\
\hline 76 & PÚBLICAS & 2 & 25 & 0,04 & 26,5 & 0 \\
\hline 77 & CARLOS & 3 & 28 & 0,04 & 26,9 & 0 \\
\hline 78 & ESPAÇOS & 0 & 18 & 0,03 & 27,5 & 0 \\
\hline 79 & APOIAR & 0 & 18 & 0,03 & 27,5 & 0 \\
\hline 80 & NESTE & 36 & 0,04 & 85 & 0,12 & 27,8 \\
\hline 81 & PAULISTA & 2 & 26 & 0,04 & 27,9 & 0 \\
\hline 82 & UCS & 2 & 26 & 0,04 & 27,9 & 0 \\
\hline
\end{tabular}




\begin{tabular}{|c|c|c|c|c|c|c|}
\hline 83 & VALE & 25 & 0,03 & 69 & 0,1 & 28 \\
\hline 84 & IEB & 1 & 23 & 0,03 & 28,1 & 0 \\
\hline 85 & QUEDISMO & 1 & 23 & 0,03 & 28,1 & 0 \\
\hline 86 & FICHAS & 1 & 23 & 0,03 & 28,1 & 0 \\
\hline 87 & DIRETRIZES & 6 & 36 & 0,05 & 28,1 & 0 \\
\hline 88 & PARTICIPAÇÃO & 17 & 0,02 & 57 & 0,08 & 28,7 \\
\hline 89 & MERCADO & 33 & 0,04 & 82 & 0,12 & 28,9 \\
\hline 90 & IF & 0 & 19 & 0,03 & 29,1 & 0 \\
\hline 91 & TURISTA & 18 & 0,02 & 59 & 0,08 & 29,1 \\
\hline 92 & FUNDAÇÃO & 8 & 41 & 0,06 & 29,1 & 0 \\
\hline 93 & TURÍSTICA & 21 & 0,03 & 64 & 0,09 & 29,2 \\
\hline 94 & TURÍSTICOS & 19 & 0,02 & 61 & 0,09 & 29,4 \\
\hline 95 & PROGRAMAÇÃO & 5 & 35 & 0,05 & 29,7 & 0 \\
\hline 96 & AUTORES & 4 & 33 & 0,05 & 30,2 & 0 \\
\hline 97 & ÓRGÃOS & 10 & 0,01 & 46 & 0,06 & 30,4 \\
\hline 98 & CANANÉIA & 0 & 20 & 0,03 & 30,6 & 0 \\
\hline 99 & ESTRUTURAÇÃO & 0 & 20 & 0,03 & 30,6 & 0 \\
\hline 100 & ARTIGO & 0 & 20 & 0,03 & 30,6 & 0 \\
\hline 101 & CIVIL & 6 & 38 & 0,05 & 30,6 & 0 \\
\hline 102 & TABELA & 2 & 28 & 0,04 & 30,7 & 0 \\
\hline 103 & ASSISTÊNCIA & 1 & 25 & 0,04 & 31 & 0 \\
\hline 104 & TURÍSTICO & 42 & 0,05 & 98 & 0,14 & 31,5 \\
\hline 105 & SEGMENTO & 17 & 0,02 & 60 & 0,08 & 31,8 \\
\hline 106 & DOS & 450 & 0,55 & 559 & 0,79 & 32 \\
\hline 107 & UNIVERSIDADES & 0 & 21 & 0,03 & 32,1 & 0 \\
\hline 108 & BOTELHO & 1 & 26 & 0,04 & 32,5 & 0 \\
\hline 109 & ENTORNO & 9 & 0,01 & 46 & 0,06 & 32,6 \\
\hline 110 & MUNICIPAIS & 4 & 35 & 0,05 & 32,8 & 0 \\
\hline 111 & PRESENTE & 9 & 0,01 & 47 & 0,07 & 33,8 \\
\hline 112 & $\mathrm{PE}$ & 4 & 36 & 0,05 & 34,1 & 0 \\
\hline 113 & EDIÇÃO & 4 & 36 & 0,05 & 34,1 & 0 \\
\hline 114 & CONSELHOS & 0 & 23 & 0,03 & 35,2 & 0 \\
\hline 115 & REPRESENTATIVA+ & 1 & 28 & 0,04 & 35,4 & 0 \\
\hline 116 & PROJETOS & 17 & 0,02 & 64 & 0,09 & 36 \\
\hline 117 & DAS & 356 & 0,44 & 471 & 0,66 & 36,2 \\
\hline 118 & IMPLANTAÇÃO & 27 & 0,03 & 81 & 0,11 & 36,3 \\
\hline 119 & PREVE & 0 & 24 & 0,03 & 36,7 & 0 \\
\hline 120 & PÁRA & 5 & 41 & 0,06 & 37,4 & 0 \\
\hline 121 & CAPACITAÇÃO & 13 & 0,02 & 59 & 0,08 & 38,6 \\
\hline 122 & ATIVIDADES & 151 & 0,19 & 247 & 0,35 & 38,7 \\
\hline 123 & OBRAS & 8 & 49 & 0,07 & 38,8 & 0 \\
\hline 124 & PREFEITURAS & 3 & 37 & 0,05 & 39,1 & 0 \\
\hline 125 & SUSTENTÁVEL & 43 & 0,05 & 109 & 0,15 & 39,6 \\
\hline 126 & RALLY & 0 & 26 & 0,04 & 39,8 & 0 \\
\hline 127 & ETAPAS & 5 & 43 & 0,06 & 40 & 0 \\
\hline 128 & APRESENTAÇÃO & 4 & 41 & 0,06 & 40,7 & 0 \\
\hline 129 & JACUPIRANGA & 1 & 32 & 0,05 & 41,3 & 0 \\
\hline 130 & REPRESENTAM & 3 & 40 & 0,06 & 43,2 & 0 \\
\hline 131 & ESTRATÉGIA & 6 & 48 & 0,07 & 43,3 & 0 \\
\hline 132 & ESTRATÉGIAS & 2 & 37 & 0,05 & 43,3 & 0 \\
\hline 133 & INTERVALES & 1 & 34 & 0,05 & 44,2 & 0 \\
\hline
\end{tabular}




\begin{tabular}{|c|c|c|c|c|c|c|}
\hline 134 & RIBEIRA & 20 & 0,02 & 78 & 0,11 & 45,2 \\
\hline 135 & 1 & 9 & 0,01 & 59 & 0,08 & 48,4 \\
\hline 136 & CONSERVAÇÃO & 107 & 0,13 & 208 & 0,29 & 48,6 \\
\hline 137 & SETOR & 24 & 0,03 & 89 & 0,13 & 49,4 \\
\hline 138 & COMUNIDADES & 28 & 0,03 & 96 & 0,14 & 49,5 \\
\hline 139 & COMPLEMENTARES & 1 & 38 & 0,05 & 50,1 & 0 \\
\hline 140 & BUSQUE & 0 & 33 & 0,05 & 50,5 & 0 \\
\hline 141 & ORGANIZAÇÃO & 14 & 0,02 & 72 & 0,1 & 51,3 \\
\hline 142 & RESUMO & 1 & 39 & 0,06 & 51,6 & 0 \\
\hline 143 & VERIFICAR & 0 & 35 & 0,05 & 53,6 & 0 \\
\hline 144 & ETAPA & 2 & 45 & 0,06 & 54,8 & 0 \\
\hline 145 & CARDOSO & 0 & 36 & 0,05 & 55,1 & 0 \\
\hline 146 & ATIVIDADE & 91 & 0,11 & 196 & 0,28 & 55,4 \\
\hline 147 & CADA & 65 & 0,08 & 160 & 0,23 & 55,7 \\
\hline 148 & REGULAMENTAÇÃO & 3 & 49 & 0,07 & 55,8 & 0 \\
\hline 149 & ESTADUAIS & 6 & 59 & 0,08 & 57,8 & 0 \\
\hline 150 & FLORESTAL & 7 & 63 & 0,09 & 59,7 & 0 \\
\hline 151 & IMPACTOS & 36 & 0,04 & 125 & 0,18 & 65,3 \\
\hline 152 & SECRETARIA & 11 & 0,01 & 79 & 0,11 & 67,8 \\
\hline 153 & DESENVOLVIMENT+ & 94 & 0,12 & 217 & 0,31 & 68,7 \\
\hline 154 & REGIONAL & 17 & 0,02 & 93 & 0,13 & 68,9 \\
\hline 155 & PÚBLICA & 7 & 75 & 0,11 & 75,7 & 0 \\
\hline 156 & SEMINÁRIO & 0 & 51 & 0,07 & 78 & 0 \\
\hline 157 & GESTÃO & 18 & 0,02 & 104 & 0,15 & 79,6 \\
\hline 158 & ESTADUAL & 39 & 0,05 & 144 & 0,2 & 79,6 \\
\hline 159 & ILHABELA & 0 & 53 & 0,07 & 81,1 & 0 \\
\hline 160 & DE & 4.637 & 5,69 & 4.857 & 6,85 & 86,7 \\
\hline 161 & ENTIDADES & 1 & 63 & 0,09 & 87,4 & 0 \\
\hline 162 & UNIDADES & 37 & 0,05 & 148 & 0,21 & 87,7 \\
\hline 163 & ESTADO & 88 & 0,11 & 232 & 0,33 & 88,9 \\
\hline 164 & PAULO & 47 & 0,06 & 167 & 0,24 & 89,2 \\
\hline 165 & SET & 0 & 59 & 0,08 & 90,3 & 0 \\
\hline 166 & AÇÕES & 19 & 0,02 & 116 & 0,16 & 91,6 \\
\hline 167 & RESPONSABILIDA+ & 10 & 0,01 & 99 & 0,14 & 97,2 \\
\hline 168 & TEXTOS & 1 & 73 & 0,1 & 102,4 & 0 \\
\hline 169 & VISITAÇÃO & 36 & 0,04 & 161 & 0,23 & 104,2 \\
\hline 170 & PROJETO & 62 & 0,08 & 245 & 0,35 & 143,8 \\
\hline 171 & TURISMO & 201 & 0,25 & 463 & 0,65 & 146,4 \\
\hline 172 & SMA & 3 & 117 & 0,17 & 154,8 & 0 \\
\hline 173 & PARQUES & 20 & 0,02 & 255 & 0,36 & 272,2 \\
\hline
\end{tabular}

\section{p_amb x gov (português / ambientalistas x governo)}

\begin{tabular}{|r|l|r|r|r|r|r|}
\hline $\mathbf{N}$ & WORD & FREQ. & WLP_AMB.LST \% & FREQ. & WLP_GOV.LST \% & \multicolumn{1}{|c|}{ KEYNESS } \\
\hline 1 & WWF & 127 & 0,2 & 3 & 163,1 & 0 \\
\hline 2 & CERTIFICAÇÃO & 109 & 0,17 & 3 & 137,4 & 0 \\
\hline 3 & FRIO & 81 & 0,12 & 0 & 119,7 & 0 \\
\hline 4 & CABO & 82 & 0,13 & 1 & 111,7 & 0 \\
\hline
\end{tabular}




\begin{tabular}{|c|c|c|c|c|c|c|}
\hline & FIECOTUR & 67 & 0,1 & 0 & 99 & 0 \\
\hline 6 & ORG & 70 & 0,11 & 1 & 94,3 & 0 \\
\hline 7 & TEIA & 60 & 0,09 & 0 & 88,7 & 0 \\
\hline 8 & $\mathrm{BR}$ & 87 & 0,13 & 8 & 0,01 & 84,1 \\
\hline 9 & PANTANAL & 81 & 0,12 & 7 & 80 & 0 \\
\hline 10 & BRASIL & 236 & 0,36 & 93 & 0,13 & 77,9 \\
\hline 11 & FEIRA & 51 & 0,08 & 0 & 75,4 & 0 \\
\hline 12 & DIRETOR & 55 & 0,08 & 1 & 72,6 & 0 \\
\hline 13 & ATEIA & 47 & 0,07 & 0 & 69,5 & 0 \\
\hline 14 & SUSTENTABILIDA+ & 111 & 0,17 & 25 & 0,04 & 66,8 \\
\hline 15 & WWW & 47 & 0,07 & 1 & 61 & 0 \\
\hline 16 & NATUREZA & 129 & 0,2 & 40 & 0,06 & 57,7 \\
\hline 17 & LAGOS & 59 & 0,09 & 6 & 55 & 0 \\
\hline 18 & UM & 567 & 0,87 & 386 & 0,54 & 53 \\
\hline 19 & HOMEM & 65 & 0,1 & 10 & 0,01 & 50,2 \\
\hline 20 & SUSTENTÁVEL & 221 & 0,34 & 109 & 0,15 & 49,6 \\
\hline 21 & SOCIAL & 82 & 0,13 & 19 & 0,03 & 48,2 \\
\hline 22 & POLÍTICAS & 73 & 0,11 & 15 & 0,02 & 47 \\
\hline 23 & CBTS & 30 & 0,05 & 0 & 44,3 & 0 \\
\hline 24 & ARQUEOLOGIA & 30 & 0,05 & 0 & 44,3 & 0 \\
\hline 25 & ALDEIA & 30 & 0,05 & 0 & 44,3 & 0 \\
\hline 26 & 0 & 1.679 & 2,59 & 1.455 & 2,05 & 43,3 \\
\hline 27 & SALVATI & 26 & 0,04 & 0 & 38,4 & 0 \\
\hline 28 & INTERNACIONAL & 70 & 0,11 & 19 & 0,03 & 35,8 \\
\hline 29 & PARTES & 24 & 0,04 & 0 & 35,5 & 0 \\
\hline 30 & THE & 32 & 0,05 & 2 & 34,7 & 0 \\
\hline 31 & PRESIDENTE & 35 & 0,05 & 3 & 34,6 & 0 \\
\hline 32 & HOTEL & 28 & 0,04 & 1 & 34 & 0 \\
\hline 33 & MEIO & 215 & 0,33 & 125 & 0,18 & 32,9 \\
\hline 34 & CULTURAL & 104 & 0,16 & 43 & 0,06 & 31,9 \\
\hline 35 & SÉRGIO & 21 & 0,03 & 0 & 31 & 0 \\
\hline 36 & NOVEMBRO & 34 & 0,05 & 4 & 29,9 & 0 \\
\hline 37 & PUBLICAÇÃO & 25 & 0,04 & 1 & 29,8 & 0 \\
\hline 38 & PROF & 20 & 0,03 & 0 & 29,6 & 0 \\
\hline 39 & ECOLÓGICO & 66 & 0,1 & 21 & 0,03 & 28,7 \\
\hline 40 & PEDRO & 26 & 0,04 & 2 & 26,6 & 0 \\
\hline 41 & SIG & 18 & 0,03 & 0 & 26,6 & 0 \\
\hline 42 & ECOGÉNESE & 18 & 0,03 & 0 & 26,6 & 0 \\
\hline 43 & GERALDO & 18 & 0,03 & 0 & 26,6 & 0 \\
\hline 44 & MUNDO & 76 & 0,12 & 29 & 0,04 & 26,2 \\
\hline 45 & RJ & 22 & 0,03 & 1 & 25,6 & 0 \\
\hline 46 & SOS & 28 & 0,04 & 3 & 25,6 & 0 \\
\hline 47 & HTTP & 25 & 0,04 & 2 & 25,3 & 0 \\
\hline 48 & ECOTURISMO & 431 & 0,66 & 327 & 0,46 & 25,3 \\
\hline 49 & PCTS & 17 & 0,03 & 0 & 25,1 & 0,000001 \\
\hline 50 & ASPAC & 17 & 0,03 & 0 & 25,1 & 0,000001 \\
\hline 51 & ABRIL & 21 & 0,03 & 1 & 24,2 & 0,000001 \\
\hline 52 & TURISTA & 15 & 0,02 & 59 & 0,08 & 24,2 \\
\hline 53 & DAS & 301 & 0,46 & 471 & 0,66 & 24,2 \\
\hline 54 & DE & 4.011 & 6,19 & 4.857 & 6,85 & 24,5 \\
\hline 55 & IF & 0 & 19 & 0,03 & 24,7 & 0,000001 \\
\hline
\end{tabular}




\begin{tabular}{|c|c|c|c|c|c|c|}
\hline & NÚCLEOS & 0 & 19 & 0,03 & 24,7 & 0,000001 \\
\hline 57 & PREFEITURAS & 5 & 37 & 0,05 & 24,8 & 0,000001 \\
\hline 58 & PRESENTE & 9 & 0,01 & 47 & 0,07 & 25 \\
\hline 59 & ESTRUTURA & 33 & 0,05 & 94 & 0,13 & 25,4 \\
\hline 60 & ESTRUTURAÇÃO & 0 & 20 & 0,03 & 26 & 0 \\
\hline 61 & CAVALGADA & 0 & 20 & 0,03 & 26 & 0 \\
\hline 62 & PAULISTA & 1 & 26 & 0,04 & 26,7 & 0 \\
\hline 63 & LITORAL & 5 & 39 & 0,06 & 26,9 & 0 \\
\hline 64 & VALE & 18 & 0,03 & 69 & 0,1 & 27,5 \\
\hline 65 & MUNICÍPIOS & 25 & 0,04 & 83 & 0,12 & 27,9 \\
\hline 66 & $B$ & 1 & 27 & 0,04 & 27,9 & 0 \\
\hline 67 & QUEDISMO & 0 & 23 & 0,03 & 29,9 & 0 \\
\hline 68 & NÚCLEO & 4 & 39 & 0,06 & 30 & 0 \\
\hline 69 & CARDOSO & 3 & 36 & 0,05 & 30 & 0 \\
\hline 70 & POSIÇÃO & 3 & 36 & 0,05 & 30 & 0 \\
\hline 71 & MERGULHO & 8 & 0,01 & 50 & 0,07 & 30,2 \\
\hline 72 & LIVRE & 2 & 33 & 0,05 & 30,5 & 0 \\
\hline 73 & ATRATIVOS & 18 & 0,03 & 73 & 0,1 & 30,9 \\
\hline 74 & PROGRAMAÇÃO & 2 & 35 & 0,05 & 32,9 & 0 \\
\hline 75 & VERIFICAR & 2 & 35 & 0,05 & 32,9 & 0 \\
\hline 76 & RALLY & 0 & 26 & 0,04 & 33,8 & 0 \\
\hline 77 & UCS & 0 & 26 & 0,04 & 33,8 & 0 \\
\hline 78 & BOTELHO & 0 & 26 & 0,04 & 33,8 & 0 \\
\hline 79 & PROJETO & 119 & 0,18 & 245 & 0,35 & 34,1 \\
\hline 80 & REPRESENTAM & 3 & 40 & 0,06 & 34,6 & 0 \\
\hline 81 & RAFTING & 0 & 27 & 0,04 & 35,1 & 0 \\
\hline 82 & MODALIDADES & 2 & 37 & 0,05 & 35,2 & 0 \\
\hline 83 & BUSQUE & 1 & 33 & 0,05 & 35,3 & 0 \\
\hline 84 & REPRESENTATIVA+ & 0 & 28 & 0,04 & 36,4 & 0 \\
\hline 85 & PÚBLICA & 16 & 0,02 & 75 & 0,11 & 36,5 \\
\hline 86 & ESTADUAIS & 9 & 0,01 & 59 & 0,08 & 36,8 \\
\hline 87 & REGIONAL & 24 & 0,04 & 93 & 0,13 & 37,6 \\
\hline 88 & ATIVIDADE & 83 & 0,13 & 196 & 0,28 & 37,6 \\
\hline 89 & RESUMO & 2 & 39 & 0,06 & 37,6 & 0 \\
\hline 90 & VÔO & 0 & 29 & 0,04 & 37,7 & 0 \\
\hline 91 & PETAR & 0 & 31 & 0,04 & 40,3 & 0 \\
\hline 92 & ETC & 10 & 0,02 & 65 & 0,09 & 40,3 \\
\hline 93 & OBRAS & 4 & 49 & 0,07 & 41,2 & 0 \\
\hline 94 & JACUPIRANGA & 0 & 32 & 0,05 & 41,6 & 0 \\
\hline 95 & ETAPAS & 2 & 43 & 0,06 & 42,5 & 0 \\
\hline 96 & INTERVALES & 0 & 34 & 0,05 & 44,2 & 0 \\
\hline 97 & CAVERNAS & 0 & 35 & 0,05 & 45,5 & 0 \\
\hline 98 & NESTE & 15 & $\overline{0,02}$ & 85 & 0,12 & 48,1 \\
\hline 99 & RESPONSABILIDA+ & 21 & 0,03 & 99 & 0,14 & 48,4 \\
\hline 100 & COMPLEMENTARES & 0 & 38 & 0,05 & 49,4 & 0 \\
\hline 101 & SEGURANÇA & 4 & 57 & 0,08 & 50,4 & 0 \\
\hline 102 & EQUIPAMENTOS & 11 & 0,02 & 78 & 0,11 & 51 \\
\hline 103 & IMPACTOS & 31 & 0,05 & 125 & 0,18 & 52,7 \\
\hline 104 & PÁRA & 0 & 41 & 0,06 & 53,3 & 0 \\
\hline 105 & FLORESTAL & 4 & 63 & 0,09 & 57,5 & 0 \\
\hline 106 & ETAPA & 0 & 45 & 0,06 & 58,5 & 0 \\
\hline
\end{tabular}




\begin{tabular}{|r|l|r|r|r|r|r|}
\hline 107 & ATIVIDADES & 92 & 0,14 & 247 & 0,35 & 60,5 \\
\hline 108 & PAULO & 45 & 0,07 & 167 & 0,24 & 64,3 \\
\hline 109 & LLHABELA & 0 & 53 & 0,07 & 68,9 & 0 \\
\hline 110 & RIBEIRA & 5 & 78 & 0,11 & 70,9 & 0 \\
\hline 111 & UNIDADES & 31 & 0,05 & 148 & 0,21 & 73,1 \\
\hline 112 & VISITAÇÃO & 0,06 & 161 & 0,23 & 73,2 \\
\hline 113 & SÃO & 203 & 0,31 & 447 & 0,63 & 73,7 \\
\hline 114 & SET & 0 & 59 & 0,08 & 76,7 & 0 \\
\hline 115 & CADA & 32 & 0,05 & 160 & 0,23 & 82,2 \\
\hline 116 & ESTADUAL & 23 & 0,04 & 144 & 0,2 & 87,2 \\
\hline 117 & TEXTOS & 0 & 73 & 0,1 & 94,9 & 0 \\
\hline 118 & ESTADO & 39 & 0,06 & 232 & 0,33 & 135,9 \\
\hline 119 & AVENTURA & 11 & 0,02 & 165 & 0,23 & 148,4 \\
\hline 120 & SMA & 0 & 117 & 0,17 & 152,1 & 0 \\
\hline 121 & PARQUES & 18 & 0,03 & 255 & 0,36 & 225,5 \\
\hline
\end{tabular}




\section{ANEXO H - PALAVRAS-CHAVE: CRUZAMENTO ENTRE AS LISTAS DE PALAVRAS-CHAVE EM INGLÊS}

ig_ag $\mathrm{x}$ amb (inglês / agências $\mathrm{x}$ ambientalistas)

\begin{tabular}{|c|c|c|c|c|c|c|}
\hline No. & WORD & FREQ. & WLI_AG.LST \% & FREQ. & WLI_AMB.LST \% & KEYNESS \\
\hline 1 & NEW & 476 & 1,2 & 278 & 0,44 & 185,7 \\
\hline 2 & ZEALAND & 395 & 1 & 206 & 0,33 & 180,9 \\
\hline 3 & OUR & 224 & 0,57 & 68 & 0,11 & 176 \\
\hline 4 & YOU & 258 & 0,65 & 107 & 0,17 & 154,2 \\
\hline 5 & WE & 248 & 0,63 & 101 & 0,16 & 151 \\
\hline 6 & TRACK & 97 & 0,25 & 17 & 0,03 & 105,2 \\
\hline 7 & $\mathrm{CO}$ & 106 & 0,27 & 27 & 0,04 & 93,9 \\
\hline 8 & MOUNTAIN & 63 & 0,16 & 5 & 89,1 & 0 \\
\hline 9 & ECOTOURS & 47 & 0,12 & 1 & 80,7 & 0 \\
\hline 10 & DAY & 92 & 0,23 & 24 & 0,04 & 80,3 \\
\hline 11 & RIVER & 72 & 0,18 & 12 & 0,02 & 79,8 \\
\hline 12 & DOLPHINS & 68 & 0,17 & 12 & 0,02 & 73,5 \\
\hline 13 & ECO & 83 & 0,21 & 22 & 0,04 & 71,6 \\
\hline 14 & TOURS & 129 & 0,33 & 64 & 0,1 & 62,8 \\
\hline 15 & NZ & 152 & 0,38 & 86 & 0,14 & 61,9 \\
\hline 16 & UNIQUE & 61 & 0,15 & 14 & 0,02 & 57,5 \\
\hline 17 & HIKING & 35 & 0,09 & 2 & 53 & 0 \\
\hline 18 & HTTP & 99 & 0,25 & 47 & 0,07 & 50,8 \\
\hline 19 & TOUR & 77 & 0,19 & 30 & 0,05 & 48,8 \\
\hline 20 & ADVENTURE & 47 & 0,12 & 9 & 0,01 & 48,8 \\
\hline 21 & WALKS & 52 & 0,13 & 13 & 0,02 & 46,6 \\
\hline 22 & YOUR & 97 & 0,25 & 49 & 0,08 & 46,1 \\
\hline 23 & SEA & 57 & 0,14 & 17 & 0,03 & 45,3 \\
\hline 24 & WALKING & 62 & 0,16 & 21 & 0,03 & 44,6 \\
\hline 25 & BIKING & 30 & 0,08 & 2 & 44,1 & 0 \\
\hline 26 & WWW & 109 & 0,28 & 63 & 0,1 & 42,9 \\
\hline 27 & KAYAKING & 29 & 0,07 & 2 & 42,3 & 0 \\
\hline 28 & ZEALAND'S & 50 & 0,13 & 14 & 0,02 & 41,6 \\
\hline 29 & LAKE & 34 & 0,09 & 5 & 39,7 & 0 \\
\hline 30 & WALK & 56 & 0,14 & 20 & 0,03 & 38,5 \\
\hline 31 & HTM & 35 & 0,09 & 6 & 38,3 & 0 \\
\hline 32 & RAFTING & 29 & 0,07 & 3 & 38,2 & 0 \\
\hline 33 & GUIDED & 47 & 0,12 & 14 & 0,02 & 37,4 \\
\hline 34 & CREEK & 19 & 0,05 & 0 & 36,1 & 0 \\
\hline 35 & LODGE & 37 & 0,09 & 8 & 0,01 & 36,1 \\
\hline 36 & NATURAL & 114 & 0,29 & 76 & 0,12 & 35,4 \\
\hline 37 & SOUNDS & 25 & 0,06 & 2 & 35,3 & 0 \\
\hline 38 & WATCHING & 38 & 0,1 & 9 & 0,01 & 35,2 \\
\hline 39 & WITH & 301 & 0,76 & 295 & 0,47 & 34,7 \\
\hline 40 & STUNNING & 18 & 0,05 & 0 & 34,2 & 0 \\
\hline 41 & RAGLAN & 18 & 0,05 & 0 & 34,2 & 0 \\
\hline
\end{tabular}




\begin{tabular}{|c|c|c|c|c|c|c|}
\hline 42 & A & 818 & 2,07 & 988 & 1,57 & 33,8 \\
\hline 43 & TRIPS & 40 & 0,1 & 11 & 0,02 & 33,7 \\
\hline 44 & PHP & 21 & 0,05 & 1 & 32,8 & 0 \\
\hline 45 & PUNAKAIKI & 23 & 0,06 & 2 & 31,8 & 0 \\
\hline 46 & BUSH & 45 & 0,11 & 16 & 0,03 & 31 \\
\hline 47 & NATURE & 90 & 0,23 & 57 & 0,09 & 30,6 \\
\hline 48 & SCENERY & 31 & 0,08 & 7 & 0,01 & 29,5 \\
\hline 49 & PACK & 15 & 0,04 & 0 & 28,5 & 0 \\
\hline 50 & SWIM & 15 & 0,04 & 0 & 28,5 & 0 \\
\hline 51 & BEACHES & 23 & 0,06 & 3 & 28,1 & 0 \\
\hline 52 & BEAUTIFUL & 31 & 0,08 & 8 & 0,01 & 27,2 \\
\hline 53 & COASTLINE & 26 & 0,07 & 5 & 27 & 0 \\
\hline 54 & TRIP & 39 & 0,1 & 14 & 0,02 & 26,7 \\
\hline 55 & WAIMANGU & 14 & 0,04 & 0 & 26,6 & 0 \\
\hline 56 & RINGS & 14 & 0,04 & 0 & 26,6 & 0 \\
\hline 57 & SEALS & 20 & 0,05 & 2 & 26,6 & 0 \\
\hline 58 & AMAZING & 22 & 0,06 & 3 & 26,4 & 0 \\
\hline 59 & VALLEY & 37 & 0,09 & 13 & 0,02 & 25,8 \\
\hline 60 & QUEST & 17 & 0,04 & 1 & 25,6 & 0 \\
\hline 61 & ISLAND & 107 & 0,27 & 82 & 0,13 & 25 \\
\hline 62 & AWAROA & 13 & 0,03 & 0 & 24,7 & 0,000001 \\
\hline 63 & BED & 13 & 0,03 & 0 & 24,7 & 0,000001 \\
\hline 64 & DISTANCE & 13 & 0,03 & 0 & 24,7 & 0,000001 \\
\hline 65 & LORD & 13 & 0,03 & 0 & 24,7 & 0,000001 \\
\hline 66 & WHITEWATER & 13 & 0,03 & 0 & 24,7 & 0,000001 \\
\hline 67 & ALPINE & 26 & 0,07 & 6 & 24,4 & 0,000001 \\
\hline 68 & CONSERVATION & 74 & 0,19 & 220 & 0,35 & 23,9 \\
\hline 69 & RESPONSES & 0 & 25 & 0,04 & 24,4 & 0,000001 \\
\hline 70 & BUSINESSES & 3 & 42 & 0,07 & 24,7 & 0,000001 \\
\hline 71 & OPERATIONS & 5 & 0,01 & 50 & 0,08 & 24,8 \\
\hline 72 & SAYS & 1 & 33 & 0,05 & 25,1 & 0,000001 \\
\hline 73 & NGATI & 0 & 26 & 0,04 & 25,4 & 0 \\
\hline 74 & DIRECT & 2 & 39 & 0,06 & 25,9 & 0 \\
\hline 75 & SEX & 0 & 27 & 0,04 & 26,4 & 0 \\
\hline 76 & VOLUNTEERS & 0 & 27 & 0,04 & 26,4 & 0 \\
\hline 77 & VISITORS & 40 & 0,1 & 149 & 0,24 & 26,5 \\
\hline 78 & WELLINGTON & 3 & 45 & 0,07 & 27,2 & 0 \\
\hline 79 & EFFECTIVE & 0 & 28 & 0,04 & 27,3 & 0 \\
\hline 80 & FUNDING & 0 & 28 & 0,04 & 27,3 & 0 \\
\hline 81 & $E$ & 3 & 46 & 0,07 & 28,1 & 0 \\
\hline 82 & COUNTRIES & 6 & 0,02 & 58 & 0,09 & 28,2 \\
\hline 83 & SPTO & 0 & 29 & 0,05 & 28,3 & 0 \\
\hline 84 & EXPENDITURE & 0 & 29 & 0,05 & 28,3 & 0 \\
\hline 85 & COUNCIL & 1 & 37 & 0,06 & 28,8 & 0 \\
\hline 86 & SOCIAL & 3 & 47 & 0,07 & 28,9 & 0 \\
\hline 87 & ISSUES & 13 & 0,03 & 82 & 0,13 & 29 \\
\hline 88 & ATLANTIC & 0 & 31 & 0,05 & 30,3 & 0 \\
\hline 89 & VALUES & 8 & 0,02 & 68 & 0,11 & 30,5 \\
\hline 90 & HORTICULTURE & 0 & 32 & 0,05 & 31,3 & 0 \\
\hline 91 & MANIAPOTO & 0 & 32 & 0,05 & 31,3 & 0 \\
\hline 92 & OVERFISHED & 0 & 33 & 0,05 & 32,2 & 0 \\
\hline
\end{tabular}




\begin{tabular}{|r|l|r|r|r|r|r|}
\hline 93 & ET & 0 & 33 & 0,05 & 32,2 & 0 \\
\hline 94 & AL & 0 & 34 & 0,05 & 33,2 & 0 \\
\hline 95 & NMPA & 0 & 34 & 0,05 & 33,2 & 0 \\
\hline 96 & SURVEY & 1 & 42 & 0,07 & 33,4 & 0 \\
\hline 97 & ORG & 45 & 0,07 & 36,2 & 0 \\
\hline 98 & ENVIRONMENTAL & 35 & 0,09 & 155 & 0,25 & 36,5 \\
\hline 99 & RESEARCH & 9 & 0,02 & 80 & 0,13 & 37 \\
\hline 100 & GOVERNMENT & 2 & 52 & 0,08 & 37,5 & 0 \\
\hline 101 & MEAN & 1 & 47 & 0,07 & 38,1 & 0 \\
\hline 102 & SCORE & 0 & 39 & 0,06 & 38,1 & 0 \\
\hline 103 & USE & 14 & 0,04 & 100 & 0,16 & 39,4 \\
\hline 104 & STRATEGIES & 0 & 41 & 0,07 & 40,1 & 0 \\
\hline 105 & SUSTAINABLE & 21 & 0,05 & 125 & 0,2 & 41,8 \\
\hline 106 & ECONOMIC & 8 & 0,02 & 83 & 0,13 & 42,1 \\
\hline 107 & INDUSTRY & 13 & 0,03 & 101 & 0,16 & 42,5 \\
\hline 108 & NMPAS & 0 & 47 & 0,07 & 45,9 & 0 \\
\hline 109 & STOCK & 1 & 56 & 0,09 & 46,5 & 0 \\
\hline 110 & CONSIDERED & 1 & 56 & 0,09 & 46,5 & 0 \\
\hline 111 & STOCKS & 0 & 50 & 0,08 & 48,8 & 0 \\
\hline 112 & MANAGEMENT & 16 & 0,04 & 127 & 0,2 & 54,3 \\
\hline 113 & WERE & 30 & 0,08 & 176 & 0,28 & 58 \\
\hline 114 & THAT & 206 & 0,52 & 600 & 0,95 & 62 \\
\hline 115 & SPECIES & 35 & 0,09 & 197 & 0,31 & 62,3 \\
\hline 116 & VISITOR & 16 & 0,04 & 141 & 0,22 & 64,8 \\
\hline 117 & DATA & 1 & 79 & 0,13 & 68,3 & 0 \\
\hline 118 & DEVELOPMENT & 12 & 0,03 & 133 & 0,21 & 70 \\
\hline 119 & TOURISM & 114 & 0,29 & 523 & 0,83 & 129,8 \\
\hline & & & & & \\
\hline
\end{tabular}

i_ag x gov (inglês / agências x governo)

\begin{tabular}{|r|l|r|r|r|r|r|}
\hline N & WORD & FREQ. & WLI_AG.LST \% & FREQ. & WLI_GOV.LST \% & KEYNESS \\
\hline 1 & TOURS & 129 & 0,33 & 12 & 0,02 & 183,5 \\
\hline 2 & YOU & 258 & 0,65 & 129 & 0,19 & 136,7 \\
\hline 3 & CO & 106 & 0,27 & 14 & 0,02 & 135,6 \\
\hline 4 & DAY & 92 & 0,23 & 8 & 0,01 & 133,1 \\
\hline 5 & NZ & 152 & 0,38 & 47 & 0,07 & 126 \\
\hline 6 & TRACK & 97 & 0,25 & 14 & 0,02 & 120,2 \\
\hline 7 & TOUR & 37 & 0,19 & 6 & 114,3 & 0 \\
\hline 8 & ZEALAND & 395 & 1 & 296 & 0,45 & 111,9 \\
\hline 9 & PARK & 90 & 0,23 & 14 & 0,02 & 108,3 \\
\hline 10 & ISLAND & 107 & 0,27 & 25 & 0,04 & 106,1 \\
\hline 11 & RIVER & 72 & 0,18 & 6 & 105,2 & 0 \\
\hline 12 & DOLPHINS & 68 & 0,17 & 5 & 102,2 & 0 \\
\hline 13 & WALK & 56 & 0,14 & 1 & 101,2 & 0 \\
\hline 14 & ECO & 83 & 0,21 & 13 & 0,02 & 99,6 \\
\hline 15 & WALKING & 62 & 0,16 & 5 & 91,3 & 0 \\
\hline 16 & MOUNTAIN & 63 & 0,16 & 6 & 89 & 0 \\
\hline 17 & WWW & 109 & 0,28 & 37 & 0,06 & 84,1 \\
\hline
\end{tabular}




\begin{tabular}{|c|c|c|c|c|c|c|}
\hline 18 & ECOTOURS & 47 & 0,12 & 1 & 83,8 & 0 \\
\hline 19 & NEW & 476 & 1,2 & 438 & 0,66 & 82,4 \\
\hline 20 & HTTP & 99 & 0,25 & 32 & 0,05 & 79,4 \\
\hline 21 & WE & 248 & 0,63 & 182 & 0,27 & 73,1 \\
\hline 22 & HIKING & 35 & 0,09 & 0 & 69 & 0 \\
\hline 23 & GUIDED & 47 & 0,12 & 4 & 68,3 & 0 \\
\hline 24 & BIRD & 55 & 0,14 & 10 & 0,02 & 61,9 \\
\hline 25 & TRIPS & 40 & 0,1 & 3 & 59,9 & 0 \\
\hline 26 & COAST & 52 & 0,13 & 9 & 0,01 & 59,8 \\
\hline 27 & LODGE & 37 & 0,09 & 2 & 59 & 0 \\
\hline 28 & OUR & 224 & 0,57 & 177 & 0,27 & 56,6 \\
\hline 29 & WATCHING & 38 & 0,1 & 3 & 56,2 & 0 \\
\hline 30 & HOURS & 35 & 0,09 & 2 & 55,3 & 0 \\
\hline 31 & SEA & 57 & 0,14 & 14 & 0,02 & 54,9 \\
\hline 32 & BIKING & 30 & 0,08 & 1 & 51,2 & 0 \\
\hline 33 & WALKS & 52 & 0,13 & 13 & 0,02 & 49,6 \\
\hline 34 & LAKE & 34 & 0,09 & 3 & 49 & 0 \\
\hline 35 & NORTH & 50 & 0,13 & 12 & 0,02 & 48,8 \\
\hline 36 & DAYS & 38 & 0,1 & 5 & 48,6 & 0 \\
\hline 37 & SPECTACULAR & 31 & 0,08 & 2 & 47,9 & 0 \\
\hline 38 & VALLEY & 37 & 0,09 & 5 & 46,9 & 0 \\
\hline 39 & HTM & 35 & 0,09 & 4 & 46,9 & 0 \\
\hline 40 & PUNAKAIKI & 23 & 0,06 & 0 & 45,3 & 0 \\
\hline 41 & BEACHES & 23 & 0,06 & 0 & 45,3 & 0 \\
\hline 42 & BOAT & 23 & 0,06 & 0 & 45,3 & 0 \\
\hline 43 & ADVENTURE & 47 & 0,12 & 12 & 0,02 & 44,2 \\
\hline 44 & KAYAKING & 29 & 0,07 & 2 & 44,2 & 0 \\
\hline 45 & SOUTH & 69 & 0,17 & 29 & 0,04 & 44 \\
\hline 46 & SCENERY & 31 & 0,08 & 3 & 43,6 & 0 \\
\hline 47 & BEAUTIFUL & 31 & 0,08 & 3 & 43,6 & 0 \\
\hline 48 & HISTORY & 35 & 0,09 & 5 & 43,5 & 0 \\
\hline 49 & SOUNDS & 25 & 0,06 & 1 & 41,7 & 0 \\
\hline 50 & NATIONAL & 94 & 0,24 & 54 & 0,08 & 41,5 \\
\hline 51 & PHP & 21 & 0,05 & 0 & 41,4 & 0 \\
\hline 52 & RAFTING & 29 & 0,07 & 3 & 40 & 0 \\
\hline 53 & UNIQUE & 61 & 0,15 & 25 & 0,04 & 39,9 \\
\hline 54 & GREAT & 58 & 0,15 & 23 & 0,03 & 39,1 \\
\hline 55 & BIRDS & 45 & 0,11 & 13 & 0,02 & 39,1 \\
\hline 56 & COASTLINE & 26 & 0,07 & 2 & 38,7 & 0 \\
\hline 57 & MT & 28 & 0,07 & 3 & 38,3 & 0 \\
\hline 58 & CREEK & 19 & 0,05 & 0 & 37,4 & 0 \\
\hline 59 & NATURE & 90 & 0,23 & 54 & 0,08 & 37,3 \\
\hline 60 & WEST & 31 & 0,08 & 5 & 36,7 & 0 \\
\hline 61 & AMAZING & 22 & 0,06 & 1 & 36 & 0 \\
\hline 62 & STUNNING & 18 & 0,05 & 0 & 35,5 & 0 \\
\hline 63 & RAGLAN & 18 & 0,05 & 0 & 35,5 & 0 \\
\hline 64 & BUNGY & 18 & 0,05 & 0 & 35,5 & 0 \\
\hline 65 & BIRDING & 18 & 0,05 & 0 & 35,5 & 0 \\
\hline 66 & OFF & 38 & 0,1 & 10 & 0,02 & 35,1 \\
\hline 67 & ALPINE & 26 & 0,07 & 3 & 34,7 & 0 \\
\hline 68 & HOME & 39 & 0,1 & 11 & 0,02 & 34,4 \\
\hline
\end{tabular}




\begin{tabular}{|c|c|c|c|c|c|c|}
\hline 69 & $\mathrm{BEACH}$ & 21 & 0,05 & 1 & 34,2 & 0 \\
\hline 70 & MARLBOROUGH & 17 & 0,04 & 0 & 33,5 & 0 \\
\hline 71 & JUMPING & 17 & 0,04 & 0 & 33,5 & 0 \\
\hline 72 & QUEST & 17 & 0,04 & 0 & 33,5 & 0 \\
\hline 73 & SEALS & 20 & 0,05 & 1 & 32,3 & 0 \\
\hline 74 & BAY & 28 & 0,07 & 5 & 31,8 & 0 \\
\hline 75 & OCEAN & 16 & 0,04 & 0 & 31,5 & 0 \\
\hline 76 & RUGGED & 16 & 0,04 & 0 & 31,5 & 0 \\
\hline 77 & WESTLAND & 16 & 0,04 & 0 & 31,5 & 0 \\
\hline 78 & BIRDWATCHING & 16 & 0,04 & 0 & 31,5 & 0 \\
\hline 79 & MOUNT & 24 & 0,06 & 3 & 31,2 & 0 \\
\hline 80 & $A$ & 818 & 2,07 & 1.059 & 1,6 & 31,1 \\
\hline 81 & $\mathrm{EACH}$ & 42 & 0,11 & 15 & 0,02 & 31,1 \\
\hline 82 & WILDLIFE & 55 & 0,14 & 26 & 0,04 & 31 \\
\hline 83 & TRANSPORT & 19 & 0,05 & 1 & 30,4 & 0 \\
\hline 84 & EXPERIENCE & 77 & 0,19 & 48 & 0,07 & 30,1 \\
\hline 85 & SCENIC & 25 & 0,06 & 4 & 29,7 & 0 \\
\hline 86 & FOX & 21 & 0,05 & 2 & 29,7 & 0 \\
\hline 87 & MINUTES & 21 & 0,05 & 2 & 29,7 & 0 \\
\hline 88 & ROCKS & 15 & 0,04 & 0 & 29,5 & 0 \\
\hline 89 & SWIM & 15 & 0,04 & 0 & 29,5 & 0 \\
\hline 90 & CRUISE & 15 & 0,04 & 0 & 29,5 & 0 \\
\hline 91 & PACK & 15 & 0,04 & 0 & 29,5 & 0 \\
\hline 92 & ROCK & 15 & 0,04 & 0 & 29,5 & 0 \\
\hline 93 & IT'S & 34 & 0,09 & 10 & 0,02 & 29,2 \\
\hline 94 & ZEALAND'S & 50 & 0,13 & 23 & 0,03 & 29 \\
\hline 95 & DOWN & 26 & 0,07 & 5 & 28,5 & 0 \\
\hline 96 & HERE & 46 & 0,12 & 20 & 0,03 & 28,4 \\
\hline 97 & STAY & 24 & 0,06 & 4 & 28,1 & 0 \\
\hline 98 & OFFER & 33 & 0,08 & 10 & 0,02 & 27,7 \\
\hline 99 & NATUREQUEST & 14 & 0,04 & 0 & 27,6 & 0 \\
\hline 100 & STEWART & 14 & 0,04 & 0 & 27,6 & 0 \\
\hline 101 & ALONG & 38 & 0,1 & 14 & 0,02 & 27,4 \\
\hline 102 & NOW & 45 & 0,11 & 20 & 0,03 & 27,1 \\
\hline 103 & TRIP & 39 & 0,1 & 15 & 0,02 & 27 \\
\hline 104 & US & 58 & 0,15 & 32 & 0,05 & 27 \\
\hline 105 & ROAD & 31 & 0,08 & 9 & 0,01 & 26,8 \\
\hline 106 & GET & 40 & 0,1 & 16 & 0,02 & 26,8 \\
\hline 107 & LAKES & 28 & 0,07 & 7 & 0,01 & 26,7 \\
\hline 108 & SWIMMING & 19 & 0,05 & 2 & 26,1 & 0 \\
\hline 109 & TASMAN & 21 & 0,05 & 3 & 26,1 & 0 \\
\hline 110 & WHITEWATER & 13 & 0,03 & 0 & 25,6 & 0 \\
\hline 111 & AWAROA & 13 & 0,03 & 0 & 25,6 & 0 \\
\hline 112 & DURATION & 13 & 0,03 & 0 & 25,6 & 0 \\
\hline 113 & DISTANCE & 13 & 0,03 & 0 & 25,6 & 0 \\
\hline 114 & MEALS & 13 & 0,03 & 0 & 25,6 & 0 \\
\hline 115 & WILDERNESS & 30 & 0,08 & 9 & 0,01 & 25,4 \\
\hline 116 & STUDY & 27 & 0,07 & 7 & 0,01 & 25,2 \\
\hline 117 & PENGUINS & 16 & 0,04 & 1 & 24,8 & 0,000001 \\
\hline 118 & FAMOUS & 16 & 0,04 & 1 & 24,8 & 0,000001 \\
\hline 119 & SIDE & 22 & 0,06 & 4 & 24,8 & 0,000001 \\
\hline
\end{tabular}




\begin{tabular}{|c|c|c|c|c|c|c|}
\hline 120 & ALL & 121 & 0,31 & 105 & 0,16 & 24,4 \\
\hline 121 & COMPANY & 20 & 0,05 & 3 & 24,4 & 0,000001 \\
\hline 122 & BEECH & 18 & 0,05 & 2 & 24,3 & 0,000001 \\
\hline 123 & RAINFOREST & 18 & 0,05 & 2 & 24,3 & 0,000001 \\
\hline 124 & ENCOUNTER & 18 & 0,05 & 2 & 24,3 & 0,000001 \\
\hline 125 & ACHIEVING & 0 & 26 & 0,04 & 24,3 & 0,000001 \\
\hline 126 & COMMISSIONER & 0 & 26 & 0,04 & 24,3 & 0,000001 \\
\hline 127 & SUBMISSIONS & 0 & 26 & 0,04 & 24,3 & 0,000001 \\
\hline 128 & LANDOWNER & 0 & 26 & 0,04 & 24,3 & 0,000001 \\
\hline 129 & MANAGED & 4 & 0,01 & 48 & 0,07 & 24,6 \\
\hline 130 & GOVT & 1 & 34 & 0,05 & 24,7 & 0,000001 \\
\hline 131 & SHOULD & 18 & 0,05 & 95 & 0,14 & 25,2 \\
\hline 132 & ALREADY & 0 & 27 & 0,04 & 25,3 & 0 \\
\hline 133 & PRODUCTIVE & 0 & 28 & 0,04 & 26,2 & 0 \\
\hline 134 & NGATI & 0 & 28 & 0,04 & 26,2 & 0 \\
\hline 135 & PLANTATION & 3 & 46 & 0,07 & 26,4 & 0 \\
\hline 136 & KNOWLEDGE & 14 & 0,04 & 85 & 0,13 & 26,4 \\
\hline 137 & SUGGESTED & 1 & 36 & 0,05 & 26,4 & 0 \\
\hline 138 & MINISTRY & 1 & 36 & 0,05 & 26,4 & 0 \\
\hline 139 & USES & 2 & 42 & 0,06 & 27 & 0 \\
\hline 140 & RULES & 0 & 29 & 0,04 & 27,1 & 0 \\
\hline 141 & $\mathrm{E}$ & 3 & 47 & 0,07 & 27,2 & 0 \\
\hline 142 & WOULD & 20 & 0,05 & 105 & 0,16 & 27,7 \\
\hline 143 & PRODUCTION & 2 & 43 & 0,06 & 27,8 & 0 \\
\hline 144 & GROWTH & 3 & 48 & 0,07 & 28 & 0 \\
\hline 145 & TO & 899 & 2,27 & 1.861 & 2,8 & 28,2 \\
\hline 146 & LACK & 1 & 38 & 0,06 & 28,2 & 0 \\
\hline 147 & ISSUE & 1 & 38 & 0,06 & 28,2 & 0 \\
\hline 148 & INDUSTRY & 13 & 0,03 & 85 & 0,13 & 28,4 \\
\hline 149 & COMMERCIAL & 9 & 0,02 & 72 & 0,11 & 28,6 \\
\hline 150 & DEVELOPING & 9 & 0,02 & 72 & 0,11 & 28,6 \\
\hline 151 & CONSERVATION & 74 & 0,19 & 243 & 0,37 & 28,6 \\
\hline 152 & RELATIONSHIP & 0 & 33 & 0,05 & 30,9 & 0 \\
\hline 153 & COMMENTED & 0 & 34 & 0,05 & 31,8 & 0 \\
\hline 154 & MANIAPOTO & 0 & 34 & 0,05 & 31,8 & 0 \\
\hline 155 & NON & 12 & 0,03 & 87 & 0,13 & 31,9 \\
\hline 156 & EXPRESSED & 2 & 48 & 0,07 & 32 & 0 \\
\hline 157 & SERVICES & 6 & 0,02 & 66 & 0,1 & 32,3 \\
\hline 158 & PARTICULARLY & 3 & 54 & 0,08 & 32,9 & 0 \\
\hline 159 & EXOTIC & 1 & 44 & 0,07 & 33,5 & 0 \\
\hline 160 & DISCUSSED & 0 & 36 & 0,05 & 33,7 & 0 \\
\hline 161 & ECOSYSTEMS & 2 & 52 & 0,08 & 35,5 & 0 \\
\hline 162 & MARKETS & 0 & 38 & 0,06 & 35,5 & 0 \\
\hline 163 & NEED & 10 & 0,03 & 86 & 0,13 & 36 \\
\hline 164 & STRATEGY & 2 & 54 & 0,08 & 37,2 & 0 \\
\hline 165 & VALUE & 8 & 0,02 & 82 & 0,12 & 38,5 \\
\hline 166 & PAPER & 4 & 0,01 & 66 & 0,1 & 39 \\
\hline 167 & PLANTING & 0 & 44 & 0,07 & 41,2 & 0 \\
\hline 168 & LANDS & 0 & 44 & 0,07 & 41,2 & 0 \\
\hline 169 & PRIVATE & 13 & 0,03 & 105 & 0,16 & 42 \\
\hline 170 & COULD & 8 & 0,02 & 89 & 0,13 & 43,8 \\
\hline
\end{tabular}




\begin{tabular}{|c|c|c|c|c|c|c|}
\hline 171 & POTENTIAL & 4 & 0,01 & 75 & 0,11 & 46,4 \\
\hline 172 & FUNDING & 0 & 55 & 0,08 & 51,5 & 0 \\
\hline 173 & $\mathrm{BE}$ & 169 & 0,43 & 521 & 0,79 & 52,2 \\
\hline 174 & DISCUSSION & 0 & 57 & 0,09 & 53,3 & 0 \\
\hline 175 & SECTOR & 2 & 73 & 0,11 & 53,8 & 0 \\
\hline 176 & CERTIFICATION & 0 & 58 & 0,09 & 54,3 & 0 \\
\hline 177 & FORESTS & 42 & 0,11 & 214 & 0,32 & 54,4 \\
\hline 178 & OF & 1.235 & 3,12 & 2.659 & 4,01 & 56,1 \\
\hline 179 & ACT & 2 & 76 & 0,11 & 56,4 & 0 \\
\hline 180 & FORESTRY & 3 & 82 & 0,12 & 56,7 & 0 \\
\hline 181 & DEVELOPMENT & 12 & 0,03 & 122 & 0,18 & 57 \\
\hline 182 & MARKET & 2 & 77 & 0,12 & 57,3 & 0 \\
\hline 183 & COUNTRIES & 6 & 0,02 & 98 & 0,15 & 57,6 \\
\hline 184 & ECONOMIC & 8 & 0,02 & 108 & 0,16 & 58,6 \\
\hline 185 & NATIVE & 70 & 0,18 & 303 & 0,46 & 61,3 \\
\hline 186 & LANDOWNERS & 0 & 68 & 0,1 & 63,6 & 0 \\
\hline 187 & 1 & 27 & 0,07 & 185 & 0,28 & 64,6 \\
\hline 188 & INTERNATIONAL & 11 & 0,03 & 129 & 0,19 & 65,3 \\
\hline 189 & STATED & 0 & 71 & 0,11 & 66,4 & 0 \\
\hline 190 & LAND & 32 & 0,08 & 208 & 0,31 & 69,2 \\
\hline 191 & PRODUCTS & 26 & 0,07 & 194 & 0,29 & 72,9 \\
\hline 192 & COUNCIL & 1 & 89 & 0,13 & 74,3 & 0 \\
\hline 193 & GOVERNMENT & 2 & 101 & 0,15 & 78,7 & 0 \\
\hline 194 & TIMBER & 9 & 0,02 & 149 & 0,22 & 88,1 \\
\hline 195 & PLANTS & 27 & 0,07 & 222 & 0,33 & 90 \\
\hline 196 & USE & 14 & 0,04 & 180 & 0,27 & 95,5 \\
\hline 197 & ROLE & 0 & 103 & 0,16 & 96,4 & 0 \\
\hline 198 & SUSTAINABLE & 21 & 0,05 & 212 & 0,32 & 98,7 \\
\hline 199 & BIODIVERSITY & 3 & 140 & 0,21 & 107,8 & 0 \\
\hline 200 & FOREST & 47 & 0,12 & 337 & 0,51 & 122,7 \\
\hline 201 & RESEARCH & 9 & 0,02 & 199 & 0,3 & 129,9 \\
\hline 202 & SUBMITTERS & 0 & 139 & 0,21 & 130,1 & 0 \\
\hline 203 & MANAGEMENT & 16 & 0,04 & 241 & 0,36 & 137,3 \\
\hline 204 & TRADE & 0 & 162 & 0,24 & 151,6 & 0 \\
\hline 205 & INDIGENOUS & 5 & 0,01 & 202 & 0,3 & 151,9 \\
\hline 206 & THAT & 206 & 0,52 & 849 & 1,28 & 159,3 \\
\hline 207 & SUBMITTER & 0 & 178 & 0,27 & 166,6 & 0 \\
\hline
\end{tabular}

\section{i_amb x gov (inglês / ambientalistas x governo)}

\begin{tabular}{|l|r|r|r|r|r|}
\hline WORD & FREQ. & WLI_AMB.LST \% & FREQ. & WLI_GOV.LST \% & KEYNESS \\
\hline TOURISM & 523 & 0,83 & 297 & 0,45 & 76,5 \\
\hline STOCKS & 50 & 0,08 & 0 & 72,1 & 0 \\
\hline NMPAS & 47 & 0,07 & 0 & 67,8 & 0 \\
\hline VISITOR & 141 & 0,22 & 43 & 0,06 & 60,6 \\
\hline WERE & 176 & 0,28 & 65 & 0,1 & 59,4 \\
\hline PARK & 82 & 0,13 & 14 & 0,02 & 57,1 \\
\hline SCORE & 39 & 0,06 & 0 & 56,2 & 0 \\
\hline
\end{tabular}




\begin{tabular}{|c|c|c|c|c|c|}
\hline COAST & 68 & 0,11 & 9 & 0,01 & 54,5 \\
\hline DATA & 79 & 0,13 & 14 & 0,02 & 53,8 \\
\hline MEAN & 47 & 0,07 & 2 & 53,7 & 0 \\
\hline SURVEY & 42 & 0,07 & 1 & 52,4 & 0 \\
\hline CENTRE & 70 & 0,11 & 11 & 0,02 & 51,2 \\
\hline ORG & 45 & 0,07 & 2 & 51 & 0 \\
\hline NMPA & 34 & 0,05 & 0 & 49 & 0 \\
\hline OVERFISHED & 33 & 0,05 & 0 & 47,6 & 0 \\
\hline TOURIST & 61 & 0,1 & 9 & 0,01 & 46,2 \\
\hline KIWI & 61 & 0,1 & 9 & 0,01 & 46,2 \\
\hline STOCK & 56 & 0,09 & 7 & 0,01 & 46,1 \\
\hline TOURISTS & 64 & 0,1 & 11 & 0,02 & 44,4 \\
\hline TRAVEL & 53 & 0,08 & 7 & 0,01 & 42,5 \\
\hline PACIFIC & 82 & 0,13 & 21 & 0,03 & 42 \\
\hline TOURS & 64 & 0,1 & 12 & 0,02 & 42 \\
\hline SPTO & 29 & 0,05 & 0 & 41,8 & 0 \\
\hline SEX & 27 & 0,04 & 0 & 38,9 & 0 \\
\hline STUDY & 49 & 0,08 & 7 & 0,01 & 37,8 \\
\hline ATLANTIC & 31 & 0,05 & 1 & 37,1 & 0 \\
\hline GARDENS & 40 & 0,06 & 4 & 36,2 & 0 \\
\hline ISLAND & 82 & 0,13 & 25 & 0,04 & 35,2 \\
\hline TABLE & 33 & 0,05 & 2 & 34,9 & 0 \\
\hline RESPONDENTS & 36 & 0,06 & 3 & 34,7 & 0 \\
\hline CRUISE & 24 & 0,04 & 0 & 34,6 & 0 \\
\hline SITE & 68 & 0,11 & 18 & 0,03 & 33,8 \\
\hline HORTICULTURE & 32 & 0,05 & 2 & 33,6 & $\underline{0}$ \\
\hline SPAWNING & 23 & 0,04 & 0 & 33,2 & 0 \\
\hline GARDEN & 28 & 0,04 & 1 & 33 & 0 \\
\hline BEHAVIOUR & 30 & 0,05 & 2 & 31 & 0 \\
\hline SANCTUARY & 47 & 0,07 & 9 & 0,01 & 30,4 \\
\hline ESTIMATES & 21 & 0,03 & 0 & 30,3 & 0 \\
\hline RESERVE & 29 & 0,05 & 2 & 29,6 & 0 \\
\hline RESPONSES & 25 & 0,04 & 1 & 28,9 & $\underline{0}$ \\
\hline RED & 25 & 0,04 & 1 & 28,9 & 0 \\
\hline STRATEGIES & 41 & 0,07 & 7 & 0,01 & 28,6 \\
\hline SAYS & 33 & 0,05 & 4 & 27,6 & 0 \\
\hline VISITORS & 149 & 0,24 & 77 & 0,12 & 27,5 \\
\hline TNC & 19 & 0,03 & 0 & 27,4 & 0 \\
\hline EXPERIENCES & 54 & 0,09 & 14 & 0,02 & 27,4 \\
\hline CITY & 35 & 0,06 & 5 & 27 & 0 \\
\hline WEST & 35 & 0,06 & 5 & 27 & 0 \\
\hline TOP & 23 & 0,04 & 1 & 26,2 & 0 \\
\hline SNAPPER & 18 & 0,03 & 0 & 25,9 & 0 \\
\hline CODE & 36 & 0,06 & 6 & 25,4 & 0 \\
\hline SOUTH & 77 & 0,12 & 29 & 0,04 & 25,3 \\
\hline SPECIES & 197 & 0,31 & 118 & 0,18 & 24,6 \\
\hline $\mathrm{FI}$ & 17 & 0,03 & 0 & 24,5 & 0,000001 \\
\hline PRO & 17 & 0,03 & 0 & 24,5 & 0,000001 \\
\hline OVERFISHING & 17 & 0,03 & 0 & 24,5 & 0,000001 \\
\hline HABITAT & 49 & 0,08 & 13 & 0,02 & 24,3 \\
\hline WELLINGTON & 45 & 0,07 & 11 & 0,02 & 24 \\
\hline
\end{tabular}




\begin{tabular}{|c|c|c|c|c|c|}
\hline ENVIRONMENTAL & 155 & 0,25 & 86 & 0,13 & 24 \\
\hline HARVESTING & 2 & 27 & 0,04 & 24,3 & 0,000001 \\
\hline PLANTATIONS & 2 & 27 & 0,04 & 24,3 & 0,000001 \\
\hline LANDSCAPE & 12 & 0,02 & 52 & 0,08 & 24,8 \\
\hline WAITAKI & 0 & 19 & 0,03 & 25,3 & 0 \\
\hline RESILIENCE & 0 & 19 & 0,03 & 25,3 & 0 \\
\hline NON & 30 & 0,05 & 87 & 0,13 & 26 \\
\hline FOR & 655 & 1,04 & 898 & 1,35 & 26,4 \\
\hline PROGRESS & 3 & 32 & 0,05 & 26,5 & 0 \\
\hline ACT & 23 & 0,04 & 76 & 0,11 & 27,1 \\
\hline VEGETATION & 8 & 0,01 & 46 & 0,07 & 27,5 \\
\hline SUBMISSIONS & 1 & 26 & 0,04 & 27,5 & 0 \\
\hline MINISTRY & 4 & 36 & 0,05 & 27,7 & 0 \\
\hline SUSTAINABLY & 0 & 21 & 0,03 & 28 & 0 \\
\hline NEW & 278 & 0,44 & 438 & 0,66 & 28 \\
\hline STRATEGY & 11 & 0,02 & 54 & 0,08 & 28,7 \\
\hline MANAGING & 1 & 27 & 0,04 & 28,8 & 0 \\
\hline MANAGEMENT & 127 & 0,2 & 241 & 0,36 & 30,1 \\
\hline DEVELOPING & 19 & 0,03 & 72 & 0,11 & 30,1 \\
\hline RELATION & 0 & 23 & 0,03 & 30,7 & 0 \\
\hline RAISED & 0 & 23 & 0,03 & 30,7 & 0 \\
\hline THAT & 600 & 0,95 & 849 & 1,28 & 30,9 \\
\hline STATED & 18 & 0,03 & 71 & 0,11 & 31 \\
\hline TARIFF & 0 & 24 & 0,04 & 32 & 0 \\
\hline SECTION & 7 & 0,01 & 48 & 0,07 & 32,1 \\
\hline ANOTHER & 15 & 0,02 & 67 & 0,1 & 32,9 \\
\hline TROPICAL & 9 & 0,01 & 54 & 0,08 & 33,3 \\
\hline WRC & 0 & 25 & 0,04 & 33,3 & 0 \\
\hline VALUE & 22 & 0,04 & 82 & 0,12 & 33,7 \\
\hline LANDOWNER & 0 & 26 & 0,04 & 34,7 & 0 \\
\hline COMMISSIONER & 0 & 26 & 0,04 & 34,7 & 0 \\
\hline FARMERS & 2 & 36 & 0,05 & 35,2 & 0 \\
\hline PRODUCTIVE & 0 & 28 & 0,04 & 37,3 & 0 \\
\hline COMMENTED & 1 & 34 & 0,05 & 37,7 & 0 \\
\hline GOVT & 1 & 34 & 0,05 & 37,7 & 0 \\
\hline ON & 421 & 0,67 & 650 & 0,98 & 38 \\
\hline EXPRESSED & 5 & 48 & 0,07 & 38,1 & 0 \\
\hline AQUACULTURE & 0 & 30 & 0,05 & 40 & 0 \\
\hline EXOTIC & 3 & 44 & 0,07 & 40,7 & 0 \\
\hline USES & 2 & 42 & 0,06 & 42,6 & 0 \\
\hline MARKETS & 1 & 38 & 0,06 & 42,8 & 0 \\
\hline OUR & 68 & 0,11 & 177 & 0,27 & 44,6 \\
\hline DISCUSSION & 6 & 57 & 0,09 & 45 & 0 \\
\hline 1 & 72 & 0,11 & 185 & 0,28 & 45,5 \\
\hline MAORI & 18 & 0,03 & 87 & 0,13 & 45,7 \\
\hline RESEARCH & 80 & 0,13 & 199 & 0,3 & 46,2 \\
\hline WOOD & 4 & 53 & 0,08 & 47,4 & 0 \\
\hline PLANTATION & 2 & 46 & 0,07 & 47,6 & 0 \\
\hline ROLE & 24 & 0,04 & 103 & 0,16 & 48,8 \\
\hline BIODIVERSITY & 40 & 0,06 & 140 & 0,21 & 53,6 \\
\hline CERTIFICATION & 3 & 58 & 0,09 & 57,7 & 0 \\
\hline
\end{tabular}




\begin{tabular}{|l|r|r|r|r|r|}
\hline PRIVATE & 18 & 0,03 & 105 & 0,16 & 63,5 \\
\hline KNOWLEDGE & 9 & 0,01 & 85 & 0,13 & 66,9 \\
\hline FORESTRY & 7 & 0,01 & 82 & 0,12 & 70,4 \\
\hline LANDOWNERS & 2 & 68 & 0,1 & 75,4 & 0 \\
\hline LAND & 47 & 0,07 & 208 & 0,31 & 101,4 \\
\hline FORESTS & 35 & 0,06 & 214 & 0,32 & 133,7 \\
\hline INDIGENOUS & 19 & 0,03 & 202 & 0,3 & 167,3 \\
\hline NATIVE & 58 & 0,09 & 303 & 0,46 & 169,6 \\
\hline TIMBER & 3 & 149 & 0,22 & 173,5 & 0 \\
\hline FOREST & 71 & 0,11 & 337 & 0,51 & 174,8 \\
\hline PRODUCTS & 13 & 0,02 & 194 & 0,29 & 180,4 \\
\hline SUBMITTERS & 0 & 139 & 0,21 & 185,4 & 0 \\
\hline TRADE & 3 & 162 & 0,24 & 190,4 & 0 \\
\hline PLANTS & 19 & 0,03 & 222 & 0,33 & 190,5 \\
\hline SUBMITTER & 0 & 178 & 0,27 & 237,4 & 0 \\
\hline
\end{tabular}


